Development of U.S. Regulations for the Transportation of Radioactive Materials A Look Back Over the Past 40 Years

R. S. Hafner

September 6, 2005

Companion Guide to the ASME Boiler \& Pressure Vessel Code 
This document was prepared as an account of work sponsored by an agency of the United States Government. Neither the United States Government nor the University of California nor any of their employees, makes any warranty, express or implied, or assumes any legal liability or responsibility for the accuracy, completeness, or usefulness of any information, apparatus, product, or process disclosed, or represents that its use would not infringe privately owned rights. Reference herein to any specific commercial product, process, or service by trade name, trademark, manufacturer, or otherwise, does not necessarily constitute or imply its endorsement, recommendation, or favoring by the United States Government or the University of California. The views and opinions of authors expressed herein do not necessarily state or reflect those of the United States Government or the University of California, and shall not be used for advertising or product endorsement purposes. 


\title{
Development of U.S. Regulations FOR THE TRANSPORTATION OF Radioactive Materials - A Look Back over the Past 40 Years
}

\author{
Ronald S. Hafner
}

\subsection{INTRODUCTION}

The discussion in this Chapter is a relatively straightforward, chronological description of the development of U.S. transportation regulations for radioactive materials over the past 40 years. Although primarily based on the development of U.S. regulations for the shipment of what is now known as Type $B$ quantities of radioactive materials, the information presented details the interactions between a number of U.S. governmental agencies, commissions, and departments, and the International Atomic Energy Agency (IAEA).

For the most part, the information that follows was taken directly from the Federal Register, between 1965 and 2004, which, within the boundaries of the U.S., is considered law, or at least policy at the federal level. Starting in 1978, however, the information presented also takes a look at a series of socalled Guidance Documents, including Regulatory Guides (Reg. Guides), NUREGs, and NUREG/CRs. ${ }^{*}$ Developed originally by the U.S. Atomic Energy Agency (AEC), and later adapted by the U.S. Nuclear Regulatory Commission (NRC),

As is noted by their descriptions, Reg. Guides and NUREGs are guidance documents developed by the NRC, whereas NUREG/CRs are guidance documents developed for the NRC by NRC contractors. The primary difference between the three types of documents is that Reg. Guides specify NRC policy, NUREGs make recommendations speaking for the NRC, and NUREG/CRs make recommendations speaking for NRC contractors. the NUREGs and NUREG/CRs cited in this Chapter clearly specify a preferred methodology that can be used to meet the regulatory requirements of Title 10 of the Code of Federal Regulations, Part 71 (10 CFR Part 71, or, more simply, 10 CFR 71). As is appropriate for the discussion in this Chapter, the methodology preferred by the NRC, not as law but as guidance, was adapted directly from the requirements of the ASME's Boiler \& Pressure Vessel Code.

The information provided below is provided with little embellishment. By taking the information directly from the Federal Register, it becomes a story that tells itself. The information is self-consistent, and it provides all of the details behind the numerous policy decisions that led to the development of the U.S. regulations, as they were in their time, and as they are now.

\subsection{BACKGROUND}

In 1958, at the request of the Economic and Social Council of the United Nations, the IAEA undertook the development of international regulations for the safe transportation of radioactive materials. The initial regulations published by the IAEA in 1961 were recommended to member states as the basis for national regulations and for application to international transportation. That began the process, in the United States, of a series of revisions to the U.S. regulations governing the transportation of radioactive materials. 
In the hierarchical structure of the U.S. transportation regulations for hazardous materials, the Department of Transportation (DOT) sits at the top. DOT is responsible for the transportation of all hazardous materials within the physical boundaries of the United States. DOT is also responsible for the transportation of all hazardous materials into and out of the United States. In that capacity, the DOT functions as the Competent Authority for the United States in all regulatory matters dealing with the transportation of hazardous materials of any kind on a national and international basis.

From a regulatory standpoint, however, radioactive materials are considered to be a subset of hazardous materials. Termed Class 7 materials in DOT's regulatory language, radioactive materials are currently subdivided into two additional subcategories: Type A quantities and Type B quantities, based on the relative hazard of the radionuclide(s) in question, and the total amount of the activity being shipped in a given package. Although the DOT generally defers to the NRC in technical matters dealing with the transportation of radioactive materials, the regulatory requirements for the transportation of Type A (i.e., relatively small) quantities of radioactive material fall under the purview of DOT regulations (in Title 49 of the Code of Federal Regulations, Parts 173-178, i.e., 49 CFR 173-178), whereas regulatory requirements for the transportation of Type B (i.e., relatively large) quantities of radioactive material fall under the purview of NRC regulations, in 10 CFR 71. But, whether it is a Type A package under the purview of the DOT, or a Type B package under the purview of the NRC, the one major subtheme that is constantly at work is the consistency between the regulations of the United States and those of the IAEA.

In this Chapter, we will take a look at the development of the regulations, the policies, and the recommendations, for the transportation of radioactive material. Although the primary focus will be on the development of the regulations for Type B shipping containers (10 CFR 71), we will also, out of necessity, take an occasional look at the development of some of the regulations that fall under the purview of the DOT (49 CFR 173-178). Along the way, we will also delve into a second major subtheme that was identified above: compliance with the requirements of the ASME Boiler \& Pressure Vessel Code, used as a metric to quantify the U.S. regulatory requirements.

\subsection{TITLE 10, CODE OF FEDERAL REGULATIONS, PART 71 (10 CFR 71)}

The first, real version of what we would now recognize as 10 CFR 71 was published in the Federal Register on July 22, 1966.[1] This version would become the cornerstone, because it combined the existing regulatory requirements from the older version of 10 CFR 71[2] with a recently proposed revision to $10 \mathrm{CFR} 71[3]$ and the proposed regulatory requirements from a then proposed $10 \mathrm{CFR}$ 72.[4, 5] It also went on to describe the initial framework that separated the regulatory jurisdiction of the then existing Atomic Energy Commission $^{\dagger}$ from the then existing Interstate Commerce

The Atomic Energy Commission would later be subdivided into the Nuclear Regulatory Commission (NRC) and the Energy Resource and Development Agency (ERDA). ERDA would later become the Department of Energy (DOE).
Commission. ${ }^{*}$ It went on to describe the origins of the development of what we now refer to as 'specification packages,' and it provided a direct linkage between the U.S. regulations for the transportation of radioactive materials with those of the IAEA.[6]

\subsubsection{CFR 71 - 1965 Proposed Rule}

Because an earlier version of the 1966 Final Rule had been published as a Proposed Rule Making on December 21, 1965,[7] an examination of this proposed rule becomes worthwhile, because the differences between these proposed regulations and the then existing regulations were as different as night and day. The text of the preamble for the 1965 proposed rule follows below:

"The regulations of the Atomic Energy Commission, Parts 30, 40, and 70 of Title 10, code of Federal Regulations (10 CFR), require that before the Commission approves an application for license to receive, possess, use, or transfer byproduct, source, or special nuclear material, it must determine that the applicant's proposed program is adequate to protect health and minimize danger to life and property.

"In 1958, the Commission adopted 10 CFR Part 71, 'Regulations To Protect Against Accidental Conditions of Criticality in the Shipment of Special Nuclear Material.' This regulation established procedures for approval of transport of special nuclear material, but set only limited standards. Certain small shipments under specified conditions were made exempt from the licensing requirement.

"In 1960 and again in 1961, the Atomic Energy Commission published for public comment its proposed 10 CFR Part 72, 'Protection Against Radiation in the Shipment of Irradiated Fuel Elements,' to regulate the increasing number of shipments of irradiated solid nuclear fuel. That proposed regulation has never been adopted by the Commission as an effective regulation, although its previsions [sic] have been used as licensing criteria since their publication.

"On March 5, 1963, the Commission published a proposed revision of Part 71 (28 F.R. 2134), incorporating standards developed as the result of licensing experience as well as from the Commission's experience as a shipper of special nuclear material. In that proposed revision, the concept of different classes of packages of special nuclear material was introduced. This concept, which has been developed by the International Atomic Energy Agency at that time, is intended to distinguish among classes of packages according to the degree of control which must be exercised in transport in order to avoid criticality.

"Public response to the proposed revision of Part 71 to a large extent suggested that (1) the regulation should emphasize performance standards, insofar as possible, rather than detailed design specifications for

The Interstate Commerce Commission would later become the Department of Transportation (DOT). 
shipping containers and shipping procedures, and (2) the method of shipment to satisfy those performance standards should be left to the ingenuity of the shippers. It was suggested that the detailed standards proposed might impair the growth of the industry and development of improved safety concepts and that the standards were already outdated and were in some cases inapplicable, inadequate, or overly restrictive. The comments indicated that licensing requirements based on performance standards would allow needed flexibility to develop improved shipping methods. It was also suggested that the regulatory relationship between the Atomic Energy Commission and the Interstate Commerce Commission be made clear.

"As a result of the numerous public comments and further study, the notice of proposed rule making issued on March 5, 1963, is withdrawn, and is superseded by this notice. The revision of $10 \mathrm{CFR}$ Part 71 here proposed has deleted the detailed design standards of that proposal, and emphasizes performance standards to determine the adequacy of proposed shipping methods. The performance standards of this proposed revision are compatible with those developed by the International Atomic Energy Agency during the past few years.

"In response to public comments received on the proposed Part 72 dealing with the transport of irradiated fuel elements, and to provide flexibility of approach in that rapidly growing field, a revision was also undertaken of Part 72 . As in Part 71, the requirements have, as far as possible, been modified into performance standards. Since the nuclear safety requirements of Part 71 are applicable to the shipment of irradiated as well as unirradiated special nuclear material, the two Atomic Energy Commission transport regulations, Parts 71 and 72 have been combined into a single document in the interest of clarity and to avoid duplication. The notice of proposed rule making issued on September 23, 1961, 10 CFR 72 (26 F.R. 8982), and a minor amendment issued March 5, 1963 (28 F.R. 2142), are withdrawn and superseded by this notice.

"A proposed amendment dated March 5, 1963, to 10 CFR Part 40, 'Licensing of Source Material,' would have provided transport control over certain large masses of source material which, when shipped in combination with materials having unusual moderating properties, might present a possibility of accidental criticality (28 F.R. 2111). Public comments on this proposed amendment questioned the level at which control would be imposed, and questioned the practical need for any control at all. Upon further consideration, the Commission determined that there is no practical need for the proposed control at this time. Accordingly, the notice of proposed rule making issued on March 5, 1963, to 10 CFR Part 40 (28 F.R. 2111) is withdrawn.
"Since 1948 shipments of radioactive material in interstate and foreign commerce have been regulated by the Interstate Commerce Commission under the Transportation of Explosives and other Dangerous Articles Act (18 U.S.C. 831-835). The Atomic Energy Commission has provided a safety evaluation of the same shipments in some cases, both as part of its regulation of the activities of its licensees and its control of its own shipments. To coordinate these efforts under a proposed agreement between the two agencies, the Atomic Energy Commission would adopt standards for the transport of large quantities of licensed radioactive material, as specified in the regulation, as well as the transport of all fissile material because of the additional potential hazard of criticality. The Commission would issue regulations applicable to its licensees, and would apply the same standards in rendering technical advice to the Interstate Commerce Commission for shipments requiring their approval. In regulating the transport of radioactive materials, the Interstate Commerce Commission would take into account the authority to ship granted by the Commission to its licensees and contractors, and the technical advice rendered to the Interstate Commerce Commission by the Commission.

"In summary, the revised Part 71 contains: (1) The substance of the earlier Part 71 which covered the shipment of unirradiated fissile materials, as revised to emphasize performance standards, (2) standards and requirements for the shipment of irradiated fissile materials, and (3) standards and procedures for the shipment of 'large quantities' of licensed material.

"Persons specifically licensed to receive, possess, use, or transfer source material have been included in the scope of this regulation because it is intended that any source material be considered in the evaluation of a package or shipment which also contains byproduct and special nuclear material in sufficient quantities that the standards of Part 71 apply. It is recognized that the exemption provisions of the proposed $\S 71.5$ would probably apply to most, if not all, packages or shipments of source material per se.

“A 'large quantity' of licensed material is defined in the regulation in terms of the 'transport group' of the radionuclide in question (which is based on relative potential hazard in transport), and in terms of 'special form' of the licensed material. A 'special form' is a nondispersible form, so that there is no need for further consideration of the hazard of ingestion of the material by a human being. The criteria used to determine whether the material is in 'special form' are given in the definition of 'special form' in $\S 71.4(\mathrm{~s})$, and depend upon the inherent properties of the material and the properties of a capsule in which it may be transported. It is anticipated that, under proposed regulations now being developed, responsibility for determining 'special form' by virtue of the inherent properties of the material will 
remain with the shipper. When 'special form' is based on encapsulation, it is anticipated that approval of the capsule design and properties will be required by the Interstate Commerce Commission.

“The proposed $\S 71.6(\mathrm{c})$ includes a general license for the transport of fissile material and large quantities of licensed material in 'specification packages' as they are and will be authorized in the regulations of the Interstate Commerce Commission for that purpose. At present, the Interstate Commerce Commission regulations (49 CFR Part 78) contain a number of 'specification containers' but these are authorized only for small quantities of nonfissile radioactive material ( $§ 73.393$ of 49 CFR Part 73). It is anticipated that the Interstate Commerce Commission will soon publish some specifications for packages for use in the transport of fissile materials and large quantities of radioactive materials, at which time such 'specification packages' may be used, in accordance with $\S 71.6$ (c), without further approval by the Atomic Energy Commission. The Atomic Energy Commission will review and approve 'specification containers' before they are listed by the Interstate Commerce Commission.

"The proposed new Part 71 is divided into four subparts:

"Subpart A, 'General Provisions,' imposes the requirement of a license for certain shipments of licensed material (including fissile material). It specifies the quantities and methods of transport which are exempt and those which are under a general license. Exemption and general license provisions are applicable to shipments which are not dependent for safety on an individual packaging evaluation other than that provided under the regulations of the Interstate Commerce Commission.

“Subpart B, 'License Applications,' specifies the information which must be submitted to the Commission for specific licensing of any method of shipment not authorized under Subpart A.

"Subpart C, 'Package Standards,' specifies the standards which a package must meet for the shipment of fissile material or a large quantity of licensed material, and certain special requirements for the transport of Fissile Class II and Fissile Class III shipments.

'Subpart D, 'Operating Procedures,' specifies the general package determinations and shipping precautions required in order to assure the effectiveness of approved shipping methods.

"In order to provide reasonable assurance of adequate radiation shielding, containment of the radioactive material, and absence of nuclear criticality during transport, the performance of the package and the control exercised over it during transport must be evaluated for normal transport conditions and for potential accident conditions. To avoid inconsistencies involved in guarding against every conceivable condition which could be encountered in transport, Part 71 specifies the transport conditions against which a shipping system must be evaluated. It specifies a set of 'normal conditions of transport' intended to represent conditions which may normally occur during transport. Packages must be designed to withstand these normal conditions. The regulation further specifies a set of 'hypothetical accident conditions' consisting of a 30-foot drop onto a flat surface, followed by a 40-inch drop onto a 6-inch diameter steel bar, followed by exposure to an environment at a temperature of $1475^{\circ} \mathrm{F}$ for 30 minutes, followed by immersion in water. The hypothetical accident conditions prescribed in the regulation are not intended to represent any one accident, but are so chosen that satisfactory performance of a package exposed to them may be considered to give reasonable assurance of satisfactory performance in accidents likely to occur in transportation.

"A package is not expected to withstand without damage the hypothetical accident conditions specified. The extent of allowable damage to a package depends on the effect of that damage on the containment, shielding, and nuclear safety characteristics of the package. It is expected that, in accordance with the Interstate Commerce Commission, Coast Guard, or Federal Aviation Agency regulations, any package which is damaged in transport would not be carried further in normal transport until any necessary repairs were made.

“The 'Package Standards' in Subpart C, in prescribing the performance standards for a single package and for a permissible array of packages, require that a 'sample package' be subjected, by test or other assessment, to the specified transport tests and conditions. The 'sample package' must fairly represent the actual package to be introduced into transport. In some cases of Fissile Class III shipments, where the entire shipment is to be controlled during transport, the 'sample package' may be considered to be the entire shipment together with the transporting vehicle. It is the intent of these regulations that any analytical treatment which has a reasonable degree of certainty may be employed to predict the performance of a package under the specified test conditions. The results of subjecting a package to the test conditions might be determined by engineering analysis, by physical testing of prototype packages or of scale model packages, by testing of package components, or by any other method as long as a reasonable degree of certainty is established for the results. A great deal of effort has gone into the establishment of the test conditions to make it possible to use calculative methods of solution. It is hoped that good calculative methods will be developed so as to avoid, at least to some extent, the performance of physical tests which otherwise would be necessary.

"Basically, two aspects must be controlled to provide reasonable assurance of safe transport. First, an 
individual package of radioactive material must be so designed and its contents so limited so as not to cause criticality or intolerable losses in radiation shielding or in containment of radioactive material. Second, where a number of packages of fissile material are likely to accumulate, the effect of that accumulation must not be sufficient to cause criticality. This problem is unique to fissile material. Even though adequate measures are taken to assure nuclear safety of individual packages or shipments, a criticality incident may be caused by an unsafe accumulation of packages unless a system is established to control the numbers and types of packages which may accumulate in a single vehicle or storage area. The performance standards for an array of packages of fissile material in Part 71 are directed to the avoidance of such an unsafe accumulation.

"Part 71 establishes three transport classes, consistent with the 'Fissile Classes' developed by the International Atomic Energy Agency, based upon the packaging requirements and controls to be exercised during transport. For Fissile Class I and Fissile Class II, shipment methods do not depend for safety on control by the shipper during transport, either for individual packages or collections of packages. Fissile Class I packages are so designed that administrative control during shipment is not required for nuclear safety. Fissile Class II packages are so designed and labeled that the only control necessary during transport is accomplished by the personnel of the carrier, through application of the ' 40 unit rule' of the Interstate Commerce Commission, Federal Aviation Agency, and the Coast Guard.

"If a proposed method of shipment of fissile material is not within Fissile Class I or II, it may be approved only as a Fissile Class III shipment. The nuclear safety of a Fissile Class III shipment depends on control by the shipper to assure that other fissile material is not brought within an unsafe distance of the shipment and that the conditions under which the shipment is authorized are maintained. A Fissile Class III shipment must be transported with a courier accompanying it, by exclusive use of the vehicle, or with the use of some other transport control method specifically approved by the Commission.

"In most cases, safety in the transport of radioactive material is dependent on packaging to provide containment and shielding. In the case of fissile material, safety may depend on moderation and absorption of neutrons, control of shape of the fissile material, and prevention of accidental entry of water. In view of the importance of packaging, it must be evaluated to determine that it will withstand both normal and hypothetical accident conditions likely to occur in transport.

"The allowable fissile content of any single package is so limited by Subpart $\mathrm{C}$ that the package, as it may be damaged after subjection to the hypothetical accident conditions, would be subcritical. The regulation requires the assumption of close water reflection since considerable reflection may occur due to immersion in water, burial in soil, placement in the corner of a room with concrete walls and floor, etc. In addition, the regulation requires the assumption of leakage of water into any single package containment vessel. This assumption is intended to protect against the possibility that the package might become critical in itself because of a packing error, such as the omission of a gasket or complete tightening of the lid, which would allow water to enter the containment vessel.

"There is no limitation on the number of Fissile Class I packages since the package design is required to be such that an unlimited number of such undamaged packages would be subcritical in any arrangement when mixed with any number of other Fissile Class I packages. The possibility that other Fissile Class I packages might be mixed with the particular package requires that consideration be given to moderator [sic] present in the other packages interspersed between packages of the design under consideration. Therefore the design of a Fissile Class I package must assume that, in addition to the moderation already contained in the particular package, interspersed hydrogenous moderation is present if it would contribute to the reactivity of the array. The package must in addition be sufficiently sturdy that even after subjection to the accident test conditions, 250 such packages would be subcritical under conditions of close water reflection and the addition of interspersed hydrogenous moderation if it would add to the reactivity. Under such stringent standards, no control is necessary over the number of Fissile Class I packages which may be transported together. Furthermore, because of the design of the Fissile Class I packages and the control of Fissile Class II packages, intermixing of any number of Fissile Class I packages with the allowable number of Fissile Class II packages is safe.

"The number of Fissile Class II packages which may be collected and transported together is to be controlled during transport by carrier personnel through application of the ' 40 unit rule' limitation already in use under the Interstate Commerce Commission, Coast Guard, and Federal Aviation Agency regulations. Packages are required by their standards and procedures to bear labels on which the correctly determined number of 'units' is designated so that the number of units would total no more than 40 on the labels of the packages which can be safely transported together. Carrier personnel, by counting 'units' and limiting packages so that no more than 40 'units' are located in one place, would provide effective control over fissile packages. By the use of the 'unit' system for controlling numbers of fissile packages, different types of fissile packages may be intermixed at one location. If the number of units on each package is correctly determined and the number of packages, regardless of their types, origins, and 
destinations, is limited so that no more than 40 'units' are located in one place, criticality will be avoided. The number of units assigned to each package is determined in the following manner. The number of Fissile Class II packages which may be transported together is so determined that (1) at least five times that number, in any arrangement and undamaged, would not be critical assuming close reflection by water on all sides; and (2) twice that number, following such damage as would result from the hypothetical accident conditions, would not be critical assuming close reflection, optimum interspersed moderation, and any package arrangement. This assures that they will remain subcritical during transport with a sufficient margin of safety to protect against any inadvertent accumulation likely to occur. The number of 'units' assigned to each package is equal to the number 40 divided by the number of packages so determined.

"For Fissile Class III shipments, the number of packages that may be transported together depends on the analysis and evaluation of each shipment or type of shipment. Fissile Class III shipments are shipper-controlled so that any necessary limitations in terms of numbers of packages, type and amount of material, dimensions of packages and containment vessels, or other limitation will be specified in the license. In approving such shipments, special controls over the shipment such as tiedown, bracing, control of vehicle speeds, and handling techniques may be taken into account when adequately justified.

"In addition to the standards which determine if a package performs adequately when subjected to the normal and accident conditions of transport, there are certain design requirements directed to structural integrity, temperature, radiation shielding, and other general design features of a package. The design requirements directed toward package lifting and tiedown systems are intended to assure that such devices are not torn from the package during use, and that stresses delivered to the package through the lifting or tiedown systems would not damage the package.

“The proposed $\S 71.13$, 'Limited exemption for transport of special nuclear material' would require that every licensee now authorized to transport fissile material file a consolidated application for a superseding license. Information and procedures developed by applicants in past years, and embodied in license applications which have in turn been incorporated by reference in existing licenses, will in most cases require reevaluation. Moreover, many licenses have been the subject of numerous amendments which have incorporated by reference material in previous applications. It is the view of the Commission that issuance of new licenses based on consolidated applications, submitted in accordance with the technical standards of the proposed Part 71, will contribute significantly to the effective administration of these licenses, and ultimately to nuclear safety. The Commission has determined from its review that the continued use of certain existing packages (casks) now used for the transport of irradiated nuclear fuel does not constitute an undue risk to the health and safety of the public. The proposed $\S 71.42$ therefore exempts from the package standards existing packages which have been approved since 1961 under the criteria of proposed Part 72.

"The proposed $\S 71.14$, 'Limited exemption for transport of large quantities of licensed material' would provide a period of time for licensees to obtain approval of shipping procedures before the requirements of Part 71 come into effect. The Commission proposes to evaluate, on an individual basis, licensed material packages which have been constructed prior to the effective date of the regulation using the package standards of Part 71 . Loss of shielding resulting from the puncture test followed by the thermal test will not be considered, in itself, ground for disapproval of such a package which meets all the other standards of Part 71.

"Notice is hereby given that adoption of the following rules is contemplated. All interested persons who desire to submit written comments and suggestions for consideration in connection with the proposed rules should send them in triplicate ... within 60 days after publication of this notice in the FEDERAL REGISTER. ${ }^{\S}$ Comments received after that period will be considered if it is practical to do so, but assurance of consideration cannot be given except as to comments filed within the period specified...."[7]

\subsubsection{CFR 71 - 1966 Final Rule}

The July 22, 1966 version of 10 CFR Part 71 was published as the final regulation, with the differences between the proposed rule and the final rule described appropriately in the preamble:

"The regulations of the Atomic Energy Agency (AEC), 10 CFR Parts 30, 40, and 70, require that before the AEC approves an application for license to receive, possess, use or transfer byproduct, source, or special nuclear material, it must determine that the applicant's proposed program is adequate to protect health and minimize danger to life and property.

"In 1958, the AEC adopted 10 CFR Part 71, 'Regulations to Protect Against Accidental Conditions of Criticality in the Shipment of Special Nuclear Material.' This regulation established procedures for approval of transport of special nuclear material, but set only limited standards.

$\S$ Author's Note: Normally, the preferred format for the term Federal Register would be in italics. In this case, however, the format shown, i.e., Federal Register, was provided by the U.S. Government Printing Office. This will show up again, repeatedly, throughout the remainder of the document. 
Certain small shipments under specified conditions were exempted from the licensing requirement.

"On March 5, 1963, the AEC published a proposed revision of Part 71 (28 F.R. 2134), incorporating many detailed specifications regarding acceptable shipping methods. Public response to that proposed revision suggested that the detailed standards proposed might impair the growth of the industry and development of improved safety concepts and that the regulation should emphasize performance standards rather than detailed design standards. Proposed Part 72, 'Protection Against Radiation in the Shipment of Irradiated Fuel Elements' (26 F.R. 8982, 28 F.R. 2142), which proposed standards and procedures for packaging and transport of irradiated solid nuclear fuel, elicited a similar public response.

"On December 21, 1965, the AEC published for comment a proposed revision of Part 71 (30 F.R. 15748). The proposed revision combined the standards for unirradiated and irradiated fissile material previously proposed separately as Parts 71 and 72 , and added standards and procedures for the shipment of large quantities of licensed material. It emphasized performance standards to determine the adequacy of proposed shipping methods, with the method of satisfying those performance standards left to the ingenuity of the shippers. The proposed performance standards would be comparable with those developed by the International Atomic Energy Agency during the past 2 years.

"Subsequent to the publication of [the] proposed Part 71, a Memorandum of Understanding between the Interstate Commerce Commission (ICC) and AEC was signed. In the Memorandum, the two agencies agreed, subject to their respective statutory authorities, that (1) ICC will adopt appropriate regulations and requirements applicable to transport of all radioactive materials, and to shippers of all types and quantities of radioactive materials, but will avoid duplicatory standards with respect to preparation for shipments of fissile materials and large quantities of radioactive material, and (2) AEC will adopt appropriate regulations applicable to standards for the preparation for shipment of fissile material and large quantities of radioactive material and will be responsible for the adoption of regulations and requirements applicable to its licensees or contractors as may be necessary to protect against radiation and criticality hazards in the transportation of all radioactive material where shipment is outside the regulatory jurisdiction of ICC.

"Under the Memorandum of Understanding, the ICC will utilize the assistance of AEC on container approvals for fissile materials and large quantities of radioactive materials. The AEC and ICC are working together to develop criteria for additional 'specification containers' in order to reduce the number of special container permits issued by the ICC.

"Several changes have been incorporated in the regulation, as adopted, as a result of the Memorandum of Understanding, and the publication of amendments to ICC regulations on April 29, 1966 (31 F.R. 6492), covering some of the same areas covered in the notice of proposed rule making published by the AEC on December 21, 1965 (30 F.R. 15748). Thus, the following provisions that were contained in that AEC proposed rule have been omitted in the effective rule ... :

1. Section 71.11 of the proposed rule, which would have imposed ICC requirements through AEC authority;

2. References throughout the proposed rule to transport of radioactive material by a licensee;

3. The radiation level limitations in proposed $\S 71.34$;

4. The definitions of 'milliroentgen per hour or equivalent' and 'transport unit' in proposed $\S 71.4(\mathrm{j})$ and $(\mathrm{u})$;

5. The requirement in proposed $\S 71.40$ (b) that a Fissile Class II package be labelled [sic] as prescribed by ICC, although the procedure for determining the minimum 'radiation unit' for criticality control has been retained;

6. The requirement in proposed $\S 71.40$ that a licensee not transport or deliver to a carrier more than 40 units of Fissile Class II packages, nor a single package with a calculated radiation unit of more than 10 ;

7. The requirement in proposed $\S 71.41$ (b) for Fissile Class III transport procedures to protect against commingling with other fissile material;

8. The requirement in proposed $\S 71.54$ for routine determinations with regard to the radiation level limits, surface contamination limits, and transport procedures.

"The definition of 'carrier' in proposed $\S 71.4$ has been modified to conform to usage under the Transportation of Explosives and Other Dangerous Articles Act (18 U.S.C. $\S \S ~ 832-837)$, which is administered by the ICC.

"Other significant differences from the regulation published for comment are:

1. The definition of the term 'fissile material' has been restricted to those isotopes of uranium and plutonium which must now be controlled during transport to avoid criticality.

2. A requirement in proposed $\S 71.31$ (b) which imposed a temperature standard on the materials and fabrication of packaging has been deleted. Correspondingly, the temperature to be considered for Normal Conditions of Transport set out in Appendix A has been increased from $100^{\circ} \mathrm{F}$. to $130^{\circ} \mathrm{F}$. This increased ambient temperature would provide for the more extreme 
conditions which might be encountered in normal transport.

3. The requirement in proposed $\S 71.31$ (e) that primary coolant not circulate outside of the shielding has been deleted.

4. The lifting and tie-down device requirements in proposed $\S 71.31$ (f) and (g) have been modified to make it clear that the standards apply only to devices which are a structural part of the packaging. The modified requirements are included in $\S 71.31$ (c) and (d) ....

5. The pressure design standards of the proposed $\S 71.32(\mathrm{~b})-(\mathrm{d})$, including that for a pressure relief device, have been replaced by an internal pressure test to be initially performed on each individual package which will be subjected to significant internal pressure, set out in $\S 71.53(\mathrm{~b})$.

6. The specific temperature restriction, contained in proposed $\S 71.33$, on large quantity packages, assuming loss of coolant and cooling devices, has been omitted, as has the corresponding test requirement of proposed $\S 71.53(\mathrm{~b})$. Temperature restrictions will be effectuated through the performance standards of $\S \S 71.35$ and 71.36. Requirements have been included in $\S 71.35 \ldots$ to assure that there will be no loss of coolant under the Normal Conditions of Transport.

7. The limitation on loss of shielding under Hypothetical Accident Conditions (Appendix B) has been revised to specify an allowable increase in radiation levels to 1,000 milliroentgens per hour or equivalent at 3 feet from the external surface of the package.

8. The provisions relating to assumed inleakage of water to and outleakage of liquids from fissile material packages in determining subcriticality in proposed $\S 71.37(\mathrm{~b})(3)$ have been revised and redesignated $\S 71.33$.

9. The requirement in proposed $\S 71.39$ (a) that Fissile Class I packages be considered with other types of Fissile Class I packages has been deleted as unnecessary in view of the provision for assumed interspersed moderation.

10. The requirement in proposed $\$ 71.51$ (a) for licensee quality control procedures has been replaced by a performance requirement in $\S 71.53$ (c) ... that the licensee assure that the packaging is fabricated in accordance with the design approved by the AEC.

11. The list of items to be included in a licensee's operating procedures required by proposed $\S 71.51(\mathrm{~b})$ has been deleted from the regulation.

"Additional minor changes from the proposed rule have been incorporated in the effective rule.

"The rule ... establishes packaging standards for the shipment of fissile material, both unirradiated and irradiated, and of large quantities of licensed radioactive material. The rule specifies the quantities and methods of transport which are exempt from
Part 71 requirements and those which are under a general license. The exemption and general license provisions are applicable to shipments which from a safety standpoint do not require an AEC packaging evaluation. Those shipments are subject to regulation by federal transport agencies. For shipments not exempted or generally licensed, the rule prescribes the determinations which must be made with respect to packaging and shipping precautions required in order to assure nuclear safety of shipping methods.

"With a few exceptions, the basic organization and standards ... have not been changed significantly from those contained in the notice of proposed rule making, issued on December 21, 1965 (30 F.R. 15748). A detailed explanation of the organization and standards of Part 71 is made in the notice of proposed rule making.

"The rule ... divides radionuclides into a number of groups, each having a comparable potential hazard in transport. These groups were derived from the International Atomic Energy Agency's Safety Series No. 6, 'Regulations for the Safe Transport of Radioactive Materials,' 1964 Revised Edition....

"Published simultaneously with proposed 10 CFR Part 71 on December 21, 1965, were certain proposed amendments to 10 CFR Parts 30 and 70 (30 F.R. 15748), the basic licensing regulations for byproduct and special nuclear material, respectively, containing a reference to Part 71. Those amendments are no longer considered necessary and that notice of proposed rule making is, accordingly, withdrawn.

"Pursuant to the Atomic Energy Act of 1954, as amended, and the Administrative Procedure Act of 1946, the following revision of 10 CFR Part 71 is published as a document subject to codification, to be effective 30 days after publication in the FEDERAL REGISTER....'[1]

Thus, with little fanfare, the first, real version of what we would now recognize as 10 CFR 71 went into effect on August 21, 1966. For Type B packaging requirements, we have been living within the basic constraints of those regulations ever since.

\subsection{MAJOR CHANGES - 1968}

In 1968, a series of substantive changes was introduced into the U.S. regulations for the transportation of radioactive materials. Two of these changes, a proposed rule and a final rule, were introduced into the DOT regulations; one month later, a set of miscellaneous changes was introduced into the AEC's regulations. Each of these changes will be examined in more detail below.

\subsubsection{DOT Changes - 1968 Proposed Rule}

In January, 1968, the DOT (formerly the ICC) introduced a major set of proposed rule changes to its existing Hazardous Materials Transportation Regulations (49 CFR 170-190).[8] In order to demonstrate the interactive linkage between the regulations of the DOT, the AEC, and the IAEA, the text of the 
preamble for this set of proposed rule changes is, for the most part, reproduced below:

"On April 1, 1963, the Interstate Commerce Commission (ICC) published its Notice No. 58 in Docket No. 3666. The notice proposed to modify the ICC Regulations for transporting radioactive materials to bring them into accord with the recommended regulations of the International Atomic Energy Agency (IAEA). Based upon the comments received pursuant to that notice of proposed rule making and after discussion with representatives of the U.S. Atomic Energy Commission (USAEC), it became apparent that it would not be in the public interest to adopt those amendments at that time. This area of regulation was transferred to the Department of Transportation by the Department of Transportation Act (80 Stat. 931).

"Since that time this Department, the ICC, and the Atomic Energy Commission have worked toward the preparation of a revision to the radioactive materials regulations. Many meetings have been held between industry and Government representatives. Several significant 'enabling' regulatory amendments have been adopted which now make it practical to propose a revised major revision of these regulations. In 1966, the USAEC published its packaging standards in Part 71 of Title 10, CFR. At the same time, the ICC published Order No. 70 relating to transportation of fissile radioactive materials. Early in 1967, the ICC also published Order No. 74 which made further modifications regarding radioactive materials.

"During the past 18 months, a task force comprised of representatives of the USAEC and its contractors prepared a series of draft regulatory changes designed to incorporate the principles of the recommended regulations of the IAEA into the regulations as amended by Orders 70 and 74. These drafts were further modified as a result of participation by representatives of the ICC, Federal Aviation Administration, U.S. Coast Guard, and various atomic energy and transportation industry personnel. The results of all of these reviews and discussions are reflected in this notice of proposed rule making.

"This notice includes proposed amendments to the Hazardous Materials Regulations of the Department of Transportation (49 CFR Parts 171-178) (formerly a part of the ICC Regulations) and Part 103 of the Federal Aviation Regulations (14 CFR Part 103). The purpose of this notice is to request public comment on procedures proposed for the transportation of radioactive materials. Interested persons are invited to participate in the making of proposed rules by submitting such written data, views, or arguments as they may desire....

"Communications received ... would be considered by the Board before taking final action on the notice. All comments will be available for examination by interested persons ... both before and after the closing date for comments. The proposals contained in this notice may be changed in light of comments received.

"Several references are made in the proposed regulatory amendments to authorizations issued under Part 170 of Title 49, CFR. Part 170 has been reserved for the Rules of Procedure for the Hazardous Materials Regulations Board. Part 170 has been published as a notice of proposed rule making but has not yet been adopted. It is expected that Part 170 will be in effect before the expiration of the comment period for this notice of proposed rule making. Part 170 will include the procedures for general rule making as well as those for handling applications for special permits.

"The basic consideration in the transportation of radioactive materials is that they may present radiation and contamination hazards to transportation workers, passengers, and the general public. In addition, radiation exposure may damage other materials in transport, such as undeveloped photographic film. The proposed regulatory amendments will provide for the control of these potential hazards by considering the three basic factors of (1) relative hazard potential (2) packaging performance and (3) the transportation environment. The existing regulations place the primary emphasis on the packaging requirements for normal conditions of transportation. The proposed revisions will provide a system of allowing sufficient emphasis to be placed not only on the normal conditions of transportation, but also on the environmental conditions which a packaging of radioactive materials might encounter in an accident.

"This notice of proposed rule making establishes a separate hazard classification category for radioactive materials, apart from the poisonous category. Radioactive materials would be classified as radioactive materials and not as Class ... D poisons as they currently are. Appropriate changes are being proposed to the commodity list in Part 172.

"Several provisions which are presently contained in the regulations of the U.S. Atomic Energy Commission, title 10 CFR Part 71, have been incorporated into this proposed revision. Examples are the definitions of 'special form,' 'normal form,' and 'large quantities' of radioactive materials.

"A major change is proposed in the method of hazard identification of radioactive materials. Assignments of hazard categories which are based solely upon the type of radiation emanating from the package is [sic] not truly representative of the transportation hazards to be considered. The proposed system is based instead upon the radiotoxicity of the isotope concerned. The hazard potential of radioactive materials is defined by consideration of radiotoxicity and physical form, and by assigning each radionuclide to an appropriate 'transport group.' In addition, some special classes of materials are 
considered, such as very large or very small quantities, low specific activity materials, and fissile materials. This system is presently prescribed in [the] regulations of the Atomic Energy Commission, 10 CFR Part 71.

"Another major area of change is in package identification. A new labeling system is proposed to conform to the recommendations of the United Nations and the IAEA. The labels will also be used to determine the need for placarding of vehicles. A later regulatory proposal will incorporate the remainder of the U.N. labels for other hazardous materials.

"The proposed regulatory changes will provide more types of specification packaging[s], increased flexibility for the shipper in terms of new package development, and a clearer definition of the criteria which the Department will be using to evaluate the adequacy of various packaging methods.

"A further change would allow an increase in the amount of radioactive material that may be carried aboard a vehicle from 40 to 50 units. This revision would also change the name for the term 'radiation unit' to 'transport index.'

"Proposed new $\S 173.393$ contains a number of general packaging requirements, many of which are in the existing regulations. Sections 173.394 and 173.395 contain the particular packaging requirements for special form and normal form radioactive materials. These two sections could be combined into a single section but there have been indications from industry sources of the desirability of separation. Section 173.396 proposes specific packaging requirements for fissile material. This section is essentially unchanged from the present regulations except for some additional flexibility in the packaging of small amounts of fissile materials. Sections 173.396[a] and 173.397 incorporate the provisions included in the existing $\S 173.392$ for 'exempt quantities,' and also make an additional provision for the transportation of contaminated items and bulk low specific activity materials. Section 173.398 prescribes the special test conditions for special form material and for the hypothetical accident conditions of transportation. These provisions are presently contained in Part 71 of the USAEC regulations. Section 173.399 prescribes new labeling requirements. Section 173.399[a] consolidates and updates the general contamination control requirements.

"Appropriate changes are proposed for Parts 174, 175, and 177 to incorporate the new placarding requirements, to increase the transport index from 40 to 50 , to delete certain consignee requirements that are not within the jurisdiction of these regulations, and to provide for more comprehensive distancetime handling provisions.

"In Part 178 revisions are made to specifications $6 \mathrm{~L}$ and 12B, and two new specifications are being proposed. Specification $6 \mathrm{~L}$ is being modified to provide a wider flexibility in drum size and centering mechanisms. Tests have shown the inadequacy of the present closure requirements and the specification is being modified to require higher strength locking rings. A newer specification $6 \mathrm{M}$ metal package is being proposed for both fissile and nonfissile radioactive materials. ${ }^{* *}$ The special specification 12B fiberboard box for radioactive materials would be deleted since the requirements contained therein would now be included in $\S 173.393$. A new specification 7A general package is being proposed for radioactive materials. Specification 7A provides for performance criteria rather than detailed engineering design requirements. The shipper would be given a great deal of flexibility in the exact design of his specification 7A package.

"A number of editorial changes are being proposed in this Notice which do not directly bear on substantive requirements for the transportation of radioactive materials, but are being made in related provisions as a part of the general updating of the regulations. Examples are in the changes being proposed for $\S \S 173.22,173.23,173.24$, and 173.28.

"In Part 103 of 14 CFR appropriate amendments are being proposed to incorporate the provisions of the general revision into the Hazardous Materials Regulations applicable to aviation. At the same time, $\S 103.3$ is being amended to reflect Amendment No.75 regarding shipping paper requirements. Several other minor changes are being proposed to provide consistency between Parts 174-177 and Part 103.

"Since the Federal Aviation Administration does not exercise jurisdiction over the handling and storage of hazardous materials in air freight terminals or other storage locations outside of aircraft, the provisions for handling, storage, and accidents are limited to aircraft only. However, the Department is considering the need for providing similar safeguards in connection with the storage and handling of radioactive materials at all times once they have entered into the realm of air transportation.

"Paragraph (d) of $\S 103.23$ would be deleted from Part 103 under this proposed amendment. This provision makes the shipper and the carrier jointly

Author's Note: As a DOT Specification package, the 6M package was, in effect, a Type B fissile shipping container that would be used extensively throughout the AEC-, the ERDA-, and the DOE-Complex, for more than 30 years. As a DOT Specification package, however, the $6 \mathrm{M}$ was not subject to the Hypothetical Accident Condition test requirements specified in 10 CFR 71 . While this was not a problem in 1968, it would become a problem when the majority of the licensing responsibilities for Type B packages was transferred from the DOT to the AEC. (See Sections 52.5.1 and 52.5.2.) Although it would still be around for decades, the beginning of the end of the $6 \mathrm{M}$ package would eventually come with the regulatory changes introduced in 2002, and finalized in 2004. (See Sections 52.16 and 52.17, respectively.) 
responsible for providing personnel monitoring devices. There are no similar requirements for rail, highway, and water, and the experience of the transportation industry has been that none are required $[s i c]$ in these regulations. The Atomic Energy Commission, the Department of Labor, and the Department of Health, Education and Welfare already have established standards for exposure control of people. Removal of the requirement does not, of course, preclude the carrier or the shipper from fulfilling his responsibilities in this area.

"This amendment is proposed under the authority of Title 18, United States Code, section 9 of the Department of Transportation Act (49 U.S.C. 1657), and Title VI and section 902(h) of the Federal Aviation Act of 1958 (49 U.S.C. 1421-1430 and 1472(h))

"In consideration of the foregoing, it is proposed to amend Titles 14 and 49 of the Code of Federal Regulations as hereinafter set forth...."[8]

\subsubsection{DOT Changes - 1968 Final Rule}

In October 1968, the DOT published the final version of its regulatory changes, based on the comments it had received as a result of its proposed rulemaking, earlier in the year.[9] The text of the preamble for this final set of rule changes is, for the most part, reproduced below:

"On January 20, 1968, the Hazardous Materials Regulations Board published Docket No. HM-2; Notice No. 68-1 (33 F.R. 750), which proposed amendments to the Department's Hazardous Materials Regulations (49 CFR Parts 170-190 and 14 CFR Part 103). These proposals dealt with a major revision to the regulations for the transportation of radioactive materials, along with a number of other general packaging modifications. The public was given 90 days for comment. Numerous comments were filed and have been studied by the Department staff. Several meetings and discussions were held with staff personnel of the U.S. Atomic Energy Commission (AEC), as required by 18 U.S.C. 834(b), and the amendments reflect the results of those discussions. All other comments suggesting changes, additions, or deletions were carefully considered.

"One of the most controversial items in the notice of proposed rule making involved the proposed changes in the regulations for the transportation of radioactive materials by air and bus. Restrictions on shipments of radioactive liquids and shipments of packages having significant external radiation levels had been proposed. After consideration of the comments received, and after evaluation of the impact of the proposal on the atomic energy industry, particularly with regard to the use of radiopharmaceuticals, those proposed restrictions have been deleted, and the present provisions for such shipments have been retained. No regulatory restrictions on [the] shipment of large quantities of radioactive materials are considered necessary since each such shipment is covered by a Department special permit. Each situation can then be analyzed on its own merits, and appropriate restrictions can be imposed in the language of the permit.

"Numerous comments were received regarding suggested changes to the Department's proposed labeling system for radioactive materials packages. The proposed system was in harmony with the regulations of the International Atomic Energy Agency (IAEA) and the proposed regulations of the United Nations. Certain parties in the United States felt that those international standards are not appropriate in all respects for U.S. usage, and asked that the use of the labels be modified accordingly. However, the Department believes that the interests of international harmony in this area are overriding, and has retained the IAEA-type labels and labeling criteria. The Department will pursue the item further with the IAEA to determine if changes could be made in the international standards which would reflect the total United States interests.

"Many of the modifications in these amendments will require parallel changes in the AEC regulations (10 CFR Part 71) to assure harmony between the two complementary sets of regulations. The AEC has indicated that it expects to be able to publish the necessary amendments to its Part 71 prior to the effective date of these amendments.

"Many of the new procedures prescribed in these amendments have been previously authorized by Departmental special permits. Special Permit No. 5000 authorized the use of a drum-type birdcage now listed as the Specification $6 \mathrm{M}$ package. Special Permit No. 5300 authorized the use of a type of packaging now listed as the Specification 7A package. Special Permit No. 5400 provided for the shipment of enriched uranium under the terms of $\S 71.6$ of the AEC regulations, and the terms of that permit are now included in $\S 173.396$ of these regulations. Special Permit No. 5417 provided for the transportation of radioactively contaminated items, and the terms of that permit are not included in the low specific activity provisions of $\S 173.392$. Accordingly, those special permits are no longer appropriate, and are hereby terminated. Several of the carriers objected to increasing the transport index from the present limit of 40 to a new limit of 50 . Although this increase means that more radioactive materials could be carried aboard a vehicle, it does not present a significant increase in hazard. The extra packages may only be carried under additional transport controls for segregation of packages from passengers, transportation workers, and film. The increase is not mandatory, but only allows more packages to be carried. Each carrier is still free to load his vehicles as he sees fit within the overall regulatory limitations. Studies have shown that the previous limit of 40 was greatly overconservative 
[sic], and that the new limit of 50 would still provide adequate safety in transportation. The new limit will also provide a higher degree of consistency with the international regulations which already provide for a transport index of 50 .

"A large number of special permits have been issued for the transportation of fissile radioactive materials under Fissile Class II conditions. Because these amendments reflect the international standard of a transport index limit of 50, rather than the 40 radiation unit maximum presently prescribed in the U.S. regulations, a modification of these permits must be made in order that the number of Fissile Class II packages per vehicle remains the same. Therefore, for all special permits issued prior to September 26, 1968, the allowable transport index listed for Fissile Class II packages is increased by a factor of 1.25; i.e., an increase of 25 percent over the present assignments. All holders of such permits will receive individual notification of this change. Future special permits and revisions to existing permits will reflect the new criteria in making transport index assignments.

"The notice of proposed rule making did not utilize the Type A-Type B quantity provisions of the IAEA regulations, but instead referred only to specified quantities of radioactive materials for the various categories of packaging. This was done at the request of a number of interested parties in the atomic energy field. These parties felt that there was a certain stigma attached to these terms as a result of previous unsuccessful rule making efforts by the Interstate Commerce Commission. However, the comments received indicated that the use of those IAEA terms would be not only acceptable but would clarify and simplify the packaging provisions. Accordingly, those terms are defined and used in these amendments.

"On February 28, 1969, all existing Bureau of Explosives (Association of American Railroads) permits for radioactive materials packages will expire. Many comments indicated that the regulations were not sufficiently clear as to whether those previously authorized containers could ever be used again. The acceptability of these containers after February 28, 1969, will be a function of their ability to meet the prescribed structural integrity, shielding, and thermal resistance criteria. In each case, the shipper should examine the design and construction details of his container and compare them to the new regulations. If the container does not fit within one of the prescribed categories or usages, he may not use the container after that date without first having secured a Department special permit. The Department's safety evaluation of each of those containers will be based upon the criteria in these amendments. The detailed procedures for petitioning the Department for a special permit are prescribed in Part 170 of these regulations. Part 170 was published in the FeDERAL Register on June 3, 1968 (33 F.R. 68-6562)...

"The present regulations in $\S 173.393$ mention that containers authorized by the Interstate Commerce Commission (now the Department) under special permit may be used for the transportation of radioactive materials. In the light of the recent publication of Part 170, those statements are extraneous, and have been deleted. This does not mean to imply, however, that special permits are no longer available. Any person may petition the Department to use a container which is not prescribed in the regulations, whether for radioactive materials or any of the other hazardous materials covered in the regulations.

"A number of comments were received, primarily from carrier interests, objecting to the shifting of responsibility for vehicle monitoring from the consignee to the carrier. They stated that they had neither the trained personnel nor the equipment to perform such services. The Transportation of Explosives Act (18 U.S.C. 831-835), which gives the Department the responsibility for developing and administering regulations for the safe transportation of hazardous materials, limits the Department's jurisdiction to shippers and carriers. The Department cannot impose requirements on consignees since it has no jurisdiction over them. Carriers have historically been responsible for cleaning up spills of other hazardous materials in their vehicles or on their property. Their responsibility with respect to radioactive materials is no different. The amended regulations prescribe performance standards for monitoring and cleanup of spills. The carrier may utilize the services of any qualified person, including the consignee, in performing the required functions. The present regulations often refer to actions to be carried out by the shipper or his authorized agent. Since 18 U.S.C. 831 includes a shipper's authorized agent in the definition of a shipper, the use of both terms in the same regulatory provision is redundant. Where the term shipper appears in the regulations, it is implied that the term includes his authorized agent. Accordingly, several of the sections have been modified to delete the reference to the authorized agent.

"The Department acts as the U.S. competent authority as that term is used in the IAEA regulations. In issuing special permits for radioactive materials packages, the Department is often asked to provide the certificate required of competent authorities in the IAEA regulations. The details of these certificates are outlined in Marginal C-6 of those regulations. In order to provide this information, it will be necessary for the petitioner for the special permit to certify in his petition that his packaging, and the contents (particularly with respect to the special form criteria), meet all of the standards prescribed in the IAEA regulations. Although these amendments will bring the $\mathrm{U}$ S. regulations more in harmony with the 
international standards, there are still some significant differences that will be dealt with in future rule making actions. It is the shipper's responsibility, as prescribed in $\S 173.393$, to make the determination that his package meets all of the requirements of the foreign countries as well as the United States, and the shipper must certify to the Department that he has made that determination. He must present to the Department the basis of his evaluation that those standards have been met. The Department will review the petitioner's data and, if it is satisfied that the petitioner has in fact made a proper determination, it will issue the necessary IAEA certificate as a part of the special permit.

"Several comments indicated that there will be difficulty in complying with the placarding requirements unless there was some indication on the shipping papers as to the type of label required for the packages being shipped. The Board agrees that the shipping paper should contain adequate information from which the placarding requirement can be determined and has therefore amended $\S 173.427$ to require that the shipping paper description include the type of label required.

"A number of additional editorial changes have been made throughout the regulations to correct such items as references to radioactive materials as Class D poisons, correction of paragraph references, and incorrect format.

"At the request of a number of interested parties, the order of presentation of the radioactive materials packaging criteria in Part 173 has been modified to clarify the applicability of certain requirements, and to simplify the use of the regulations. This modified order of presentation is also more in harmony with the regulations for transportation of other hazardous materials.

"In addition to the general changes discussed above, a number of specific changes to the notice of proposed rule making are worthy of highlighting.

"Proposed $\S 173.22$ has been modified to separate the subject of shipper's responsibility from the types of packages authorized under 'grandfather clauses.' The latter have been included in a new $\S 173.23$. In $\S 173.23$, two additional months have been provided for continued use of packages operating under permits from the Bureau of Explosives. The expiration date of the $\mathrm{B}$ of $\mathrm{E}$ permits is now February 28, 1969.

"A table of steel thicknesses has been added to the general construction standards in $\S 173.24$. The general prohibition against vented packages has been deleted.

"In $\S 173.29$, the 'Empty' label is now required to be affixed to empty radioactive materials packagings.

"In $\S 173.389$, the definition of 'fissile materials' has been clarified so that it agrees with the current definition in 10 CFR Part 71 of the USAEC
Regulations. The use of the transport index numbers has also been clarified. New definitions for 'large quantity' radioactive materials 'Type $A$ ' and 'Type B' quantities, and 'Type A' and 'Type B' packaging have been included to obviate the need for repetitive definitions throughout the packaging regulations.

"In $\$ 173.390$, an additional transport group, Group VII, has been added to conform with the IAEA regulations, and to obviate the need for descriptive limits throughout the packaging regulations. The provisions for determining the transport group of unknown mixtures have been expanded to conform with the IAEA definition.

"In $\S 173.391$, a total package limit has been placed on the amount of tritium which may be shipped under the exemption. The permissible contamination limits for the exempt packages has [sic] been changed from 'detectable' to 'significant removable.' The requirement for the marking 'Radioactive' on exempt devices has been deleted, and the maximum radioactivity content of each such device has been modified to conform with the IAEA regulations. An exemption has been added to provide for packagings in which natural or depleted uranium (such as shipping casks) is incorporated into the packaging.

"Proposed $\S 173.393$ has been modified to provide for a security seal, similar to the present special permit requirements, and in accord with the IAEA provisions. Section 173.393(d) has been clarified with regard to the requirements for internal bracing. Section 173.393 now includes restrictions on the surface temperatures in order to prevent injury to employees and to reduce the fire hazard to other cargo. The temperature restrictions are those commonly provided in special permits. Special permits are required for all shipments involving high internal decay heat, so this addition represents no change from present practice. Pyrophoric liquids are not authorized for air transportation under either the IATA $^{\dagger \dagger}$ or the IAEA regulations, and that restriction has been noted in $\S 173.393(\mathrm{f})$. Section 173.393(g) has been modified to remove the requirement that the inner container be made of metal. Section 173.393(j) has been reworded for clarification as to its applicability. The radiation level restrictions for occupied positions in private vehicles have been removed, since radiation exposures to personnel operating or riding in those vehicles are adequately controlled by existing regulations of the AEC and the Department of Labor.

"Proposed $\S 173.394$ and 173.395 have been modified to provide for delivery of IAEA Type A packages to their destination in the United States without need for special permit. Type B packages, other than Spec. 55 or 6M, will require Departmental

\footnotetext{
Author's Note: The IATA is the International Air Transport Association.
} 
approval in every case at the present time due to a lack of specification containers for Type B quantities.

"Proposed $\S 173.396$ has been modified to provide for package limits for the Specs. $6 \mathrm{~L}$ and $6 \mathrm{M}$ metal packages. The limits are presently specified in Part 178.

"Proposed $\S 173.398$ has been modified to prescribe the criteria for Type A packages (normal conditions incident to transportation) as well as the previously prescribed criteria for Type B packages (hypothetical accident conditions). The allowable release of radioactive material from packages under the Type $B$ tests, and the test conditions themselves, have been clarified to conform with the present requirements of 10 CFR Part 71 of the AEC or the IAEA regulations.

"In proposed $\S 173.399$, the reference to a zero transport index for the white label has been deleted. An additional example of dual labeling requirements is shown for radioactive materials containing nitric acid. Provisions have been included in $\S 173.402$ to require two radioactive materials labels on opposite sides of each package, and to allow the use of foreign labels which conform to the IAEA regulations. Labels for other hazardous materials which are required for air transportation are authorized for surface transportation as well.

"The proposed change in the package marking requirements for full-load shipments of all hazardous materials has been retained. These requirements have been in effect for all shipments by water and for Department of Defense shipments for many years.

"The provisions of paragraph (b) have been modified to reflect the shipping paper requirements of $\S 173.427$, which itself has been changed to include informational material required on the shipping papers for radioactive materials shipments. These informational modifications conform to the IAEA regulations. Section 173.430 has been modified to allow for the use of an optional reference to IATA regulations for air shipments.

"Proposed $\S 177.870(\mathrm{~g})$ has been modified to allow transportation of radioactive materials on buses under essentially the same conditions as [is] presently provided for. Storage and loading restrictions have been prescribed in place of the proposed prohibitions for Category II and III packages.

"Specification $2 \mathrm{R}$, in $\S 178.34$, has been modified to provide for reduced size of the letters of identification.

"A number of cylinder specifications have been corrected to reflect the proper cross-references to Part 173.

"Specification 6L, in $\S 178.103$, has been modified to provide for additional types of spacers ('spiders'). The total quantity of required vermiculite has been deleted as extraneous because the required density provides automatically for the total weight control. Marking requirements have been modified to conform with other steel drum requirements. Closure requirements have been modified to require a specified metal thickness and locking ring attachment. Recent accident tests demonstrated the inadequacy of the more common lightweight locking rings. Loading capacity limitations have been relocated to $\S 173.396$.

"Section 103.31 of Title 14 has been modified to clarify the identification of certain labels used on mixed cargoes.

"Because of the complex nature of these amendments, and the impact that they will have on the transportation of radioactive materials, and to allow a reasonable time for compliance with the changes made herein, the effective date of the amendments is December 31, 1968. However, compliance with these amendments is authorized on and after the date of publication in the FEDERAL REGISTER.

"In consideration of the foregoing, the Hazardous Materials Regulations of the Department of Transportation (14 CFR Part 103 and 49 CFR Parts 170-190) are amended effective December 31, 1968 ....'[9]

\subsubsection{Miscellaneous Changes, AEC -1968}

In November 1968, a set of miscellaneous amendments was introduced into the requirements of 10 CFR 71.[10] The purpose of this set of amendments was to bring the requirements of $10 \mathrm{CFR} 71$ into agreement with the recently introduced changes in the requirements of 49 CFR Parts 170 190. [8, 9] Again, for the most part, the text of the preamble for this set of amendments to 10 CFR 71 has been reproduced below:

"On July 22, 1966, the Atomic Energy Commission published in the Federal Register (31 F.R. 9941) regulations for the packaging of fissile material and large quantities of licensed radioactive material, 10 CFR Part 71. The explanatory statement indicated the relationship of those regulations to the safety regulations of the Interstate Commerce Commission (ICC). Among other things, the regulations of the ICC under the Transportation of Explosives and Other Dangerous Articles Act prescribed the conditions of transportation for shipments prepared in accordance with 10 CFR Part 71.

"On April 1, 1967, the functions of the ICC under the Transportation of Explosives and Other Dangerous Articles Act were transferred to the Department of Transportation (DOT). The DOT has continued to apply the former ICC regulations pertaining to safety in the transportation of radioactive materials; those regulations are now known as the DOT's Hazardous Materials Regulations (49 CFR Parts 170-190, 14 CFR Part 103).

"On January 20, 1968, the DOT published in the Federal Register (33 F.R. 750) for comment, as Notice 68-1, Docket No. HM-2, a proposed major revision of its regulations for transporting radioactive material. The DOT has given due consideration to the numerous comments received and, after 
consultation with the AEC and the atomic energy industry, has made modifications in the proposed requirements. On October 4, 1968, the DOT published in the Federal Register (33 F.R. 14918) a revision of its regulations pertaining to safety in transport of radioactive material, authorizing compliance on publication and making the amendments effective on December 31, 1968. The changes in the Commission's 10 CFR Part 71 set out below will conform 10 CFR Part 71 with the revision of the DOT regulations. Since the revision of the DOT regulations was published for public comment, the Commission has found that good cause exists for omitting notice of proposed rulemaking and public procedure thereon with respect to the following changes to $10 \mathrm{CFR}$ Part 71 , to the revision of the DOT regulations, as unnecessary.

"One change in the DOT regulations which directly affects AEC licensees is the change from a limit of 40 radiation units to a maximum transport index of 50 in a single vehicle or storage area. To implement that change, all existing licenses which authorize Fissile Class II packages are amended by a new $\S 71.14$ to increase the minimum number to be placed on each Fissile Class II packaged [sic] by a factor of 1.25. All holders of such licenses will receive individual notification of this amendment.

"Pursuant to the Atomic Energy Act of 1954, as amended, and sections 552 and 553 of the United States Code, the ... amendments of 10 CFR Part 71 are published as a document subject to codification, to be effective December 31, 1968. Compliance with these amendments is authorized on and after the date of publication in the FEDERAL REGISTER."[10]

\subsection{TRANSFER OF LICENSING RESPONSIBILITIES FROM DOT TO AEC}

In 1971 and in 1973, the AEC published a proposed rulemaking and a final rulemaking, respectively, the title of which, in both cases, was the Approval of Type B, Large Quantity and Fissile Material Packagings.[11, 12] In both cases, the rulemakings had to do with the transfer of specific licensing requirements from the DOT to the AEC. The preambles, for both sets of rulemakings, are presented below.

\subsubsection{Approval of Type B, Large Quantity and Fissile Material Packagings - 1971 Proposed Rule}

"On January 8, 1971, with the agreement of the Atomic Energy Commission, the Hazardous Materials Regulations Board of the Department of Transportation (DOT) published in the FEDERAL Register a notice (Docket No. HM-73; Notice 71-1) proposing to transfer the administrative requirement for approvals of radioactive materials packages from the Department to the U.S. Atomic Energy Commission (AEC). Interested persons were invited to comment on the proposal within 60 days after publication of the notice in the FEDERAL REGISTER. After consideration of the comments and consultation with the AEC and the atomic energy industry, in a separate document published on page 22181, the DOT is publishing a revised notice of proposed rule making proposing amendments to 49 CFR Part 173 which would transfer the administrative requirement for approvals of radioactive materials packages to the AEC. The amendment would provide, inter alia, that DOT discontinue issuing special permits for packagings except for waivers or exemptions from DOT regulations and that shippers be required to have AEC approval for routine packaging for type B, large quantity, and fissile material shipments.

"The proposed changes in 10 CFR Part 71 set out below would provide a means for implementing the transfer of packaging approvals from DOT to AEC by adding to Part 71, standards and requirements for AEC approval of type $B$ packagings and describing the procedures for obtaining AEC approval of type B, large quantity, and fissile material packagings.

"The provisions of Part 71, in effect since August 1966, require AEC licensees who wish to ship fissile material or large quantities of byproduct, source, or special nuclear material to apply to the AEC for a license or license amendment indicating AEC approval of the type of package to be used. The amendments published herein would require AEC licensees also to apply for a license or license amendment approving of the package to be used to deliver to a carrier type $\mathrm{B}$ quantities of radioactive material.

"The proposed amendments to the DOT regulations, published concurrently, would require AEC approval of packagings, other than specification packagings prescribed in the DOT regulations, which are used to ship any quantity of fissile material, or more than a type A quantity (i.e., a type B or large quantity) of other radioactive material. AEC approval could be (1) a license (either specific or general) or license amendment issued under 10 CFR Part 71, (2) an administrative approval issued to AEC contractors by AEC field offices in accordance with standards and procedures published in the AEC manual, or (3) an approval issued by the AEC's Division of Materials Licensing to persons under DOT jurisdiction who are not AEC licensees. The latter category of non-AEC licensees would include, for example, agreement State licensees and radium shippers who wish to ship type B or large quantities of radioactive material.

"To obtain AEC approval, all persons, other than AEC license-exempt contractors, would be required to submit an application to the Director, Division of Materials Licensing, U.S. Atomic Energy Commission, Washington, D.C. 20545. The contents of the application are set forth in $\S \S 71.21,71.22$, 71.23, and 71.24 of 10 CFR Part 71. 
"AEC license-exempt contractors would apply to the appropriate AEC field office for approval in accordance with the provisions of the AEC manual.

"Provisions would be made for uninterrupted use of containers which have been in use under DOT special permits which are valid on the date the revised rule goes into effect. Each AEC licensee would be permitted to continue to use fissile material and large quantity packagings under the AEC license or license amendment which was issued to him by the AEC under 10 CFR Part 71. Under the proposed $\S 71.8$, an AEC licensee using a type B container under a valid DOT special permit would be allowed to continue to use that container until the AEC acts on an application which he had submitted no later than 90 days after the effective date of the rule or the expiration date of the special permit, whichever date is later.

"A non-AEC licensee, other than a license-exempt contractor, would be considered to have AEC approval for continued use of a type of packaging for which he had a DOT special permit in effect on the effective date of the amendments provided he submitted to the AEC a request for approval of that type of packaging within 90 days of the effective date or prior to the date on which the special permit expires, whichever date is later. This AEC approval would remain in effect until the application has been approved or rejected by the Commission.

"The proposed amendment to the DOT regulations, published concurrently, would authorize the use of packaging approved by the AEC. The amendment to DOT regulations also would require each person using a design of packaging approved for use by another to register with AEC prior to first use and to comply with the conditions of the original approval. AEC licensees are already required to follow that same procedure under the conditions of the general license in $\S 71.1(\mathrm{~b})$ of the AEC regulations.

"Other changes being proposed in 10 CFR Part 71 are minor editorial changes, redesignation of some sections to bring together the exemption provisions, and addition of a new $\S 71.7$ to exempt certain fissile materials from the nuclear criticality safety provisions of Part 71. Section 71.12, Limited exemption for shipment of special nuclear material would be deleted, since the authority granted by that section has expired.

"Pursuant to the Atomic Energy Act of 1954, as amended, and section 553 of title 5 of the United States Code, notice is hereby given that adoption of the following amendments to 10 CFR Part 71 is contemplated. All interested persons who desire to submit written comments or suggestions for consideration in connection with the proposed amendments should send them ... within 60 days after publication of the notice in the FEDERAL REGISTER. Comments received after that period will be considered if it is practical to do so, but assurance of consideration cannot be given except as to comments filed within the period specified..."[11]

In a prelude of things to come, the following new definitions were added to the proposed regulations:

“(q) 'Type A quantity' and 'Type B quantity' means [sic] a quantity of radioactive material the aggregate radioactivity of which does not exceed that specified in the following table:

\begin{tabular}{ccr}
\hline $\begin{array}{c}\text { Transport Groups } \\
\text { (Paragraph (p) } \\
\text { of this section) }\end{array}$ & $\begin{array}{c}\text { Type A } \\
\text { quantity } \\
\text { (in curies) }\end{array}$ & $\begin{array}{c}\text { Type B } \\
\text { quantity } \\
\text { (in curies) }\end{array}$ \\
\hline I $\ldots \ldots \ldots \ldots \ldots \ldots \ldots$. & 0.001 & 20 \\
II $\ldots \ldots \ldots \ldots \ldots \ldots \ldots$. & 0.05 & 20 \\
III $\ldots \ldots \ldots \ldots \ldots \ldots \ldots$. & 3 & 200 \\
IV $\ldots \ldots \ldots \ldots \ldots \ldots \ldots$ & 20 & 200 \\
V $\ldots \ldots \ldots \ldots \ldots \ldots$. & 20 & 5,000 \\
VI and VII $\ldots \ldots \ldots \ldots$ & 1,000 & 50,000 \\
Special Form ........ & 20 & 5,000 \\
\hline
\end{tabular}

Although the values cited in the above table would not last, the concept of Type A and Type B quantities of radioactive material had finally been introduced into the U.S. regulations. It was a concept that was here to stay.

\subsubsection{Approval of Type B, Large Quantity and Fissile Material Packagings - 1973 Final Rule}

"On November 20, 1971, the Atomic Energy Commission published in the Federal Register (36 FR 22184) proposed amendments to 10 CFR part 71 of its regulations. The proposed amendments would provide a means for implementing the transfer of the approval of type B packagings from the Department of Transportation (DOT) to the AEC (in its regulatory function) by adding to part 71 standards and requirements for AEC approval of type B packagings, and procedures for obtaining AEC regulatory staff approval of type B, large quantity, and fissile material packagings. The transfer of the approval function for packages used by license-exempt AEC contractors is being implemented by a change in AEC manual, chapter 5201. Proposed amendments to DOT regulations, published concurrently, would require AEC approval of packagings, other than specification packagings prescribed in the DOT regulations and packagings approved by a foreign national competent authority under the 1967 regulations of the International Atomic Energy Agency, used to ship quantities of fissile material which exceed the small quantities specifically exempted by DOT regulations or to ship quantities of other radioactive material which exceed type A quantities, as defined in DOT regulations.

"After consideration of the comments received and other factors involved, the Commission has adopted the amendments published for comment with the following changes: 
1. The definition of a 'Type A quantity' in $\S 71.4(q)$ has been modified to limit Californium-252 in special form to 2 curies instead of 20 curies, to conform to that limit recently introduced into DOT regulations.

2. The general license provided in $\S 71.12$ for shipment in DOT specification containers and in packages licensed for use by licensees has been amended to include packaging approved by a foreign national competent authority. The amendment to the DOT regulations, to be made effective concurrently, requires that packages approved by a foreign competent authority be revalidated by DOT before use in the United States.

3. In $\S 71.10$ the period during which persons are exempted from the requirements for an AEC approval for Type B packages being used under a DOT special permit has been lengthened from 3 to 6 months after the effective date of the amendments.

"Other minor corrective and editorial changes have been made.

"The amended regulation permits uninterrupted use of type B containers approved under DOT special permits. Pursuant to $\S 71.10$, an AEC licensee using a type B container under a valid DOT special permit is allowed to use that container until the AEC acts on an application for license submitted within 6 months of the effective date of the amendments or prior to the date on which the special permit expires, whichever is later. The corresponding DOT amendments, published February 14, 1973 (38 FR 4396), authorize the use of AEC-approved packagings, and provide that special permits issued by DOT will continue in effect until their stated expiration date.

"AEC approval of packagings will consist of: (1) A license or license amendment issued under part 71, (2) an administrative approval issued to AEC licenseexempt contractors in accordance with standards and procedures published in the AEC manual, or (3) an approval issued by the AEC's Directorate of Licensing to persons subject to DOT jurisdiction who are not AEC licensees. The latter category includes agreement State licensees, and persons who ship type B quantities or large quantities of radium.

"To obtain AEC approval, all persons, other than AEC license-exempt contractors, are required to submit an application .... The contents of the application are set forth in $\S \S 71.21,71.22,71.23$ and 71.24 of 10 CFR part 71. AEC license-exempt contractors must apply for approval in accordance with the provisions of the AEC manual chapter 5201.

"Pursuant to the Atomic Energy Act of 1954, as amended, and sections 552 and 553 of title 5 of the United States Code, the ... amendments to Title 10, Chapter I, Code of Federal Regulations, part 71, are published as a document subject to codification to become effective June 30, 1973...."[12]

\subsection{DOUBLE CONTAINMENT FOR PLUTONIUM, AND QUALITY ASSURANCE REQUIREMENTS - 1973 TO 1978}

Between August 1973 and June 1978, a series of changes was introduced into the requirements of 10 CFR 71. Centered on two major focal points, the changes had to do with plutonium issues and with Quality Assurance issues. As will be seen below, all of the changes would have a long-lasting impact on the requirements specified in 10 CFR 71.

\subsubsection{Double Containment for Plutonium - 1973 Proposed Rule}

In August 1973, the AEC published a Proposed Rule in the Federal Register, a proposed rule that would eventually require double containment for plutonium.[13] For the most part, the preamble for that proposed rule reads as follows:

"The Atomic Energy Commission is considering the amendment of its regulations in 10 CFR Part 71, 'Packaging of Radioactive Material for Transport and Transportation of Radioactive Material Under Certain Conditions' to require that all plutonium in quantities greater than 20 curies shall be packaged for shipment as a solid in capsules which meet the requirements for special form and shall be shipped inside packaging that meets the requirements of Part 71 for radioactive material in normal form. The proposed requirements would become effective three years after the effective date of the amendment.

"In light of anticipated significant changes in the characteristics and quantity of plutonium to be transported in the future, the Commission has considered the matter of form for shipping plutonium from the standpoint of public health and safety. Existing regulations permit the shipment of plutonium in any chemical or physical form, including liquid plutonium nitrate. Using the present criteria and requirements of Part 71, hundreds of plutonium nitrate shipments have been made with no reported instances of plutonium leakage from the containment vessel.

"However, the present situation with respect to plutonium transportation in the private sector is expected to change drastically over the next several years. Increasingly larger quantities of plutonium will be recovered from power reactor fuel. Consequently, increases in quantities of plutonium shipped and number of shipments made are expected. For example, the amount of plutonium available for recovery is estimated to be $500 \mathrm{~kg}$ in 1973 as compared to $21,000 \mathrm{~kg}$ in 1980.

Author's Note: In 1977, President Carter signed the documentation which effectively killed the prospects for fuel reprocessing in the United States. As a consequence, this part of the NRC's 1973 argument would later become a moot point. Although the double containment rule would, in fact, become a regulatory requirement in 1974 (see 
specific activity of the plutonium will increase with higher reactor fuel burnup, resulting in higher gamma and neutron radiation levels, greater heat generation, and greater pressure generation potential from plutonium nitrate solutions in shipping containers.

"Because of these expected changes in plutonium transport and the inherent susceptibility of liquids to leakage, the Commission believes that safety would be significantly enhanced if the basic form for shipments of plutonium were changed from liquid to solid and if the solid form of plutonium were required to be shipped in a package providing at least double containment of the contents. Such a change is considered to be feasible from an economic and technological standpoint.

"The Commission's assessment indicates that there will not be a significant increase in the quantities of plutonium available for recovery in the next few years. However, the Commission believes that any change in the requirements regarding the form of plutonium for shipment should be announced promptly so that firms that design and build fuel reprocessing and fuel fabrication plants can make timely plans to accommodate this change. It is anticipated that if a solid form for shipment is required, plutonium recovered at fuel reprocessing plants would be converted to the oxide form for shipment to fuel fabricators. Based on the Commission's assessment of process and equipment changes necessary to permit shipment of plutonium as oxide, and the time when increased plutonium shipments will occur, about three years appears to be a sufficient time period. Accordingly, if the proposed amendments are adopted, the effective date would be specified as three years from the effective date of such adoption....'[13]

The preamble for the proposed rule ended with one additional paragraph that dealt primarily with administrative information. The text of the actual proposed rule then followed:

"1. A new $\S 71.42$ would be added to read as follows:

$\S 71.42$ Special requirements for plutonium shipments.

(a) Notwithstanding the exemptions in $\S 71.9$, plutonium in excess of 20 curies per package shall be shipped as a solid encapsulated to meet the requirements of special form as defined in $\S 71.4(\mathrm{o})(2)$ of this part, and shall be shipped inside an outer package which meets the requirements of this part for packaging of material in normal form.

(b) Authority provided in AEC licenses issued pursuant to this part for the delivery to a carrier for transport of plutonium in a liquid form in quantities exceeding 20 curies per

Section 52.6.3), it would later be removed from the requirements of 10 CFR 71. Before it could be removed, however, it would take another 30 years. (See Sections 52.15.2, 52.16, and 52.17.) package shall expire on (three years from the date of adoption of this amendment)...."[13]

\subsubsection{Quality Assurance Requirements for 10 CFR 71 - 1973 Proposed Rule}

In December 1973, the proposed rule for Quality Assurance requirements for 10 CFR 71 was published in the Federal Register.[14] For the most part, the preamble for that proposed rule reads as follows:

"The Atomic Energy Commission has under consideration amendments to its regulations in 10 CFR Part 71 'Packaging of Radioactive Material for Transport and Transportation of Radioactive Material Under Certain Conditions,' to upgrade requirements for quality assurance in the design, fabrication, assembly, testing, use and maintenance of packagings for shipping and transporting licensed radioactive material. The amendments would also revoke, subject to a timely application for reapproval [sic], the present authority to use certain shipping casks for solid irradiated nuclear fuel which had been approved under criteria used before the current standards were developed.

"Under the proposed amendments which follow, each licensee subject to 10 CFR Part 71 would be required to assess the adequacy of his quality assurance program against the upgraded standards and requirements, and to make whatever changes are required to comply with those standards and requirements. AEC would verify compliance with the standards through its licensing and inspection programs. Each applicant for a license or license amendment under 10 CFR Part 71 would be required to describe his quality assurance program to be applied to the design, fabrication, assembly, testing, maintenance and use of his proposed packaging. The applicant would further be required to identify the codes, standards and general requirements to be imposed under the program. Within this framework, the licensee would be required to document his quality assurance program in detailed written procedures and requirements, and follow those procedures and requirements in his operations. The adequacy of the detailed written documents and the licensee's implementation of them would be determined through the Commission's compliance program. That adequacy will be judged in part on the complexity and proposed use of the package under consideration, and on the complexity and importance of safety of its components.

"The quality assurance requirements proposed here would apply to a licensee's design, fabrication, assembly, testing, use and maintenance of a Type B, Large Quantity or Fissile material package which he constructs for himself or has someone else construct it for him. In the case of a licensee using a package approved for another licensee's use, in accordance 
with the general license provisions of present $\S 71.12$, the quality assurance requirements of the licensee for whom the package was first approved must be followed in the use, testing and maintenance of the package by the second licensee. Any changes in the program must be approved by the Commission.

"A new provision would require notification of the Commission's Directorate of Regulatory Operations before fabrication is begun of packaging with certain heat loads or anticipated internal pressures. This would facilitate communication between the licensee and the Commission's regulatory staff to resolve any differences on the adequacy of the quality assurance program before significant expenditures and irretrievable effort are committed to packaging of such importance.

"To assure that external contamination of packages is kept as low as practicable, a new provision would require that external surfaces of packaging be designed and finished to facilitate decontamination.

"Authority to use certain shipping casks for solid irradiated nuclear fuel is contained in $\S 71.41$ of Part 71 'Previously constructed packages for irradiated solid nuclear fuel.' This authority applies to shipping casks approved after September 23, 1961 and constructed by January 1, 1967, when the current package standards system was first adopted in the United States. Under these proposed amendments, any such casks still in use must be shown to comply with current package standards, either in their present condition or after modification.

"Pursuant to the Atomic Energy Act of 1954, as amended, and section 553 of title 5 of the United States Code, notice is hereby given that [the] adoption of ... amendments to 10 CFR Part 71 is contemplated. All interested persons who desire to submit written comments or suggestions for consideration in connection with the proposed amendments should send them .... Copies of comments on the proposed amendments may be examined at the Commission's Public Document Room ....”[14]

\subsubsection{Double Containment for Plutonium - 1974 Final Rule}

In June 1974, the final rule for double containment for plutonium was published in the Federal Register.[15] For the most part, the preamble for that final rule reads as follows:

"On August 1, 1973, the Commission published in the FEDERAL REGISTER a notice of proposed rulemaking (38 FR 20482) that would have required that all plutonium in excess of twenty curies per package be shipped as a solid material contained within a 'special form' capsule placed within a package meeting the conditions for normal form material. The effective date proposed was three years after the adoption of the amendment. All interested persons were invited to submit written comments and suggestions for consideration in connection with the proposed amendment within 60 days after publication of the notice of proposed rulemaking in the FEDERAL RegisTer. After careful consideration of the comments received and other factors involved, the Commission has adopted the amendments as published for comment with the following changes:

(1) The proposed requirement that the inner containment vessel meet the 'special form' capsule requirement has been replaced with a requirement that the inner containment vessel must maintain its integrity after the entire package has been subjected to the normal and accident test conditions prescribed by Part 71 . The effect of the amended provisions is still to require double containment of the contents. A number of commenters [sic] expressed the view that while double containment of plutonium is an important safety objective, a requirement that the inner container meet the stringent performance specifications required of a 'special form' capsule was unnecessary. The Commission considers it most important that solid form plutonium be doubly contained and that both barriers in the packaging maintain their integrity under normal and accident test conditions. The present packaging required for normal form material provides the outer barrier. In specifying the 'inner barrier' in the proposed rule, the Commission proposed a form of encapsulation that was already defined in Part 71, with corresponding performance specifications. Since the inner containment requirements are intended to take into account the fact that the plutonium may not be in a 'nonrespirable' form, the Commission has concluded that if it can be demonstrated that the inner container will maintain its integrity in the packaging after the package is subjected to the normal and accident test conditions, sufficient protection will be afforded.

(2) Solid plutonium in the following forms has been exempted from the double containment requirements: (a) Reactor fuel elements; (b) metal or metal alloy; and (c) other plutonium bearing solids that the Commission determines suitable for such exemption. Since the double containment provision compensates for the fact that the plutonium may not be in a 'nonrespirable' form, solid forms of plutonium that are essentially nonrespirable should be exempted from the double containment requirement; [sic] Therefore, it appears appropriate to exempt from the double containment requirements reactor fuel elements, metal or metal alloy, and other plutonium bearing solids that the Commission determines suitable for such exemption. The latter category provides a means for the Commission to evaluate, on a case-by-case basis, requests for exemption of other solid material where the 
quantity and form of the material permits a determination that double containment is unnecessary.

(3) The implementation period has been extended from three to four years. Many comments suggested that the proposed three-year implementation period was not long enough, considering the necessary plant design effort, licensing, and construction of facility modifications necessary to meet the requirements. Additional time was requested. The Commission believes that the increases in the amounts of plutonium to be shipped and the changing characteristics of plutonium will not change significantly in the next four years when compared to years beyond 1978. The four-year period for compliance should give the nuclear industry a sufficient period for implementation....'[15]

The preamble for the final rule ended with two additional paragraphs, both of which dealt primarily with administrative information. The text of the actual final rule then followed:

"1. A new $\S 71.42$ is added to read as follows:

$\S 71.42$ Special requirements for plutonium shipments after June 17, 1978.

(a) Notwithstanding the exemption in $\$ 71.9$, plutonium in excess of twenty (20) curies per package shall be shipped as a solid.

(b) Plutonium in excess of twenty (20) curies per package shall be packaged in a separate inner container placed within outer packaging that meets the requirements of Subpart $\mathrm{C}$ for packaging of material in normal form. The separate inner container shall not release plutonium when the entire package is subjected to the normal and accident test conditions specified in Appendices A and B. Solid plutonium in the following forms is exempt from the requirements of this paragraph:

(1) Reactor fuel elements;

(2) Metal or metal alloy; or

(3) Other plutonium bearing solids that the Commission determines should be exempt from the requirements of this section.

(c) Authority in AEC licenses issued pursuant to this part for delivery of plutonium to a carrier for transport under conditions which do not meet the limitations of paragraphs (a) and (b) of this section shall expire on June 17, 1978...'[15]

\subsubsection{Quality Assurance Requirements for 10 CFR 71 - 1977 Final Rule}

In August 1977, the final rule for Quality Assurance Requirements for Transport Packages was published in the Federal Register.[16] For the most part, the preamble for that final rule reads as follows:
"SUMMARY: The Nuclear Regulatory Commission is amending its regulations for packaging of radioactive material for transportation and transportation of radioactive materials. The amendments would upgrade requirements for quality assurance in the design, fabrication, assembly, testing, use, and maintenance of packagings for shipping and transporting licensed radioactive material. The amendments would also revoke, subject to a timely application for re-approval, the present authority for licensees to use certain shipping casks for solid irradiated nuclear fuel which had been approved under criteria used before the current standards in these regulations were adopted.

"EFFECTIVE DATE: October 18, 1977....

"SUPPLEMENTAL INFORMATION:

On

December 28, 1973, the Atomic Energy Commission published in the Federal Register (36 FR 35490) proposed amendments to 10 CFR Part 71 of its regulations. Interested persons were invited to submit written comments and suggestions. Further action on the proposed rule was delayed almost three years while developing acceptable methods of implementation.

\section{"COMMENTS RECEIVED \\ "COMMENTS ON PROPOSED RULE}

"Comments were received from ten persons who manufacture or use the shipping packages which were the subject of the proposed amendments, and from one state regulatory agency. Most of the comments urged clarification, modification, or deletion of specific provisions of the proposed rule.

\section{"COMMENTS ON PROPOSED SPECIFIC TESTS}

"More than half the comments were concerned with the proposed provisions of $\S 71.53$, 'Initial determinations and tests.' The comments were varied and concerned the clarity and appropriateness of the proposed requirements and their applicability to certain types of packages. The Commission recognizes the validity of those comments and has not adopted those requirements in the amendments .... Further consideration will be given to such requirements after experience is gained in their application as license conditions in appropriate cases.

"A number of comments were submitted with respect to the proposed addition of specific tests in $\S 71.54$, 'Routine determinations.' Many of these are reflected in the amendments adopted. Some comments noted that certain tests, and in particular those relating to pressure relief devices, should be tailored to the package design. The wording of $\S 71.54(\mathrm{~h})$ and of 'quality assurance program bases' in section 2 of Appendix $\mathrm{E}$ permit the tests and determinations to be fashioned around the package design and the safety function which the design features provide. 


\section{“COMMENTS ON IDENTIFYING RESPONSIBLE INDIVIDUAL}

"Some comments questioned the need to submit the title and qualifications of the individual in the applicant's organization who is responsible for assuring that packages have been prepared in accordance with all applicable requirements, as would have been required by proposed $\S 71.24(\mathrm{~b})$. Since it is recognized that a licensee's entire management is responsible for licensed activities, the requirement has been deleted.

\section{“COMMENTS ON ‘GRANDFATHER CLAUSE’ IN $\S 71.41$}

"A number of commenters [sic] misunderstood the proposed amendment of $\S 71.41$ and judged it to retroactively impose quality assurance requirements, including records, on the construction of irradiated fuel casks fabricated during the 1961-1967 period. This is not the purpose of the amendment. Present $\S 71.41$ has provided a 'grandfather clause' authority for the use of irradiated solid nuclear fuel casks which were constructed prior to 1967 before the current packaging standards became effective. The proposed changes to $\S 71.41$ would phase out this 'grandfather clause' authority. The proposed changes deal with the design characteristics of these old casks and the extent to which those characteristics satisfy the present packaging standards. The proposed changes are unrelated to the proposed quality assurance provisions in the notice of proposed rule making.

\section{"COMMENTS ON RESPONSIBILITY FOR QUALITY} ASSURANCE

"A number of commenters [sic] suggested that clarification be provided as to whether the package manufacturer or the licensee is responsible for providing information to the Commission on specific aspects of quality assurance, and as to who is responsible for carrying out those specific aspects of quality assurance in the manufacture and use of the package.

"The licensee who is the applicant for the package approval provides the descriptions of quality assurance programs governing the manufacture and use of the package. If the package is approved by the Nuclear Regulatory Commission for use in the transportation of radioactive material, a package approval is issued which incorporates the package description and identification, its safety evaluation, and a description of the applicant's specific quality assurance provisions for design, fabrication, assembly, testing, use, and maintenance of the package. In the absence of reasons to the contrary, the package approval will be issued for use by any licensee who possesses the applicable documents incorporated by reference into the package approval, who has had his general quality assurance program approved by the Commission, and who will adhere to the conditions of the package approval. The authority for any licensee to use the package once it is approved is contained in the general license in 10 CFR Part 71, § 71.12, 'General License for Shipment in DOT specification containers, in packages approved for use by another person, and in packages approved by a foreign national competent authority.' The general license requires that each licensee who uses the general license register his name and certain other information with the Commission prior to the first use of the package and have a quality assurance program approved by the Commission.

"A licensee who uses a package under the authority of the general license in $\S 71.12$ must comply with the provisions of the general license. One provision of the general license, as clarified by the amendments ..., is that the licensee use approved packages only in accordance with a quality assurance program which has been approved by the Commission. Another provision of the general license is that the package be used in accordance with the terms and conditions of the package approval. Quality assurance requirements specific to the particular package design would be specified in the package approval. A licensee's quality assurance program for the use of packages in transportation would then consist of the following:

1. The general provisions which satisfy to the extent necessary each of the applicable criteria of Appendix E of Part 71. These general provisions would apply to the use, testing, and maintenance of any package (and its design and fabrication if applicable), and such general provisions would have to be approved by the Commission; and

2. The specific provisions specified or referenced in the package approval which are applicable to the particular package design.

"A licensee who delivers licensed material to a carrier for transport under the authority of $\S 71.12$ must be assured that the package is as described in the package approval, and that it is used, tested, and maintained in accordance with both the general and specific portions of the approved quality assurance program. While information may be submitted by any interested person to the Commission in support of an application for package approval, it is the licensee who delivers a package of radioactive material to a carrier who must assure himself and the Commission that the quality assurance program, on which approval of the package design is based, has been followed.

\section{“COMMENTS ON GENERAL PROVISIONS IN APPENDIX E}

"A number of commenters [sic] suggested changes in the provisions of proposed Appendix E to Part 71, which contains the general provisions relative to all package quality assurance programs. It was observed that proposed Appendix E was patterned closely after 
Appendix B of 10 CFR Part 50, 'Licensing of Production and Utilization Facilities.' Comments were offered that transportation packages differ in many ways from nuclear facilities, and that the same quality assurance provisions should not be applied to both. However, the quality assurance provisions of proposed Appendix E are general in nature and with minor modifications are applicable to a wide variety of types of quality assurance programs. Flexibility in applying the provisions of Appendix E, section 2, 'Quality Assurance Program' has been emphasized by the second paragraph of that section dealing with the importance, complexity, and other characteristics of the package or component to be controlled. While some suggested clarifications of Appendix E have been adopted, the general requirements of that Appendix, parallel to the general requirements of Appendix B of Part 50, have been retained. (Under $\S 71.51(\mathrm{~d})$, a licensee may use a Commission approved quality assurance program, based on Appendix B of 10 CFR Part 50, which is established, maintained and executed with regard to transport packages.) As with the Part 50 requirements, more specific package quality assurance guidelines will be developed and published in the form of Regulatory Guides, beginning in FY 78. The comments which have been offered with respect to Appendix E will be further considered in connection with these guidelines.

"Pursuant to the Atomic Energy Act of 1954, as amended, the Energy Reorganization Act of 1974, as amended, and sections 552 and 553 of Title 5 of the United States Code, the following amendments to Title 10, Chapter I, Code of Federal Regulations, Part 71, are published as a document subject to codification. The Commission invites all interested persons who desire to submit written comments or suggestions in connection with the amendments to send them.... Consideration will be given such submissions with the view to possible further amendments...."[16]

\subsubsection{Extension of the Implementation Period for QA Requirements - 1978 Effective Rule}

In June 1978, an effective rule for Quality Assurance Requirements for Transport Packages was published in the Federal Register.[17] The purpose of the Effective Rule was to extend the effective date for the rule that had previously been proposed. For the most part, the preamble for that final rule reads as follows:

"SUMMARY: The U.S. Nuclear Regulatory Commission extends until January 1, 1979, the date for filing a description of a quality assurance program for transportation packages. The original deadline of July 1, 1978 appeared in amendments published in the Federal Register on August 1, 1977. This extension is in response to requests from interested persons to delay implementation of the quality assurance criteria.

“EFFECTIVE DATE: June 23, 1978....
"SUPPLEMENTARY INFORMATION: On August 4, 1977, the Nuclear Regulatory Commission published effective amendments to its regulations in 10 CFR Part 71. These amendments included a requirement to file a description of a quality assurance (QA) program satisfying the criteria of Appendix E by July 1, 1978 (42 FR 39364). Although written comments or suggestions to these amendments were invited at that time, none were $[$ sic $]$ received.

"The Commission has since received letters from interested persons questioning the applicability of these QA requirements to Agreement State licensees. Also, the Commission has received requests to delay implementation of the Appendix E criteria.

"The Commission is in the process of addressing the question of the applicability of these QA requirements to Agreement State licensees. Because of this effort, and having considered other factors involved, the NRC has determined that a delay of 6 months in implementing the Appendix E criteria appears justified. A short-term delay will have no significant adverse effect on public health and safety because of existing specific QA provisions in Part 71 and the requirement for a QA program, which the staff imposes for approved packages for shipping irradiated fuel, high level waste, and plutonium. Accordingly, the Commission is amending its regulations by extending the date for filing a description of a QA program in $\S 71.51$ to January 1, 1979.

"Because this amendment relates solely to procedural matters, the Commission had found that good cause exists for omitting notice of proposed rule making, and public procedure thereon, as unnecessary. Since the amendment relieves licensees from restrictions under regulations currently in effect, it may be effective upon publication in the FEDERAL REGISTER.

"Pursuant to the Atomic Energy Act or 1954, as amended, the Energy Reorganization Act of 1974, as amended, and sections 552 and 553 of Title 5 of the United States Code, the following amendment to Title 10, Chapter I, Code of Federal Regulations, Part 71 is published as a document subject to codification.

"In $\S 71.51$, paragraphs (a), (b) and (c) are amended by deleting 'July 1, 1978' and substituting therefor [sic] 'January 1, 1979'.’'[17]

\subsection{NRC REGULATORY GUIDE 7.6}

In March 1978, the NRC introduced Revision 1 of its Regulatory Guide (Reg. Guide) 7.6 into the situation.[18] Although a previous version of this Reg. Guide had been introduced some 13 months earlier, this was the first version to have some real meat in the content, and it was this version that would be relied upon for the next 13 years.

The title of Reg. Guide 7.6 was (is) Design Criteria for the Structural Analysis of Shipping Cask Containment Vessels. Because this was the first of the NRC Guidance documents to 
introduce ASME Boiler \& Pressure Code requirements into their recommendations for the design for shipping containers for Type B quantities of radioactive materials, the full text of this Reg. Guide is reproduced below.

\section{“A. INTRODUCTION}

"Sections 71.35 and 71.36 of 10 CFR Part 71, 'Packaging of Radioactive Material for Transport and Transportation of Radioactive Material Under Certain Conditions,' require that packages used to transport radioactive materials meet the normal and hypothetical accident conditions of Appendices A and $\mathrm{B}$, respectively, to Part 71. This guide describes design criteria acceptable to the NRC staff for use in the structural analysis of the containment vessels of Type B packages used to transport irradiated nuclear fuel. Alternative design criteria may be used if judged acceptable by the NRC staff in meeting the structural requirements of $\S \S 71.35$ and 71.36 of 10 CFR Part 71.

\section{"B. DISCUSSION}

"At present, there are no design standards that can be directly used to evaluate the structural integrity of the containment vessels of shipping casks for irradiated fuels. This guide presents containment vessel design criteria that can be used in conjunction with an analysis which considers the containment vessel and other principal shells of the cask (e.g., outer shell, neutron shield jacket shell) to be linearly elastic. A basic assumption for the use of this guide is that the principle of superposition can be applied to determine the effect of combined loads on the containment vessel. However, use of this guide does not preclude appropriate nonlinear treatment of other cask components (e.g., impact limiters and lead shielding).

"Design criteria for nonlinear structural analyses are not presented in this guide because of the present lack of data sufficient to formulate substantial nonlinear criteria. The NRC staff will review criteria other than those given in this guide on a case-by-case basis.

"Section III of the ASME Boiler and Pressure Code contains requirements for the design of nuclear power plant components. Portions of the Code that use a 'design-by-analysis' approach for Class 1 components have been adapted in this guide to form acceptable design criteria for shipping cask containment vessels. The design criteria for normal transport conditions, as defined in 10 CFR Part 71, are similar to the criteria for Level A Service Limits (formerly called 'normal conditions') of Section III, and the design criteria for accident conditions are similar to those for Level D Service Limits (formerly called 'faulted conditions'). However, Section III was developed for reactor components, not fuel casks, and many of the Code's requirements may not be applicable to fuel cask design.

"The criteria in this guide reflect the designs of recently licensed shipping casks. The containment vessels having these designs were made of austenitic stainless steel, which is ductile even at low temperatures. Thus, this guide does not consider brittle fracture. Likewise, creep is not discussed because the temperatures of containment vessels for irradiated fuel are characteristically below the creep range, even after the hypothetical thermal accident requirement of $10 \mathrm{CFR}$ Part 71 . The nature of the design cyclic thermal loads and pressure loads is such that thermal ratchetting $[\mathrm{sic}]$ is not considered a realistic failure mode for cylindrical containment vessels. Containment vessel designs that are significantly different from current designs (in shape, material, etc.) may necessitate the consideration of the above failure modes.

"Regulatory positions 2 and 6 ensure that failure due to gross unrestrained yielding across a solid section does not occur. Secondary stresses (i.e., stresses that are self-limiting) are not considered to cause gross unrestrained yielding but are considered in fatigue and shakedown analyses.

"Regulatory position 3 ensures that fatigue failure does not occur, and regulatory position 4 ensures that the structure will shake down to elastic behavior after a few cycles. Both of these positions address only the stress range of normal operation. Recent studies ${ }^{\S \S}$ have shown that fatigue strength decreases beyond $10^{6}$ cycles for certain materials. Regulatory position 3.b addresses the possibility of fatigue strength reduction beyond $10^{6}$ cycles.

"Regulatory position 5 states that buckling of the containment vessel should not occur. While it is recognized that local or gross buckling of the containment vessel could occur without failure (i.e., leakage), the stress and strain limits given in this guide are based on linear elastic analysis and are inappropriate for determining the integrity of a postbuckled vessel. If the analysis of a containment vessel indicates the likelihood of structural instability, the design criteria of this guide should not be used.

"Regulatory position 7 places a limit on the extreme range of the total stresses due to the initial and fabrication states (see definition 9 below) and the normal operating and accident states of the containment vessel. The 10-cycle value of $S_{a}$ (taken from the ASME design fatigue curves) is used. Because this value is in the extreme low-cycle range, this regulatory position is actually a limit on strain rather than stress.

"Design criteria for bolted closures are not presented in this guide. Insufficient information exists, particularly for response to impact loading, to establish such criteria.

$\S \S$ "C.E. Jaske and W.J. O'Donnell, 'Fatigue Design Criteria for Pressure Vessel Alloys,' ASME Paper 77-PVP-12." (This footnote was part of the original citation.) 
"The following terms are presented with the definitions used in this guide:

"1. Stress intensity means twice the maximum shear stress and is equal to the largest algebraic difference between any two of the three principal stresses.

"2. Primary stress means a stress that is necessary to satisfy the laws of equilibrium of forces and moments due to applied loadings, pressure loadings, and body (inertial) loadings. Primary stresses are not self-limiting because local yielding and minor distortions do not reduce the average stress across a solid section.

"3. Secondary stress means a stress that is selflimiting. Thermal stresses are considered to be secondary stresses since they are strain-controlled rather than load-controlled, and these stresses decrease as yielding occurs.

"The bending stress at a gross structural discontinuity, such as where a cylindrical shell joins a flat head, is generally self-limiting and is considered to be a secondary stress. However, when the edge moment at the shell and head junction is needed to prevent excessive bending stresses in the head, the stress at the junction is considered a primary stress. The bending stress at a joint between the walls of a rectangular cross-section shell is considered a primary stress.

"4. Primary membrane stress means the average normal primary stresses across the thickness of a solid section. Primary bending stresses are the components of the normal primary stresses that vary linearly across the thickness of a solid section.

"5. Alternating stress intensity, $\mathrm{S}_{\mathrm{alt}}$, means one-half the maximum absolute value of $\mathrm{S}_{12}{ }_{12}, \mathrm{~S}_{23}, \mathrm{~S}_{31}$, for all possible stress states $i$ and $j$ where $\sigma_{1}, \sigma_{2}$, and $\sigma_{3}$, are principal stresses and

$$
\begin{aligned}
& \mathrm{S}^{\prime}{ }_{12}=\left(\sigma_{1 \mathrm{i}}-\sigma_{1 \mathrm{j}}\right)-\left(\sigma_{2 \mathrm{i}}-\sigma_{2 \mathrm{j}}\right) \\
& \mathrm{S}^{\prime}{ }_{23}=\left(\sigma_{2 \mathrm{i}}-\sigma_{2 \mathrm{j}}\right)-\left(\sigma_{3 \mathrm{i}}-\sigma_{3 \mathrm{j}}\right) \\
& \mathrm{S}^{\prime}{ }_{31}=\left(\sigma_{3 \mathrm{i}}-\sigma_{3 \mathrm{j}}\right)-\left(\sigma_{1 \mathrm{i}}-\sigma_{1 \mathrm{j}}\right)
\end{aligned}
$$

$\sigma_{1}$, etc., follow the principal stresses as their directions rotate if the directions of the principal stresses at a point change during the cycle.

"6. Stresses caused by stress concentrations means stress increases due to local geometric discontinuities (e.g., notches or local thermal 'hot spots'). These stresses produce no noticeable distortions.

"7. Type B quantity is defined in $\$ 71.4(\mathrm{q})$ of 10 CFR Part 71. Normal conditions of transport and hypothetical accident conditions are defined in Appendices A and B, respectively, to 10 CFR Part 71.

"8. Containment vessel means the receptacle on which principal reliance is placed to retain the radioactive material during transport.

"9. Fabrication means the assembly of the major components of the casks (i.e., the inner shell, shielding, outer shell, heads, etc.) but not the construction of the individual components. Thus, the phrase fabrication stresses includes the stresses caused by interference fits and the shrinkage of bonded lead shielding during solidification but does not include the residual stresses due to plate formation, welding, etc. The prefabrication state is designated as the initial state and is treated as having zero stress.

"10. Shakedown means the absence of a continuing cycle of plastic deformation. A structure shakes down if, after a few cycles of load application, the deformation stabilizes and subsequent structural response is elastic.

\section{"C. REGULATORY POSITION}

"The following design criteria are acceptable to the NRC staff for assessing the adequacy of designs for containment vessels of irradiated fuel shipping casks in meeting the structural requirements in $\$ \S 71.35$ and 71.36 of 10 CFR Part 71. References to the ASME Boiler and Pressure Vessel Code indicate the 1977 edition.

"1. The values for material properties, design stress intensities $\left(\mathrm{S}_{\mathrm{m}}\right)$, and design fatigue curves for Class 1 components given in Subsection NA of Section III of the ASME Boiler and Pressure Vessel Code should be used for the materials that meet the ASME specifications. For other materials, the method discussed in Article III-2000 of Subsection NA should be used to derive design stress intensity values. ASTM material properties should be used, if available, to derive design stress intensity values. The values of material properties that should be used in the structural analysis are those values that correspond to the appropriate temperatures at loading.

"2. Under normal conditions, the value of the stress intensity resulting from the primary membrane stress should be less than the design stress intensity, $\mathrm{S}_{\mathrm{m}}$, and the stress intensity resulting from the sum of the primary membrane stresses and the primary bending stresses should be less than $1.5 \mathrm{~S}_{\mathrm{m}}$.

" 3 . The fatigue analysis for stresses under normal conditions should be performed as follows:

a. $\mathrm{S}_{\mathrm{alt}}$ is determined (as defined in the Discussion). The total stress state at each point in the normal operating cycle should be considered so that a maximum range may be determined.

b. The design fatigue curves in Appendix I of Section III of the ASME Boiler and Pressure Vessel Code should be used for cyclic loading less than or equal to $10^{6}$ cycles. Consideration should be given to further reduction in fatigue strength when loading exceeds $10^{6}$ cycles.

c. $\mathrm{S}_{\text {alt }}$ should be multiplied by the ratio of the modulus of elasticity given on the design fatigue curve to the modulus of elasticity used in the analysis to obtain a value of stress to be used with the design fatigue curves. The corresponding number of cycles taken from the appropriate 
design fatigue curve is the allowable life if only one type of operational cycle is considered. If two or more types of stress cycles are considered to produce significant stresses, the rules for cumulative damage given in Article NB-3222.4 of Section III of the ASME Boiler and Pressure Vessel Code should be applied.

d. Appropriate stress concentration factors for structural discontinuities should be used. A value of 4 should be used in regions where this factor is unknown.

"4. The stress intensity, $\mathrm{S}_{\mathrm{n}}$, associated the range of primary plus secondary stresses under normal conditions should be less than $3 \mathrm{~S}_{\mathrm{m}}$. The calculation of this stress intensity is similar to the calculation of $2 \mathrm{~S}_{\text {alt }}$; however, the effects of local stress concentrations that are considered in the fatigue calculations are not included in this stress range.

"The $3 \mathrm{~S}_{\mathrm{m}}$ limit given above may be exceeded if the following conditions are met (these conditions can generally be met only in cases where the thermal bending stresses are a substantial portion of the total stress):

a. The range of stresses under normal conditions, excluding stresses due to stress concentrations and thermal bending stresses, yields a stress intensity, $\mathrm{S}_{\mathrm{n}}$, that is less than $3 \mathrm{~S}_{\mathrm{m}}$.

b. The value $S_{a}$ used for entering the design fatigue curve is multiplied by the factor $\mathrm{K}_{\mathrm{e}}$, where:

$$
\begin{aligned}
\mathrm{K}_{\mathrm{e}} & =1.0, \text { for } \mathrm{S}_{\mathrm{n}} \leq 3 \mathrm{~S}_{\mathrm{m}} \\
& =1.0+\frac{(1-\mathrm{n})}{\mathrm{n}(\mathrm{m}-1)}\left(\frac{\mathrm{S}_{\mathrm{n}}}{3 \mathrm{~S}_{\mathrm{m}}}-1\right), \text { for } 3 \mathrm{~S}_{\mathrm{m}}<\mathrm{S}_{\mathrm{n}}<3 \mathrm{mS}_{\mathrm{m}} \\
& =\frac{1}{\mathrm{n}}, \text { for } \mathrm{S}_{\mathrm{n}} \geq 3 \mathrm{mS}_{\mathrm{m}}
\end{aligned}
$$

$\mathrm{S}_{\mathrm{n}}$ is as described in regulatory position 4.a.

The values of the material parameters $m$ and $n$ are given for the various classes of materials in the following table:

\begin{tabular}{lcccc} 
& \multicolumn{4}{c}{$\mathrm{T}_{\max }$} \\
& $\mathrm{m}$ & $\mathrm{n}$ & ${ }^{\circ} \mathrm{F}$ & ${ }^{\circ} \mathrm{C}$ \\
Low-Alloy Steel & 2.0 & 0.2 & 700 & 371 \\
Martensitic Stainless Steel & 2.0 & 0.2 & 700 & 371 \\
Carbon Steel & 3.0 & 0.2 & 700 & 371 \\
Austenitic Stainless Steel & 1.7 & 0.3 & 800 & 427 \\
Nickel-Chromium-Iron & 1.7 & 0.3 & 800 & 427
\end{tabular}

c. The temperatures do not exceed those listed in the above table for the various classes of materials.

d. The ratio of the minimum specified yield strength of the material to the minimum specified ultimate strength is less than 0.8 .

"5. Buckling of the containment vessel should not occur under normal or accident conditions. Suitable factors should be used to account for eccentricities in the design geometry and loading. An elastic-plastic buckling analysis may be used to show that structural instability will not occur; however, the vessel should also meet the specifications for linear elastic analysis given in this guide.

"6. Under accident conditions, the value of the stress intensity resulting from the primary membrane stresses should be less than the lesser value of $2.4 \mathrm{~S}_{\mathrm{m}}$ and $0.7 \mathrm{~S}_{\mathrm{u}}$, (ultimate strength); and the stress intensity resulting from the sum of the primary membrane stresses and the primary bending stresses should be less than the lesser value of $3.6 \mathrm{~S}_{\mathrm{m}}$ and $\mathrm{S}_{\mathrm{u}}$.

"7. The extreme total stress intensity range between the initial state, the fabrication state (see definition 9 in the Discussion), the normal operating conditions, and the accident conditions should be less than twice the adjusted value (adjusted to account for modulus of elasticity at the highest temperature) of $\mathrm{S}_{\mathrm{m}}$ at 10 cycles given by the appropriate design fatigue curves.

"Appropriate stress concentration factors for structural discontinuities should be used. A value of 4 should be used in regions where this factor is unknown."[18]

While this may have been the first, real example of where the Code has been invoked for the design and fabrication of Type B shipping containers for the transportation of radioactive materials, it would not be the last. (See Sections 52.9, 52.11, and 52.13.)

\subsection{PROPOSED RULE, 10 CFR 71}

In August 1979, a proposed rule for major changes to 10 CFR 71 was published in the Federal Register.[19] For the most part, the preamble for that proposed rule reads as follows:

"SUMMARY: The Nuclear Regulatory Commission is considering revising its regulations for the transportation of radioactive material to make them compatible with those of the International Atomic Energy Agency (IAEA) and thus with those of most major nuclear nations of the world. Although several substantive changes are proposed in order to provide a more uniform degree of safety for various types of shipments, the Commission's basic standards for radioactive material packaging would remain unchanged. The Department of Transportation is also proposing a corresponding rule change to its Hazardous Materials Transport Regulations....

"SUPPLEMENTARY INFORMATION: In 1968 the Atomic Energy Commission (AEC) amended its regulations in $10 \mathrm{CFR}$ Part 71, then entitled 'Packaging of Radioactive Material for Transport' (33 FR 17621), to be compatible with the Department of Transportation's revision (33 FR 14918) of its regulations pertaining to safety in the transport of radioactive material. The $\mathrm{AEC}$ regulations at that time applied to the packaging and transportation of 
radioactive materials in greater than 'Type B' quantities and of fissile materials.

"Subsequently, AEC regulations were extended to include Type B (greater than Type A) quantities. Among the requirements adopted was one that packages for greater than Type A quantities of radioactive materials and packages for fissile materials had to satisfy certain specified performance criteria when subjected to severe conditions known as 'hypothetical accident conditions.'

"A Type A quantity of non-fissile material is considered not a serious hazard if packaging failure occurs in an accident; however, Type A packages must be able to withstand a wide range of specified conditions which may be experienced in normal transport. The regulations of the Department of Transportation in 49 CFR Parts 170-179 specify the requirements for these packages.

"The regulations in the AEC's 10 CFR Part 71, as revised in 1968, were substantially in accord with the recommendations of the International Atomic Energy Agency (IAEA) as published in IAEA Safety Series No. 6, 'Regulations for the Safe Transport of Radioactive Materials' (1967 edition). Only minor changes have been made to 10 CFR Part 71 since that time except for the change in the administration of Type B packaging requirements and the addition of $\S 71.42$ placing restrictions on shipment of plutonium.

"No special restriction on air transport of plutonium is imposed by the present or proposed 10 CFR Part 71, because the congressional legislation restricting such shipment and resulting in the NRC development of a Plutonium Air Transport (PAT) package is a separate and overriding requirement. A separate rulemaking is being undertaken by the Commission to address restrictions on the air transport of plutonium.

"Several years of experience in the United States and other countries indicated the IAEA regulations were generally sound and practical and that they provided a reasonable degree of safety. Although several Type B packages (i.e., packages containing more than a Type A quantity) have been involved in severe accidents in the United States, no known escape of radioactive material has resulted. It did appear, however, that a more uniform degree of safety for various designs and for different package contents was desirable and could be achieved without undue restriction by some modification of the design

*** "Present regulations distinguish among Type A quantity (the maximum amount of a particular radionuclide that may be transported in a package designed to withstand specified conditions of normal transportation but not the simulated accident conditions). Type B quantity (a specified amount greater than a Type A quantity but ordinarily requiring no special provision for heat removal), and large quantity (greater than a Type B quantity)." (Note: This footnote was part of the original citation.) requirements and performance criteria of the IAEA regulations.

"The IAEA convened panels in 1971 and 1972 to review their transportation regulations and to recommend appropriate amendments. All member countries with a well developed nuclear industry and many international organizations were represented on the panels. [T]he United States participated in the program and in fact initiated many of the amendments. The IAEA subsequently issued the 1973 edition of Safety Series No. 6, 'Regulations for the Safe Transport of Radioactive Materials.' Reasons for significant changes from the 1967 edition are documented in proposals submitted in advance to the IAEA by member countries, in working papers prepared by study groups during the course of the meetings, and in the taped record. Much of this background information is summarized in IAEA Safety Series No. 37, 'Advisory Material for the Application of the IAEA Transport Regulations.'

"Based on figures compiled for the calendar year 1975, more than 10,000 packages of radioactive material are exported annually from the United States. In order to minimize complication and delay and encourage uniform safety of these export shipments and those which are imported, revision of United States domestic regulations in 10 CFR Part 71 is proposed. This revision, in combination with a corresponding amendment by DOT of Title 49 of the Code of Federal Regulations, will bring the U.S. regulations into accord with relevant portions of the IAEA design and performance requirements to the extent considered feasible, thereby making them compatible with the domestic regulations of most of the international community; remaining differences are discussed below. Although procedures for implementing and enforcing the regulations necessarily vary somewhat among countries, the IAEA administrative requirements are also being adopted where appropriate.

"Packages of design having a valid certificate of compliance as of the effective date of this amendment will be treated as complying with the amended regulations provided fabrication is in accordance with design and has been completed within two years after the effective date or before expiration of the certificate of compliance, whichever is later.

"It is essential that NRC and Department of Transportation regulations be consistent and that related changes to the regulations of the two agencies be made simultaneously. The proposed changes to DOT's 49 CFR Parts 170-179 and DOT's proposed new Part 127 to Title 49 to make them consistent with the relevant portions of the 1973 IAEA requirements have already been published in the January 8, 1979 issue of the Federal Register. ${ }^{\dagger \dagger \dagger}$

it Author's Note: The lack of emphasis in the term Federal Register is, again, courtesy of the U.S. Government Printing Office. 


\section{"Major Changes}

"The major changes to 10 CFR Part 71 being proposed deal with assignment of individualized Type A quantities for each radionuclide, and the addition of new Type $\mathrm{B}(\mathrm{U})$ and Type $\mathrm{B}(\mathrm{M})$ packaging standards. These major changes are discussed in the following paragraphs.

\section{“Individualized Type A Quantities}

"One important change that would be made by the proposed regulations is the elimination of the system used to specify the quantity of radioactive material permitted in Type A packages. Under the present system, radionuclides are divided into seven transport groups which take account of toxicity and specific activity, plus a 'special form' category for materials which are not dispersible because of their inherent physical form or because of suitable encapsulation. Under this system, the allowable number of curies for each radionuclide in a group is in most cases the same as the allowable number of curies for the most toxic member of the group. This method is unnecessarily restrictive when applied to the less toxic group members, which in some cases have a maximum permissible body burden more than ten times that of the more toxic members.

"The proposed regulation eliminates transport groups. Instead, it assigns to each radionuclide two values, $A_{1}$ and $\mathrm{A}_{2}$, which are the maximum number of curies permitted in Type A packages in special form and normal form, respectively. The $A_{1}$ and $A_{2}$ values for various radionuclides are listed in the proposed regulation.
"The value of $A_{1}$ for special form material is intended to limit the possible external radiation dose rate to $1 \mathrm{rem} /$ hour at 3 meters from the source if the contents of the package are released, except that an upper limit of 100 curies is imposed. Special form material must also be nondispersible as determined by certain stringent criteria (which differ somewhat from present criteria for special form) which are set forth in Appendix D of Part 71.

"The bases for the $A_{2}$ value for normal material (that is, material not in special form) are: (1) and [an] [sic] accident of moderate severity might release $0.1 \%$ of the contents, and $0.1 \%$ of the amount released might then be taken into the body of a human being in the vicinity; this intake should not exceed half the maximum permissible annual intake for workers as given in IAEA Safety Series No. 9, 'Basic Safety Standards for Radiation Protection' (1967 Edition); and (2) $A_{2}$ shall not exceed $A_{1}$. Intake values are based on the International Commission on Radiological Protection (ICRP) 1966 recommended limits for radiation exposure.

"The following table compares the present special form and normal form limits with the limits that would be applicable under the proposed rule, for several of the more commonly shipped radionuclides.

"The adoption of $\mathrm{A}_{1}$ and $\mathrm{A}_{2}$ values will sometimes permit a single Type A package to replace two or more present Type A packages. Also, some of the small number of Type B packages with contents near the lower limit for Type B could be reclassified as Type A. However, the number of Type A packages and the total amount of material in Type A packages is not expected to be significantly affected.

\begin{tabular}{|c|c|c|c|c|c|}
\hline & \multirow{3}{*}{ Present Group } & \multicolumn{4}{|c|}{ Limit in Type A packages, in cures } \\
\hline & & \multicolumn{2}{|c|}{ Present } & \multicolumn{2}{|c|}{ Proposed } \\
\hline & & Special Form & Normal Form & Special Form & Normal Form \\
\hline${ }^{241} \mathrm{Am} \ldots \ldots \ldots \ldots$ & $\mathrm{I} \ldots \ldots \ldots \ldots \ldots$ & 20 & 0.001 & 8 & 0.008 \\
\hline${ }^{14} \mathrm{C}$. & IV ... & 20 & 20 & 1000 & 100 \\
\hline${ }^{252} \mathrm{Cf}$. & $\mathrm{I} \ldots \ldots \ldots \ldots \ldots$ & 2 & 0.001 & 2 & 0.009 \\
\hline 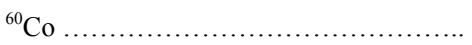 & II $\ldots \ldots \ldots \ldots \ldots$ & 20 & 3 & 7 & 7 \\
\hline${ }^{137} \mathrm{Cs} \ldots \ldots$. & II ............... & 20 & 3 & 30 & 20 \\
\hline${ }^{131} \mathrm{I}$. & II ............... & 20 & 3 & 40 & 10 \\
\hline 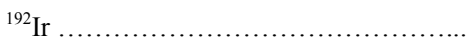 & II $\ldots \ldots \ldots \ldots \ldots$ & 20 & 3 & 20 & 20 \\
\hline ................... & IV ............... & 20 & 20 & 100 & 100 \\
\hline 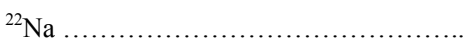 & IV ............... & 20 & 20 & 5 & 5 \\
\hline${ }^{239} \mathrm{Pu}$ & $\mathrm{I} \ldots \ldots \ldots \ldots \ldots$ & 20 & 0.001 & 2 & 0.002 \\
\hline 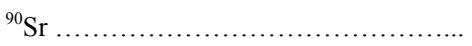 & II $\ldots \ldots \ldots \ldots \ldots$ & 20 & 0.05 & 10 & 0.4 \\
\hline 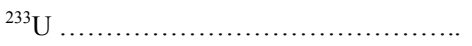 & II $\ldots \ldots \ldots \ldots \ldots$ & 20 & 3 & 100 & 0.2 \\
\hline
\end{tabular}

"For some radioactive materials in special form the Type A limit will be increased and for some the Type A limit will be decreased. The change in the number of such packages is also expected to be small.

\section{"Type B(U)_Type B(M) Packaging Standards}

"Type B packages regulated by the NRC currently fall into two categories: those containing Type B quantities and those containing 'large quantities' of radioactive material. The present upper limit for Type B quantities and the designation of amounts 
greater than that limit as 'large quantity' were established at a time when large quantities of radioactive material, particularly in the form of irradiated fuel, were thought to require special provision for heat removal and special consideration of the possible escape of coolant under accident conditions. However, experience has shown that, while some present Type B quantities do require special consideration of heat removal, some large quantities do not require such consideration. Also, the hazard associated with escape of radioactive material is not appreciably dependent upon whether the accompanying non-radioactive material is classified as a coolant. Therefore, the proposed rule would combine the existing Type B and large quantities.

"Two classifications of Type B packaging, designated as Type $\mathrm{B}(\mathrm{M})$ and Type $\mathrm{B}(\mathrm{U})$ have been established by the IAEA and are included in the proposed regulations. For international shipment, the Type $\mathrm{B}(\mathrm{M})$ package requires approval by the competent authority of each country into or through (but not over) which the package is transported, i.e., multilateral approval. Any special design features or operational controls of the Type $\mathrm{B}(\mathrm{M})$ package will thus be subject to review for consistency with the practices and procedures of more than one country. The Type $\mathrm{B}(\mathrm{U})$ package is intended to require approval only by the country of origin (i.e., unilateral approval) and for this reason has numerous special features of design and performance as described in proposed $\S 71.34$. Proposed Part 71, however, makes no distinction between Type $\mathrm{B}(\mathrm{M})$ and Type $\mathrm{B}(\mathrm{U})$ package designs with respect to required approvals. Both types will fall within the general license provisions of $\S 71.12$ for import and export, and will require specific NRC approvals for shipments wholly within the United States. In some circumstances, the NRC must also approve the conditions of transport for a Type $\mathrm{B}(\mathrm{M})$ package.

\section{“Comparison With Current Regulations}

"Set forth below in a cross-index of paragraphs contained in the proposed revision of Part 71, the present Part 71, and IAEA Safety Series No. 6, 'Regulations for the Safe Transport of Radioactive Materials' (1973 Revised Edition). Omissions from proposed Part 71 of requirements in IAEA Safety Series No. 6 are not shown; however, such omissions of a technical and substantive nature are discussed later. Where no entry is shown, there is no closely corresponding paragraph or section.

"The administrative requirements in the United States for application to the Nuclear Regulatory Commission for approval of a package design, for review by the Commission staff, and for documentation of design and approvals necessarily differ from those described in IAEA Safety Series No. 6. For most of these items, no cross-index with IAEA Safety Series No. 6 is shown.

\begin{tabular}{|c|c|c|c|}
\hline \multicolumn{4}{|l|}{ "Cross Index } \\
\hline & $\begin{array}{l}\text { Proposed } \\
\text { regulation }\end{array}$ & $\begin{array}{c}\text { Present } \\
\text { regulation }\end{array}$ & $\begin{array}{l}\text { IAEA safety } \\
\text { series No. } 6\end{array}$ \\
\hline \multicolumn{4}{|l|}{ SUBPART A-GENERAL PROVISIONS } \\
\hline Purpose & $71.1 \ldots \ldots \ldots \ldots$ & $71.1 \ldots \ldots \ldots \ldots$ & \\
\hline Scope $\ldots \ldots \ldots \ldots \ldots$ & $71.2 \ldots \ldots \ldots \ldots$ & $71.2 \ldots \ldots \ldots \ldots$ & \\
\hline Requirement for license ............ & $71.3 \ldots \ldots \ldots \ldots$ & 71.3 & \\
\hline Definitions ................... & 71.4 & 71.4 & \\
\hline Transportation of licensed material & 71.5 & 71.5 & \\
\hline Specific exemptions . & 71.6 & 71.6 & \\
\hline Exemption of physicians & 71.7 & 71.8 & \\
\hline Exemption for low level materials & 71.8 & 71.7 & \\
\hline Exemption for fissile material . & 71.9 & 71.9 & \\
\hline $15 \mathrm{gm} \ldots \ldots \ldots \ldots \ldots \ldots$ & $71.9(\mathrm{a})$ & 71.9 (a) & 601(a) \\
\hline Nat or depl U ................... & 71.9 & 71.9 & 601(b) \\
\hline Homogeneous hyd. mixt ........................ & $71.9(\mathrm{c}) \ldots \ldots \ldots$ & $71.9(\mathrm{~d}) \ldots \ldots$ & $601(\mathrm{c})$ \\
\hline $\mathrm{U}$ up to $1 \%$ enr ............. & $71.9(\mathrm{~d})$ & $71.9(\mathrm{c})$ & $601(\mathrm{~d})$ \\
\hline Fissile matl. $<5 \mathrm{gm} / 101 \ldots$. & $71.9(\mathrm{e}) \ldots \ldots \ldots$ & $71.9(\mathrm{e}) \ldots \ldots$ & 601(e) \\
\hline $1 \mathrm{Kg} \mathrm{Pu} \ldots$ & $71.9(\mathrm{f}) \ldots \ldots \ldots$ & ................. & 601(f) \\
\hline Uranyl nitrate sol .. & $71.9(\mathrm{~g}) \ldots \ldots \ldots$ & $\ldots \ldots \ldots \ldots \ldots$ & $601(\mathrm{~g})$ \\
\hline Limited exemption for type B & .................... & 71.10 & ........... \\
\hline General license, fissile matl ... & $71.11 \ldots \ldots \ldots \ldots$ & $71.11 \ldots \ldots \ldots$ & \\
\hline Fissile class II, Case $1 \ldots \ldots \ldots$ & $71.11(\mathrm{a}) \ldots \ldots \ldots$ & $71.11(\mathrm{~b}) \ldots \ldots$ & \\
\hline Fissile class II, Case 2 .......... & $71.11(\mathrm{~b}) \ldots \ldots \ldots$ & ................. & 620 \\
\hline Fissile class III, Case $1 \ldots \ldots \ldots$ & $71.11(\mathrm{c}) \ldots \ldots \ldots$ & $71.11(\mathrm{a}) \ldots \ldots$ & \\
\hline Fissile class III, Case $2 \ldots \ldots \ldots \ldots$ & $71.11(\mathrm{~d}) \ldots \ldots \ldots$ & ............... & 623 \\
\hline Fissile class III, Case $3 \ldots \ldots . .$. & $71.11(\mathrm{e}) \ldots \ldots \ldots$ & $\ldots \ldots \ldots \ldots \ldots$ & 624 \\
\hline General license, approved packages . & $71.12 \ldots \ldots \ldots \ldots$ & 71.12 & \\
\hline Communications ......................... & 71.13 & 71.13 & \\
\hline Interpretations . & $71.14 \ldots \ldots \ldots \ldots$ & 71.14 & \\
\hline Additional requirements . & $71.15 \ldots \ldots \ldots \ldots$ & $71.15 \ldots \ldots \ldots$ & \\
\hline
\end{tabular}


"Cross Index - Continued

\begin{tabular}{|c|c|c|c|}
\hline & $\begin{array}{l}\text { Proposed } \\
\text { regulation }\end{array}$ & $\begin{array}{l}\text { Present } \\
\text { regulation }\end{array}$ & $\begin{array}{l}\text { IAEA safety } \\
\text { series No. } 6\end{array}$ \\
\hline Amendment of existing licenses . & & 71.16 . & \\
\hline \multicolumn{4}{|l|}{ SUBPART B-APPLICATION FOR PACKAGE APPROVAL } \\
\hline Contents of application . & 71.21 & 71.21. & \\
\hline Package description . & 71.22 & 71.22 & \\
\hline Package evaluation . & 71.23 & 71.23 & \\
\hline Quality assurance. & 71.24 & 71.24 . & \\
\hline Additional information ... & $71.25 \ldots \ldots \ldots \ldots$ & $71.25 \ldots \ldots \ldots$ & \\
\hline \multicolumn{4}{|l|}{ SUBPART C-PACKAGE STANDARDS } \\
\hline Demonstration of compliance ................... & $71.31 \ldots \ldots \ldots \ldots$ & $71.34(a) \ldots \ldots$ & $\begin{array}{l}701-702 \\
707-708\end{array}$ \\
\hline Standards for all type B packages & 71.32 & 71.31. & \\
\hline Lifting attachments . & $71.32(\mathrm{a}) \ldots \ldots \ldots$ & $71.31(\mathrm{c}) \ldots \ldots$ & 204 \\
\hline Minimum dimension .. & $71.32(\mathrm{~b}) \ldots \ldots \ldots$ & $173.393(\mathrm{c}) \ldots$ & 210 \\
\hline Seal. & $71.32(\mathrm{c}) \ldots \ldots \ldots$ & $173.393(b) \ldots$ & 211 \\
\hline Fastening device . & $71.32(\mathrm{~d})$. & $71.31(\mathrm{~b}) \ldots \ldots$ & 216 \\
\hline Tie-down device .. & $71.32(\mathrm{e}) \ldots \ldots \ldots . .$. & $71.31(\mathrm{~d}) \ldots \ldots$ & 224 \\
\hline Materials of construction & $71.32(\mathrm{f}) \ldots \ldots \ldots$ & $71.31(\mathrm{a}) \ldots \ldots$ & 219 \\
\hline Valves . & $71.32(\mathrm{~g}) \ldots \ldots \ldots . .$. & & 222 \\
\hline 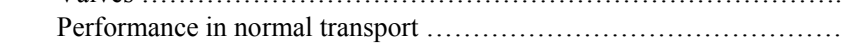 & $71.32(\mathrm{~h})$ & $71.35(\mathrm{a}) \ldots \ldots$ & 225 \\
\hline Additional requirements for $\mathrm{B}(\mathrm{M}) \mathrm{pkgs}$; Performance in accidents . & $71.33(\mathrm{a}) .$. & $71.36(a) \ldots \ldots$ & 229,243 \\
\hline \multirow{2}{*}{\multicolumn{4}{|c|}{ 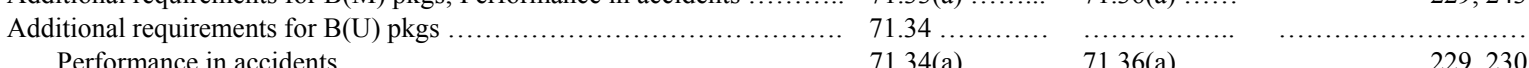 }} \\
\hline & $71.34(\mathrm{a}) \ldots \ldots \ldots$ & $71.36(a) \ldots \ldots$ & 229,230 \\
\hline Filters, cooling system & $71.34(\mathrm{~b}) \ldots \ldots \ldots . .$. & ................. & 234 \\
\hline Ventir & $71.34(\mathrm{c}) \ldots \ldots \ldots$ & $\ldots \ldots \ldots$ & 235 \\
\hline Presst & $71.34(\mathrm{~d}) \ldots \ldots \ldots$ & ...... & 236 \\
\hline Operating pressure limit .. & $71.34(\mathrm{e}) \ldots \ldots \ldots$ & ...... & 239 \\
\hline Operating pressure, structural & $71.34(\mathrm{f}),(\mathrm{g}) \ldots$ & .......... & 237,238 \\
\hline \multicolumn{4}{|l|}{ 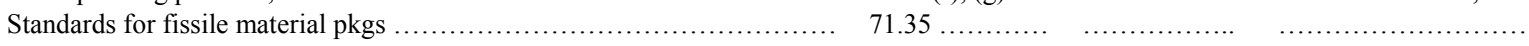 } \\
\hline 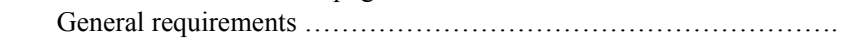 & $71.35(\mathrm{a})(1) \ldots .$. & & 601 \\
\hline Liquid leakage assumption . & $71.35(\mathrm{a})(2) \ldots .$. & $71.33 \ldots$ & 602 \\
\hline Performance in normal transport. & $71.35(\mathrm{a})(3) \ldots \ldots$ & $71.35(\mathrm{~b}) \ldots \ldots$ & 605 \\
\hline Performance in accidents .. & $71.35(\mathrm{a})(4) \ldots .$. & $71.36(b) \ldots \ldots$ & 607,617 \\
\hline Special anti-leak design . & $71.35(\mathrm{a})(5) \ldots .$. & $71.33(\mathrm{c}) \ldots \ldots$ & 607,617 \\
\hline Fissile class I .............. & $71.35(\mathrm{~b}) \ldots \ldots \ldots$ & $71.38 \ldots \ldots \ldots$ & 608 \\
\hline Fissile class II . & $71.35(\mathrm{c}) \ldots \ldots \ldots$ & $71.39 \ldots \ldots \ldots$ & 618 \\
\hline 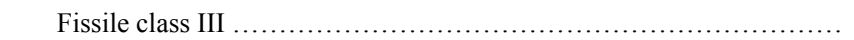 & $71.35(\mathrm{~d}) \ldots \ldots \ldots$ & $71.40 \ldots \ldots \ldots$ & 621 \\
\hline 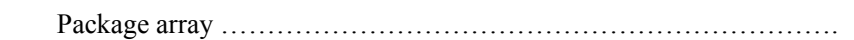 & $71.35(\mathrm{e}) \ldots \ldots \ldots$ & $71.37 \ldots \ldots \ldots$ & \\
\hline Special plutonium requirements . & $71.35 \ldots \ldots \ldots \ldots$ & $71.42 \ldots \ldots \ldots$ & \\
\hline \multirow{2}{*}{\multicolumn{4}{|c|}{ 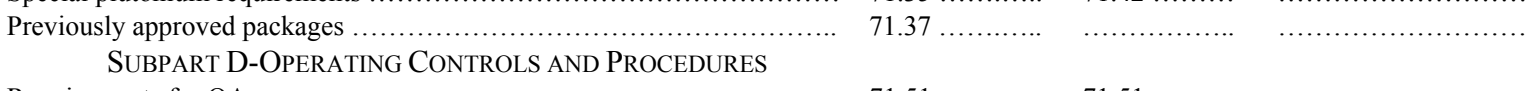 }} \\
\hline & & & \\
\hline 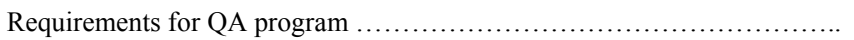 & $71.51 \ldots \ldots \ldots \ldots$ & $71.51 \ldots \ldots \ldots$ & \\
\hline Assumptions as to unknown properties . & 71.52 & 71.52 & 603 \\
\hline Preliminary determinations . & $71.53 \ldots$ & $71.53 \ldots \ldots \ldots$ & 733 \\
\hline Routine determinations .............. & $71.54(\mathrm{a}) \ldots \ldots \ldots$ & $71.54 \ldots \ldots \ldots$ & 733 \\
\hline Allowable external radiation levels . & $71.54(\mathrm{~b}) \ldots \ldots \ldots$ & $173.393(\mathrm{j}) \ldots$ & $508,534,537$ \\
\hline Allowable surface temperatures . & $71.54(\mathrm{c}) \ldots \ldots \ldots$ & $173.393(\mathrm{e})(2)$ & \\
\hline 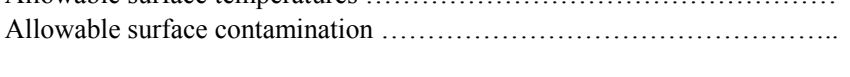 & $71.54(\mathrm{~d}) \ldots \ldots \ldots$ & $\begin{array}{l}173.393(\mathrm{~h}) \ldots \\
173.397 \ldots \ldots\end{array}$ & 502 \\
\hline Opening instructions . & 71.55 & $71.55 \ldots \ldots \ldots$ & \\
\hline Reports ................ & $71.61 \ldots \ldots \ldots \ldots$ & $71.61 \ldots$ & \\
\hline Records . & 71.62 . & 71.62 . & \\
\hline Inspection and audits . & 71.63 & 71.63 & \\
\hline \multirow{2}{*}{\multicolumn{4}{|c|}{$\begin{array}{r}\text { Violations ................ } \\
\text { APPENDIXES }\end{array}$}} \\
\hline & & & \\
\hline \multirow[t]{2}{*}{ Normal conditions of transport .. } & App. A ......... & App. A ........ & 232 \\
\hline & & $71.32(\mathrm{~b}) \ldots \ldots$ & $703-714$ \\
\hline Hyp. accident conditions ...... & App. B ......... & App. B ......... & $718-724$ \\
\hline 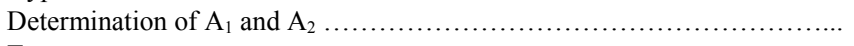 & App. C ......... & $\ldots \ldots \ldots \ldots \ldots \ldots$ & $403-411$ \\
\hline 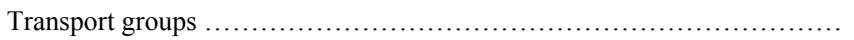 & .................... & App. C ........ & ........... \\
\hline 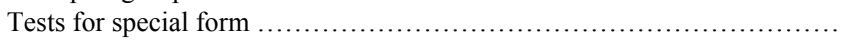 & App. D. ......... & App. D ........ & $726-737$ \\
\hline QA requirements. & App. E . & App. E ........ & \\
\hline
\end{tabular}




\section{"Detailed Changes}

"In addition to the major substantive changes to Part 71 previously discussed and numerous editorial changes for the purpose of clarity or conciseness, there are several other minor modifications. These changes are described below and are accompanied by a reference to the section or paragraph of the proposed rule where the change appears.

1. Section 71.4-Definitions. Many definitions needed to reflect the proposed changes to Part 71 have been added, and some existing definitions have been appropriately modified. These changes reflect the meanings of terms as used in the proposed revision to the regulations.

The term 'containment system,' defined in proposed $\S 71.4(\mathrm{c})$, replaces the existing term 'containment vessel.' The containment system may include a vessel as well as other components intended to retain the radioactive material during transport.

A new classification of radioactive material, 'low level solid' (LLS) radioactive material, is being added to the regulations. It is defined in proposed $\S 71.4(\mathrm{~g})$ and is similar to "low specific activity' (LSA) material, except that the LLS concept permits a greater concentration of radioactive material in the contents of a package and a higher surface contamination, while imposing greater restrictions on the dispersibility and on the permissible method of shipment.

Some changes have also been made for LSA material, defined in proposed $\S 71.4(\mathrm{~h})$. The specific activity limits will be related to $A_{2}$ values rather than to transport group. Articles such as contaminated equipment with non-fixed surface contamination have been included within the LSA definition. Methods of concentrating the activity in transport, such as leaching and evaporation, must now be considered. Finally, the limit for tritium oxide in aqueous solution, after consideration of the hazards due to wetting of the skin and to possible inhalation of vapors, has been increased from 5 curies/liter to 10 curies/liter.

The IAEA regulations define 'maximum normal operating pressure' (MNOP) as the maximum pressure that would develop in one year without venting or special cooling, under expected but unspecified ambient conditions for that period of time. The concept is applied in those regulations only to Type $\mathrm{B}(\mathrm{U})$ packages, for which upper limits of allowable pressure and allowable stresses are imposed.

In the regulatory changes proposed herein, the MNOP concept is applied to Type $\mathrm{B}(\mathrm{M})$ packages, and the MNOP is then assumed to be a normal condition of transport at the time of the tests described in Appendices A and B. At the same time the regulations recognizes [sic], in $\S 71.31(\mathrm{c})$, that in some cases operational controls, as with sole-use shipment, may justify a period of time shorter than a year for pressure buildup.

A definition of 'stress intensity' has been added in proposed $\S 71.4(q)$. This term is used in proposed $\S 71.34(\mathrm{f})$ and $(\mathrm{g})$.

2. Section 71.8-Exemption for low level materials. Low-level solid materials and low specific activity materials, even if they should escape from the packaging, present little hazard to individuals in the public because the concentration of radioactivity is small and individuals have a limited capability for inhalation and ingestion of the material. The risk to an individual does not depend to a significant extent on the curie quantity. These materials have therefore been exempted from the requirements of the proposed Part 71, but must satisfy the requirements of the applicable regulations of the Department of Transportation. This exemption was requested in three petitions currently pending before NRC. Type A quantities continue to be exempt from the requirements of Part 71.

3. Section 71.9-[E]xemption for fissile material. Proposed $\S 71.9$ (a) will require that for up to 15 grams of fissile material to be exempt from the requirements of $\S 71.35$ (standards for fissile material packages), the smallest external dimension of the package shall be not less than $10 \mathrm{~cm}$. Since 15 grams of some fissile materials could physically be contained in a smaller package, the requirement is consistent with proposed $\$ 71.35(\mathrm{a})(3)(\mathrm{iv})$ relating to size of aperture in [the] outer surface of packaging. Paragraphs (c) through (g) of $\S 71.9$ contain several changes and additions to the exemptions for fissile material. These changes and additions to the exemption standards for fissile material include:

a. Reduction from 7600 to 5200 of the minimum value of the atomic ratio of hydrogen to fissile material $(\mathrm{H} / \mathrm{X})$ that must be exceeded for 500 grams of any fissile radionuclide to be exempt from the packaging requirements of proposed $\S 71.35$. A concentration limit of 5 grams per liter will be imposed on this material. These changes eliminate the need for the $\mathrm{H} / \mathrm{X}$ requirements presently imposed by $\S 71.7(\mathrm{~b})(4)$ (iii) and $\S 71.9(\mathrm{~d})(3)$.

b. Application of quantity limits for bulk shipment to the vehicle rather than to the package. 
c. Extension to uranium metal of the present limitations for exemption of uranium compounds.

d. Removal of the restriction on the total amount of fissile radio-nuclides [sic] per package, provided the concentration does not exceed 5 grams per 10 liters.

e. Exemption from fissile material packaging requirements of plutonium up to 1 kilogram, but with imposition of certain restrictions on its isotopic composition.

f. Exemption of uranyl nitrate solutions, subject to certain restrictions on fissile content.

4. Section 71.11-General license for shipment of licensed material. Paragraphs 71.11(b), (d), and (e) of the proposed regulations for certain fissile Class II and Class III packages correspond to paragraphs 620, 623, and 624 of IAEA Safety Series No. 6 and are added specifications within the scope of a general license.

5. Section 71.23-Package evaluation. In accordance with the basis for establishing Type $\mathrm{B}(\mathrm{M})$ and $\mathrm{B}(\mathrm{U})$ packages, the proposed package evaluation must include a description of any special controls or precautions during the shipping and handling of Type $\mathrm{B}(\mathrm{M})$ packages.

6. Section 71.32-Standards for all Type B packages. Proposed $\S 71.32(\mathrm{a})$, which relates to the strength of lifting attachments, is more general than the existing $\S$ 71.31(e). The proposed rule will require the package to withstand abrupt lifting without developing unsafe stresses. At present, packages must withstand three times the weight of the package (or lid) without exceeding yield strength. This change will permit adjustment of the strength requirement in situations where a factor other than three may be appropriate or where the design is intended to safely accommodate a stress exceeding yield strength in some component. In addition, the proposed rule requires the package to satisfy the performance standards even if the lifting attachments should fail under excessive load, as is required for tiedown devices in present and proposed regulations. This new requirement for lifting attachments takes account of the possibility of some obstruction or wedging while handling the package during transshipment.

Proposed paragraphs (b), (c) and (d) of $\S 71.32$, imposing package design features, correspond respectively to present 49 CFR 173.393 (c) and (b) and 10 CFR 71.31(b).

Proposed $\S 71.32(\mathrm{e})$, relating to tie-down, is a modification of the existing $\S 71.31(\mathrm{~d})$. The present specification of strength corresponding to 2,10 , and 5 times the weight of the package in the vertical, longitudinal, and lateral directions, respectively, has been eliminated because for normal transport the required strength depends on the shipping mode and is addressed in DOT regulations, and for accident conditions the tiedown attachments are assumed to fail.

Proposed $\S 71.32(f)$, dealing with reactions among package components, corresponds to the present $\S$ 71.32(a), but with the added requirement that the consequences of any credible water inleakage must be taken into account. This requirement is included because packages sometimes contain substances that are highly reactive with water.

Proposed $\S 71.32(\mathrm{~g})$, corresponding to paragraph 222 of IAEA Safety Series No. 6, requires protection of valves. Although this requirement is not in the present regulations, such protection is needed for safety and has been provided in practice.

Proposed $\S$ 71.32(h) sets forth general acceptance criteria for normal conditions of transport. This corresponds to paragraphs 225 and 231(a) of IAEA Safety Series No. 6. However, the proposed regulations will require design to be based on an unattended time period of one year for all Type B packages except when, in accordance with $\S 71.31(\mathrm{c})$, a shorter time is justified by operational controls. During this time, which allows for possible delays in shipping, pressure may continue to develop as a result of chemical reaction (e.g., corrosion) and radiolytic decomposition. By way of comparison, the IAEA regulations in paragraphs 231 (a) and 242 require considering for all Type B packages only the effects of heat and only for one week; the one year period is specified only for Type $\mathrm{B}(\mathrm{U})$ packages (by requiring them to be designed to withstand 'maximum normal operating pressure.')

Paragraphs 233A and 243 of Safety Series No. 6 permit escape of radioactive material at the rate of $\mathrm{A}_{2} \times 10^{-6}$ per hour in normal transport. This amount is considered to be an insignificant hazard, and was introduced in the 1973 edition of Safety Series No. 6 in recognition of the fact that zero leakage is neither necessary nor attainable for some types of shipments. The requirements of 'no loss or dispersal' in normal transport is being retained in proposed Part 71, but with an acceptance test sensitivity of $10^{-6} \mathrm{~A}_{2}$, per hour or better. The acceptance criteria and methods of demonstration, which take account of the relative toxicities of the various radionuclides, are addressed in Regulatory Guide 7.4, 'Leakage Tests on Packages for Shipment of Radioactive Materials.' 
The IAEA option of designing Type B(M) packages for continuous venting, with specified limits for escape of radioactive material, $\mathrm{h}[\mathrm{a}] \mathrm{s}$ been omitted from proposed Part 71. There is no apparent need for such design in the United States at present; if the need should arise and if the adequacy of controls is demonstrated, exemptions might be granted on an individual basis.

The present requirement of $\S 71.32$ (a) that the strength of a package be analyzed as a simple beam has been eliminated because greater strength is required in order to satisfy the impact tests of the hypothetical accident.

The following IAEA package requirements have been omitted from revised Part 71; several of them are subjects for discussion in existing and contemplated regulatory guides:

a. Paragraphs 201-203 relating to means for handling.

b. Paragraphs 206-207 relating to external crevices or pockets and to decontaminability.

c. Paragraph 208 requiring that any features added at the time of transport shall not reduce safety. Currently in the United States, any such features are considered in the safety analysis.

d. Paragraph 212 requiring that external protrusions be avoided as far as practicable.

e. Paragraph 213 requiring consideration of the ambient temperature range and calling attention to the phenomenon of brittle fracture.

f. Paragraph 214 requiring fusion joints to be in accordance with recognized standards.

g. Paragraph 217 permitting credit to be taken for 'special form' as a means of containment. Special form is advantageous because it permits a larger amount of radioactive material per Type A package than does normal form. However, the indispersible nature of special form material in Type B quantities is necessarily taken into account in the evaluation of containment.

h. Paragraph 218 requiring a separate fastening device for a containment system that is a separate unit of the packaging.

i. Paragraph 223 requiring a separate fastening device for a radiation shield that encloses a part of the containment system.

j. Paragraph 233 requiring thermal protection (e g., insulation) to remain effective under normal and accident conditions and under other conditions, such as cutting or skidding, not simulated in the specified tests. Effectiveness under specified normal and accident conditions is necessarily considered in the safety analysis. The nature of other conditions such as cutting or skidding would require further definition before inclusion in Part 71.

7. Section 71.33-Additional requirements for Type B(M) packages. Proposed § 71.33(a)(2) specifies the allowable radiation level after the hypothetical accident as $1000 \mathrm{mrem} /$ hour at 1 meter rather than at $3 \mathrm{ft}$ from the package surface. This change will not significantly affect package design or performance.

The requirements of paragraph 244 of IAEA Safety Series No. 6 that limit stress in the containment system to the yield strength under normal and accident test conditions have not been included in proposed Part 71 because, as specified in the American Society of Mechanical Engineers, Boiler and Pressure Vessel Code, acceptable stresses may be higher or lower depending on details of design. In particular, stresses above yield strength are acceptable at points of stress concentration where local deformation provides stress relief. This subject is treated in Regulatory Guide 7.6, 'Stress Allowables for the Design of Shipping Cask Containment Vessels.' [See Section 52.7, above.]

The proposed allowable escape of radioactive material from Type $\mathrm{B}(\mathrm{M})$ packages under accident conditions is not greatly different from existing limits except to the extent $\mathrm{A}_{2}$ values differ from present transport group values. Present regulations restrict the loss to gases or contaminated coolant. This restriction is deleted in the proposed revised regulations because the concept of an identifiable coolant is no longer included in the regulations. The following tabulation shows the changes in the allowable release for some radionuclides of particular concern in the shipment of irradiated fuel. The proposed revised regulations specify that the allowable release must not be exceeded in a period of one week.

Allowable Release in Hypothetical Accident

\begin{tabular}{lcc}
\multicolumn{3}{c}{ (Curies) } \\
\hline & $\begin{array}{c}\text { Present }^{1} \\
\text { (total) }\end{array}$ & $\begin{array}{c}\text { Proposed } \\
\text { (in one week) }\end{array}$ \\
\hline${ }^{137} \mathrm{Cs}$ & 10 & 20 \\
${ }^{131} \mathrm{I}$ & 10 & 10 \\
${ }^{239} \mathrm{Pu}$ & 0.01 & 0.002 \\
${ }^{133} \mathrm{Xe}$ & 1,000 & 1,000 \\
${ }^{85} \mathrm{Kr}$ & 1,000 & 10,000 \\
\hline
\end{tabular}

${ }^{1}$ Or $0.1 \%$ of contents, whichever is less.

In most cases the release rate would decrease shortly after the accident, and the recovery of the damaged package would be expected within less than a week. However, a time limit is necessary for demonstration of compliance, and 
the NRC considers that the one week specified in IAEA regulations is adequate for corrective action.

Because of its relatively innocuous nature and rapid dispersion in air, special consideration was given to $\mathrm{Kr}-85$, and its limit was increased from 1,000 to 10,000 curies. On the other hand, the allowable release of many present Group I radionuclides will be reduced because the present limit of 0.01 curie[s] exceeds the $\mathrm{A}_{2}$ value. This is illustrated by the values for ${ }^{239} \mathrm{Pu}$ in the table.

8. Section 71.34-Additional requirements for Type $B(U)$ packages. Only a few of the requirements for Type $B(U)$ packages have counterparts in the present regulations. These are identified in the cross-index.

Analysis taking into account the atmospheric dispersal and possible inhalation has shown that any serious radiological injury due to release of an amount $\mathrm{A}_{2}$ from a package is quite unlikely. The proposed allowable release of this amount from a Type $\mathrm{B}(\mathrm{M})$ package under hypothetical accident conditions is thus considered adequately safe. As an added factor of safety for Type $\mathrm{B}(\mathrm{U})$ packages, which are intended to be universally acceptable without review by countries other than the country of origin, the specified maximum release under hypothetical accident conditions is smaller than the Type $\mathrm{B}(\mathrm{M})$ limit by a factor of 1000 . This factor takes into account the possible differences in methods of evaluation in different countries and the freedom from any restrictions on handling or shipment.

Proposed $\S 71.34$ (f) and (g), imposing internal pressure limitations, correspond to paragraphs 237 and 238 of Safety Series No. 6, but use the term 'stress intensity' rather than simply 'stress,' and state which stresses to consider. This change should help to clarify this requirement. Although these requirements, in amplified form, might seem more appropriate for a regulatory guide, they are included in proposed part 71 because of the need for consistency with IAEA regulations, particularly for Type B(U) packages.

9. Section 71.35-Standards for fissile material packages. The editorial arrangement of proposed $\S 71.35$, which contains the revised requirements for fissile material packaging, differs significantly from that of IAEA Safety Series No. 6. However, there is no essential difference in technical requirements and assumptions for evaluation of criticality or in controls required during shipment, except that the requirement for no more than $5 \%$ reduction of volume or spacing and no aperture greater than $10 \mathrm{~cm}$ in normal transport applies to all fissile material packages in the existing and proposed Part 71, but only to Fissile Class II packages in IAEA Safety Series No. 6. Retention in Part 71 of these requirements for all fissile material packages is considered justified by the added margin of safety for package integrity.

10. Section 71.54-Routine determinations. Proposed $\S 71.54(\mathrm{~b})$ corresponds to the present 49 CFR 173.393(j) and to paragraphs 534 and 537 of IAEA Safety Series No. 6. A change from the present regulations is that the allowable maximum radiation level for a package transported as a full load in a closed vehicle will be $1000 \mathrm{mrem} / \mathrm{h}$ on the surface of the package, rather than at $3 \mathrm{ft}$ from the surface as presently measured. In practice, only small packages are affected since the controlling radiation level for large packages remains the allowable radiation level at the edge of the vehicle or at $2 \mathrm{~m}$ from the vehicle. The change reduces allowable surface radiation levels and thus for small packages increases the margin of safety in handling.

Proposed $\S 71.54(\mathrm{c})$, specifying allowable surface temperatures, corresponds to the present 49 CFR 173.393(e)(2) and to paragraphs 231(b) and 240 of IAEA Safety Series No. 6. Present NRC and DOT regulations, however, do not specify the ambient air temperature. In accordance with IAEA regulations, ambient air temperature will be assumed to be $38^{\circ} \mathrm{C}$ $\left(100^{\circ} \mathrm{F}\right)$.

The IAEA regulations, however, impose only on Type $\mathrm{B}(\mathrm{U})$ packages the limit of $82^{\circ} \mathrm{C}\left(180^{\circ} \mathrm{F}\right)$ for the temperature of readily accessible surfaces with full load shipment; Part 71 will impose this limit on both Type $\mathrm{B}(\mathrm{U})$ and Type $\mathrm{B}(\mathrm{M})$ packages.

Proposed $\S$ 71.51(d), limiting external radioactive contamination, corresponds to present 49 CFR 173.397.

11. Section 71.62-Records. Proposed § 71.62(a) defines the records that must be kept for shipment of fissile material and Type B quantities of radioactive material.

12. Appendix A.-Normal conditions of transport. Proposed Appendix A describes environmental conditions considered to represent normal transport. Paragraph 232 of IAEA Safety Series No. 6 Specifies $[\mathrm{sic}] 38^{\circ} \mathrm{C}\left(100^{\circ} \mathrm{F}\right)$ as ambient temperature. However, the matter of diurnal variation is not addressed. There are only a few spots in the United States (e.g., Death Valley) where a few days in the year the daily average temperature exceeds $38^{\circ} \mathrm{C}$, and then it exceeds that temperature by only a small amount. However, to avoid the need for more complex analysis to consider diurnal variation, and 
because of other considerations which may increase ambient temperature above that of outside air (e.g., closed vehicles, assembly of multiple heat producing packages, insulating effects of other cargo), the present ambient temperature of $54^{\circ} \mathrm{C}\left(130^{\circ} \mathrm{F}\right)$ has been retained.

The present Part 71 does not specify ambient temperature or internal pressure preceding the normal transport and accident tests. The IAEA regulations specify an ambient temperature of $38^{\circ} \mathrm{C}\left(100^{\circ} \mathrm{F}\right)$ but do not specify a time period during which pressure could develop. Proposed Part 71 will require selecting the most unfavorable ambient temperature between $-29^{\circ} \mathrm{C}\left(-20^{\circ} \mathrm{F}\right)$ and $38^{\circ} \mathrm{C}\left(100^{\circ} \mathrm{F}\right)$ and internal pressure equal to the MNOP adjusted for ambient temperature. Although the high temperature is unfavorable with respect to the effects of fire, a low temperature is unfavorable with respect to possible brittle fracture and perhaps other effects. Thus some intermediate temperature may be most unfavorable for a prescribed sequence of tests.

The present $\S$ 71.32(b) and Part 71, Appendix A, paragraph 3, require the package to withstand ambient pressures of $25 \mathrm{psig}$ and 0.5 atmosphere, respectively. The requirement to withstand an ambient pressure of 25 psig without damage is not contained in the IAEA regulations, although there is an accident test of immersion in $15 \mathrm{~m}$ of water, which results in a pressure of about $21 \mathrm{psig}$. The resistance to external pressure is considered desirable as a way of providing ruggedness for unspecified rough handling conditions and is in most cases easily satisfied. The low ambient pressure in the proposed Appendix A, as in IAEA Safety Series No. 6 , is about 0.25 atmosphere rather than the presently specified 0.5 atmosphere. This change recognizes the possibility of transporting packages in unpressurized compartments of aircraft at altitudes of $10 \mathrm{~km}$ or about $33,000 \mathrm{ft}$.

Although proposed Part 71 requires a water spray test, details of this test as given in IAEA Safety Series No. 6 will be omitted because they are more suitable for a regulatory guide. The specifications for the compression test in proposed paragraph (d), which contemplates packages being stacked, have been converted to the metric system by applying the test to packages up to $5000 \mathrm{~kg}$ rather than $10,000 \mathrm{lb}$ and by adopting the IAEA load value of $1300 \mathrm{~kg} / \mathrm{m}^{2}\left(1.85 \mathrm{lb} / \mathrm{in}^{2}\right)$ rather than the previous $2 \mathrm{lb} / \mathrm{in}^{2}$. The IAEA regulations do not specify an upper limit for weight. However, such stacking is not contemplated for packages such as spent fuel casks, and thus the test will not be applied to packages greater than $5000 \mathrm{~kg}$.

13. Appendix B-Hypothetical accident conditions. As in Appendix A for normal transport conditions, the ambient temperature and internal pressure are specified for the package entering the test sequence. Paragraph (c), describing the thermal test, will be revised for clarity and will require consideration of convective heat input when significant. When the main body of a package is surrounded by and directly exposed to fire, the convective heat input is small compared to radiant heat input. However, some packages are protected partially or wholly by a radiation shield through which air and combustion gases may circulate. In such cases, convective heat input may be significant and must be included since the test is intended to simulate realistic fire conditions with respect to expected total heat input.

A requirement will be added that artificial cooling shall not be applied and that any combustion of materials of construction shall be allowed to proceed until natural termination. The IAEA regulations permit artificial cooling after 3 hours. However, 3 hours may be inadequate for control of fire even in populated areas. Also, unrecognized smoldering may continue for a much longer time.

Proposed paragraph (e) adds an accident test condition of immersion in $15 \mathrm{~m}$ of water, since some harbors have such depth and a package might be dropped overboard during handling. Immersion to a greater depth within the United States could occur in one of the Great Lakes, but such occurrence is very improbable.

14. Appendix $C$-Determination of $A_{1}$ and $A_{2}$. A few of the radioisotopes listed in Appendix $\mathrm{C}$ of the present Part 71 have been omitted from the table of $A_{1}$ and $A_{2}$ values in propose Part 71, because these radioisotopes have seldom if ever been shipped in recent years. However, the proposed Appendix $\mathrm{C}$ provides procedures for determining the $A_{1}$ and $A_{2}$ values for any radioisotope. A new entry has been included for the radionuclide lead-201 a medical isotope, in response to a petition currently pending before NRC.

15. Appendix $D$-Requirements for special form radioactive material. The qualification tests for special-form radioactive material in proposed Appendix D have been modified, primarily by adding a bending test, providing more detailed instructions for the immersion or leaching procedure, and changing the maximum loss by leaching to 0.05 microcurie in each of two determinations rather than the present $0.005 \%$ for a single determination. Long, slender objects are more likely to suffer bending under rough handling or accident conditions than are short or spherical objects; hence, a minimum length of $10 \mathrm{~cm}$ and a minimum length-to-width ratio of 10 have been selected for application of the bending test. The proposed leaching test 
specified by the IAEA regulations has been selected as suitable and should yield uniform results. An absolute amount leached is better related to the hazard than is a fixed percentage. Although 0.05 microcurie is much smaller than any of the $A_{2}$ quantities, in this case it is specified as a measure of the indispersibility and is equivalent to the maximum permissible nonfixed surface contamination on an area of $50 \mathrm{~cm}^{2}$ of a package surface.

Existing regulations require that 'special form radioactive material' have either (1) no dimension less than $0.5 \mathrm{~mm}$ or (2) at least one dimension greater than $5 \mathrm{~mm}$. It is now proposed that special form radioactive material must have at least one dimension not less than $5 \mathrm{~mm}$. The first option has been removed because of the possible difficulty of identifying, for safe handling, an object as small as $0.5 \mathrm{~mm}$ in every dimension.

16. Miscellaneous. Several changes and additions that experience indicates will be useful are proposed in the requirements for exemption of fissile material from the provisions of Part 71 and in the specifications for packages of fissile material that are generally licensed. Criticality studies showed that these proposed modifications satisfy the requirements for avoidance of criticality. The IAEA regulations also include some examples of specific packages that the IAEA considers to satisfy criticality requirements but nevertheless to require approval by the competent authority before use. These examples are not included in the proposed revision of 10 CFR Part 71.

"The metric system, as represented by the International System of Units (SI), has been incorporated in the proposed regulation. Roundedoff values of equivalents for the English system are given in parentheses, except in a few cases where the conversion seems unnecessary or inappropriate....

"Pursuant to the Atomic Energy Act of 1954, as amended, the Energy Reorganization Act of 1974, as amended, and section 553 of title 5 of the United States Code, notice is hereby given that adoption of the following revision to 10 CFR Part 71 in its entirety is contemplated."'[19]

\subsection{NUREG/CR-1815, 1981}

In June of 1981, the NRC published NUREG/CR-1815, Recommendations for Protecting Against Failure by Brittle Fracture in Ferritic Steel Shipping Containers Up to Four Inches Thick.[20] Written by W. R. Holman and R. T. Langland of Lawrence Livermore National Laboratory, this NUREG/CR became the second NRC guidance document to link the requirements of 10 CFR 71 with the requirements of the ASME Boiler \& Pressure Vessel Code.
Holman and Langland noted in their Executive Summary,

"This report addresses the problem of brittle fracture in ferritic steels and recommends fracture toughness criteria that will provide three levels of safety in shipping containers licensed for transporting radioactive materials. Recommendations are given for defining three categories of fracture toughness criteria that will provide degrees of safety appropriate to the various materials transported in the containers....'[20]

Holman and Langland further recommended that

1) A fracture control plan be implemented for each container design;

2) Fracture-critical components be identified and treated as specified in the report;

3) Specific fracture toughness testing requirements be established; and

4) Appropriate specification and qualification procedures be adopted for all fracture critical welds.

With respect to the category requirements, Holman and Langland went on to note that

"The largest margin of safety is provided in Category I by requiring sufficient toughness to assure that there is no crack propagation at the lowest service temperature. Steels with this level of toughness can tolerate large flaws under dynamic loading conditions.

"A smaller margin of safety is allowed for Category II, in which the minimum level of toughness at the lowest service temperature is specified at somewhat above the level of toughness at the plane strain limit for dynamic loading conditions. If the shock mitigating system is effective in reducing the loading rate in the fracture critical components, then an intermediate loading rate can be assumed and an additional reduction in the minimum toughness is permitted for Category II.

"The level of safety required for Category III is less than that for Category II, and the minimum toughness requirements are correspondently reduced. Good engineering practices and selection of steels with a low NDT $^{*}$ temperature make it unlikely that brittle fracture will occur....'[20]

This was the first of three NUREG/CRs that would eventually lead to the publication of Reg. Guide 7.11. (See Section 52.13.)

\subsection{FINAL RULE, 10 CFR 71}

In August 1983, the final rule for major changes to 10 CFR 71 was published in the Federal Register.[21] This was the follow-up to the 1979 proposed rule described above in Section 52.8:

Author's Note: NDT means the Nil-Ductility Temperature. 
"SUMMARY: The U.S. Nuclear Regulatory Commission is revising its regulations for the transportation of radioactive material to make them compatible with those of the International Atomic Energy Agency (IAEA) and thus with those of most major nuclear nations of the world. Although several substantive changes are made to provide a more uniform degree of safety for various types of shipments, the Commission's basic standards for radioactive material packaging remain unchanged. Some deletions from the proposed rule have been made to account for changes expected in the 1984 revision of the IAEA regulations (begun since the NRC proposed rule was issued) which will bring those regulations closer to those of the United States. The regulations apply to all NRC specific licensees who place byproduct, source, or special nuclear material into transportation. The special restriction on the air transport of plutonium has been included in this revision in its final form.

"EFFECTIVE DATE: September 6, 1983. In order to minimize negative impacts through the period before this rule becomes effective, during which there are some inconsistencies between the presently effective regulations of the NRC and the Department of Transportation (DOT), the NRC staff has adopted a policy of flexibility. In practical terms, in those situations where compliance with a new DOT requirement would be in conflict with a current 10 CFR Part 71 requirement, NRC would in most cases accept compliance with the new DOT requirement. NRC would reserve judgement [sic], however, to take enforcement action in an appropriate case....

\section{"SUPPLEMTARY INFORMATION: \\ "Background}

"On August 17, 1979, the Nuclear Regulatory Commission published in the Federal Register ${ }^{\dagger}$ (44 FR 48234) a proposed revision of 10 CFR Part 71 of its regulations pertaining to the transportation of radioactive material. Interested persons were invited to submit written comments and suggestions on the proposal and/or the supporting value/impact analysis by October 16,1979 . The public comment period was subsequently extended to December 17, 1979. Based on the public comments and other considerations, the Commission has adopted the proposed revision, with modifications as set forth below. The regulations apply to all NRC licensees who place byproduct, source, or special nuclear material into transportation.

"The revision, as proposed, in combination with a corresponding amendment of Title 49 of the Code of Federal Regulations by the Department of Transportation (DOT), would bring the U.S. regulations into accord with relevant portions of the

$\dagger$ Author's Note: Emphasis added by the U.S. Government Printing Office. This will show up again, repeatedly, throughout the remainder of this Chapter.
International Atomic Energy Agency (IAEA) design and performance requirements to the extent considered feasible, thereby making U.S. regulations compatible with the domestic regulations of most of the international community.

"One important change proposed was a change in the system used to specify the quantities of radioactive materials permitted in packages (designated Type A packages) not required to survive severe transportation accidents. These quantities, derived from criteria limiting individual radiation exposure resulting from transportation accidents, have since 1988 , been based on grouping all radionuclides in seven transport groups and limiting all radionuclides in the group according to the toxicity of the most hazardous member. There was, in addition, a 'special [form]' category for radioactive materials which are not dispersible because of their inherent physical form or because of suitable encapsulation. This system is unnecessarily restrictive when applied to the less toxic group members, which in some cases are less than one-tenth as toxic as other group members. The proposed change would eliminate the transport groups and instead assign to each radionuclide two values, $A_{1}$ and $A_{2}$, which are the maximum quantity of that radionuclide permitted in Type A packages in special form and non-special from, respectively.

"The other major proposed change was to create two classifications of packages (designated Type B packages) which are resistant to transportation accidents. The two classifications are the Type $\mathrm{B}(\mathrm{M})$ package which for international shipment requires approval of the package design by the competent authority of each country into or through which the package is transported (i.e., multilateral approval) and the Type $\mathrm{B}(\mathrm{U})$ package which requires package design approval only of the country of origin (i.e., unilateral approval). Requirements for the Type $\mathrm{B}(\mathrm{U})$ package approval would be more stringent to assure that all countries affected would be satisfied with the package design as approved by the country of origin.

"Other changes were proposed dealing with definitions, requirements for transporting low specific activity materials, small quantities of fissile material, and standards for leak tightness. A large number of changes were proposed to bring U.S. domestic rules as close as possible to the international standards. However, the basic systems of control remain unchanged as do the basic standards which define the required level of safety.

\section{“Other Considerations}

"IAEA Activities

"During September 1980 and March 1982, revision panels were assembled by IAEA to draft changes for the scheduled 1984 revision of its transportation regulations. Decisions made by these revision panels, consisting of representatives of most major 
countries involved in nuclear material transportation, would make IAEA regulations more compatible with present U.S. regulations. NRC, in consultation with DOT, has decided not to include in its final revision of 10 CFR Part 71 those requirements introduced in the IAEA regulations in 1973 which are expected to be removed from IAEA regulations in the 1984 revision. This results in elimination of the 'additional requirements for Type $\mathrm{B}(\mathrm{U})$ packages' in proposed $\S 71.34$. The design criteria of $\S 71.34$ (f) and (g) are deleted. All other distinctions between $\mathrm{B}(\mathrm{U})$ and $\mathrm{B}(\mathrm{M})$ packages are eliminated except those related to internal pressure limitations and pressure relief devices for $\mathrm{B}(\mathrm{U})$ packages, which are now contained in the definition of a Type B package.

"The IAEA, as part of its effort to maintain the continued adequacy of the regulations, has adopted a modified system for determining $A_{1}$ and $A_{2}$ values. This new system will be incorporated in the 1984 revision of the IAEA regulations which is being prepared. The system was adopted in principle by the IAEA at the March 1982 Advisory Group on the revision and it was subsequently refined by a special Work Group which met in August 1982. When the IAEA circulates the '3rd Draft' version of the regulations, DOT will be making it available and will seek public comment.

"It has become apparent to NRC that the new system incorporates a radiological exposure pathway which has not been considered previously. This pathway involves consideration of the dose to the skin of a person contaminated with a radionuclide. For most radionuclides this is not a limiting pathway as other considerations in both the present and proposed systems are generally more limiting. Examples of the other more limiting considerations are radiation levels from unshielded material and internal pathways such as inhalation. For some beta emitting nuclides, however, the contaminated skin consideration is limiting. In some cases the Type A limits calculated under the newly adopted system are significantly lower than the previously accepted $A_{1}$ values and some are even lower than the earlier Transport Group values.

"The NRC believes that it cannot ignore the contribution that the contaminated skin consideration makes toward a complete system for calculating Type A values. This is particularly true for radionuclides which have high $\mathrm{A}_{2}$ values under the 1973 IAEA regulations and would have considerably lower $\mathrm{A}_{2}$ values under the new IAEA system due to their potential for significant dose to contaminated skin. Of these radionuclides, some have values below the old transport group values (Case 1) and some have values between the old transport group and the 1973 IAEA values (Case 2).

"The NRC believes that it is prudent to both accept this new pathway as necessary to provide a complete system for setting Type A values and to minimize unnecessary fluctuations in the Type A limits. While there is some uncertainty as to the exact values which will result from the final, accepted new IAEA system, the NRC is confident that the values now available are conservative and will most probably not be lowered. Therefore, for those nuclides which are limited by the skin exposure pathway, values have been selected as follows:

"Case 1: The transport group values are adopted as the new $\mathrm{A}_{2}$ values.

"Case 2: The values now available are adopted in lieu of the 1973 IAEA values.

"These two cases can be represented graphically as:

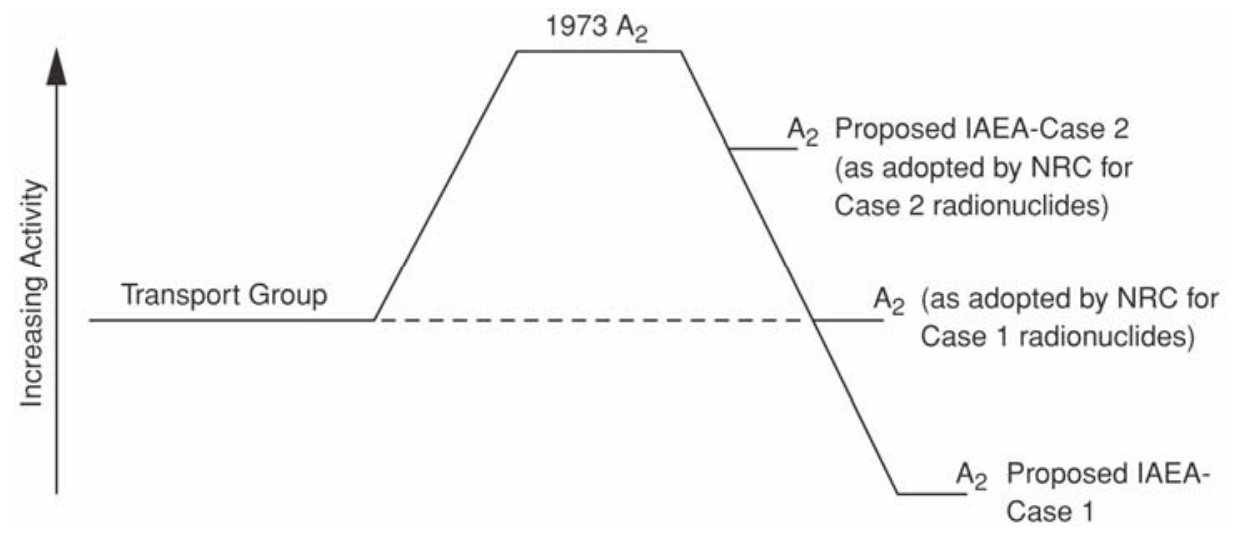


"The radionuclides which are affected in Case 1 are:

$\begin{array}{lll}\text { Ag-111 } & \text { Mo-99 } & \text { Sc-47 } \\ \text { As-77 } & \text { Nd-147 } & \text { Si-31 } \\ \text { Au-198 } & \text { Nd-149 } & \text { Sm-153 } \\ \text { Cd-115 } & \text { Os-193 } & \text { Te-127m } \\ \text { Ce-143 } & \text { Pd-109 } & \text { Te-127 } \\ \text { Dy-165 } & \text { Pm-149 } & \text { Te-129 } \\ \text { Er-171 } & \text { Pr-143 } & \text { W-187 } \\ \text { Gd-159 } & \text { Pt-197m } & \text { Zn-69m } \\ \text { In-115m } & \text { Pt-197 } & \text { Zn-69 } \\ & \text { Re-186 } & \end{array}$

"The radionuclides which are affected in Case 2 are:

$\begin{array}{lll}\text { Au-199 } & \text { Eu-155 } & \text { Rh-105 } \\ \text { Br-77 } & \text { Hf-181 } & \text { Ru-103 } \\ \text { C-14 } & \text { Hg-203 } & \text { S-35 } \\ \text { Ca-45 } & \text { I-133 } & \text { Sb-125 } \\ \text { Ce-141 } & \text { In-111 } & \text { Sr-89 } \\ \text { Cl-36 } & \text { Ir-192 } & \text { Tb-160 } \\ \text { Cs-134m } & \text { K-43 } & \text { Tc-99 } \\ \text { Cs-135 } & \text { Lu-177 } & \text { Te-129m } \\ \text { Cs-137 } & \text { N-13 } & \text { Th-231 } \\ \text { Cu-64 } & \text { Np-239 } & \text { Tl-204 } \\ \text { Cu-67 } & \text { Os-191 } & \text { Tm-170 } \\ \text { Er-169 } & \text { Pm-147 } & \text { W-185 } \\ \text { Eu-152 } & \text { Rb-81 } & \text { Yb-175 }\end{array}$

"In both cases the values adopted herein are no lower than the previously existing transport group values and yet are lower than the previously proposed 1973 IAEA $\mathrm{A}_{2}$ values. For the radionuclides listed under Case 1 , the $A_{2}$ is set at the old limit of 20 curies as each nuclide was previously in transport group IV which had this limit. The nuclides listed in Case 2 have been assigned the currently available values under the new IAEA system. These values are between the old transport group and the 1973 IAEA values. When the new IAEA system is fully implemented by the IAEA, and the skin exposure pathway is taken into due account, then NRC expects to complete the alignment of $\mathrm{A}_{2}$ values between the U.S. and the IAEA.

"It is expected that there will be a complete revision of the IAEA criteria governing the definition and transportation of low specific activity material. In anticipation of the future IAEA changes, the proposed definitions of low-level solid radioactive material (LLS) and of low specific activity material (LSA) are withdrawn, and the definition of low specific activity material in the present rule is retained with some minor changes to make it consistent with the new $A_{1} / A_{2}$ system for defining Type A quantities of radioactive material. The proposed exemption from NRC regulation for LSA and LLS materials has been withdrawn pending resolution of this issue. A separate NRC rulemaking action to upgrade the LSA standards will be undertaken in the near future.

\section{"United States Activities}

"New guidelines have been issued by the Office of the Federal Register on the use of numbering systems for regulations, and on the use of appendices. These new guidelines, and others concerning the writing of regulations in 'plain English,' have resulted in large but nonsubstantive changes in the format of 10 CFR Part 71. Existing Appendices A, B, D, and E have all been incorporated as new sections in the body of the rule and large, complex sections have been divided for clarity.

"Two recent NRC decisions have resulted in minor changes from the Transportation rules proposed in 1979. The definition of 'radioactive material' has been deleted because it duplicated, in a less effective manner, the function of the long standing exemption in proposed $\S 71.8$ (a) (now $\S 71.10(\mathrm{a})$ ) which avoids any regulatory requirements for radioactive material having a specific activity not greater than .002 microcuries per gram. Although this leaves NRC rules without a definition of radioactive material corresponding to those of DOT and IAEA, there is no substantive inconsistency because the exemption provisions are retained.

"NRC has also decided to require reporting of package defects within 30 days of discovery to assist the staff in follow-on evaluations of approved package designs. Reporting of defects is already required by 10 CFR Part 21, 'Reporting of Defects and Noncompliance,' and is added to the proposed reporting requirement in $\S 71.61$ (now $\S 71.95$ ) for clarity and emphasis. The information to be reported has been moved from the 10 CFR Part 71 record keeping requirement of $\S 71.62$ (now $\S 71.91$ ) to the reporting requirement in $\S 71.95$.

\section{"Other Rulemaking Actions Included}

"On November 2, 1979, the NRC published in the Federal Register (44 FR 63083) a final rule to require all shipments of radioactive material made by NRC specific licensees to be made in accordance with the regulations of DOT. The effect of the rule was to allow the NRC to inspect the activities of its licensees involved with shipment of radioactive materials against the requirements in DOT regulations. Licensees who violate the referenced DOT standards also violate NRC regulations. Those changes are incorporated in this revised rule.

"On January 6, 1982, the NRC published in the Federal Register (47 FR 596) a final rule to require advance notification to the governor of any state prior to transport of certain types of nuclear waste, including spent fuel, to, through, or across the boundary of that state. That requirement has been repositioned in this revised rule for clarity, and is now codified as $\S 71.97$ 'Advance notification of shipment of nuclear waste.' The associated definition of 'nuclear waste' has been incorporated into § 71.97.

"The preamble to the final rule imposing the advance notification requirement recognized that the term 
'large quantity,' which establishes the level of radioactivity at which the advance notification is required, was being eliminated from the regulations. The original purpose of the term, as a designator of the quantities of radioactive materials which generate sufficient decay heat to warrant consideration of heat dissipation in the package design and approval, is antiquated, as all Type B packages are now evaluated for heat dissipation under both normal and accident conditions. In addition, the elimination of the transport group system for classifying radionuclides in favor of the $A_{1} / A_{2}$ system has removed the basis on which the term 'large quantity' was defined. This final rule retains the advance notification requirement with the same limits on reportable quantities. There have been some minor changes made to make the requirement consistent with the new $A_{1} / A_{2}$ system for defining Type A quantities of radioactive material.

"On November 13, 1981 the NRC published in the Federal Register (46 FR 55992) a proposed rule to restrict the air transport of plutonium. Under the proposed rule, plutonium could be transported by air only in a package specifically certified by NRC as air-crash resistant unless the plutonium is in a medical device for individual human use or is shipped in quantities or concentrations small enough to present no significant hazard to the public health and safety even if the plutonium were released in an air crash. Only one public comment was received with respect to the proposed rule, and that was favorable. The final rule, as proposed, is therefore included in this overall revision of Part 71.

"The original restriction on the air transport of plutonium was imposed by NRC order dated August 15, 1975. This order was imposed after the U.S. Congress, in Pub. L. 94-79, prohibited the NRC from licensing any shipments of plutonium by air until the NRC certified to the Congress that a safe container had been developed and tested which would not rupture under crash and blast-testing equivalent to the crash and explosion of a high-flying aircraft. A second order was issued on September 1, 1978, superseding the first order dated August 15, 1975, after the first air-crash resistant package, the Model PAT-1 package, had been certified by NRC to the Congress. The second order allowed the use of the PAT-1 package for the air transport of plutonium. With the finalization of this regulatory revision and the imposition of 10 CFR Part 71.88 to implement the restriction of Pub. L. 94-79, the NRC's second order dated September 1, 1978 is being revoked by the Provisions of $\S 71.88$. However, in addition to the NRC orders, restrictive conditions were also placed in the licenses of persons authorized to possess plutonium, restricting its air shipment. Those license conditions will be automatically removed from the licenses when the licenses are processed by NRC for renewal or amendment. Any licensee who needs that license condition removed earlier should request that action.
There will be no licensing fee for removal of the condition....”[21]

\subsection{ADDITIONAL REGULATORY GUIDANCE, NRC, 1985}

In 1985, two additional regulatory guidance documents were produced by the NRC: NUREG/CR-3019 and NUREG/CR-3854.[22, 23]

\subsubsection{NUREG/CR-3019}

In March of 1985, the NRC published NUREG/CR-3019, Recommended Welding Criteria for Use in the Fabrication of Shipping Containers for Radioactive Materials.[22] Written by R. E. Monroe, H. H. Woo, and R. G. Sears of Lawrence Livermore National Laboratory, this NUREG/CR became the third in a series of NRC guidance documents to link the requirements of $10 \mathrm{CFR} 71$ with the requirements of the ASME Boiler \& Pressure Vessel Code. $\quad$ More importantly, this particular NUREG/CR became the first to reference the ASME Code requirements to quantify the welding requirements for 10 CFR 71 transport packages.

As Monroe, Woo, and Sears noted in their Summary,

"This NUREG presents the recommended criteria for welding and related operations used in the fabrication of shipping containers for radioactive materials. The welding criteria given ... are divided into three categories that are associated with the levels of safety for the type of containers and radioactive contents being transported. Category I provided the largest margin of safety; Categories II and III provide lesser margins of safety consistent with the characteristics and quantities of the radioactive material being transported. The same Category designations also have been used in the development of fracture toughness criteria applicable to the containment vessel. [See Section 52.9.] For each category, the welding criteria are further divided into three weld types that are associated with the functions of the welds. The three types are containment-related welds, criticality-related welds, and other safetyrelated welds.

"The welding criteria include a number of related elements to ensure adequate control. The ten key elements are as follows:

1. Base Materials

2. Welding and Brazing Materials

3. Joint Preparation

4. Welding

5. Brazing

6. Heat Treatment

7. Qualification of Procedures and Personnel

8. Examination

Author's Note: As was noted in Section 52.7 with the development of Reg. Guide 7.6, the NRC had long since found it convenient to recommend the requirements of the ASME Boiler \& Pressure Vessel Code as a metric to quantify the often subjective requirements of the regulations. 
9. Quality Assurance

10. Fracture Toughness.

"For each Weld Type and Category, the selected welding criteria are based on an appropriate Section of the ASME Boiler and Pressure Vessel Code, as summarized in [the Table below]. These selected Code sections provide a level of confidence consistent with the Category and Weld Type...."[22]

"Summary of Recommended Welding Criteria for Use in the Fabrication of Shipping Containers

\begin{tabular}{|l|lll|}
\hline Weld Type & Category I & Category II & Category III \\
\hline $\begin{array}{l}\text { Containment- } \\
\text { Related Welds }\end{array}$ & $\begin{array}{l}\text { ASME Code } \\
\text { Section III, } \\
\text { Subsection NB }\end{array}$ & $\begin{array}{l}\text { ASME Code } \\
\text { Section III, } \\
\text { Subsection ND }\end{array}$ & $\begin{array}{l}\text { ASME Code } \\
\text { Section VIII- } \\
\text { Division 1 }\end{array}$ \\
\hline $\begin{array}{l}\text { Criticality- } \\
\text { Related Welds }\end{array}$ & \multicolumn{3}{|c|}{ ASME Code Section III, Subsection NG } \\
\hline $\begin{array}{l}\text { Other Safety- } \\
\text { Related Welds }\end{array}$ & \multicolumn{3}{|c|}{ ASME Code Section VIII-Div. 1 or Section III, } \\
\hline
\end{tabular}

\subsubsection{NUREG/CR-3854}

In March of 1985, the NRC also published NUREG/CR-3854, Fabrication Criteria for Shipping Containers.[23] Written by L. E. Fischer and W. Lai of Lawrence Livermore National Laboratory, this NUREG/CR became the fourth in a series of NRC guidance documents to link the requirements of $10 \mathrm{CFR} 71$ with the requirements of the ASME Boiler \& Pressure Vessel Code. Published as a companion document to NUREG/CR-3019, this particular NUREG/CR also became the first to link the ASME Code requirements to the fabrication requirements for $10 \mathrm{CFR} 71$ transport packages.

Fischer and Lai noted in their Summary,

"This NUREG provides fabrication criteria from the metal components of shipping containers used for transporting radioactive materials. The criteria are divided into three categories that are associated with the levels of safety for the types and quantities of radioactive materials being transported. For each category, the fabrication criteria are subdivided into three component safety groups that are formed according to their safety function. The categories and component safety group designations are the same as those used in developing the welding criteria in [NUREG/CR-3019].

"The fabrication criteria are based on the American Society of Mechanical Engineers Boiler and Pressure Vessel Code ..., as summarized in [the Table below] for each of the categories and component safety groups.... The selected ASME Code criteria provide levels of confidence in controlling fabrication processes consistent with the categories and component safety groups. The criteria should be used with the welding criteria contained in [NUREG/CR-3019] when fabricating shipping containers for transporting radioactive materials...."[23]
"Summary of Fabrication Criteria Based on the ASME Code

\begin{tabular}{|l|l|l|l|}
\hline \multirow{2}{*}{$\begin{array}{l}\text { Component } \\
\text { Safety Group }\end{array}$} & \multicolumn{3}{|c|}{ Container Contents } \\
\cline { 2 - 4 } Containment & Category I & Category II & Category III \\
\hline Subsection NB, & $\begin{array}{l}\text { Section III, } \\
\text { Subsection ND }\end{array}$ & $\begin{array}{l}\text { Section VIII, } \\
\text { Division 1 }\end{array}$ \\
\hline Criticality & \multicolumn{2}{|c|}{ Section III, Subsection NG } \\
\hline $\begin{array}{l}\text { Other Safety- } \\
\text { Related }\end{array}$ & \multicolumn{2}{|c|}{ Section VIII, Division 1, or Section III, } \\
Subsection NF
\end{tabular}

\subsection{MAJOR CHANGES, 10 CFR 71, 1988 PROPOSED RULE}

In June 1988, the proposed rule for major changes to 10 CFR 71 was published in the Federal Register.[24] For the most part, the preamble for that final rule reads as follows:

"On August 5, 1983, the NRC published in the Federal Register (48 FR 35600) a final revision of 10 CFR Part 71, 'Packaging and Transportation of Radioactive Material.' That revision, in combination with a parallel revision of the hazardous materials transportation regulations of the U.S. Department of Transportation (DOT), brought United States domestic transport safety regulations at the Federal level in accord with relevant portions of the International Atomic Energy Agency (IAEA) design and performance requirements to the extent considered feasible. This action made U.S. regulations compatible with the domestic regulations of most of the international community.

"In 1980, 1982, and November 1983, the IAEA assembled revision panels to draft changes for the scheduled 1984 revision of its transportation regulations. The revision was eventually issued in early 1985 . The revision panels, which consisted of representatives of most major countries involved in nuclear material transportation, made IAEA regulations more compatible with U.S. regulations through some of their decisions. When NRC and DOT were finalizing their transportation regulations in 1983, they anticipated some of the changes that IAEA was making in the revision of its regulations. The 1983 NRC and DOT rules were written to incorporate, to the extent possible, some of the IAEA changes. Where is was not possible to incorporate IAEA changes, the 1983 rules were written so as to minimize the number of changes that would have to be made when the IAEA revision was completed. Those changes and other changes, not anticipated by NRC and DOT in 1983, are being incorporated into this proposed rulemaking.

\footnotetext{
"Discussion of Major Changes

"The major proposed changes to 10 CFR Part 71 are additional accident test requirements for certain packages, an expansion in the number of radionuclides with listed limits for the quantity of radioactive material in a single package, a number of changes in the listed limits, simplification of the
} 
fissile material transport classes, updating requirements for shipment of low-specific-activity materials and inclusion of the criteria for air transport of plutonium. These major changes are discussed in the following paragraphs.

\section{"Additional Accident Test Requirements}

"A deep water immersion test has been added to the regulations for a Type $\mathrm{B}$ package containing irradiated nuclear fuel in excess of $10^{6} \mathrm{Ci}(37 \mathrm{PBq})$. If such a package were lost in relatively shallow coastal waters due to the sinking or capsizing of a ship or barge the probability is high that an attempt would be made to recover the package and its contents. The deep immersion test (200m) requirement, which can be satisfied through engineering evaluation or actual physical test ( $§ 71.41)$, is to assure that the package containment system does not rupture from the water pressure at $200 \mathrm{~m}(656 \mathrm{ft})$ which would create radiological problems for the recovery operation or an additional environmental risk.

"While the NRC staff believes that many existing Type B cask designs now approved by NRC will satisfy this additional test without need for modification, adding the test to the regulations will assure that foreign casks and future U.S. designs will also have the ability to survive deep immersion in water. Adding the deep immersion test to the regulations also introduces the cost involved in having licensees analyze existing package designs to assure and demonstrate that presently approved casks for transporting irradiated nuclear fuel satisfy the requirement. These costs can be avoided if no additional casks of the same design will be fabricated beyond a specified date, and if the casks will not be used for international transport beyond a specified date. In that case, existing casks of the approved design can continue to be used domestically with no further qualification regarding deep immersion.

"A dynamic crush test has been added to the Type B package rules in addition to the $9 \mathrm{~m}(30 \mathrm{ft})$ drop test for packages which are minimally vulnerable to damage in the drop test, but which have a high potential for radiation hazard if package failure occurs. The crush test requirement, which can also be satisfied through provisions of 71.41, is applied to packages which are both lightweight, up to $500 \mathrm{~kg}$ $(1100 \mathrm{lb})$ and low density (up to $1,000 \mathrm{~kg} / \mathrm{m}^{3}$, i.e., $\left.1 \mathrm{~g} / \mathrm{cm}^{3}\right)$, and which have a high radioactive material content (over $1000 \mathrm{~A}_{2}$ ) in normal form. The dynamic crush test consists of the drop of a $500 \mathrm{~kg}(1,100 \mathrm{lb})$ mild steel plate from $9 \mathrm{~m}$ onto the package resting on an unyielding support. IAEA applies the crush test in place of the $9 \mathrm{~m}$ drop test for the lightweight packages specified. In the absence of experience using the crush test, and because the crush test and drop test evaluate different features of a package, $\mathrm{NRC}$ is requiring both the crush test and the $9 \mathrm{~m}$ drop test for lightweight packages.
"There are a limited number of lightweight, low density, and high radioactive material content package designs to which the crush test would apply. Of those, some would pass the crush test so that no package design modification would be necessary. A limited amount of analysis would suffice to requalify the package design to the new standards. If the package design is not used internationally, and no further packages will be fabricated after a specific date, no effort to satisfy the new crush test standard would be necessary, and existing packages could be used in domestic transportation to the end of their useful lives.

\section{"Changes in Radionuclide Limits}

"The preamble to the August 5, 1983 revision of 10 CFR Part 71 (48 FR 35800) notes that the IAEA, as part of its effort to maintain the continued adequacy of the regulations, had adopted a modified system for determining $A_{1}$ and $A_{2}$ values. The $A_{1}$ and $A_{2}$ values are the maximum quantity of a particular radionuclide permitted in Type A packages in special form and normal form, respectively. Type A packages are those which provide adequate containment, shielding, and criticality control under normal conditions of transport and minor accidents, but are not designed to survive severe transportation accidents. Instead, there are limits placed on Type A package radioactive material contents. Accident resistant packages are identified as Type $B$. Radioactive material in special form is either a nondispersible solid or sealed in a capsule so that the dispersibility, and therefore the radiological hazard, of the radioactive material is diminished. This system of limiting the radioactive content of Type A packages to $A_{1}$ and $A_{2}$ values depending on the dispersibility of the contents is the regulatory scheme for limiting the potential radiological hazard of a serious transportation accident involving packages of radioactive material.

“The IAEA's modified system for determining $\mathrm{A}_{1}$ and $\mathrm{A}_{2}$ values is based on achieving essentially the same limitation on potential accident radiological hazards as its predecessor system. However, the new system has the following advantages:

1. It states the radiation protection criteria employed more clearly;

2. It incorporates the data and conclusions on metabolic pathways provided over the years 1977-1981 by the International Commission on Radiological Protection (ICRP);

3. It includes dosimetric routes not previously considered; and

4. It harmonizes IAEA regulations with ICRP recommendations on radiological safety in Publications ICRP-28 and ICRP-30. ${ }^{\dagger}$

$\dagger \quad$ "ICRP Publications are available for sale at Pergamon Press, Inc., Maxwell House, Fairview Park, Elmsford, 
"The effect of IAEA's adoption of this new system for calculating $A_{1}$ and $A_{2}$ values, and the subsequent incorporation of the new values in U.S. domestic regulations, is that most current $A_{1}$ and $A_{2}$ values are changing in this revision. Of the 284 radionuclide entries in 10 CFR Part $71, \mathrm{~A}_{2}$ values are being raised in 129 cases and lowered in 95 cases. Of the $\mathrm{A}_{1}$ values, 144 are being raised and 73 are being lowered. Based on our most current knowledge of radioactive material shipments in the United States, the economic impacts of these changes are not likely to be large. However, any situations where a potential exists for significant economic impacts as a result of changes in the $A_{1}$ or $A_{2}$ values should be brought to the Commission's attention in public comments.

"The new IAEA system for calculating $A_{1}$ and $A_{2}$ values is described in Appendix I, 'The Q System for the Calculation of $A_{1}$ and $A_{2}$ values,' of IAEA Safety Series No. 7, 'Explanatory Material for the IAEA Regulations for the Safe Transport of Radioactive Material (1985 Edition).' Single copies of Appendix I are available free of charge from the contact for this rulemaking.

\section{"Expansion of Radionuclide List}

"Based on numerous proposals for additions to the table of radionuclides in which limits are listed for the quantity of radioactive material in a single package, IAEA concluded that its table needed to include all radionuclides which have the potential for transportation. As a result, Table A-1 in Part 71, which provides $A_{1}$ and $A_{2}$ values, has been expanded from 284 entries to 378 entries. Because there now should be few instances where unlisted radionuclides would be transported, the rules for calculating values for unlisted radionuclides have been simplified. The determination of limits for unlisted radionuclides, except for very conservative values, will be made subject to Commission approval.

\section{"Simplification of Fissile Material Classes}

"As a result of the evolution of the fissile material criteria, IAEA recognized that the current three fissile classes could be combined and simplified into a single system. The effect of the simplification of the IAEA system now being proposed for U.S. regulations is:

1. Elimination of the three fissile class designations;

2. Establishment of a single set of criteria for all packages of fissile materials;

NY 10523.” (This footnote was part of the original citation.)

* "Transport of Radioactive Materials in the United States, SRI International, SAND 84-7174, April 1985, is available from the National Technical Information Services, U.S. Department of Commerce, 5288 Port Royal Road, Springfield, VA 22181.” (This footnote was also part of the original citation.)
3. Use of the transport index as the primary control of accumulations of packages in transport under nearly all conditions; and

4. Use of special arrangements for packages which do not meet the criteria.

"Updating of Requirements for Shipment of LSA Material

"Over the last two major revisions of its transport regulations, IAEA has been working to update its requirements for shipment of LSA material to recognize the developing need for transportation of irradiated and contaminated parts and equipment from decommissioned nuclear plants. Although these developing LSA requirements were not factored into U.S. regulations when last updated in 1983, it is believed that the IAEA standards are now mature enough to be adopted as U.S. standards.

"Updating the LSA regulations consists of the following:

1. An expansion of the LSA definition to include new types of material;

2. A new definition of 'surface contaminated object' (SCO) which is treated in a manner similar to LSA material; and

3. An increase of specific activity limits for nondispersible, nonrespirable forms of LSA material while at the same time limiting the quantity of LSA material which can be shipped in other than a Type B package. The package quantity limit is intended to limit external radiation levels produced as a result of shielding loss in a transportation accident.

"The NRC and DOT have overlapping statutory authority for the regulation of the transportation of radioactive material, so the regulations of either or both agencies may apply, depending on the circumstances involved. In order that DOT may act as the only regulator of LSA materials and SCO in quantities below those where external radiation levels become important, the NRC is proposing a new exemption in $\S 71.10$. This provision would exempt licensees from most provisions of 10 CFR Part 71 for shipment and carriage of LSA/SCO materials which can be transported in bulk without packages (LSA-I and SCO-I), and also in their shipment and carriage of LSA/SCO materials in packages containing up to a $2 \mathrm{~A}_{1}$ quantity of radioactive material. At this level of activity, NRC regulations become applicable and Type B packages, the design of which must be approved by NRC, are required. This action, if adopted, would have the effect of raising the threshold level of radioactivity at which NRC regulates shipments of LSA radioactive material from the Type B quantity level to the level at which Type B packages are required.

"Although the regulations proposed by the NRC at $\S 71.10$ specify $2 \mathrm{~A}_{1}$ as the level of contained radioactive material which causes $\mathrm{NRC}$ regulations and Type B packages to become applicable, the 
IAEA corresponding standard is expressed as an external radiation level at $3 \mathrm{~m}$ from the unshielded material or object of $1 \mathrm{rem} / \mathrm{hr}(10 \mathrm{mSv} / \mathrm{h})$. The value $A_{1}$ for any specified radionuclide is the quantity of that radionuclide as a point source which produces a radiation level of $1 \mathrm{rem} / \mathrm{h}$ at a distance of $3 \mathrm{~m}$. Considering the LSA and SCO materials are bulk sources with considerable self-shielding, the value $2 \mathrm{~A}_{1}$ was chosen as a close approximation of the IAEA standard of $1 \mathrm{rem} / \mathrm{h}$ at $3 \mathrm{~m}$. The NRC staff, in implementing the IAEA standard in 10 CRF Part 71, takes the position that the radiation level standard would be very difficult for the industry to apply, and that expressing the limit in units of radioactivity would be a more reasonable approach. The approach recommended by the staff will make U. S. regulations inconsistent with those of IAEA, although in an area where there is little international transport. The NRC is particularly interested in whether industry shares the NRC staff view that this limit should be expressed as a limit on radioactivity because a radiation level limit as adopted by IAEA is impractical for the industry to implement.

"Part 71 Inclusion of Criteria for Air Shipment of Plutonium

"As a result of Congressional action in 1975, Pub. L 94-79 prohibited the NRC from licensing the air shipment of plutonium in any form until the NRC certified to the Congress that a safe contained had been developed and tested such that the container 'will not rupture under crash and blast-testing equivalent to the crash and explosion of a highflying aircraft.' The NRC developed and certified to the Congress package criteria which is believed corresponded to the Public Law and published these criteria in NUREG-0360, 'Qualification Criteria to Certify a Package for Air Transport of Plutonium,' dated January 1978. This rulemaking action would amend $10 \mathrm{CRF}$ Part 71 to include these criteria in $\S \S 71.64,71.74$, and 71.88 .

"It is the Commission's view that the import/export or domestic transport of plutonium by air pursuant to the requirements of Pub. L. 94-79, as implemented by $\S \S 71.64,71.74$, and 71.88 of this part, is not affected by section 5062 of Pub. L. 100-203. Certification of containers for the air transport of plutonium for shipments subject to section 5062 and the development of appropriate test criteria for such certification are not within the scope of this proposed rule. These matters will be considered by the Commission separately from this rulemaking action.

\section{"Detailed Changes}

"Detailed substantive changes as proposed by the $\mathrm{NRC}$ for public comment are described in the following paragraphs, arranged by section number:

1. Section 71.4, 'Definitions,' would be amended as follows:
- The definition of fissile classes would be deleted to correspond to the major change of eliminating fissile classes. Fissile material would be defined as the listed radionuclides, and the definition of fissile radionuclides would be deleted.

- The definition of low-specific-activity (LSA) material would be extensively changed to correspond to that of IAEA. The one remaining significant difference would be the addition of a provision in NRC regulations for transportation of contaminated earth in a closed vehicle in unpackaged form. Extensive removal of contaminated earth has been found necessary in decommissioning facilities in the United States, a process apparently not yet required in most other IAEA Member States. Most LSA material would be subsequently exempted from Part 71 control by the Provisions of $\S 71.10$, 'Exemption for low level materials.' The DOT regulations would specify the requirements for packaging LSA material.

- The grandfather clause for special form radioactive material encapsulation would be updated.

-A new definition of Surface Contaminated Object (SCO) would be added to correspond to the parallel definition in IAEA regulations. SCO would be treated in the regulations similarly to LSA materials, with industrial packaging required for most applications. As with LSA materials, most SCO would be exempted from Part 71 control by the provisions of $\S 71.10$, 'Exemption for low level materials.'

- Some progress has been made in expressing radiological limits in dual units, in that limits currently expressed in units of Rems and Curies now also show the International System of Units (SI) equivalents in Sieverts and Bequerels along with the customary units. In most cases the limits in customary units have been extended to 3 significant figures so they are equal to the limits expressed in SI units to a tenth of a percent. Limits on length, pressure, weight, and temperature are expressed in SI units in the current 10 CFR Part 71, with approximate values in customary units following in parentheses. Those values in customary units have been extended to 3 significant figures to make them equal to the limits expressed in SI units. The objective of this approach is to maintain consistency with international regulations while allowing U.S. shippers to use the units with which they are most familiar. In the case of the special limits on shipments of plutonium in NRC 
regulations, for which there are no comparable international rules, the limits expressed in SI units have been carried out to three significant figures to make them equal to the U.S. limits expressed in customary units. The end result of this effort is that licensees can use either limit expressed in the regulations as they are considered to be equal. The Commission is particularly interested in public comments on this method of expressing dual units in the regulations.

2. Section 71.5, 'Transportation of licensed material,' would be amended to correct a number of referencing errors.

3. Section 71.10, 'Exemption for low level materials,' would be amended to include exemptions for LSA material and SCO. The categories LSA-I and SCO-I would be limited to very low concentrations of radioactive material which would be allowed to be transported unpackaged. Their exemption would be specified separately in a new paragraph $71.10(\mathrm{c})$, without restriction on total quantity. LSA-II and LSA-III materials and SCO-II would be required to be packaged and thus would be specified in paragraph 71.10(b) of the regulations with a package quantity limit as explained earlier in this preamble.

4. Section 71.12, 'General License: NRC-approved package,' would be amended in paragraph (e) to clarify that previously approved fissile material packages would be subject to the restrictions of 71.13, 'Previously approved package.'

5. Section 71.13, 'Previously approved package,' would be amended to update the restrictions for packages approved under previous editions of the regulations. In line with parallel provisions of IAEA transport regulations, packages acceptable under the 1967 NRC transport regulations (which correspond to the 1967 IAEA regulations) can no longer be manufactured for use but may continue to be used. These packages must be marked with a unique serial number for identification and control. International use of these packages requires multilateral approval of all countries involved in their use. Packages acceptable under the 1983 NRC transport regulations (which correspond to the 1973 IAEA regulations) can be manufactured until the end of 1995. They will be subject to multilateral approval for international use of the package after 1992. Approvals for any package design can be upgraded to present status through an application which demonstrates that current standards are satisfied.

6. Section 71.14, 'General license: DOT specification container,' would be amended to reflect the 1985 IAEA grandfathering provisions.
7. Sections 71.16-71.24, general licenses for foreign approved packages and for fissile material packages, would be amended to clarify that those general licenses are subject to the quality assurance requirements of Subpart $\mathrm{H}$ of Part 71, requirements already imposed by $\S 71.101$, but whose applicability has been misunderstood by some persons. Minor technical changes have also been introduced to make those general license provisions correspond to standards in IAEA transport rules.

8. Section 71.31, 'Contents of application,' would be amended so that $\S 71.31(\mathrm{a})(3)$ may be satisfied by submittal of a 'quality assurance program description' as required by $\S 71.37$ or by 'reference to a previously approved quality assurance program' in an application for package design approval. Whether or not an applicant has a previously approved quality assurance program to which it can refer, the applicant should recognize that the package design work necessary to develop the descriptions included in its application for NRC approval must be done under the quality assurance program eventually approved by NRC regarding that package design. To avoid the situation where package design work is invalidated because changes become necessary in a quality assurance program under which the package design work was done, an applicant may wish to obtain approval of its quality assurance program prior to investing a large amount of effort in the package design program. The NRC encourages new applicants, who do not yet have NRC approved quality assurance programs, to obtain at least a partial approval of the design portion of the program. In addition, $\S 71.37(\mathrm{~b})$ was moved to $\S 71.37(\mathrm{c})$ as a more appropriate location.

9. A new $\S 71.38$, 'Renewal of a certificate of compliance or quality assurance program approval,' would extend the concept of 'timely renewal' from the NRC licensing regulations in 10 CFR Parts 30, 40, and 70 to the package design and quality assurance approvals in 10 CFR Part 71. Submittal of an application for renewal of a package certificate of compliance or quality assurance approval at least 30 days prior to its expiration would automatically extend the expiration date of the existing approval until the NRC makes a final decision regarding the application. The provision also would require that a renewal application consolidate the prior approval and all subsequent revisions.

10. Section 71.43, 'General standards for all packages,' would be amended as follows:

- Paragraph (c) would require that a positive fastening device protect against a rise in internal pressure; 
- Paragraph (d) would require that behavior of materials under irradiation be considered in assuring the absence of significant chemical, galvanic, or other reaction among package components and the package contents;

- Paragraph (f) could continue to require that there be 'no significant increase' in external radiation levels as a result of subjecting a package to the normal conditions of transport. The IAEA has quantified that increase as being no more than 20 percent, a value the NRC staff believes is too large for the consequences of normal handling or minor accidents which can occur more than once during transport and for which no corrective action normally would be taken. The NRC proposes to continue to approve shielding retention of package designs on an ad hoc basis until what it considers to be a more reasonable standard is determined.

- Paragraph (h) would continue to prohibit continuous venting during transport but would allow intermittent venting when the associated operational controls are approved by the Commission. While the IAEA regulations no longer prohibit continuous venting, that prohibition would be continued in NRC transport regulations because the staff considers continuous venting to be poor engineering practice.

11. Section 71.51, 'Additional requirements for Type B packages,' would be amended as follows:

—Paragraph (a)(1), as in $\S 71.43(\mathrm{f})$, would continue to require that there be 'no significant increase' in external radiation levels as a result of subjecting a package to the normal conditions of transport notwithstanding the IAEA's determination that a 20 percent increase constitutes no significant increase; and

-Paragraph (a)(2) would reduce allowable krypton-85 releases under the hypothetical accident conditions from $10,000 \mathrm{Ci}$ to $10 \mathrm{~A}_{2}$ or $2,700 \mathrm{Ci}(10 \mathrm{TBq})$.

12. Section 71.52, 'Exemption for low-specificactivity (LSA) packages,' would be written as two exemptions from certain Type B package requirements for packages containing only LSA material and transported as exclusive use. The broader of these exemptions, in paragraph (b), would be identical to the present exemption, but would be conditioned to expire one year after the effective date of these amendments. While it is in effect, the broader exemption of paragraph (b) would deal with nonapplicability of accident resistance requirements to quantities of LSA material in excess of Type B quantities in a single package, recognizing the very low toxicity of low-specific-activity radioactive material. Elimination of that provision would subject LSA material in excess of the quantity $2 \mathrm{~A}_{1}$ in a single package to all Type $\mathrm{B}$ package standards including the hypothetical accident conditions. The one-year delay in discontinuing this exemption is intended to allow the industry to develop and fabricate enough Type B waste packages to satisfy the need which would be brought on if this change were adopted. Information provided to NRC indicates that only 5 Type B waste packages are now in existence, while many more would be needed to satisfy the need which would be created if this proposed change were adopted.

"The more narrow exemption of paragraph (a) would continue to recognize the low toxicity of LSA material, but to a lesser extent than paragraph (b), by providing an exemption from the Type B requirement in $\S 71.51(\mathrm{a})(1)$ which limits the loss or dispersal of radioactive contents under normal conditions of transport. That provision requires that leak-tightness of a Type $\mathrm{B}$ package be demonstrated to a sensitivity of $10^{-6} \mathrm{~A}_{2}$, a specification unnecessary for the low toxicity LSA material. Although it would be exempt from the sensitivity provision, the LSA package design would still have to satisfy the general standard of $\S 71.43$ (f) that there be no loss or dispersal of radioactive contents as a result of subjecting a package to the normal conditions of transport.

13. Section 71.53, 'Fissile material exemptions' would be amended as follows:

—Present § 71.53(b), specifying an exemption for natural and depleted uranium which has been irradiated in a thermal reactor, would be deleted because the material described would, by definition, no longer be fissile material; and

-The existing paragraph (g) would be redesignated $\S 71.53(\mathrm{f})$, and it would place an additional limitation on the nitrogen-touranium atomic ratio.

14. Section 71.57, 'Specific standards for a Fissile Class 1 package,' and Section 71.61, 'Specific standards of a Fissile Class III shipment,' would be deleted because the three fissile classes would be combined into new section 71.59, 'Standards for arrays of fissile material packages.'

15. A new section 71.61, 'Special requirement for irradiated nuclear fuel shipments,' imposing a deep water immersion test would be added.

16. Section 71.63, 'Special requirements for plutonium shipments,' would be revised to accept a suggestion received from the E. I. DuPont Savannah River Plant during the last major revision of 10 CFR Part 71. The 
suggestion was that the special requirements for solid form and double containment now applied to shipments of all isotopes of plutonium be applied only to the extremely radiotoxic isotopes of plutonium (excluding plutonium-241) and to other extremely radiotoxic radionuclides as well (including for example, americium-241 and actinium-227). While this suggestion was favorably received, it was beyond the scope of that rulemaking action and is proposed now. While the change seems reasonable from [a] health and safety standpoint, any significant technical and economic impacts of the change should be included in comments to the Commission so they may be considered.

17. Section 71.73, 'Hypothetical accident conditions,' would be amended to add a dynamic crush test for certain packages, and to make minor modifications to the thermal test in accordance with changes made to IAEA regulations. Times specified for the immersion tests seem superfluous and have been deleted. Determination of acceptance under the standard should not depend on the time of immersion.

18. Section 71.75, 'Qualifications of special form radioactive materials,' would add an alternative method to qualify a special form capsule under the tests prescribed in the specified standard of the International Organization for Standardization (ISO).

19. Section 71.77, 'Tests for special form radioactive material,' would add an alternative method to qualify special form radioactive material under the specific impact and temperature tests prescribed in the specified standard of the ISO.

20. Section 71.95, 'Reports,' would include a new paragraph (c) to require reporting by a licensee if any conditions of approval in the certificate of approval were not observed in making a shipment.

21. Section 71.97, 'Advance notification of shipment of nuclear waste,' would be amended to redefine the level of radioactivity at which advance notification is required for shipments of spent nuclear fuel and radioactive waste to make that level more uniform across the range of radionuclides transported. The new level specified would correspond to that at which the DOT imposes its routing and training requirements, and to that at which IAEA imposes additional administrative requirements such as multilateral shipment approvals. The effect of this change is expected to decrease the overall number of packages subject to advance notification and to increase reporting of packages containing large amounts of transuranic alpha-emitting nuclides.

\section{"Other Regulatory Actions}

"Three petitions for rulemaking were filed with the NRC in connection with the rules for transporting LSA radioactive material. The substance of the three petitions was essentially the same, to request that NRC exempt LSA materials from its requirements in 10 CFR Part 71. This would have left the regulation of all LSA material to the DOT. The control of LSA material, as with the control of all radioactive material, was divided at that time, as it is today, between NRC and DOT. DOT controlled carriers and shippers of small quantities of all radioactive materials through provisions in its regulations in 49 CFR, while NRC controlled shippers of fissile material and of larger quantities of other radioactive materials through its regulations in $10 \mathrm{CFR}$ and its licensing program.

"The petitioners were the Energy Research and Development Administration (now the U.S. Department of Energy) in its letter dated July 23, 1975 (PRM-71-1); the American National Standards Institute (ANSI) Committee N14 in its letter dated March 10, 1976 (PRM-71-2); and ChemNuclear Systems, Inc., in its letter dated November 22, 1976 (PRM-71-4). All three petitioners argued that the control NRC was exerting over transportation of LSA materials created an inconsistency between NRC regulations and those of the IAEA and should be discontinued. A proposed rule that would have provided the exemption for LSA materials requested in the petitions was published by NRC for public comment on August 17, 1979 (44 FR 48234). Prior to finalization of that rule, however, a deficiency in the new LSA requirements, as proposed, was recognized so that the entire LSA proposal, including the exemption, was withdrawn. In the interim, the deficiency in the LSA requirements in the IAEA regulations was recognized and corrected. That correction is discussed under the 'major changes' section of this preamble. The correction introduces a distinction between the requirements for small quantities of LSA material and those for larger quantities. This distinction is implemented in the U.S. regulatory scheme as one set of requirements in DOT regulations for small quantities of LSA material and as a different set of requirements in NRC regulations for larger quantities of LSA material.

"As a result of these changes in LSA requirements, the exemption requested in the three petitions cannot be provided. The requirements proposed for inclusion in NRC regulations are consistent with the regulatory schemes of both DOT and IAEA. Because the level of radioactivity at which NRC controls are imposed in the proposed rule is somewhat higher than in the current rule, there is an exemption provided in $\S 71.10$ for LSA materials up to the level where NRC regulations impose additional packaging requirements. This exemption is of limited scope, 
however, and does not satisfy the intent of the petitions. For the above reasons, the NRC plans to deny the three petitions if changes proposed for the LSA portions of this rulemaking are carried forward to the final rule....'[24]

\subsection{NRC REGULATORY GUIDE 7.11, 1991}

In June 1991, the NRC issued Reg. Guide 7.11, Fracture Toughness of Base Material for Ferritic Steel Shipping Cask Containment Vessels with a Maximum Wall Thickness of 4 Inches.[25] As an NRC policy statement, this document became a cornerstone in its own right because, for the first time, it provided the direct linkage between the Category I, Category II, and Category III criteria from NUREG/CR-1815, NUREG/CR-3019, NUREG/CR-3854, and the $\mathrm{A}_{1}$ and $\mathrm{A}_{2}$ values specified in 10 CFR 71 . For the most part, the full text of the document is reproduced below:

\section{“A. INTRODUCTION}

"Part 71, 'Packaging and Transportation of Radioactive Material,' of Title 10 of the Code of Federal Regulations requires that packages used to transport radioactive materials withstand the conditions in $\S 71.71$, 'Normal Conditions of Transport,' and $\S 71.73$, 'Hypothetical Accident Conditions.' In this guide, the terms packaging, shipping cask, and shipping container are used interchangeably.

"The regulations require that accident conditions with an initial temperature as low as $-20^{\circ} \mathrm{F}\left(-29^{\circ} \mathrm{C}\right)$ be considered. At this temperature, several types of ferritic steels are brittle and subject to fracture. This guide describes fracture toughness criteria and test methods acceptable to the NRC staff for use in evaluating Type B (U) and Type B $(\mathrm{M})^{\S}$ ferritic steel shipping cask containment vessel base material having a maximum thickness of 4 inches $(0.1 \mathrm{~m})$ and having a maximum static yield strength of $100 \mathrm{ksi}$ $(690 \mathrm{kPa})$. The containment vessel is a major component of the containment system as defined in $\S 71.4$ of 10 CFR Part 71 . This guide is applicable to the containment vessel only and not to other components of the package.

"Alternative fracture toughness criteria and test methods may be used provided the applicant can demonstrate that their use will ensure equivalent safety.

"Any information collection activities mentioned in this regulatory guide are contained as requirements in 10 CFR Part 71, which provides the regulatory basis for this guide. The information collection requirements in $10 \mathrm{CFR}$ Part 71 have been cleared under OMB Clearance No.3150-0008.

$\S \quad$ "Type $\mathrm{B}(\mathrm{U})$ and Type $\mathrm{B}(\mathrm{M})$ packages are defined in 10 CFR 71.4." (This footnote was part of the original citation.)

\section{"B. DISCUSSION}

"This guide presents fracture toughness criteria and test methods that can be used for evaluating ferritic steel containment vessel base material having a maximum wall thickness of 4 inches $(0.1 \mathrm{~m})$ with a maximum static yield strength of $100 \mathrm{ksi}(690 \mathrm{kPa})$.

"Section III of the ASME Boiler and Pressure Vessel Code ... contains requirements for material fracture toughness; however, these requirements were developed for reactor components only and do not address hypothetical accident conditions appropriate for packaging (e.g., severe impact loads at low temperatures). Therefore, the code requirements are not directly applicable to shipping container design.

"NUREG/CR-1815, 'Recommendations for Protecting Against Failure by Brittle Fracture in Ferritic Steel Shipping Containers up to Four Inches Thick' [Ref. 20], contains background and other information pertinent to the development of the criteria in this guide. These criteria are divided into three categories that are associated with the levels of safety appropriate for the radioactive contents being transported. Table 1 in this guide identifies the radioactivity limits for each of the three categories. Tables 4, 5, and 6 in NUREG/CR-1815 ${ }^{* *} \ldots$ list the fracture toughness criteria associated with each category. ... A qualitative description of the margins of safety against brittle failure for each of the three categories is given in Appendix $\mathrm{C}$ to NUREG/CR-1815 [Ref. 20].

\begin{tabular}{llll}
\hline \multicolumn{3}{c}{ Table 1 } \\
\hline Low & Category I & Category II & Category III \\
Specific & & Greater than & Less than \\
Activity & & $\begin{array}{l}30,000 \mathrm{Ci} \text { or } \\
\text { greater than }\end{array}$ & $\begin{array}{l}30,000 \mathrm{Ci} \\
\text { and less than }\end{array}$ \\
& & $3,000 \mathrm{~A}_{1}{ }^{*}$ or & $3,000 \mathrm{~A}_{1}$ and \\
& & greater than & less than \\
& & $3,000 \mathrm{~A}_{2}{ }^{*}$ & $3,000 \mathrm{~A}_{2}$ \\
Special & Greater than & Between & Less than \\
Form & $3,000 \mathrm{~A}_{1}$ or & $3,000 \mathrm{~A}_{1}$ and & $30 \mathrm{~A}_{1}$ and \\
& greater than & $30 \mathrm{~A}_{1}$ and not & less than \\
& $30,000 \mathrm{Ci}$ & greater than & $30,000 \mathrm{Ci}$ \\
& & $30,000 \mathrm{Ci}$ & \\
Normal & Greater than & Between & Less than \\
Form & $3,000 \mathrm{~A}_{2}$ or & $3,000 \mathrm{~A}_{2}$ and & $30 \mathrm{~A}_{2}$ and \\
& greater than & $30 \mathrm{~A}_{2}$ and not & less than \\
& $30,000 \mathrm{Ci}$ & greater than & $30,000 \mathrm{Ci}$ \\
& & $30,000 \mathrm{Ci}$ & \\
\hline * Defined in $10 \mathrm{CFR} 71.4$ & &
\end{tabular}

** "The following corrections should be made to the NUREG: Table 1, Category III revise to read '...Fine Grain Practice...'; Table 4, Criteria..., third line 'has $\sigma_{\mathrm{ys}}$ $\geq 70$ ksi, either:'; Figure 6, vertical scale should be '...0, 20, 40...'; Section 5.3.1, subsection 1, 'By selecting a normalized steel ...." (This footnote was also part of the original citation.) 
"Additional information regarding the basis for the criteria is contained in Appendix B of NUREG/CR-1815 [Ref. 20].

"Regulatory Position 1 endorses a portion of the criteria contained in Section 5 of NUREG/CR-1815. These criteria identify material properties in accordance with the standards specified in Tables 4, 5, and 6 of NUREG/CR-1815, as appropriate.

"For Category II and III containers, the highest nil ductility transition temperature $\left(\mathrm{T}_{\mathrm{NDT}}\right)$ specified for the material in Table 3 of NUREG/CR-1815 ... may be used in lieu of conducting tests to determine the actual $\mathrm{T}_{\mathrm{NDT}}$ of the material.

"Although NUREG/CR-1815 [Ref. 20] addresses the use of ferritic steels only, it does not preclude the use of austenitic stainless steels. Since austenitic stainless steels are not susceptible to brittle failure at temperatures encountered in transport, their use in containment vessels is acceptable to the staff and no tests are needed to demonstrate resistance to brittle failure.

"NUREG/CR-3019, 'Recommended Welding Criteria for Use in the Fabrication of Shipping Containers for Radioactive Materials' [Ref. 22], and NUREG/CR-3854, 'Fabrication Criteria for Shipping Containers' [Ref. 23], also contain information applicable to shipping containers, as does a related Regulatory Guide 7.12, 'Fracture Toughness Criteria of Base Material for Ferritic Steel Shipping Cask Containment Vessels with a Wall Thickness Greater than 4 Inches $(0.1 \mathrm{~m})$ But Not Exceeding 12 Inches $(0.3 \mathrm{~m}){ }^{\prime}$ [Ref. 26].

\section{"C. REGULATORY POSITION}

"1. The criteria contained in Section 5 of NUREG/CR-1815 [Ref. 20], other than for full-scale destructive testing (5.1.4 and 5.2.4) and qualifying procedures for reduced stress levels (5.1.2), are acceptable to the NRC staff for assessing the fracture toughness of thin-wall base material (up to and including 4 inches $(0.1 \mathrm{~m})$ ) ferritic steel containment vessels for the categories identified in Table 1 of this guide. In 5.1.2, only a value of $\sigma / \sigma_{\mathrm{yd}}$ equal to 1 is acceptable.

"2. A Category I container qualified in accordance with this guide is acceptable for transporting either Category II or Category III radioactive materials. Similarly, a Category II container qualified in accordance with this guide is acceptable for transporting Category III materials.

\section{"D. IMPLEMENTATION}

"The purpose of this section is to provide information to applicants and licensees regarding the NRC staff's plans for using this regulatory guide.

"Except in those cases in which an applicant or licensee proposes an acceptable alternative method for complying with specified portions of the Commission's regulations, the methods described in this guide (which reflects public comments) will be used by the NRC staff in evaluating base material for all applications for new package designs and all requests that existing package designs be designated as Type B (U) or Type B (M) packages submitted after September 30, 1991...’’[25]

\subsection{CFR 71, 1995 FINAL RULE}

In September 1995, the final rule for major changes to 10 CFR 71 was published in the Federal Register.[27] For the most part, the preamble for that final rule reads as follows:

"The U.S. Nuclear Regulatory Commission is revising its regulations, for the safe transportation of radioactive material to make them compatible with those of the International Atomic Energy Agency (IAEA) and to incorporate new criteria for packages used to transport plutonium by air. The revised rule, in combination with a corresponding amendment of Title 49, Code of Federal Regulations, by the U.S. Department of Transportation (DOT), would bring U.S. regulations into general accord with IAEA regulations (Regulations for the Safe Transport of Radioactive Material, 1985 Edition, Safety Series No. 6). The final rule also adopts approval criteria for packages used to transport plutonium by air. These criteria were developed in response to Public Law 94. Except for these revisions, NRC's basic standards for packaging and transportation remain essentially unchanged. These regulations apply to all NRC licensees who transport, or offer for transport, byproduct, source, or special nuclear material, and will help ensure the continued safe transportation of radioactive materials in domestic and international commerce.

"In addition, three Petitions for Rulemaking, concerning the transportation of Low Specific Activity (LSA) radioactive material, are denied in this action.

"In 1969, the IAEA, recognizing that its international transport regulations should be revised from time to time on the basis of scientific and technical advances, as well as accumulated experience, invited member states to submit comments and suggested changes to the regulations. As a result of this initiative, the IAEA issued revised regulations in 1973 (Regulations for the Safe Transport of Radioactive Material, 1973 Edition, Safety Series No. 6). The IAEA also decided to periodically review its transportation regulations, at intervals of about 10 years, to ensure that the regulations are kept current. As a result, a review of IAEA regulations was initiated, in 1979, that resulted in the publication of revised regulations in 1985 (Regulations for the Safe Transport of Radioactive Material, 1985 Edition, Safety Series No. 6).

“On August 5, 1983 (48 FR 35600) NRC published, in the Federal Register a final revision to 10 CFR Part 71, 'Packaging and Transportation of Radioactive Material.' That revision, in combination with a parallel revision of the hazardous materials 
transportation regulations of DOT, brought U.S. domestic transport regulations at the Federal level into general accord with the 1973 edition of IAEA transport regulations. Some of the revisions that were eventually included in the 1985 IAEA regulations were anticipated by $\mathrm{NRC}$ and DOT when they were finalizing their transportation regulations in 1983. These changes were incorporated in Titles 10 and 49 of the Code of Federal Regulations at that time.

"On June 8, 1988 (53 FR 21550) NRC published a proposed revision to its regulations in 10 CFR Part 71 in the Federal Register for the purpose of making U.S. transportation regulations compatible with the 1985 edition of the IAEA regulations. In a parallel rulemaking, DOT published a proposed revision to its radioactive material transportation regulations on November 14, 1989 (54 FR 47454). Several corrections to the NRC proposed rule were published in the Federal Register on June 22, 1988 (53 FR 23484). Interested persons were invited to submit written comments and suggestions on the NRC proposal and/or the supporting regulatory analysis by October 6, 1988. The public comment period was subsequently extended to February 9, 1990. On December 8, 1994, the NRC staff provided a briefing on the proposed LSA requirements and the other revisions at the 416th meeting of the Advisory Committee on Reactor Safeguards (ACRS). This meeting also provided industry and the public another opportunity to present their views on the revisions. Based on the public comments, consultations with DOT, and other considerations, the Commission is adopting the proposed rule, with some modifications.

\section{"Discussion of Major Changes From Current Requirements}

"Most of the revisions presented in the proposed rule are being adopted in the final rule. These include additional hypothetical accident test criteria for certain types of packages, an increase in the number of radionuclides with listed $A_{1}$ and $A_{2}$ values, changes in the currently listed $A_{1}$ and $A_{2}$ values for some radionuclides, simplification of fissile material transport classes, revised requirements for shipment of LSA materials, and inclusion of criteria for packages used to transport plutonium by air. These changes are discussed in more detail in the following paragraphs.

\section{“Additional Accident Test Requirements}

"IAEA deep-water immersion and dynamic crush tests are adopted in the final rule. The 200 meter $(656 \mathrm{ft})$ deepwater immersion test has been added to the requirements for Type B packages (casks) authorized for irradiated fuel content in excess of $37 \mathrm{PBq}$ $\left(10^{6} \mathrm{Ci}\right)(\S 71.61$ Special requirement for irradiated nuclear fuel shipments). The purpose of the deep immersion test, which can be satisfied through engineering evaluation or actual physical test $(\S 71.41)$, is to ensure that the cask containment system does not collapse, buckle, nor allow inleakage of water, if submerged at $200 \mathrm{~m}(656 \mathrm{ft})$.

"A dynamic crush test $(\S 71.73(\mathrm{c})(2)$ Crush) has also been added to Type B package requirements, for certain lightweight packages that are minimally vulnerable to damage in the $9 \mathrm{~m}(30 \mathrm{ft})$ drop test, but which have a high potential for radiation hazard, if package failure occurs. IAEA regulations require the

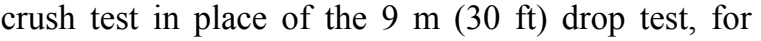
these packages. NRC is requiring both the crush test and drop test, for lightweight packages, to ensure that package response to both crush and drop forces is within applicable limits.

"These requirements only apply to package designs certified after this final rule becomes effective. Further, this rule does not apply to packages fabricated under previous versions of Part 71; however, previously fabricated packages are subject to multilateral approval, when used for international transport ( $\$ 71.13(b))$.

\section{"Expansion of Radionuclide List and Changes in Radionuclide Limits}

"Table A-1, in 10 CFR Part 71, Appendix A, lists the Type $A$ package quantity limits $\left(A_{1}\right.$ and $A_{2}$ values $)$ for many radionuclides. The final rule increases the number of radionuclides listed, from 284 to 378 . The final rule also adopts the revised $A_{1}$ and $A_{2}$ values contained in the 1985 edition of the IAEA regulations. As a result, $144 \mathrm{~A}_{1}$ values previously listed in Table A-1 are being increased, and 73 are being decreased, while $129 \mathrm{~A}_{2}$ values are being increased, and 95 decreased. In addition, the final rule modifies the method used to determine $A_{1}$ and $\mathrm{A}_{2}$ values for unlisted radionuclides.

\section{"Simplification of Fissile Material Classes}

"The final rule revises the criteria for shipment of fissile material. Specifically, the rule eliminates the three fissile class designations currently used establishes a single set of criteria for all packages of fissile material, uses the transport index as the primary control for the number of fissile packages that may be transported together, and requires special arrangements for fissile packages that do not meet the established criteria.

\section{"Inclusion of Criteria for Air Shipment of Plutonium}

"The final rule amends Part 71 to include approval criteria for packages used to transport plutonium by air ( $\S 71.64,71.74$, and 71.88). These criteria were developed as a result of Pub. L. 94-79, which prohibited NRC from licensing the air shipment of plutonium, in any form, until NRC certified to the Congress that a safe container had been developed. The NRC subsequently developed and certified package criteria to Congress and published the criteria in NUREG-0360, Qualification Criteria to 
Certify a Package for Air Transport of Plutonium, dated January 1978. This final rule incorporates these criteria. There are no corresponding criteria in IAEA regulations.

\section{"Modifications From Proposed Rule}

"The final rule differs from the proposed rule in several significant respects and are $[$ sic $]$ described as follows:

1. Package limit for Shipment of LSA and SurfaceContainment-Object (SCO) Material. In its 1985 regulations, the IAEA added a limit of $10 \mathrm{mSv} /$ hour (1 rem/hour) at 3 meters for the radiation level from the unshielded contents of LSA and SCO (Surface Contaminated Object) packages not designed to withstand accidents. This radiation level limit controls the external radiation exposures to individuals if an LSA package is severely damaged in a transportation accident.

The IAEA limit considers the loss of package shielding during an accident but it does not consider the possibility that a package's contents might be released and redistributed, causing a reduction in self-shielding of the contents. The reduction in self-shielding could result in potential accident radiation levels that significantly exceed IAEA's $10 \mathrm{mSv} / \mathrm{hour}$ ( 1 rem /hour) at 3 meters limit.

The IAEA dose rate limit provides a significant added degree of protection over the 1973 IAEA regulations (which specify no quantity limit for LSA packages). NRC and DOT did not believe, however that the IAEA limit provided the same level of safety for all types of LSA material, particularly for relatively large quantities of radioactive materials contained in dispersible LSA materials (e.g., resins and other media used in liquid radioactive waste treatment).

In lieu of the radiation level limit, DOT and NRC proposed a $2 \mathrm{~A}_{1}$ quantity limit for all LSA packages. Although this proposal addressed the accident concern by directly limiting package quantity, it was not compatible with the IAEA provisions. Both agencies received many comments from industry on the proposed $2 \mathrm{~A}_{1}$ quantity limit that objected to the impacts on occupational dose and shipping costs. Further, after a briefing on the draft final rule on December 8, 1994, the Advisory Committee on Reactor Safeguards (ACRS) issued a letter report, dated December 19, 1994, recommending, inter alia, that the requirements again be reevaluated with the objective of making them equivalent to the IAEA regulations.

After consideration of comments from ACRS and industry, DOT and NRC have agreed to adopt the IAEA LSA provisions. Accordingly, the final rule imposes a limit on the external radiation level at 3 meters from the unshielded contents of LSA-II, LSA-III, or SCO-II packages of $10 \mathrm{mSv} /$ hour (1 rem/hour) (§ 71.10(b)).

2. The final rule delays imposing the LSA package external radiation level limit for 3 years. The effect of imposing the LSA package limit is to reduce the quantity of LSA materials that can be transported in non-Type B, LSA packages. The final rule may increase demand for Type B packages, and there are very few currently available. NRC had proposed a 1 year delay in implementing the new LSA rules. Industry comments expressed the view that 1 year is not an adequate period of time to design a package, have it approved by NRC, and manufacture a reasonable number of Type $\mathrm{B}$ waste packages. NRC agrees, and has included a delay of 3 years from the effective date of this rule for implementation of this provision of the final rule (§ 71.52).

3. The proposed rule would have adopted $2 \mathrm{~A}_{1}$ as the threshold below which licensees are exempt from NRC requirements for packages containing LSA material (except for $\S \S 71.5,71.88$ and 71.53). Because NRC and DOT are adopting the IAEA LSA package limit, the final rule changes the exemption threshold to $1 \mathrm{rem} / \mathrm{h}$ at $3 \mathrm{~m}(\S 71.10(\mathrm{~b})(2))$. Thus, designs for packages used to ship LSA or SCO in quantities where the external dose rate exceeds $1 \mathrm{rem} / \mathrm{h}$ at $3 \mathrm{~m}$ from the unshielded material will be subject to NRC Type B package regulations. Package designs for lesser quantities of LSA or SCO will be selfcertified, by package designers, as meeting applicable DOT IP-1, IP-2, IP-3, Type A, or strong tight, package regulations. [Licensees should note that DOT has prescribed, in its final rule, the use of IAEA Industrial Packages (IP-1, IP-2, and IP-3) for LSA and SCO material. For domestic transportation only, DOT also provides for the use of Type A, and strong tight, containers.]

4. For compatibility with IAEA and DOT requirements, a new, ' $\$ 71.77$ Qualification of LSA-III Material,' has been added to Subpart F. This section prescribes assessment of LSA-III material leaching. (In the proposed rule, $\S 71.77$ contained 'Tests for special form radioactive material.' Those requirements have been moved to $\S 71.75$ 'Qualification of special form material,' in the final rule.)

\section{"Other Administrative Actions}

"The final rule corrects numerical errors in $\S \S 71.20(\mathrm{~b})(3)$ and $71.24(\mathrm{~b})(4)$ of the current rule $(\S \S(71.20(\mathrm{c})(3)$ and $71.24(\mathrm{c})(4)$, respectively, of the proposed rule). These errors, which were not identified at the time the proposed rule was published, resulted when the limit for graphite was expressed as an atomic ratio, instead of a mass ratio. 
The errors were inadvertently adopted, in Part 71, during a rulemaking in 1983, to make NRC regulations compatible with 1973 IAEA transportation regulations. IAEA has subsequently corrected these errors in the 1985 edition of its transportation regulations.

"Section 71.20(b)(3), as currently written, limits the mass of graphite to '***150 times the total mass of uranium-235 plus plutonium.' Section 71.20(c)(3), in the final rule, would be amended to read as follows: 'The total mass of graphite present does not exceed 7.7 times the total mass of uranium-235 plus plutonium.' Section 71.24(c)(4) would be similarly revised to change the limits on graphite from 150 to 7.7 times the total mass of uranium-235 plus plutonium.

"NRC is correcting these errors in this final rule. The affected sections may bear on the criticality safety of fissile materials in transport. In addition, these corrections are expected to have minimal impact because there are no shipping casks currently being used that were designed using the erroneous provisions....’[27]

\subsection{DOUBLE CONTAINMENT ISSUES REVISITED}

In May 1997, the proposed rule for a change to the Double Containment requirements of $10 \mathrm{CFR} 71$ was published in the Federal Register.[28] For the most part, the preamble for that proposed rule reads as follows:

\subsubsection{Elimination of Double Containment for Plutonium for Vitrified High Level Waste - 1997 Proposed Rule}

"SUMMARY: The Nuclear Regulatory Commission (NRC) is proposing to amend its regulations to remove canisters containing vitrified high-level waste (HLW) containing plutonium from the packaging requirement for double containment. This amendment is being proposed in response to a petition for rulemaking (PRM-71-11) submitted by the Department of Energy (DOE). This proposed rule would also make a minor correction to the usage of metric and English units to be consistent with existing NRC policy....

\section{"SUPPLEMENTARY INFORMATION: \\ "Background}

"In 10 CFR 71.63, the NRC imposed special requirements on licensees who ship plutonium in excess of 0.74 terabecquerels (20 curies). These requirements specify that plutonium must be in solid form and that packages used to ship plutonium must provide a separate inner containment (the 'double containment' requirement). In adopting these requirements, the NRC specifically excluded plutonium in the form of reactor fuel elements, metal or metal alloys, and, on a case-by-case basis, other plutonium-bearing solids that the NRC determines do not require double containment.

"On November 30, 1993, the DOE petitioned the NRC to amend $\S 71.63$ to add a provision that would specifically remove canisters containing plutoniumbearing vitrified waste from the packaging requirement for double containment. The NRC published a notice of receipt for the petition, docketed as PRM-71-11, in the Federal Register on February 18, 1994 (59 FR 8143), requesting public comment by May 4, 1994. On May 23, 1994 (59 FR 26608), the public comment period was extended to June 3, 1994, at the request of the Idaho National Engineering Laboratory (INEL) Oversight Program of the State of Idaho.

"Pursuant to the Nuclear Waste Policy Act of 1982, as amended, the DOE is the Federal agency responsible for developing and administering a geologic repository for the deep disposal of HLW and spent nuclear fuel. In the petition, the DOE proposes to ship the HLW from each of its three storage locations at Aiken, South Carolina; Hanford, Washington; and West Valley, New York; directly to the geologic repository in casks certified by the NRC. Currently, this HLW exists mostly in the form of liquid and sludge resulting from the reprocessing of defense reactor fuels. The DOE proposes to solidify this material into a borosilicate glass form in which the HLW is dispersed and immobilized. The glass would then be placed into stainless steel canisters for storage and eventual transport to the geologic repository. DOE's purpose in requesting an amendment to the rule is to allow the transportation and disposal of HLW in a more cost-effective and efficient manner without adversely affecting public health and safety.

"The containers used to transport canisters of vitrified HLW will be Type B packages certified by the NRC. These packages are required to meet accident resistant standards. The HLW will also be subject to the special transport controls for a 'Highway Route Controlled Quantity' pursuant to U.S. Department of Transportation regulations. In addition, the Nuclear Waste Policy Act of 1982, as amended, requires the DOE to provide technical assistance and funds to train emergency responders along the planned route.

"The DOE asserts that shipment of vitrified HLW without double containment will not adversely affect safety. This is because the canistered, vitrified HLW provides a comparable level of protection to the packaging of reactor fuel elements, which does not require double containment. The DOE also noted that the plutonium concentrations in the vitrified HLW will be considerably lower than the concentration in spent nuclear fuel and that vitrified HLW is in an essentially nonrespirable form.

"Comments on the petition were received from three parties: the U.S. Environmental Protection Agency (EPA); Nye County, Nevada (the site for the proposed spent fuel and HLW repository at Yucca 
Mountain); and the INEL Oversight Program of the State of Idaho. EPA reviewed the petition in accordance with its responsibilities under Section 309 of the Clean Air Act and had no specific comments. Nye County agreed with the rationale and arguments advanced by the DOE, and had no objection to DOE's petition. The State of Idaho commented that the petition was premature because it did not specify the parameters or performance standards that HLW must meet.

"On June 1, 1995, the NRC staff met with the DOE in a public meeting to discuss the petitioner's request and the possible alternative of requesting an NRC determination under $\S 71.63(\mathrm{~b})(3)$ to exempt vitrified HLW from the double containment requirement. The DOE informed the NRC in a letter dated January 25, 1996, of its intent to seek this exemption and the NRC received DOE's request on July 16,1996 . The DOE requested that the original petition for rulemaking be held in abeyance until a decision was reached on the exemption request.

"In response to DOE's request, the NRC staff prepared a Commission paper (SECY-96-215, dated October 8, 1996) outlining and requesting Commission approval of the NRC staff's proposed approach for making a determination under $\S 71.63(\mathrm{~b})(3)$. The determination would have been the first made after the promulgation of the original rule, 'Packaging of Radioactive Material for Transport and Transportation of Radioactive Materials Under Certain Conditions,' published on June 17, 1974 (39 FR 20960). In a staff requirements memorandum dated October 31, 1996, the Commission disapproved the NRC staff's plan and directed that this policy issue be addressed by rulemaking. In response, the NRC staff has developed this proposed rule in response to the DOE petition.

\section{"Discussion}

"In the final 1974 rule, the NRC anticipated that a large number of shipments of plutonium nitrate liquids could result from spent nuclear fuel reprocessing and revised its regulations to require that plutonium in excess of 0.74 terabequerels ( 20 curies) be shipped in solid form. The NRC did so because shipment of plutonium liquids is susceptible to leakage, particularly if a shipping package is improperly or not tightly sealed. The value of 0.74 terabequerels ( 20 curies) was chosen because it was equal to a large quantity of plutonium as defined in 10 CFR Part 71 in effect in 1974. Although this definition no longer appears in 10 CFR Part 71, the value as applied to double containment of plutonium has been retained. The concern about leakage of liquids arose because of the potential for a large number of packages (probably of more complex design) to be shipped due to reprocessing and the increased possibility of human error resulting from handling this expanded shipping load.
"The NRC treats dispersible plutonium oxide powder in the same way because it also is susceptible to leakage if packages are improperly sealed. Plutonium oxide powder was of particular concern because it was the most likely alternative form (as opposed to plutonium nitrate liquids) for shipment in a fuel reprocessing economy. To address the concern with dispersible powder, the NRC required that plutonium not only must be in solid form, but also that solid plutonium be shipped in packages requiring double containment.

"In the accompanying statement of considerations to the final 1974 rule, the NRC stated that the additional inner containment requirements are intended to take into account that the plutonium may be in a respirable form and that solid forms that are essentially nonrespirable, such as reactor fuel elements, are suitable for exemption from the double containment requirement. The Commission further stated that:

Since the double containment provision compensates for the fact that the plutonium may not be in a 'nonrespirable' form, solid forms of plutonium that are essentially nonrespirable should be exempted from the double containment requirement. Therefore, it appears appropriate to exempt from the double containment requirements reactor fuel elements, metal or metal alloy, and other plutonium bearing solids that the Commission determines suitable for such exemption. The latter category provides a means for the Commission to evaluate, on a case-bycase basis, requests for exemption of other solid material where the quantity and form of the material permits a determination that double containment is unnecessary.

"DOE's petition to amend $\S 71.63$, by adding a provision that exempts canisters containing vitrified HLW from the packaging requirement for a separate inner containment is partly based on the rationale that the vitrified HLW meets the intent of the rule because the plutonium will be in an essentially nonrespirable form. The DOE petition contends that the vitrified HLW contained in stainless steel canisters provides a comparable level of safety protection to that provided by spent fuel elements.

"Specifically, in the technical information supporting the petition ${ }^{\dagger \dagger}$, the DOE sought to demonstrate that the waste acceptance specifications and process controls in the vitrification process and the waste and canister characteristics compare favorably to spent nuclear fuel in terms of the dispersability and respirability of the contents during normal conditions of transport and after an accident. The DOE maintained that impact and leak tests on the canisters, chemical analysis of spent fuel and simulated HLW borosilicate glass, design of the HLW canister, and other studies of the levels of plutonium and other radioactive elements present in the borosilicate glass

i† "Technical Justification to Support the PRM by the DOE to Exempt HLW Canisters from 10 CFR 71.63(b), dated September 30, 1993." (This footnote was part of the original citation.) 
demonstrate that vitrified HLW canisters are more robust and contain less plutonium than spent reactor fuel elements. During actual transport conditions, the HLW canister will be enclosed within an NRCcertified shipping cask, further reducing the potential for canister damage and for release of respirable particles of HLW glass.

"The DOE petition refers to plutonium in the form of borosilicate glass as being essentially nonrespirable. This is because a minute quantity of respirable particles could result if the glass fractures such as during cooldown processes after being poured into the HLW canisters, normal handling and transport conditions, and accident conditions.

"In the technical information supporting the petition, the DOE compared the physical and chemical characteristics of the vitrified HLW glass mixture to spent nuclear fuel pellets. Because impact studies of simulated waste glass from the DOE Savannah River site (Aiken, South Carolina) have shown comparable levels of fracture resistance and similar fractions of respirable particles when compared to unirradiated uranium fuel pellets and other potential waste form materials, the fracture resistance of HLW glass is expected to be comparable to that of uranium fuel pellets.

"The DOE also compared the concentration of plutonium present in a HLW canister from the Savannah River site to that contained in a typical spent reactor fuel element and concluded that the spent reactor fuel element contains at least 100 times the concentration of plutonium expected in a HLW canister. The DOE stated that the maximum concentration of plutonium projected for the Hanford and West Valley HLW canisters is much less than that of the Savannah River canisters.

"The DOE also compared the integrity of the HLW canister to the cladding of a reactor fuel element. The wall thickness of proposed HLW canisters [sic] designs are substantially thicker than the cladding thickness of a reactor fuel element. Additionally, the DOE noted that reactor fuel elements have been exposed to high levels of radiation which effects the cladding's material properties. Consequently, the DOE concluded that the protection provided by the HLW canister would be at least comparable to that provided by spent reactor fuel cladding.

"Based on DOE documents, it is estimated that there will be 3,500 shipments of vitrified HLW by 2030 . These shipments would not start until a HLW repository or an interim storage facility becomes available. However, the DOE's statement of 3,500 shipments is based on loading two HLW canisters in each reusable shipping cask. If a separate inner containment is required, the weight of the canister would be increased. This would cause a corresponding decrease in the vitrified glass payload to remain within allowable conveyance weight and/or size limitations, potentially to the point that only one canister could be transported per shipping cask. Consequently, the number of shipments required to transport the existing quantity of waste would increase. Therefore, the proposed rule would have the following benefits: (1) Reducing the occupational dose associated with loading, unloading, decontaminating, and handling the shipping casks; (2) reducing the dose to the public during normal transport by decreasing the total number of shipments; (3) decreasing total loading and unloading time (and resultant expense); and (4) reducing the cost of the containment system.

\section{"Proposed Regulatory Action}

"The NRC is proposing to amend 10 CFR 71.63 based on our evaluation of the petition submitted by the DOE, its attachment, 'Technical Justification to Support the PRM by the DOE to Exempt HLW Canisters from 10 CFR 71.63(b),' and the three public comments received on the petition after its publication in the Federal Register. 10 CFR 71.63 specifies special provisions when shipping plutonium in excess of $0.74 \mathrm{TBq}$ (20 curies) per package, including a separate inner containment system, except when plutonium is in solid form in reactor fuel elements, metal, or metal alloys. In proposing to amend $\S 71.63$, the NRC is accepting, with modifications, the petition submitted by DOE, for the reasons set forth in the following paragraphs.

"In an accompanying statement of considerations to the 1974 rule on shipping plutonium, the Commission stated that the additional inner containment requirements are intended to take into account the fact that the plutonium may be in a respirable form. The safety goal achieved in $\S 71.63$ is the prevention of releases of respirable forms of plutonium (when shipping over $0.74 \mathrm{TBq}$ ) during both normal conditions of transportation and during accidents. The 1974 rule considered both increased numbers of shipments of potentially respirable forms of plutonium, as a result of commercial reprocessing of spent nuclear fuel, and an increased potential for a human packaging error associated with the larger shipping load. However, these large numbers of plutonium shipments have not occurred, due in part to policy, technical, and economic decisions to abandon commercial reprocessing in the late 1970s.

"Because of the material properties of the vitrified HLW, the sealed canisters, and the approved quality assurance programs as described in the petition, canisters of vitrified HLW packaged in accordance with 10 CFR Part 71 are highly unlikely to result in releases of dispersible or respirable forms of plutonium under normal transportation conditions, as identified under 10 CFR Part 71. Therefore, for normal transportation, the vitrified HLW canisters meet the intent of the $\S 71.63(\mathrm{~b})$ requirement without the need for double containment.

"As for accident conditions, transportation packages for vitrified HLW will be required to be certified by 
the NRC pursuant to Section 180 of the Nuclear Waste Policy Act of 1982, as amended (42 U.S.C. 10175), and 10 CFR Part 71. Every package for vitrified HLW will be required to meet the standards for accident resistant (i.e., Type B) packages as set forth in 10 CFR Part 71. The shipping casks for vitrified HLW are anticipated to be similar in design and robustness, and provide a comparable level of protection to shipping casks for spent nuclear fuel. Because spent nuclear fuel is excluded from the double containment requirement, a favorable comparison of the canisters of vitrified HLW to spent nuclear fuel would support removal of the vitrified HLW forms from double containment.

"The tests described in the technical justification demonstrate that the canisters containing the vitrified HLW compare favorably to the cladding surrounding spent fuel pellets in reactor assemblies. The comparison is in terms of physical integrity and containment, based upon the material properties, dimensions, and the effects of radiation damage to materials.

"The DOE analysis demonstrates much lower concentrations of plutonium in the HLW canisters than in spent reactor fuel elements. However, the DOE has not established an upper limit on plutonium concentration for these vitrified HLW canisters, and the NRC is not basing its decision to remove these canisters from the double containment requirement based on the plutonium's concentration.

"In the technical justification, the DOE described the physical characteristics and acceptance standards of the canisters of vitrified HLW, including that the canistered waste form be capable of withstanding a 7-meter drop onto a flat, essentially unyielding surface, without breaching or dispersing radionuclides. This requirement is imposed by the DOE's 'Waste Acceptance System Requirements Document (WASRD),' Rev. 0, which is referenced in the technical justification supporting the petition. This test should not be confused with the 9-meter drop test onto an essentially unyielding surface, as required by the hypothetical accident conditions in 10 CFR 71.73. The 9-meter drop test is performed on the entire package under 10 CFR Part 71 certification review by the NRC. The 7-meter drop applies to the canistered HLW, which is the content of the NRC-certified Type B package.

"The NRC agrees that the 7-meter drop test requirement is relevant to the demonstration that the canistered HLW represents an essentially nonrespirable form for shipping plutonium. It is reasonable to expect that the 7-meter drop test on the canister would be a more severe test than the 9-meter drop test on an NRC-approved Type B package, due to the energy absorption by the packaging and impact limiters. The WASRD acceptance criterion of no 'breaching or dispersing radionuclides' could be used to demonstrate that the waste is essentially nonrespirable under accident conditions.
"In some of these tests, the HLW canisters were dropped from 9 meters, 2 meters above the DOE 7-meter design standard, and portions of the testing included deliberately introducing flaws $(0.95 \mathrm{~cm}$ holes) in the canisters' walls. In these drop tests, all the HLW canisters remained intact. For those HLW canisters tested with the $0.95 \mathrm{~cm}$ holes, the quantity of respirable plutonium released through these holes was less than 20 curies. This review has provided the NRC staff confidence that DOE's petition is supportable and that vitrified HLW is essentially nonrespirable in the forms likely to be shipped.

"However, the NRC does not control the requirements in, or changes to, the DOE's WASRD. Many requirements in the WASRD are apparently derived from, or are DOE's interpretations of, the NRC or other applicable regulations. There are no NRC regulations or other requirements specifying a 7-meter drop test onto an essentially unyielding surface for canistered HLW. Accordingly, the NRC does not have assurance that this test will be retained in future revisions to the WASRD. Therefore, this test itself does not represent a sufficient basis for removing the regulatory requirement in 10 CFR 71.63 for a separate inner containment.

"To address this concern, the proposed rulemaking provides additional requirements beyond those presented in the petition for rulemaking that requested exemption of 'Canisters containing vitrified high-level waste.' The NRC is proposing to amend 10 CFR 71.63(b) by excluding sealed canisters containing vitrified HLW from the double containment requirement if these canisters meet the specific waste package design criteria in 10 CFR Part 60. The additional requirement to meet 10 CFR Part 60 is responsive to the public comment received on the DOE petition from the State of Idaho by establishing criteria relevant to the intent of the double containment rule.

"The design criteria for HLW forms in 10 CFR 60.135 (b) and (c) require that the waste be in solid form, in sealed containers, and that particulate waste forms be consolidated to limit the availability and generation of particulate. The basis for these technical requirements under $10 \mathrm{CFR}$ Part 60 is to limit particulates for reduced leaching versus limiting particulate for respirability. Nevertheless, the bases are generally consistent. The DOE WASRD, and its associated quality assurance programs, are primarily based upon compliance with 10 CFR Part 60 requirements.

"In addition, the NRC is proposing to make a minor formatting change in the language of the regulation and a minor correction to the usage of units in this section to be consistent with existing NRC policy. Metric units are reported first with English units in parenthesis....’[28] 


\subsubsection{A Petition to Eliminate the Double Containment Requirement, 1998}

In February 1998, a petition to eliminate the Double Containment requirements of 10 CFR 71 was published in the Federal Register.[29] The bulk of the text of that petition is reproduced below:

"SUMMARY: The Nuclear Regulatory Commission (NRC) has received and requests public comment on a petition for rulemaking filed by the International Energy Consultants, Inc. The petition has been docketed by the Commission and has been assigned Docket No. PRM-71-12. The petitioner requests that the NRC amend its regulations that govern packaging and transportation of radioactive material. The petitioner believes that special requirements for plutonium shipments should be eliminated....

\section{“SUPPLEMENTARY INFORMATION:}

\section{"Background}

"The Nuclear Regulatory Commission received a petition for rulemaking submitted ... on behalf of the International Energy Consultants, Inc. in the form of a letter addressed to the Secretary of the Commission, dated September 25, 1997. The petitioner believes that 10 CFR 71.63(b) should be eliminated. As an option, the petitioner believes that 10 CFR 71.63(a) should also be eliminated. This option would totally eliminate 10 CFR 71.63. The petitioner made the same recommendation in a letter dated July 22, 1997, which he provided as a comment in the Commission's proposed rulemaking amending 10 CFR 71.63(b) to remove canisters containing vitrified high-level waste from the packaging requirement for double containment.

"The petition was docketed as PRM-71-12 on October 22, 1997. The NRC is soliciting public comment on the petition. Public comment is requested on both the petition to eliminate 10 CFR 71.63(b), as well as the option to eliminate 10 CFR 71.63 totally, as discussed below.

\section{"Discussion of the Petition}

"NRC's regulations in 10 CFR Part 71, entitled 'Packaging and Transportation of Radioactive Material,' include, in $\S 71.63$, special requirements for plutonium shipments: $\S 71.63$ Special requirements for plutonium shipments.

(a) Plutonium in excess of $20 \mathrm{Ci}(0.74 \mathrm{TBq})$ per package must be shipped as a solid.

(b) Plutonium in excess of $20 \mathrm{Ci}(0.74 \mathrm{TBq})$ per package must be packaged in a separate inner container placed within outer packaging that meets the requirements of subparts $E$ and $F$ of this part for packaging of material in normal form. If the entire package is subjected to the tests specified in $\S 71.71$ ('Normal conditions of transport'), the separate inner container must not release plutonium as demonstrated to a sensitivity of $10^{-6} A_{2} / h$. If the entire package is subjected to the tests specified in $\S 71.73$ ('Hypothetical accident conditions'), the separate inner container must restrict the loss of plutonium to not more than $\mathrm{A}_{2}$ in 1 week. Solid plutonium in the following forms is exempt from the requirements of this paragraph:

(1) Reactor fuel elements;

(2) Metal or metal alloy; and

(3) Other plutonium bearing solids that the Commission determines should be exempt from the requirements of this section.

"The petitioner requests that $\S 71.63(\mathrm{~b})$ be deleted. The petitioner believes that provisions stated in this regulation cannot be supported technically or logically. The petitioner states that based on the 'Q-System for the Calculation of $\mathrm{A}_{1}$ and $\mathrm{A}_{2}$ Values,' an $A_{2}$ quantity of any radionuclide has the same potential for damaging the environment and the human species as an $\mathrm{A}_{2}$ quantity of any other radionuclide. The petitioner further states that the requirement that a Type $B$ package must be used whenever package content exceeds an $\mathrm{A}_{2}$ quantity should be applied consistently for any radionuclide. The petitioner believes that if a Type B package is sufficient for a quantity of a radionuclide $X$ which exceeds $A_{2}$, then a Type $B$ package should be sufficient for a quantity of radionuclide $\mathrm{Y}$ which exceeds $A_{2}$, and this should be similarly so for every other radionuclide.

"The petitioner states that while, for the most part, the regulations embrace this simple logical congruence, the congruence fails under $\S$ 71.63(b) because packages containing plutonium must include a separate inner container for quantities of plutonium having an activity exceeding 20 curies $(0.74 \mathrm{TBq})$. The petitioner believes that if the NRC allows this failure of congruence to persist, the regulations will be vulnerable to the following challenges:

(1) The logical foundation of the adequacy of $\mathrm{A}_{2}$ values as a proper measure of the potential for damaging the environment and the human species, as set forth under the Q-System, is compromised;

(2) The absence of a radioactivity limit for every radionuclide which, if exceeded, would require a separate inner container, is an inherently inconsistent safety practice; and

(3) The performance requirements for Type B packages as called for by $10 \mathrm{CFR}$ Part 71 establish containment conditions under different levels of package trauma. The satisfaction of these requirements should be a matter of proper design work by the package designer and proper evaluation of the design through regulatory review. The imposition of any specific package design feature such as that contained in 10 CFR 71.63(b) is gratuitous. The regulations 
are not formulated as package design specifications, nor should they be.

"The petitioner believes that the continuing presence of $\S 71.63$ (b) engenders excessively high costs in the transport of some radioactive materials without a clearly measurable net safety benefit. The petitioner states that this is so in part because the ultimate release limits allowed under Part 71 package performance requirements are identical with or without a 'separate inner container,' and because the presence of a 'separate inner container' promotes additional exposures to radiation through the additional handling required for the 'separate inner container.' The petitioner further states that ' $* * *$ excessively high costs occur in some transport campaigns,' and that one example '*** of damage to our national budget is in the transport of transuranic wastes.' Because large numbers of transuranic waste drums must be shipped in packages that have a 'separate inner container' to comply with the existing rule, the petitioner believes that large savings would accrue without this rule. Therefore, the petitioner believes that elimination of $\S 71.63(\mathrm{~b})$ would resolve these regulatory 'defects.'

"As a corollary to the primary petition, the petitioner believes that an option to eliminate $\S 71.63$ (a) as well as $\S 71.63$ (b) should also be considered. This option would have the effect of totally eliminating $\S 71.63$. The petitioner believes that the arguments propounded to support the elimination $\S 71.63(\mathrm{~b})$ also support the elimination of $\S 71.63(\mathrm{a})$.

\section{“The Petitioner's Conclusions}

"The petitioner has concluded that NRC regulations in 10 CFR Part 71 which govern packaging and transportation of radioactive material must be amended to delete the provision regarding special requirements for plutonium shipments. The petitioner believes that a Type B package should be sufficient for a quantity of radionuclide $\mathrm{Y}$ which exceeds the $A_{2}$ limit if such a package is sufficient for a quantity of radionuclide $\mathrm{X}$ which exceeds the $\mathrm{A}_{2}$ limit. It is the petitioner's view that this should be true for every other radionuclide including plutonium....’[29]

\subsubsection{Elimination of Double Containment for Plutonium for Vitrified High Level Waste - 1998 Final Rule}

In June 1998, the final rule for a change to the Double Containment requirements of 10 CFR 71 was published in the Federal Register.[30] For the most part, the preamble for that final rule reads as follows:

"SUMMARY: The Nuclear Regulatory Commission (NRC) is amending its regulations to add vitrified high-level waste (HLW) contained in a sealed canister designed to maintain waste containment during handling activities associated with transport to the forms of plutonium which are exempt from the double-containment packaging requirements for transportation of plutonium. This amendment responds to a petition for rulemaking submitted by the Department of Energy, Office of Civilian Radioactive Waste Management (DOE/OCRWM). This final rule grants the petition for rulemaking, with modifications, and completes NRC action on the petition. This final rule also will make a minor correction regarding the usage of metric and English units, to be consistent with existing NRC policy on such use.

"DATES: The effective date is July 15, 1998. The incorporation by reference of the American Society of Mechanical Engineers (ASME) Boiler and Pressure Vessel Code, Section VIII, editions through the 1995 Edition, is approved by the Director of the Federal Register as of July 15, 1998....

\section{"SUPPLEMENTARY INFORMATION:}

\section{"Background}

"In 1974, the Atomic Energy Commission (AEC) adopted the special requirements in 10 CFR 71.63 that regulate the shipment of plutonium in excess of 0.74 terabecquerels $(\mathrm{TBq})$ [20 Curies] per package. These requirements specify that plutonium must be in solid form and that packages used to transport plutonium must provide a separate inner containment (the 'double-containment' requirement). In adopting these requirements, the AEC specifically excluded from the double-containment requirement plutonium in the form of reactor fuel elements, metal or metal alloys, and, on a case-by-case basis, other plutoniumbearing solids that the agency determines do not require double containment. The Statement of Consideration for the original rule (39 FR 20960; June 17, 1974), specifies that '*** solid forms of plutonium that are essentially nonrespirable should be exempted from the double-containment requirement.'

“On November 30, 1993, DOE/OCRWM petitioned the NRC to amend $\S 71.63(\mathrm{~b})$ to add vitrified HLW contained in a sealed canister to the forms of plutonium which are exempt from the doublecontainment packaging requirements of Part 71 . The NRC published a notice of receipt for the petition, docketed as PRM-71-11, in the Federal Register on February 18, 1994 (59 FR 8143). Three comments were received on the petition.

"Pursuant to the Nuclear Waste Policy Act of 1982, as amended (NWPA), DOE is the Federal agency responsible for developing and administering a geologic repository for the deep disposal of HLW and spent nuclear fuel. DOE plans to ship the vitrified HLW in sealed canisters from four storage locations: Aiken, South Carolina; Hanford, Washington; West Valley, New York[;] and Idaho Falls, Idaho; directly to the geologic repository in transportation packages certified by the NRC. Currently, this HLW exists mostly in the form of liquid and sludge resulting from the reprocessing of defense reactor fuels. DOE proposes to encapsulate the HLW in a borosilicate glass matrix. The HLW is added to molten glass and the mixture is then poured into a stainless steel 
canister and allowed to solidify (i.e., vitrify). The canister is then seal-welded shut. The canisters will eventually be placed inside Type B transportation packages for transport to the geologic repository or an interim storage facility.

"The beneficial aspect of this amendment would be the elimination of an unnecessary requirement that DOE transport vitrified HLW in a separate inner container (i.e., a second barrier which is subject to the leak testing requirements of $\S 71.63(\mathrm{~b}))$. The Commission believes that the vitrified HLW form in its sealed canister provides sufficient defense-in-depth for protection of public health and safety and the environment, when transported inside an NRCcertified Type B transportation package. The Commission agrees with DOE's assertion that shipments of this form of plutonium are comparable to shipments of (irradiated) reactor fuel elements which are exempt from the double-containment requirement. Therefore, the Commission agrees that the double-containment requirement is unnecessary. Additional beneficial aspects of this amendment would be a reduction in DOE's costs associated with the transportation of HLW from production sites to the geologic repository or an interim storage facility; and the simplification of the NRC staff's review of DOE's application for certification of a transportation package.

"Although, in most other types of shipments, DOE is not subject to the requirements of Part 71, the NWPA requires that DOE's transport of spent nuclear fuel or HLW to a geologic repository or a monitored retrievable storage facility be in packages certified by the NRC. The packages used to transport vitrified HLW contained in sealed canisters will be certified by the NRC as Type B packages. Type B packages are designed to withstand the normal and hypothetical accident conditions specified in Part 71. The canistered vitrified HLW also will be subject to the special transport controls for a 'Highway Route Controlled Quantity' pursuant to U.S. Department of Transportation regulations contained in 49 CFR Part 397. In addition, the NWPA requires DOE to provide technical assistance and funds to train emergency responders along the planned routes.

"DOE asserted that shipments of vitrified HLW contained in a sealed canister will not adversely affect public health and safety and the environment if shipped without double containment. DOE stated that a separate inner container is unnecessary because of the high degree of confinement provided by the stainless steel waste canister and the essential nonrespirability of the solid, plutonium-bearing waste form. In addition, DOE argued that vitrified HLW in sealed canisters provides a comparable level of protection to that of irradiated reactor fuel elements, which the Commission previously determined should be exempt from the double-containment requirement (39 FR 20960).
"On June 1, 1995, the NRC staff met with DOE in a public meeting to discuss the petitioner's request and the possible alternative of requesting an NRC determination under $\S 71.63(\mathrm{~b})(3)$ to exempt vitrified HLW contained in a sealed canister from the doublecontainment requirement. DOE informed the NRC in a letter dated January 25, 1996, of its intent to seek an exemption under $\S 71.63(\mathrm{~b})(3)$. The NRC received DOE's exemption request on July 16, 1996, in which DOE also requested that the original petition for rulemaking be held in abeyance until a decision was reached on the exemption request. In response to DOE's request, the NRC staff prepared a Commission paper (SECY-96-215, dated October 8, 1996) outlining and requesting Commission approval of the NRC staff's proposed approach for making an exemption under $\S 71.63(\mathrm{~b})(3)$. However, in a staff requirements memorandum (SRM) dated October 31, 1996, the Commission disapproved the NRC staff's plan and directed that this policy issue be addressed by rulemaking rather than by exemption.

"The NRC published a proposed rule in the Federal Register on May 8, 1997 (62 FR 25146) in response to DOE's petition. The Statement of Considerations for the proposed rule contains a complete discussion of DOE's petition, comments received on the petition, and the NRC's analysis of those comments.

\section{"Discussion}

"The NRC is amending 10 CFR 71.63 based on its evaluation of the petition submitted by the DOE; the attachment to the petition, 'Technical Justification to Support the PRM by the DOE to Exempt HLW Canisters from 10 CFR 71.63(b)' (Technical Justification); the three public comments received on the petition after its publication in the Federal Register; and the seven comments on the proposed rule. In amending $\S 71.63$, the NRC is accepting, with modifications, the petition submitted by DOE, for the reasons set forth in the following paragraphs.

“In the early 1970's [sic], the AEC anticipated that a large number of shipments of plutonium nitrate liquids could result from the spent fuel reprocessing anticipated at that time. This raised a concern about leakage of liquids because of the potential for a large number of packages (probably of more complex design) to be shipped due to reprocessing and the increased possibility of human error resulting from handling this expanded shipping load.

"In 1973, the AEC proposed a rule which would deal with this problem by (a) requiring that shipments of plutonium containing greater than 20 curies be shipped in solid form, and (b) requiring that the solid plutonium be shipped in an inner container which would meet 'special form' requirements as they then existed; i.e., not only would the whole package have to meet Part 71 requirements but the inner container would separately have to meet stringent requirements. One alternative to the proposed rule 
the AEC considered was to require that shipments of plutonium be in nonrespirable form, either in a single or double containment. This alternative was rejected, apparently because fuel fabricators did not have the technology to use plutonium in a nonrespirable form.

"In 1974, the AEC published a final rule which contained two significant changes from the proposed rule:

(1) The AEC abandoned the 'special form' requirement and instead simply required 'double containment'; i.e., the inner container was required not to release plutonium when the whole package was subjected to the normal and hypothetical accident tests of Part 71, but no separate tests were required for the inner container. Double containment was required to take account of the fact that the AEC had decided not to require that the plutonium be in a nonrespirable form; and

(2) The AEC exempted two forms of plutonium altogether - reactor fuel elements and metal or metal alloy - on the basis that these forms were 'essentially nonrespirable' and therefore did not require double containment. The exemption provision placed in the regulation also indicates that the AEC saw the possibility that other forms of plutonium would be similar enough to these two forms to also qualify for exemption from the double-containment requirement because they were also essentially nonrespirable. In the statement of considerations accompanying the final rule, the AEC stated that $* * *$ solid forms of plutonium that are essentially nonrespirable should be exempt from the double containment requirements' (39 FR 20960).

"DOE's petition argues that a particular form of plutonium - vitrified high-level waste contained in a sealed canister - is similar enough to irradiated reactor fuel elements to qualify for its own exemption from the double-containment requirement. This is because of (1) the material properties of the vitrified $\mathrm{HLW},(2)$ the high degree of confinement provided by the stainless steel waste canister, and (3) the NRCapproved quality assurance program implemented by DOE makes it highly unlikely that any plutonium would be released from an NRC-certified transportation package under the normal or hypothetical accident conditions of part 71. The $\mathrm{NRC}$ is required to certify the transportation packages used for vitrified HLW pursuant to Section 180 of the NWPA and every transportation package for vitrified HLW will be required to meet the standards for accident-resistant packages (i.e., Type B packages) set forth in part 71.

"The tests described in DOE's Technical Justification demonstrate that the canisters containing the vitrified HLW provide an additional barrier to the release of radionuclides and compare favorably to the cladding surrounding spent fuel pellets in reactor fuel elements. The comparison is based upon physical drop tests, upon the material properties and dimensions of the sealed canisters, and the effects of radiation damage to materials.

"DOE's analysis demonstrates much lower concentrations of plutonium in the HLW canisters than in irradiated reactor fuel elements. However, the DOE has not established an upper limit on plutonium concentration for these vitrified HLW canisters, and the NRC is not basing its decision to remove these canisters from the double-containment requirement based on the plutonium's concentration.

"In its Technical Justification, DOE described the physical characteristics and acceptance standards of the canisters of vitrified HLW, including that the canistered waste form be capable of withstanding a 7-meter drop onto a flat, essentially unyielding surface, without breaching or dispersing radionuclides. This requirement is imposed by the DOE's 'Waste Acceptance System Requirements Document (WASRD),' Rev. 0, which is referenced in the Technical Justification. This test should not be confused with the 9-meter drop test, onto an essentially unyielding surface, which is required by the hypothetical accident conditions of $\S 71.73$. The 9-meter drop test is performed on the entire transportation package under the Part 71 certification process. The 7-meter drop test standard only applies to the canistered HLW.

"The NRC agrees that the 7-meter drop test requirement is relevant to the demonstration that the canistered HLW represents an essentially nonrespirable form for shipping plutonium. The NRC believes that the 7-meter canister drop test is a more severe challenge than the 9-meter drop test for an NRC-approved Type B package. This is because the Type B package and the impact limiters will absorb much of the energy which would otherwise be expended against the canister.

"In some of DOE's tests, the HLW canisters were dropped from 9 meters-2 meters above DOE's 7-meter design standard - and portions of the testing included deliberately introducing flaws $(0.95 \mathrm{~cm}$ holes) in the canisters' walls. For those HLW canisters tested with the $0.95 \mathrm{~cm}$ holes, the quantity of respirable plutonium released through these holes was less than $0.74 \mathrm{TBq}$ (20 curies). This review of DOE's Technical Justification has provided the NRC staff confidence that DOE's petition is supportable and that vitrified HLW in a sealed canister is essentially nonrespirable.

"The NRC does not control the requirements in, or changes to, DOE's WASRD. Because of concerns that DOE's WASRD could be changed in the future, the NRC added the requirement in the proposed rule that vitrified HLW contained in a sealed canister meet the design criteria of $\S 60.135$ (b) and (c). However, in response to comments received on the proposed rulemaking, the Commission has reconsidered its proposed imposition of referencing 
Part 60 design criteria. The final rule, instead, incorporates one of the design requirements from Part 60 into this rule. The other Part 60 design requirements are satisfied by other existing Part 71 requirements and other language in the final rule. Additionally, the Commission has included one acceptable method for meeting these design requirements for handling by referencing appropriate American Society of Mechanical Engineers Boiler and Pressure Vessel Code criteria. The explanation for this change is discussed below. Further, the NRC staff does perform technical reviews to certify package designs. For a HLW package, the review would include the sealed canister as well as the radioactive contents in the form of vitrified HLW. It is expected that an application for approval of a HLW package design would include a canister design and vitrified HLW contents with characteristics and attributes comparable to those described in the Technical Justification.

\section{"Comments on the Proposed Rule}

"This section presents a summary of the principal comments received on the proposed rule, the NRC's response to the comments, and changes made to the final rule as a result of these comments. The Commission received seven comment letters from six commenters $[s i c]$ on the proposed rule. One was from a member of the public, two were from national laboratories, one was from a transportation cask designer, one was from a consulting company, and one was from DOE. In addition, DOE submitted a subsequent letter commenting on one of the other comments. Overall, five of the six commenters [sic] supported the proposed rule and the remaining commenter [sic], while not specifically opposing the rule, proposed changes regarding the performance of the canister and limiting its contents....

"Comment. DOE and another commenter [sic] objected to the proposed rule's use of design criteria from Part 60. DOE noted that basing canistered waste approved for transport under $\S 71.63$ upon the rules for disposal of HLW under $\S 60.135$ (b) and (c) assumes that certification approval for transport packages will not take place until a repository or interim storage facility becomes available; and that this may not be the case. The commenters [sic] are concerned that if certification for transport packages under the proposed rule is sought before a license application for a repository or interim storage facility is submitted, this situation could complicate and impede progress on the HLW cask certification process. One commenter [sic] supported the use of Part 60 criteria.

"Response. The Commission has reconsidered the need to reference Part 60 criteria for canistered vitrified HLW in the amended regulation. The Commission agrees that it is best to avoid incorporating into Part 71-which contains standards for the packaging and transportation of radioactive materials-requirements referenced from Part 60 which are intended for the permanent disposal of HLW in a geologic repository. The NRC staff has analyzed the requirements contained in $\S 60.135(\mathrm{~b})$ and (c) and has determined that the intended requirement - that the canistered vitrified HLW maintain its integrity - can be achieved by reliance on existing Part 71 requirements and language from the proposed rule for all of the Part 60 requirements, but one. That one requirement is to design the canister to maintain waste containment during handling activities associated with transport. This has been added to the final rule. Additionally, the Commission has included one acceptable method for meeting these design requirements by referencing appropriate American Society of Mechanical Engineers Boiler and Pressure Vessel Code criteria.

"The design criteria in $\S 60.135$ (b) require that the waste package shall not contain explosive, pyrophoric, or chemically reactive materials or free liquids in amounts that could cause harm; that waste packages shall be designed to maintain waste containment during handling; and that waste packages have unique identification numbers. The design criteria in $\S 60.135$ (c) require that the waste be in solid form and placed in a sealed container; that any particulate waste forms be consolidated into an encapsulating matrix; and that any combustible radioactive waste be reduced to noncombustible form. As noted, the Commission believed that by referencing these criteria in the proposed rule, it could assure the integrity of the canistered vitrified HLW.

"The Commission now believes that the integrity objective can be achieved by relying on requirements in the final rule and other requirements in Part 71. First, as stated above, the final rule has added language that the canister be designed to maintain waste containment during handling activities associated with transport. Second the rule requires that the HLW be vitrified, and thus be in a solid form for encapsulation. Vitrification of HLW uses molten glass and this high temperature process will reduce any combustible radioactive waste into a noncombustible form. Finally, the Part 60 requirement that a unique identification number be attached to the HLW canister is not relevant for transportation.

"Third, the Commission believes the integrity objective can be achieved by relying on other requirements in Part 71. Part 71 already requires that the transportation packages must not contain explosive, pyrophoric, or chemically reactive materials or free liquids. Section $71.43(\mathrm{~d})$ requires that:

A package must be made of materials and construction that assure that there will be no significant chemical, galvanic, or other reaction among the packaging components, among package contents, or between the packaging components and 
the package contents, including possible reaction resulting from inleakage of water, to the maximum credible extent. Account must be taken of the behavior of materials under irradiation.

"The existing requirement in $\S 71.63(\mathrm{a})$ that the plutonium be in a solid form also will assure that the waste will be in solid form and that the waste package will be free of liquids.

"Additionally, the Commission has included one acceptable method for meeting the canister design requirements for handling by referencing appropriate American Society of Mechanical Engineers Boiler and Pressure Vessel Code criteria. Use of the ASME Boiler and Pressure Vessel Code would ensure that the canister would be designed to maintain waste containment during handling, including normal loading and unloading activities. Certain criteria of the ASME Boiler and Pressure Vessel Code, Section VIII, are excluded because they are not appropriate for a sealed canister containing vitrified HLW. For example, the criteria to include a pressure relief device and openings to inspect the interior are unnecessary and could compromise the long term integrity of the canister. Specific alternatives to the ASME Boiler and Pressure Vessel Code criteria may be considered and approved without resorting to exemptions from the regulation.

"Final Rule. The final rule has been revised to read as follows: Vitrified high-level waste contained in a sealed canister designed to maintain waste containment during handling activities associated with transport. As one method of meeting these design requirements, the NRC will consider acceptable a canister which is designed in accordance with the American Society of Mechanical Engineers (ASME) Boiler and Pressure Vessel Code, Section VIII, editions through the 1995 Edition. However, this canister need not be designed in accordance with the requirements of Section VIII, Parts UG-46, UG-115 through UG-120, UG-125 through UG-136, UW-60, UW-65, UHA-60, and UHA-65 and the canister's final closure weld need not be designed in accordance with the requirements of Section VIII, Parts UG-99 and UW-11. Necessary language to incorporate by reference the ASME Boiler and Pressure Vessel Code has also been added.

"Comment. Four of the six commenters [sic] stated that the NRC should evaluate the technical bases for $\S 71.63$, or referred to a Commission SRM to SECY-96-215, dated October 31, 1996, which directed the NRC staff to 'address whether the technical basis for 10 CFR 71.63 remains valid, or whether a revision or elimination of portions of 10 CFR 71.63 is needed to provide flexibility for current and future technologies.' One of the commenters [sic] noted that the International Atomic Energy Agency standards do not impose a doublecontainment requirement. Four of the commenters [sic] recommended that if the NRC retained the double containment provision, that the rule use performance-based criteria for dispersibility and respirability as a basis for exemption, or that double containment only be required for 'highly dispersible materials.' One of the commenters [sic] recommended that $\S 71.63$ be eliminated entirely. One commenter [sic] expressed an interest in any Commission action on $\S 71.63$, and recommended that the evaluation of $\S 71.63$ take the form of an Advanced Notice of Proposed Rulemaking.

"Response. The Commission believes that those comments to evaluate the technical basis for $\S 71.63$, to revise $\S 71.63$ (other than for vitrified HLW in canisters), or to eliminate the rule, are beyond the scope of this rulemaking. The NRC staff recently reviewed the technical bases for $\S 71.63$, as directed in the SRM to SECY-96-215. The NRC staff concluded, in SECY-97-218, dated September 29, 1997, that the technical bases remain valid, and that the provisions provide adequate flexibility for current and future technologies. Except for the changes made in this rulemaking for vitrified HLW in canisters, the NRC staff concluded that the provisions in $\S 71.63$ should remain unchanged. The NRC staff will further consider potential modifications to $\S 71.63$ in its response to a petition for rulemaking, dated September 25, 1997, (Docket No. PRM-71-12). The NRC published a notice of receipt for the petition in the Federal Register (63 FR 8362, dated February 19, 1998).

"Comment. One commenter [sic] suggested that the proposed rule be changed to require that HLW canister design, fabrication, test, and fill be conducted under a quality assurance program that meets, to the satisfaction of the NRC, the requirements of Part 71, Subpart H.

"This commenter [sic] also suggested that the proposed rule be changed to require that the exemption will only apply to canisters of HLW in shipping packages which have been demonstrated by analysis or test to adequately contain the HLW canisters without allowing canister failure under the hypothetical accident conditions of Part 71, Subpart F, when considered as a transportation system.

"Response. The technical basis given in the DOE petition for an exemption is that a separate inner container is unnecessary because of the high degree of confinement provided by the stainless steel waste canister and the non-respirability of the solid, plutonium-bearing waste form. In support of its petition, DOE submitted a Technical Justification which included a description of a representative HLW canister together with the results of 7-meter and 9-meter drop testing of the canisters and a description of the standards used for canister fabrication and filling.

"The technical review performed by the NRC staff to certify a HLW package would include the sealed canister as well as the radioactive contents in the form of vitrified HLW. It is expected that an application for approval of a HLW package design 
would include a canister design and vitrified HLW contents with characteristics and integrity comparable to those described in the DOE petition. The DOE HLW canisters will be subject to an NRC approved quality assurance plan.

"The final rule has been revised to specify that the vitrified high-level waste be contained in a sealed canister designed to maintain waste containment during handling activities associated with transport. These standards would apply to all canisters containing vitrified HLW transported under this provision and will provide reasonable assurance that the package design adequately protects public health and safety.

"Comment. One commenter [sic] suggested that the proposed rule be changed to require that the exemption will only apply to vitrified HLW from which plutonium has been removed prior to transfer to HLW storage tanks. The commenter [sic] suggested the vitrified HLW be restricted to no more than $3.7 \mathrm{TBq}(100 \mathrm{Ci})$ of plutonium.

"Response. The Statement of Considerations for the original rule (39 FR 20960) did not discuss activity limits (quantity limits); nor did the Commission adopt activity limits on the other forms of plutonium that are exempt from Sec. 71.63(b). Rather, any limitations on the quantity of plutonium that can be shipped in a transportation package - for any exempt form of plutonium - are due to the inherent design features of the specific transportation package being used. These design features are reviewed by the NRC as part of the package certification process. The commenter [sic] has not provided any technical basis for requiring activity limits on this form of plutonium. The final rule does not specify a quantity limit for this exemption.

\section{"Regulatory Action}

"The NRC is amending 10 CFR 71.63 based on its evaluation of the petition submitted by DOE; the attachment to the petition, 'Technical Justification to Support the PRM by the DOE to Exempt HLW Canisters from 10 CFR 71.63(b), the three comments received on the petition; and the seven comments received on the proposed rule. Section 71.63(b) specifies special provisions for shipping plutonium in excess of $0.74 \mathrm{TBq}(20$ curies) per package, including a separate inner containment system, except when plutonium is in solid form of reactor fuel elements, metal, or metal alloys. In amending $\S 71.63(\mathrm{~b})$, the NRC is granting, with modification, the petition submitted by DOE to eliminate these special provisions when transporting vitrified HLW contained in a sealed canister designed to maintain waste containment during handling activities associated with transport. The final rule completes NRC action on PRM-71-11. In the proposed rule, the NRC would have required that the HLW canister meet design criteria contained in
$\S 60.135(\mathrm{~b})$ and (c). The final rule, instead, incorporates these requirements into Part 71.

"In addition, the NRC has corrected the usage of units in $\S 71.63$. The metric units are used first with the English units in parenthesis...."[30]

\subsection{CFR 71, 2002 PROPOSED RULE}

In April 2002, the proposed rule for major changes to 10 CFR 71 was published in the Federal Register.[31] As before, we will be taking a look at the information presented in the preamble for the 2002 Proposed Rule. In this case, however, it important to note from the outset that the bureaucratic requirements, with respect to the format and the content, had changed dramatically between what is presented below, and what has been presented previously. While this will become very obvious on the part of the NRC, it will also become obvious, but to a lesser extent, on the part of the IAEA.

Appropriately forewarned, the bulk of the preamble for the 2002 Proposed Rule for 10 CFR 71 reads as follows:

"SUMMARY: The Nuclear Regulatory Commission (NRC) is proposing to amend its regulations on packaging and transporting radioactive material to make them compatible with the International Atomic Energy Agency (IAEA) standards and to codify other applicable requirements. These changes would be compatible with ST-1 (TS-R-1), the latest revision of the IAEA transportation standards. This rulemaking would also address the unintended economic impact of NRC's emergency final rule entitled 'Fissile Material Shipments and Exemptions' (February 10, 1997; 62 FR 5907) and a petition for rulemaking submitted by International Energy Consultants, Inc. (PRM-71-12: February 19, 1998; 63 FR 8362)....

\section{"SUPPLEMENTARY INFORMATION:}

"Contents.

"I. Background

"II. Summary of Public Comments

"III. Request for Cost-Benefit and Exposure Information

"IV. Discussion

A. TS-R-1 Compatibility Issues

Issue 1: Changing Part 71 to the International System of Units (SI) Only

Issue 2: Radionuclide Exemption Values

$\$$ Author's Note: To give the reader some added appreciation of the extent of the newer bureaucratic requirements referred to above, this is the first of the rulemakings, Proposed or Final, to need its own Table of Contents. As can be seen in the Table of Contents for the 2002 Proposed Rule, there were (are) a total of 14 (XIV) sections. For purposes of this Chapter, we will be focusing on the information in Sections I, III, $\mathrm{IV}$, and $\mathrm{V}$ of the Proposed Rule, only. Readers interested in the complete text of the 2002 Proposed Rulemaking for 10 CFR 71 are referred directly to the full text of Reference [31]. 
Issue 3: Revision of $A_{1}$ and $A_{2}$

Issue 4: Uranium Hexafluoride Package Requirements

Issue 5: Introduction of the Criticality Safety Index Requirements

Issue 6: Type C Packages and Low Dispersible Material

Issue 7: Deep Immersion Test

Issue 8: Grandfathering Previously Approved Packages

Issue 9: Changes to Various Definitions

Issue 10: Crush Test for Fissile Material Package Design

Issue 11: Fissile Material Package Design for Transport by Aircraft

B. NRC-Initiated Issues

Issue 12: Special Package Authorizations

Issue 13: Expansion of Part 71 Quality Assurance Requirements to Certificate of Compliance (CoC) Holders

Issue 14: Adoption of American Society of Mechanical Engineers (ASME) Code

Issue 15: Change Authority for Dual- Purpose Package Certificate Holders

Issue 16: Fissile Material Exemptions and General License Provisions

Issue 17: Double Containment of Plutonium (PRM-71-12)

Issue 18: Contamination Limits as Applied to Spent Fuel and High-Level Waste (HLW) Packages

Issue 19: Modifications of Event Reporting Requirements

"V. Section-By-Section Analysis

"VI. Criminal Penalties

"VII. Issues of Compatibility for Agreement States

"VIII. Plain Language

"IX. Voluntary Consensus Standards

"X. Environmental Assessment: Finding of No Significant Impact

"XI. Paperwork Reduction Act Statement

"XII. Regulatory Analysis

"XIII. Regulatory Flexibility Act Certification

"XIV. Backfit Analysis

\section{"I. Background}

"The Commission directed the NRC staff in Staff Requirements Memorandum (SRM) 00-0117 dated June 28, 2000: (1) To use an enhanced publicparticipation process (website and facilitated public meetings) to solicit public input on the part 71 rulemaking; and (2) to publish the staff's Part 71 issues paper in the Federal Register (65 FR 44360; July 17, 2000) for public comment. The issues paper presented the NRC's plan to revise Part 71 and provided a summary of all changes being considered, both IAEA-related changes and NRC-initiated changes. The NRC published the issues paper to begin an enhanced public participation process designed to solicit public input on the part 71 rulemaking. This process included establishing an interactive website and holding three facilitated public meetings: a 'roundtable' workshop at the NRC Headquarters, Rockville, MD, on August 10, 2000, and two 'townhall' meetings - one in Atlanta, GA, on September 20, 2000, and a second in Oakland, CA, on September 26, 2000.

"SRM-00-0117 also directed the staff to proceed, after completion of the public meetings, with the development of a proposed rule for submittal to the Commission by March 1, 2001. Oral and written comments received from the public meetings, by mail, and through the NRC website, in response to the issues paper, were considered in the drafting of the proposed changes contained herein.

"Past NRC-IAEA Compatibility Revisions

"Recognizing that its international regulations for the safe transportation of radioactive material should be revised from time to time to reflect knowledge gained in scientific and technical advances and accumulated experience, IAEA invited Member States (the U.S. is a Member State) to submit comments and suggest changes to the regulations in 1969. As a result of this initiative, the IAEA issued revised regulations in 1973 (Regulations for the Safe Transport of Radioactive Material, 1973 edition, Safety Series No. 6). The IAEA also decided to periodically review its transportation regulations, at intervals of about 10 years, to ensure that the regulations are kept current. In 1979, a review of IAEA's transportation regulations was initiated that resulted in the publication of revised regulations in 1985 (Regulations for the Safe Transport of Radioactive Material, 1985 edition, Safety Series No. 6).

"The NRC also periodically revises its regulations for the safe transportation of radioactive material to make them compatible with those of the IAEA. On August 5, 1983 (48 FR 35600), the NRC published in the Federal Register a final revision to part 71, 'Packaging and Transportation of Radioactive Material.' That revision, in combination with a parallel revision of the hazardous materials transportation regulations of the U.S. Department of Transportation (DOT), brought U.S. domestic transport regulations into general accord with the 1973 edition of IAEA transport regulations. The last revision to Part 71 was published on September 28, 1995 (60 FR 50248), to make part 71 compatible with the 1985 IAEA Safety Series No. 6. The DOT published its corresponding revision to Title 49 on the same date (60 FR 50291).

"The last revision to the IAEA Safety Series 6 was named Safety Standards Series ST-1, published in December 1996, and was revised with minor editorial changes in June 2000, and was redesignated as TS-R-1. This rulemaking effort is to evaluate TS-R-1 for potential adoption in Part 71 regulations.

"Historically, the NRC coordinated its Part 71 revisions with DOT, because DOT is the U.S. Competent Authority for transportation of hazardous 
materials. 'Radioactive Materials' is a subset of 'Hazardous Materials' in Title 49 regulations under DOT authority. Currently, DOT and NRC coregulate transport of nuclear material in the United States. NRC is continuing with its coordinating effort with the DOT in this rulemaking process. Refer to the DOT's corresponding rule for additional background on the positions proposed in this notice.

"Scope of 10 CFR Part 71 Rulemaking

"As directed by the Commission, NRC staff compared TS-R-1 to the previous version of Safety Series No. 6 to identify changes made in TS-R-1, and then identified affected sections of Part 71. Based on this comparison, NRC staff identified 11 areas in part 71 that needed to be addressed in this rulemaking process as a result of the changes to the IAEA regulations. The staff grouped the part 71 IAEA compatibility changes into the following issues: (1) Changing part 71 to the International System of Units (Sl) (also known as the metric system) exclusively; (2) Radionuclide specific exemption values; (3) Revision of $A_{1}$ and $A_{2}$ values; (4) Uranium hexafluoride $\left(\mathrm{UF}_{6}\right)$ package requirements; (5) Introduction of criticality safety index requirements; (6) Type $\mathrm{C}$ packages and low dispersible material; (7) Deep immersion test; (8) Grandfathering previously approved packages; (9) Adding and modifying Part 71 definitions; (10) Crush test for fissile material package design; and (11) Fissile material package design for transport by aircraft.

"Eight additional NRC-initiated issues (numbers 12 through 19) were identified by Commission direction, and through staff consideration, for incorporation in the Part 71 rulemaking process. These NRC-initiated changes are: (12) Special package approvals; (13) Expansion of Part 71 quality assurance (QA) requirements to holders of, and applicants for, a Certificate of Compliance (CoC); (14) Adoption of the requirements of American Society of Mechanical Engineers (ASME), Boiler and Pressure Vessel (B\&PV) Code for fabrication of spent fuel transportation packages; (15) Adoption of change authority; (16) Revisions to the fissile exempt and general license provisions to address the unintended economic impact of the emergency rule (SRM-SECY-99-200); (17) Decision on Petition for Rulemaking PRM-71-12, which requested deletion of the double containment requirements for plutonium; (18) Surface contamination limits as applied to spent fuel and high-level waste packages (SRM-SECY-00-0117); and (19) Part 71 event reporting requirements. NRC published the first 18 issues in an issues paper in the Federal Register on July 17, 2000 (65 FR 44360).

"The Part 71 rulemaking is being coordinated with DOT to ensure that consistent regulatory standards are maintained between NRC and DOT radioactive material transportation regulations, and to ensure coordinated publication of the final rules by both agencies. On December 28, 1999 (64 FR 72633), DOT published an advance notice of proposed rulemaking regarding adoption of TS-R-1 in its regulations....

\section{"III. Request for Cost-Benefit and Exposure Information}

“...The NRC staff, as directed by the Commission, is continuing to solicit cost-benefit and exposure data from the public and industry to quantify the impact of the proposed Part 71 amendments. The NRC believes that this data will assist the Commission in: (1) Making an informed decision regarding the proposed IAEA compatibility changes, and (2) avoiding the promulgation of amendments that may result in unforeseen and unintended negative impacts, especially in view of the fact that the current regulations in Part 71 have provided adequate protection of the public health and safety.

"To help focus the public and industry and to capture the most data, the following request for information is presented in three groups: (1) General requests that apply to all 19 issues, (2) requests that apply only to the IAEA related changes, and (3) issue-specific staff questions.

\section{"Request for Information on All 19 Issues}

"The Commission is inviting comments from all stakeholders (Agreement States, public interest groups, and industry representatives) to address the overall impact of this proposed rule. Specifically, the Commission is soliciting: (1) Quantitative information and data on the costs and benefits which might occur if these proposed changes were adopted; (2) operational data on radiation exposures (increased or reduced) that might result from implementing the Part 71 proposed changes; (3) whether the proposed changes are adequate to protect public health and safety; (4) whether other changes should be considered, including providing cost-benefit and exposure data for these suggested changes; and (5) how should specific risk considerations (i.e., data on what can happen, how likely is it, what are the consequences) be factored into the proposed amendments.

"Request for Information on the IAEA-Related Issues (Issues 1-11)

"The NRC recognizes the importance, from an international commerce standpoint, of having the packaging and transportation regulations in Part 71 compatible with the IAEA's TS-R-1. However, before adoption, the NRC seeks to quantify the impact of adopting these IAEA regulations. Development of the IAEA TS-R-1 did not directly involve the public or include a cost benefit analysis. In contrast, NRC's practice is to consider costs and benefits in its regulatory analysis, and NRC is prepared to differ from the TS-R-1 standards, at least for domestic purposes, to the extent the standards 
cannot be justified from a cost-benefit perspective, especially given the current regulations in Part 71 have provided adequate protection of the public health and safety.

"Therefore, the NRC is inviting public comments on the IAEA-related issues, Issues 1-11. Specifically, the Commission is soliciting cost-benefit data to quantify the economic impact of harmonizing with the 11 IAEA changes on the domestic commerce and international commerce of packages containing radioactive material. The NRC is interested in determining: (1) whether the benefits of harmonization with the IAEA standards may exceed the costs, or may result in other health and safety problems resulting from dual standards between domestic (Part 71) and international (TS-R-1) requirements, and (2) whether the NRC should adopt only some of the 11 IAEA changes.

"Request for Responses to Issue-Specific Questions:

"Issue 2-Radionuclide Exemption Values

"What impacts, if any, would result for industries that possess, use, or transport materials currently exempt from regulatory control (e.g., unimportant source material under 10 CFR 40.13) if adoption of the radionuclide exemption values were to occur in Part 71?

"What impacts, if any, would result for industries that transport natural material and ores containing naturally occurring radionuclides which are not intended for processing for economic use of their isotopes (e.g., phosphate mining, waste products from the oil and gas industry), if the TS-R-1 exemption values are adopted, but without the ' 10 times the applicable exemption values' provision?

"Another possible impact of the proposed radionuclide exemption values is in the area of waste disposal sites which are regulated by EPA under the Resource Conservation and Recovery Act (RCRA). The acceptance limit in these sites for materials containing radioactive residuals is the existing $70 \mathrm{~Bq} / \mathrm{g}(0.002 \mu \mathrm{Ci} / \mathrm{g})$ standard used by DOT, NRC, and EPA. Presently, only the NRC and DOT are proposing to adopt the exemption values, which may result in situations where shipment of materials with residual radioactivity would be allowed for transportation under the new exemption values but would not be allowed for disposal in RCRA sites.

"What cost impacts or other problems, if any, would result from adoption of the exemption values, in Part 71 and DOT regulations, for industries or entities involved in the shipment and disposal of materials with residual activity to RCRA sites?

"Issue 3-Revision of $\mathrm{A}_{1}$ and $\mathrm{A}_{2}$

"What impacts, if any, would result for the radiopharmaceutical industry in terms of cost and worker dose by adopting the lower international $A_{2}$ value, rather than retaining the current $A_{2}$ value for domestic shipment of molybdenum-99?
"What impacts, if any, would result for industry in terms of cost and worker dose by retaining the current $A_{1}$ and $A_{2}$ values for californium-252, rather than adopting the international $A_{1}$ and $A_{2}$ values?

"What impacts, if any, would result for industry in terms of cost and worker dose by not including in Table $A-1$ ( $A_{1}$ and $A_{2}$ Values for Radionuclides) the 16 radionuclides that are listed in the current Part 71 but not in TS-R-1?

"Issue 4-Uranium Hexafluoride $\mathrm{UF}_{6}$ Package Requirements

"Should the current practice of excluding moderators in criticality evaluations for $\mathrm{UF}_{6}$ packages be continued?

"Issue 5-Introduction of the Criticality Safety Index Requirements

"What cost or benefit impacts would result if the per package Criticality Safety Index (CSI) were to change from 10 to 50 ?

"Issue 6-Type C Packages and Low Dispersible Material

"NRC requests information on the need for Type $\mathrm{C}$ packages, specifically on the number of package designs and the timing of future requests for Type $\mathrm{C}$ package design approvals.

"Issue 8-Grandfathering Previously Approved Packages

"Under what conditions should packagings be removed from service? What are the cost or benefit impacts associated with the proposal to remove $\mathrm{B}(\mathrm{)})$ packages from service?

"Issue 10-Crush Test for Fissile Material Package Design

"What are the cost or benefit impacts of imposing the crush test requirement on fissile material package designs?

"Issue 12_-Special Package Approval

"What additional limitations, if any, should apply to the conditions under which an applicant could apply for a package authorization?

"Issue 17-Double Containment of Plutonium (PRM-71-12)

"What cost or benefit impacts would arise from removal of the double containment requirement for plutonium?

"Issue 18-Contamination Limits as Applied to Spent Fuel and High-Level Waste (HLW) Packages

"NRC requests information regarding the application of the regulatory limits for removable contamination on the external surfaces of packages used for spent fuel shipments. This information will be most helpful if respondents also indicate the cask design used and whether or not the cask is fitted with a protective cover prior to immersion in the spent fuel pool. Specifically, for previous spent fuel shipments, information is sought on: 
(1) The removable contamination level on the cask surface after the cask has been loaded, removed from the spent fuel pool, and dried;

(2) The dose attributable to any decontamination efforts, including external dose from cask and facility radiation fields and internal dose from airborne radioactivity in the cask handling/loading areas;

(3) The removable contamination level on the cask surface after decontamination efforts and before shipment; and

(4) The removable contamination levels on the cask surface upon receipt at the destination facility.

\section{"IV. Discussion}

"This section is structured to present and discuss each issue separately (with cross references as appropriate). Each issue has four parts: Background, Discussion, NRC Proposed Position, and Affected Sections. The discussion section summarizes the public comments, NRC staff consideration of public comments and of technical and policy issues, and the regulatory analysis for that issue.

“A. TS-R-1 Compatibility Issues

"Issue 1. Changing Part 71 to the International System of Units (SI) Only

"Background. TS-R-1 uses the SI units exclusively. This change is stated in TS-R-1, Annex II, page 199: 'This edition of the Regulations for the Safe Transport of Radioactive Material uses the International System of Units (SI).' The change to SI units exclusively is evident throughout TS-R-1. TS-R-1 also requires that activity values entered on shipping papers and displayed on package labels be expressed only in SI units (paragraphs 543 and 549). Safety Series No. 6 (TS-R-1's predecessor) used SI units as the primary controlling units, with subsidiary units in parentheses (Safety Series 6, Appendix II, page 97), and either units were permissible on labels and shipping papers (paragraphs 442 and 447).

"The TS-R-1 change is in conflict with the NRC Metrication Policy issued on June 19, 1996 (61 FR 31169), which allows a dual-unit system to be used (SI units with customary units in parentheses). The NRC Metrication Policy was designed to allow market forces to determine the extent and timing for the use of the metric system of measurements. The NRC is committed, in that policy, to work with licensees and applicants and with national, international, professional, and industry standardssetting bodies [e.g., American National Standards Institute (ANSI), American Society for Testing and Materials (ASTM), ASME] to ensure metriccompatible regulations and regulatory guidance. The NRC encouraged its licensees and applicants, through its Metrication Policy, to employ the metric system wherever and whenever its use is not potentially detrimental to public health and safety, or its use is economic. The NRC did not make metrication mandatory by rulemaking because no corresponding improvement in public health and safety would result, but rather, costs would be incurred without benefit. As a result, licensees and applicants use both metric and customary units of measurement.

“According to the NRC's Metrication Policy, the following documents should be published in dual units (beginning January 7, 1993): new regulations, major amendments to existing regulations, regulatory guides, NUREG-series documents, policy statements, information notices, generic letters, bulletins, and all written communications directed to the public. Documents specific to a licensee, such as inspection reports and docketed material dealing with a particular licensee, will be issued in the system of units employed by the licensee.

"Currently, Part 71 uses the dual-unit system in accordance with the NRC Metrication Policy.

"Discussion. Oral comments received at the public meetings, as well as written comments received on the issues paper, indicate opposition to the use of SI units only. Most commenters [sic] were opposed to switching to SI units only, and supported the continued use of the dual-unit system. At the August 10 meeting, a radiopharmaceutical industry representative commented that the Food and Drug Administration (FDA) requires the use of customary units (curie units), while shipping papers always list the activity in becquerels with curies in parentheses. The representative stated that while that presents some problems now, the industry is able to handle it. By moving to a system where the shipping papers are in SI units only, a situation would be created where the package contents are expressed in curies, while shipping papers and labels are expressed in becquerels. This could be confusing, especially when comparing the shipping papers to the contents. The implication is that this situation could create complications at the shipment destination as personnel would have to perform unit conversions to match package contents with the shipping papers. Furthermore, there was a concern that this could result in errors in patient administrations. Other commenters $[\mathrm{sic}]$ indicated that this change would result in significant costs for industry, with no apparent safety benefit.

"Another commenter [sic] indicated that, although the U.S. has adopted a policy of shifting to SI units, this policy has not been implemented. Several commenters [sic] argued that requiring the use of SI units only for domestic shipments of radioactive materials, when the balance of the nation's activities are conducted in customary units, would cause confusion as well as possible safety issues if misunderstandings or miscalculations were to occur. The commenters $[\mathrm{sic}]$ noted that the majority of individuals (including emergency response workers) are more accustomed to using customary units, and 
by requiring the use of SI units, problems would occur in converting customary units to SI units. As a result, the commenters [sic] believed that this could result in an increased risk of inadvertent exposure of workers to radiation.

"One commenter [sic] indicated that SI units are currently required to be used in certain cases for shipping and believed that such a change would pose little risk. However, the commenter [sic] added that any such change should be accompanied by a 3-year delay in the effective date to allow for proper transition.

"NRC staff notes that the use of SI units only would conflict with the NRC's Metrication Policy, which allows the use of a dual-unit system for measurements. The statement made in NRC's final Metrication Policy, '**** the NRC believed and continues to believe that if metrication were made mandatory by a rulemaking, no corresponding improvement in public health and safety would result but costs would be incurred without benefit,' still stands.

"The NRC draft regulatory analysis (draft RA) indicates that maintaining the existing policy of allowing the use of dual units is appropriate from a safety, regulatory, and cost perspective. A change to require SI units only would necessitate an exemption by the Commission from its dual-units policy, and would result in an inconsistency between Part 71 and other parts of the Commission's regulations. Further, anticipated costs to industry for implementing the new requirement (e.g., training, recalculations), estimated to be between $\$ 12.6$ and $\$ 16.3$ million, would be avoided if the dual-unit system is maintained. In addition, while NRC would incur $\$ 15,000$ in costs by converting from one system of units to another, this cost is offset by a savings in resources for not proceeding with rulemaking activities to implement the change. As discussed by several commenters [sic], the change to SI units only could result in the potential for adverse impact on the health and safety of workers and the general public as a result of unintended exposure in the event of shipping accidents, or medical dose errors, caused by confusion or erroneous conversion between the currently prevailing customary units and the new SI units by emergency responders or medical personnel.

"The NRC considered the Commission policy on this issue, the above public comments, and the draft RA of the impact of this change, and concluded that adopting the IAEA use of SI units only in Part 71 would have both a cost impact and potentially negative impact on workers and public health and safety.

"NRC Proposed Position. The NRC does not intend to change Part 71 to use SI units only, nor does it intend to impose on Part 71 licensees, certificate holders, or applicants for a $\mathrm{CoC}$ the use of SI units only. While TS-R-1 uses SI units only, it does not specifically prohibit the use of a dual-unit system (SI units and customary units). Therefore, the NRC will continue to use the dual-unit system in Part 71.

"Affected Sections. None (not adopted).

"Issue 2. Radionuclide Exemption Values

"Background. The DOT currently uses a specific activity threshold of $70 \mathrm{~Bq} / \mathrm{g}(0.002 \mu \mathrm{Ci} / \mathrm{g})$ for defining a material as radioactive for transportation purposes. DOT regulations apply to all materials with specific activities that exceed this value. Materials are exempt from DOT's transportation regulations if the specific activity is equal to or below this value. The $70-\mathrm{Bq} / \mathrm{g}(0.002-\mu \mathrm{Ci} / \mathrm{g})$ specific activity value is applied collectively for all radionuclides present in a material.

"Within $\S 71.10$, the NRC uses the same specific activity threshold as a means of determining if a radioactive material is subject to the requirements of Part 71. Materials are exempt from the transportation requirements in Part 71 if the specific activity is equal to or below this value. Although the materials may be exempt from any additional transportation requirements under Part 71 , the requirements for controlling the possession, use, and transfer of materials under Parts 30, 40, and 70 continue to apply, as appropriate, to the type, form, and quantity of material.

"During the development of TS-R-1, it was recognized that there was no technical justification for the use of a single activity-based exemption 70-Bq/g $(0.002-\mu \mathrm{Ci} / \mathrm{g})$ value for all radionuclides. It was concluded that a more rigorous technical approach would be to base radionuclide exemptions on a uniform dose basis, rather than a uniform specific activity (also known as activity concentration) basis.

"By 1994, the IAEA and other international healthrelated organizations had developed the International Basic Safety Standards for Protection against Ionizing Radiation and for the Safety of Radiation Sources, IAEA Safety Series No. 115. (This document is sometimes referred to informally as the Basic Safety Standards, or BSS.) During the preparation of this document, a set of principles had been developed and accepted for determining when exemption from regulation was appropriate. One of the exemption criteria was that the effective dose expected to be incurred by a member of the public from a practice (e.g., medical use of radiopharmaceuticals in nuclear medicine applications) or a source within a practice should be unlikely to exceed a value of $10 \mu \mathrm{Sv}$ ( $1 \mathrm{mrem})$ per year. IAEA Member State researchers developed a set of exposure scenarios and pathways which could result in exposure to workers and members of the public. These scenarios and pathways were used to calculate radionuclide exemption activity concentrations and exemption activities which would not exceed the recommended dose (see Safety Series No. 115, Schedule I, 'Exemptions'). 
"To investigate the exemption issue from a transportation perspective during the development of TS-R-1, IAEA Member State researchers calculated the activity concentration and activity for each radionuclide that would result in a dose of $10 \mu \mathrm{Sv}$ (1 mrem) per year to transport workers under various BSS and transportation-specific scenarios. Due to differences in radionuclide radiation emissions, exposure pathways, etc., the resulting radionuclidespecific activity concentrations varied widely. The appropriate activity concentrations for some radionuclides were determined to be less than $70 \mathrm{~Bq} / \mathrm{g} \quad(0.002 \mu \mathrm{Ci} / \mathrm{g})$, while the activity concentrations for others were much greater. However, the calculated dose to transport workers that would result from repetitive transport of each radionuclide at its exempt activity concentration was the same $[(10 \mu \mathrm{Sv})(1 \mathrm{mrem})]$ per year. For the single activity-based value, the opposite was true, i.e., the exempt activity concentration was the same for all radionuclides $(70 \mathrm{~Bq} / \mathrm{g})(0.002 \mu \mathrm{Ci} / \mathrm{g})$, but the resulting doses under the same transportation scenarios varied widely, with annual doses ranging from much less than $10 \mu \mathrm{Sv}$ (1 mrem) per year for some radionuclides to greater than $10 \mu \mathrm{Sv}$ (1 mrem) per year for others. The radionuclide-specific activity concentration values reduced the variability in doses that were likely to result from exempt transport activities.

"IAEA noted that the exempt activity concentrations calculated for transportation scenarios were less than those found in Safety Series No. 115 (BSS), Table I-I, 'EXEMPTION LEVELS: EXEMPT ACTIVITY CONCENTRATIONS AND EXEMPT ACTIVITIES OF RADIONUCLIDES (ROUNDED)', but not by more than a factor of 100 . IAEA did not believe the differences warranted a second set of exemption values, and therefore adopted the Safety Series No. 115 (BSS) values in TS-R-1. These values are found in TS-R-1, paragraphs 401-406, and in Tables I and II.

"A consequence of using the BSS exemption values for transportation is that the estimated average annual dose under the transportation scenarios exceeds the $10 \mu \mathrm{Sv}$ (1 mrem) per year criterion for some radionuclides. The staff has estimated that the average annual dose per radionuclide under the transportation scenarios using the BSS exemption values for a representative list of 20 radionuclides is $0.25 \mathrm{mSv}$ ( $25 \mathrm{mrem}$ ) per year. However, the staff estimates that the corresponding dose for the current $70 \mathrm{~Bq} / \mathrm{g}(0.002 \mu \mathrm{Ci} / \mathrm{g})$ exemption value, using the same transportation scenarios and radionuclides, is approximately $0.5 \mathrm{mSv}(50 \mathrm{mrem})$ per year. Although both the current exemption value and the BSS exemption values result in an estimated average dose per radionuclide that exceeds the criterion, the dose estimated for the BSS exemption values is significantly less than that estimated for the current $70 \mathrm{~Bq} / \mathrm{g}(0.002 \mu \mathrm{Ci} / \mathrm{g})$ exemption value.

"Note that some nuclides listed in Table I have a reference to footnote (b). These nuclides have the radiological contributions from their daughter products (progeny) already included in the listed value. For example, natural uranium [U (nat)] in Table I has a listed activity concentration for exempt material of $1 \mathrm{~Bq} / \mathrm{g}\left(2.7 \times 10^{-5} \mu \mathrm{Ci} / \mathrm{g}\right)$. This means the activity concentration of the uranium is limited to $1 \mathrm{~Bq} / \mathrm{g}\left(2.7 \times 10^{-5} \mu \mathrm{Ci} / \mathrm{g}\right)$, but the total activity concentration of an exempt material containing $1 \mathrm{~Bq} / \mathrm{g}\left(2.7 \times 10^{-5} \mu \mathrm{Ci} / \mathrm{g}\right)$ of uranium will be higher (approximately $\left.7 \mathrm{~Bq} / \mathrm{g}\left(1.9 \times 10^{-4} \mu \mathrm{Ci} / \mathrm{g}\right)\right)$ due to the radioactivity of the daughter products.

"The basis for the exemption values, as discussed in the draft Advisory Material for the Regulations for the Safe Transport of Radioactive Material, TS-G-1.1, paragraphs 107.5 and 401.3, indicates that materials with very low hazards can be safely exempted from the transportation regulations. If the exemptions did not exist, enormous amounts of material with only slight radiological risks, materials which are not ordinarily considered to be radioactive, would be unnecessarily regulated during transport.

"Based on TS-R-1, paragraph 236, when both the activity concentration for exempt material and the activity limit for an exempt consignment are exceeded, the material or consignment must meet applicable transportation regulations. Paragraph 404 of TS-R-1 specifies how exemption values may be determined for mixtures of radionuclides.

"Some of the lower activity concentration values might include NORM. As an example, ores may contain NORM. In regard to transporting NORM, one petroleum industry representative stated there are no findings that indicate the current standard fails to protect the public, and that there is no benefit in making the threshold more stringent. Further, it would have a significant impact on their operations. Other similar comments were received during the public meetings. The overall impact would be that some material formerly not subject to the radioactive material transport regulations may need to be transported as radioactive material and therefore meet the corresponding applicable DOT transport requirements.

"IAEA recognized that application of the activity concentration exemption values to natural materials and ores might result in unnecessary regulation of these shipments, and established a further exemption for certain types of these materials. Paragraph 107(e) of TS-R-1 further exempts: 'natural material and ores containing naturally occurring radionuclides which are not intended to be processed for use of these radionuclides provided the activity concentration of the material does not exceed 10 times the values specified in paragraphs $401-406$.' 
"Discussion. Comments were received on this issue during the public meetings, by mail, and on the NRC web site. One commenter [sic] stated that the NRC should reference all DOT equivalent regulations (the radionuclide exemption values and all others) to prevent conflict between the NRC and DOT regulations. Two commenters [sic] cautioned that moving from one exemption value to different values for each radionuclide could result in more complicated compliance and enforcement scenarios. For example, one commenter $[$ sic $]$ indicated that the $70-\mathrm{Bq} / \mathrm{g}(0.002-\mu \mathrm{Ci} / \mathrm{g})$ exemption limit is also used as a standard by EPA under the RCRA as the permit limit for the acceptance of material containing radioactive residuals. Any changes to this limit could result in the preclusion of certain materials for disposal at permitted disposal facilities. Some commenters [sic] indicated that the revised exemption values should apply not only to domestic shipments but to exported shipments as well.

"One commenter $[s i c]$ indicated that this change will have a significant unintended impact on its operations because most of the oil and gas shipments would not be exempt under the new rule.

"One commenter [sic] indicated that such a change would result in an increase in the number of shipments by requiring smaller quantities to be shipped due to the lower exemption values. Another commenter [sic] suggested that the use of radionuclide-specific exemption values would not result in an increase in the number of packages being shipped, but would result in more shipments being labeled as radioactive. The commenter [sic] argued that because many of these shipments are currently being made as 'nonhazardous' shipments, many of the responses to accidents will be for minimal hazard materials representing insignificant risks that do not warrant increased response safety. The commenter [sic] stated that this would not result in increased safety, but would instead divert emergency response personnel from other, more significant, tasks.

"Several commenters [sic] reflected a belief that, for some radionuclides, the new higher values would be a relaxation of the regulations, and thus will adversely impact public health and safety. A few commenters [sic] indicated that NRC should actually look at making the exemption values more stringent rather than reducing the level of protection currently afforded the public. One commenter [sic] suggested that, before adopting any of the exemption values contained in TS-R-1, NRC should scrutinize the values to determine whether they are justified as protective of human health and the environment.

"A few commenters [sic] supporting the retention of the current Part 71 exemption values indicated that a move to radionuclide-specific exemption values would result in increased costs while yielding no additional safety benefit.

"The overall impact would be that some previously exempted material may need to be transported as radioactive material and therefore would need to meet applicable DOT transport requirements. While these activity concentration values would impact certain sectors, the NRC staff believes that the impact of not adopting the international standard would be significantly greater. Therefore, the NRC is proposing to adopt the radionuclide exemption values to assure continued consistency between domestic and international regulations.

"In $\S 71.10$ (b)(3), the 0.74-TBq (20-Ci) exemption for special form americium and special form plutonium would be removed, except for ${ }^{244} \mathrm{Pu}$. This provision was originally provided in Part 71 to permit the transportation, in domestic commerce within the United States, of well-logging sealed sources containing up to $0.74 \mathrm{TBq}(20 \mathrm{Ci})$ of radioactive material in Type A packages, even though that quantity of special form americium or plutonium was greater than the individual $A_{1}$ limits for these radionuclides. However, over time, the $A_{1}$ limits have been raised so that currently only ${ }^{244} \mathrm{Pu}$ has an $\mathrm{A}_{1}$ limit less than $0.74 \mathrm{TBq}(20 \mathrm{Ci})$ (i.e., $0.4 \mathrm{TBq}$ or $10.8 \mathrm{Ci}$. Consequently, this exemption is unnecessary for special form americium and special form plutonium, but is still needed for ${ }^{244} \mathrm{Pu}$.

"To prevent an unnecessary economic impact on industry, NRC staff believes the 0.74-TBq (20-Ci) exemption for special form ${ }^{244} \mathrm{Pu}$, transported in domestic commerce, should be retained as a new $\S 71.14(\mathrm{~b})(2)$. Furthermore, an exception would be added to $\S$ 71.14(b)(1) indicating that paragraph (b)(1) does not apply to special form ${ }^{244} \mathrm{Pu}$ transported in domestic commerce. This exception to the exemption would provide regulatory consistency between paragraphs (b)(1) and (b)(2), while permitting the continued transportation, within the U.S. only, of well-logging sources in a Type A package - when the source contains more than an $\mathrm{A}_{1}$ quantity of ${ }^{244} \mathrm{Pu}$, but less than $0.74 \mathrm{TBq}(20 \mathrm{Ci})$. For international shipments, the $\mathrm{A}_{1}$ quantity limit for special form ${ }^{244} \mathrm{Pu}$ would continue to apply.

"The NRC would include the TS-R-1 exemption values in a new table in Appendix A (Table A-2). Additionally, NRC recognized that changes were also required to Appendix A. Specifically, changes would be needed to paragraph II to correct the following problems: (1) The existing paragraph is not in plain language; (2) Guidance is needed on how to determine exempt material activity concentrations and exempt consignment activity limits for unlisted radionuclides; (3) The method of requesting Commission approval, if new Table A-3 is not used, needs to be specified; and (4) The existing requirement on requesting $\mathrm{NRC}$ prior approval is not listed in the approved Information collection requirements of $\S 71.6$.

"The NRC draft RA indicates that adopting the radionuclide-specific exemption values contained in TS-R-1 is appropriate from a safety, regulatory, and 
cost perspective. Adoption of these values would provide a consistent level of protection for all radionuclides and result in enhanced regulatory efficiency for the NRC and consistency among NRC, IAEA, and DOT. In addition, adoption would result in a single system for determining if materials are subject to domestic or international regulations (e.g., an imported package from England or France, which is exempt, would also be exempt in the United States). NRC believes that this increase in regulatory efficiency and potential cost savings, in some cases, more than offsets the potential increased costs to industry. These costs are anticipated to include minor administrative and procedural changes to use radionuclide-specific exemptions. Also, industry would expend resources to identify the radionuclides in a material, measure the activity concentration of each radionuclide, and apply the 'mixture rule' to ensure that a material is exempt. This is in contrast to the current approach of verifying that the material's total concentration is less than $70 \mathrm{~Bq} / \mathrm{g}(0.002 \mu \mathrm{Ci} / \mathrm{g})$. Further, because some low-level materials may be newly brought into the scope of the regulations, some additional costs may be incurred. However, NRC believes that these costs would be offset by the fact that some materials may be moved outside the scope of the regulations, resulting in a cost savings. Cost savings for shippers of low-level materials shipping both domestically and internationally would also be decreased because they would only have to ensure compliance with one set of requirements as opposed to two distinctly separate sets of requirements. Also, nonadoption of the TS-R-1 values could result in significant negative cost impacts on international commerce. Finally, NRC does not believe that adopting these values would have a significant effect on the total number of shipments domestically or internationally. The changes would also not significantly affect the way these materials are handled.

"The NRC considered the above public comments and the draft RA of this change, and concluded that adopting the new IAEA, dose-based, exemption values would improve public health and safety by establishing a consistent dose-model application for minimizing potential dose to transport workers. Within the United States, DOT has the responsibility for regulating the classification of radioactive materials. DOT is also adopting the TS-R-1 exemption concentration activity and exempt consignment values, and the $\mathrm{NRC}$ is proposing to make conforming changes to Part 71. While these activity concentration values will impact certain sectors, the impact of not adopting the international standard would be significantly greater. By adopting the provision to allow natural material and ores containing NORM, which are not intended to be processed for the radionuclides, to have an activity 10 times the exemption value, the NRC believes that
Part 71's impact on the mineral and petroleum industries will be minimized.

"NRC Proposed Position. The NRC is proposing to adopt the radionuclide exemption values in TS-R-1 to assure continued consistency between domestic and international regulations for the basic definition of radioactive material. This adoption into NRC regulations would not impact the Memorandum of Understanding (MOU) (July 2, 1979; 44 FR 38690) between DOT and NRC. The exemptions in existing $\S 71.10$ would be revised to reflect the exempt concentration and exempt consignment values of Appendix A, Table A-2. In addition, provisions for 10 times applicable values would be included for NORM and other natural materials. These changes would conform this rule to DOT's proposed regulations.

“Affected Sections. $\S \S 71.10,71.88$, Appendix A.

"Issue 3. Revision of $\mathrm{A}_{1}$ and $\mathrm{A}_{2}$

"Background. The international and domestic transportation regulations use established activity values to specify the amount of radioactive material that is permitted to be transported in a particular packaging and for other purposes. These values, known as the $A_{1}$ and $A_{2}$ values, indicate the maximum activity that is permitted to be transported in a Type A package. The $\mathrm{A}_{1}$ values apply to special form radioactive material, and the $\mathrm{A}_{2}$ values apply to normal form radioactive material. See $\S 71.4$ for definitions.

"In the case of a Type A package, the $A_{1}$ and $A_{2}$ values as stated in the regulations apply as package content limits. Additionally, fractions of these values can be used (e.g., $1 \times 10^{-3} \mathrm{~A}_{2}$ for a limited quantity of solid radioactive material in normal form), or multiples of these values (e.g., 3,000 $\mathrm{A}_{2}$ to establish a highway route controlled quantity threshold value).

"Based on the results from an updated Q-system (see TS-G-1.1, Appendix I), the IAEA has adopted new $A_{1}$ and $A_{2}$ values for radionuclides listed in TS-R-1 (see paragraph 201 and Table I). IAEA adopted these new values based on calculations which were performed using the latest dosimetric models recommended by the International Commission on Radiological Protection (ICRP) in Publication 60, '1990 Recommendations of the ICRP.' A thorough review of the Q-system also included incorporation of data from updated metabolic uptake studies. In addition, several refinements were introduced in the calculation of contributions to the effective dose from each of the pathways considered. The pathways themselves are the same ones considered in the 1985 version of the Q-system: external photon dose, external beta dose, inhalation dose, skin and ingestion dose from contamination, and dose from submersion in gaseous radionuclides. A thorough, up-to-date radiological assessment has been performed for each radionuclide of potential exposures to an individual 
should a Type A package of radioactive material be involved in an accident during transport. The new $\mathrm{A}_{1}$ and $\mathrm{A}_{2}$ values reflect that assessment.

"While the dosimetric models and dose pathways within the Q-system were thoroughly reviewed and updated, the reference doses were unchanged. The reference doses are the dose values which are used to define a 'not unacceptable' dose in the event of an accident. Consequently, while some revised $A_{1}$ and $\mathrm{A}_{2}$ values are higher and some are lower, the potential dose following an accident is the same as with the previous $A_{1}$ and $A_{2}$ values. The revised dosimetric models are used internationally to calculate doses from individual radionuclides, and these refinements in the pathway calculations result in various changes to the $A_{1}$ and $A_{2}$ values. In other words, where an $A_{1}$ or $A_{2}$ value has increased, the potential dose is still the same- the use of the revised dosimetric models just shows that a higher activity of that radionuclide is actually required to produce the same reference dose. Conversely, where an $\mathrm{A}_{1}$ or $\mathrm{A}_{2}$ value has decreased, the revised models show that less activity of that nuclide is needed to produce the reference dose.

"Discussion. Comments on the adoption of the new $A_{1}$ and $A_{2}$ values were received during the three public meetings and on the NRC website. One commenter [sic] stated that to conduct business internationally, there needs to be consistency between the international and domestic regulations. These commenters [sic] supported the adoption of the new values into Part 71. Other industry representatives, however, indicated the values should not change as they would need to modify the computer codes at their facility to maintain the ability to accurately meet the regulatory requirements for transportation. Other commenters [sic] were concerned about the safety aspects of transportation and the emergency responder's exposure if the new values should be adopted.

"Additional comments were received concerning the $A_{1}$ and $A_{2}$ values for californium-252 and molybdenum-99, respectively. Currently, in Part 71, the $\mathrm{A}_{1}$ for californium-252 is $0.1 \mathrm{TBq}(2.7 \mathrm{Ci})$. The $\mathrm{A}_{1}$ value in TS-R-1 is $5.0 \times 10^{-2} \mathrm{TBq}(1.35 \mathrm{Ci})$. Both $\mathrm{NRC}$ and DOT have learned that IAEA is considering changing the $A_{1}$ value for californium-252 back to the value currently in 10 CFR Part 71 and 49 CFR in the next edition of TS-R-1. DOT is proposing to retain the current Part $71 A_{1}$ value for californium-252 for domestic commerce. Therefore the NRC is planning to do the same as a conforming action with DOT.

"Regarding molybdenum-99, comments were received from the radiopharmaceutical industry concerning the $A_{2}$ value. Currently in Part 71 , the $A_{2}$ value for molybdenum-99 is $0.5 \mathrm{TBq}(13.5 \mathrm{Ci})$. Further, in Appendix A, Table A-1, the $\mathrm{A}_{2}$ value for molybdenum-99 has a footnote that indicates for domestic use, the $A_{2}$ value is $0.74 \mathrm{TBq}(20 \mathrm{Ci})$.
Pharmaceutical industry representatives indicated that a change to the TS-R-1 $\mathrm{A}_{2}$ value of $0.6 \mathrm{TBq}(16.2 \mathrm{Ci})$ for molybdenum-99 would result in a significant increase in the number of packages shipped and in occupational doses due to the lower $\mathrm{A}_{2}$ value $(16.2 \mathrm{Ci}$ versus $20 \mathrm{Ci}$ ). DOT is proposing to retain the current exception for molybdenum-99 for domestic commerce, and NRC also believes the current exception for this radionuclide should be retained.

"Several commenters [sic] opposed NRC's proposal to adopt the IAEA $\mathrm{A}_{1}$ and $\mathrm{A}_{2}$ values, arguing that any increase in allowable activity levels is unacceptable, could result in increased risk, and would violate the principle of maintaining safety. One commenter [sic] stated that the proposed adoption would change from an activity-based limit system to a dose-based limit system, which is unacceptable because dose-based limits are more difficult to verify and enforce than are activity-based limits.

"Several commenters [sic] stated that NRC should provide a breakdown of which radionuclides would have increased activity levels, and which would remain the same, to allow for meaningful public comment on the proposed change.

"Several commenters [sic] indicated that adoption of ICRP-60 into NRC regulations would result in another inconsistency within the regulations. Another commenter [sic] disagreed, arguing that NRC runs the risk of eroding public confidence in its regulatory role by accepting, then ignoring, the advice of international experts. The commenter [sic] argued that there should be a very strong justification if recommendations of the ICRP are to be discounted.

"In general, the new $\mathrm{A}_{1}$ and $\mathrm{A}_{2}$ values are within a factor of about three of the earlier values; there are a few radionuclides where the new $A_{1}$ and $A_{2}$ values are outside this range. $\mathrm{A}$ few tens of radionuclides (out of more than 300) have new $A_{1}$ values higher than previous values by factors ranging between 10 and 100. This is due mainly to improved modeling for beta emitters. There are no new $\mathrm{A}_{1}$ or $\mathrm{A}_{2}$ values that are lower than the previous figures by more than a factor of 10. A few radionuclides previously listed are now excluded, but two additional ones have been added, both isomers of europium-150 and neptunium-236. Many $A_{1}$ and $A_{2}$ values remain unchanged.

"The NRC staff review of TS-R-1 against the current Part 71 has identified 16 radionuclides that are listed in Table A-1 in Part 71 Appendix A, but which do not appear in TS-R-1. These are: Ar-42, Au-196, Es-253, Es-254, Es-254m, Es-255, Fm-255, Fm-257, Ho-163, Ir-193m, Nb-92m, Po-208, Po-209, Re-183, Te-118, and Tm-168. In an effort to maintain compatibility with TS-R-1, the NRC proposes not to include $A_{1}$ and $A_{2}$ values for these radionuclides in Table A-1. Licensees can use, without NRC approval, the general values for $A_{1}$ or $A_{2}$ in Table A-3 for individual radionuclides whose identities are known (such as the above 16), but which are not 
listed in Table A-1. Alternatively, licensees can obtain NRC approval for using specific values for those radionuclides. The NRC staff consulted with the DOT staff on this issue, and DOT is also proposing not to include $A_{1}$ and $A_{2}$ values for these radionuclides in its revised table of $\mathrm{A}_{1}$ and $\mathrm{A}_{2}$ values.

"The $A_{1}$ and $A_{2}$ values were revised by IAEA based on refined modeling of possible doses from radionuclides. The NRC staff believes adoption of the IAEA standard would be an overall benefit to public and worker health and international commerce by ensuring that the $A_{1}$ and $A_{2}$ values are consistent within and between international and domestic transportation regulations.

"The NRC draft RA indicates that adopting the new $A_{1}$ and $A_{2}$ activity limits specified in TS-R-1 is appropriate from a safety, regulatory, and cost perspective. Adoption of these values would result in enhanced regulatory efficiency for the NRC and consistency among NRC, IAEA, and DOT, especially in the handling of imports and exports. Adoption would result in a single set of values for determining the activity limits for specifying the amount of radioactive material permitted to be transported in a particular package for both domestic and international shipments. In some cases, NRC believes that this increase in regulatory efficiency and potential cost savings more than offsets the potential increased costs. These costs are anticipated to include revisions to shipping programs to implement the new values, modifications to shipping processes to assure compliance with the new values, and training. These costs, however, are expected to be minor because industry already has programs in place that use the $A_{1}$ and $A_{2}$ values. In addition, $\mathrm{NRC}$ would realize additional minor implementation costs in revising the values in Part 71. The NRC draft RA indicated no significant change in the number of shipments per year; therefore, accident frequency would not be affected.

"NRC Proposed Position. The NRC is proposing to make a conforming change to Part 71 to adopt the new $A_{1}$ and $A_{2}$ values from TS-R-1 in Part 71, with the differences as discussed for molybdenum-99 and californium-252. The NRC is also proposing not to include $A_{1}$ and $A_{2}$ values for the 16 radionuclides that are currently listed in Part 71 , but which do not appear in TS-R-1 (see the Discussion section of Issue 3 ). This action would allow for continued consistency within and between international and domestic transportation regulations for radioactive materials. The DOT is also proposing to adopt the new TS-R-1 $A_{1}$ and $A_{2}$ values in its regulations, but without the 16 radionuclides cited above. NRC is requesting stakeholder input with regard to the changes focused around the $A_{1}$ and $A_{2}$ values for californium-252, molybdenum-99, and the 16 radionuclides that will be removed from
Table A-1. NRC is interested in learning what impacts these changes will have on industry.

"Affected Sections. Appendix A.

"Issue 4. Uranium Hexafluoride Package Requirements

"Background. Requirements for uranium hexafluoride $\left(\mathrm{UF}_{6}\right)$ packaging and transportation are found in both NRC and DOT regulations. The DOT regulations contain requirements that govern many aspects of $\mathrm{UF}_{6}$ packaging and shipment preparation, including a requirement that the $\mathrm{UF}_{6}$ material be packaged in cylinders that meet the ANSI N14.1 standard. NRC regulations address fissile materials and Type $\mathrm{B}$ packaging designs for all materials.

"TS-R-1 contains detailed requirements for $\mathrm{UF}_{6}$ packages designed for transport of more ... than $0.1 \mathrm{~kg} \mathrm{UF} 6$. First, TS-R-1 requires the use of the International Organization for Standardization (ISO) 7195, 'Packaging of Uranium Hexafluoride for Transport.' Second, TS-R-1 requires that all packages containing more than $0.1 \mathrm{~kg} \mathrm{UF}_{6}$ must meet the 'normal conditions of transport' drop test, a minimum internal pressure test, and the hypothetical accident condition thermal test (para 630). However, TS-R-1 does allow a competent national authority to waive certain design requirements, including the thermal test for packages designed to contain greater than $9,000 \mathrm{~kg} \mathrm{UF}$, provided that multilateral approval is obtained. Third, TS-R-1 prohibits $\mathrm{UF}_{6}$ packages from using pressure relief devices (para 631). Fourth, TS-R-1 includes a new exception for $\mathrm{UF}_{6}$ packages regarding the evaluation of criticality safety of a single package. This new exception (para 677(b)) allows $U_{6}$ packages to be evaluated for criticality safety without considering the inleakage of water into the containment system. Consequently, a single fissile $\mathrm{UF}_{6}$ package does not have to be subcritical assuming that water leaks into the containment system. This provision only applies when there is no contact between the valve body and the cylinder body under accident tests, and the valve remains leak-tight, and when there are quality controls in the manufacture, maintenance, and repair of packagings coupled with tests to demonstrate closure of each package before each shipment.

"Discussion. One commenter [sic] indicated serious concerns about the safety margins for $\mathrm{UF}_{6}$ packaging. The commenter [sic] cited the exception in TS-R-1, paragraph $677(\mathrm{~b})$, which would allow $\mathrm{UF}_{6}$ packages to be evaluated for criticality without considering the inleakage of water. The commenter [sic] cited a report describing one case where $\mathrm{UF}_{6}$ packages with manufacturing defects were used. The commenter [sic] indicated that it would be imprudent and unwise public policy to assume that water could not leak into a package containing $\mathrm{UF}_{6}$.

"Another commenter [sic] stated that a justification for the reduced regulatory burden has not been 
established and cannot be done unless a risk study, which determines the level of conservatism currently contained in Part 71, is conducted. Without this analysis, the commenter [sic] argued, reduction of regulatory burden leading to inadvertent criticality could lead to loss of life, degradation of the environment, economic repercussions, and degradation of public confidence.

"Also, comments at the public meetings supported the NRC view that ANSI N14.1 and ISO 7195 are equivalent. Further, other comments indicated that NRC-certified $\mathrm{UF}_{6}$ packages already comply with TS-R-1 paragraphs 630 and 677(b).

"The provisions of $\S 71.55(\mathrm{~b})$ specify that a fissile material package must be designed, or the contents limited, so that a single package would be critically safe if water were to leak into the containment vessel. This is a design feature that assures criticality safety in transport, in the unanticipated event that water leaks into the containment vessel, and provides moderating materials for the fissile contents. The proposed new $\S 71.55(\mathrm{~g})$ would except fissile $\mathrm{UF}_{6}$ from the requirement that a single package must be critically safe with water inleakage. This is consistent with the worldwide practice in shipping fissile $\mathrm{UF}_{6}$ and is consistent with ANSI N14.1 and ISO 7195 standards and DOT regulations.

"The proposed rule language further restricts use of the exception to a maximum enrichment of 5 weight percent uranium-235. This is the maximum enrichment currently authorized in ANSI N14.1, ISO 7195, and DOT regulations in cylinders larger than $20.3 \mathrm{~cm}$ (8 inches) in diameter. For smaller cylinders, the exception is not needed because current enrichments are critically safe by geometry for a single package. The exception, with the enrichment limit, codifies current worldwide practice in shipping fissile uranium hexafluoride. Large quantities of enriched (greater than 5 weight percent uranium-235) $\mathrm{UF}_{6}$ would require packages that meet the water inleakage standards in $\S 71.55(\mathrm{~b})$. The staff believes that it is not prudent to expand this exception to include $\mathrm{UF}_{6}$ shipments with higher uranium enrichments.

"The NRC draft RA indicates that revising the current requirements for uranium hexafluoride packages to include an exception from the requirement that single packages must be critically safe from water inleakage is appropriate from a safety, regulatory, and cost perspective. In developing the draft RA, the NRC first determined that there are no substantial differences between [the] ANSI N14.1 standard and [the] ISO 7195 standard for $\mathrm{UF}_{6}$ packaging, and therefore, there would be no significant cost impacts from this change, because NRC currently requires conformance with ANSI N14.1, but regulatory efficiency would be enhanced by making Part 71 compatible with TS-R-1. The internal pressure test and drop test requirements are currently met by existing package designs that comply with
ANSI N14.1. Therefore, there would be limited impact on licensees by this aspect of the NRC action. The NRC staff also considered the United States' earlier opposition (Taylor, 1996) to this change, i.e., the IAEA adopting the $\mathrm{UF}_{6}$ package requirements. Most of the impact of adopting the TS-R-1 $\mathrm{UF}_{6}$ provisions would fall on the 30 -inch and 48 -inch bare cylinders that are within the purview of DOT and for which there is a 'multilateral' approval option that could be used to mitigate most of this potential impact to licensees. Therefore, the adoption of the TS-R-1 requirements is not expected to have significant impact on fissile package designs for $\mathrm{UF}_{6}$. (Additional minor costs may be incurred for training for handling overpacks.) Because the changes are not expected to have significant impacts on current package designs, changes in environmental impacts are expected to be negligible.

"NRC Proposed Position. The NRC is proposing to adopt $\S 71.55(\mathrm{~g}) \quad$ to address TS-R-1, paragraph $677(\mathrm{~b})$, to exempt certain UF6 packages from the requirements of $\S 71.55(\mathrm{~b})$. The requirements in TS-R-1, paragraphs 629, 630, and 631, do not necessitate changes to Part 71 because NRC uses analogous national standards and addresses package design requirements in its design review process. All NRC-certified packages must be used in accordance with DOT requirements (including the $\mathrm{UF}_{6}$ requirement in 49 CFR 173.420).

"Affected Sections. § 71.55.

"Issue 5. Introduction of the Criticality Safety Index Requirements

"Background. Historically, the IAEA and U.S. regulations (both NRC and DOT) have used a term known as the Transport Index (TI) to determine appropriate safety requirements during transport. TI has been used to control the accumulation of packages for both radiological safety and criticality safety purposes and to specify minimum separation distances from persons (radiological safety). The TI has been a single number which is the larger of two values: the 'TI for criticality control purposes'; and the 'TI for radiation control purposes.' Taking the larger of the two values has ensured conservatism in limiting the accumulation of packages in conveyances and in-transit storage areas.

"TS-R-1 (paragraph 218) has introduced the concept of a Criticality Safety Index (CSI) separate from the old TI. As a result, the TI was redefined in TS-R-1. The CSI is determined in the same way as the 'TI for criticality control purposes,' but now it must be displayed on shipments of fissile material (paragraphs 544 and 545) using a new 'fissile material' label. The redefined TI is determined in the same way as the 'TI for radiation control purposes' and continues to be displayed on the traditional 'radioactive material' label.

"TS-R-1 (paragraph 530) also increased the allowable per package TI limit [for criticality control purposes 
(new CSI)] from 10 to 50 for nonexclusive use shipments. No change was made to the per package radiation TI limit of 10 for nonexclusive use shipments. As noted above, a consolidated radiation safety and criticality safety index existed in the past. In this consolidated index, the per package TI limit of 10 was historically based on concerns regarding the fogging of photographic film in transit, because film might also be present on a nonexclusive use conveyance. Consequently, when the single radiation and criticality safety indexes were split into the TI and CSI indexes, the IAEA determined that the CSI per package limit, for fissile material packages that are shipped on a nonexclusive use conveyance, could be raised from 10 to 50 . The IAEA believed that limiting the total CSI to less than or equal to 50 in a nonexclusive use shipment provided sufficient safety margin, whether the shipment contains a single package or multiple packages. Therefore, the per package CSI limit, for nonexclusive use shipments, can be safely raised from 10 to 50 , thereby providing additional flexibility to shippers. Additionally, no change was made to the per package CSI limit of 100 for exclusive use shipments.

"Discussion. Comments received on this proposal indicated that the industry supports the use of the new label 'CSI' in conjunction with the 'TI' labels, and stated that separate labels are more meaningful and provide additional safety in transport, as long as the two labels are distinctive, so as to avoid confusion.

"In general, public comments received at the meetings supported the use of the CSI. One commenter [sic] believed that using the TI as the means to control criticality safety does not provide emergency responders with information on the undamaged condition of the package. Other commenters [sic] suggested that NRC should provide the underlying technical justification for the term 'equivalent safety,' because otherwise, this change would seemingly allow for more packages in a single shipment. The use of CSI provides an equivalent level of safety to using a TI, because the CSI uses the same methodology ( $\S 71.59)$ that was used to calculate the criticality portion of the current TI.

"One industry commenter [sic] disagreed that the CSI requirement is appropriate. The commenter [sic] stated that the TI already incorporates the more restrictive value and provides adequate protection. The commenter [sic] believed there is no increase in safety by adding this new requirement and, in fact, it would result in more opportunities for human error. Further, the commenter $[\mathrm{sic}]$ indicated that any benefit for adding the CSI is far outweighed by the additional labor, material, training, and administration costs that would be borne by a company that ships thousands of packages each year.

"Increasing the CSI per package limit from 10 to 50 for nonexclusive use shipments was overlooked by NRC staff and was not discussed in the June 2000
Issues Paper or the associated public meetings. Consequently, no stakeholder input was obtained on this aspect of Issue 5 prior to developing the proposed rule.

"The NRC draft RA indicates that introducing new CSI requirements into part 71 is appropriate from a safety, regulatory, and cost perspective. NRC would require that applicants for fissile material package design approvals clearly indicate the CSI value for the design. The CoCs the NRC issues for these designs would also need to clearly indicate the CSI value for authorized contents. The adoption of the CSI values would make part 71 consistent with TS-R-1, therefore enhancing regulatory efficiency.

"The NRC staff believes that shipping fissile material packages on either an exclusive or nonexclusive use conveyance provides a reasonable assurance that public health and safety and the environment will be adequately protected. Furthermore, shipment on a nonexclusive use conveyance of a single package with a CSI equal to 50, a shipment of 5 packages each with a CSI equal to 10 , or 20 packages each with a CSI equal to 2.5, are all safe and provide reasonable assurance of adequate protection. While NRC staff recognizes that the reactivity per package will increase with an increase in the CSI from 10 to 50 , staff also believes the limit on the total CSI in a nonexclusive use shipment provides adequate protection against mishandling events. Accordingly, this change will not have a significant safety impact.

"The total annual estimated cost of the new label to the nuclear power licensees and material licensees is approximately $\$ 1.4$ million. ${ }^{\S}$ Some of these costs would be offset by the fact that for some shipments of fissile material packages, the accumulation of packages for criticality control purposes and the accumulation of packages (including minimum separation distances from persons) for radiological control purposes are shipped independently (the most restrictive criteria would not control the other as is the case with the current dual-use TI). Further, increased efficiency in shipping some fissile material packages could occur by avoiding the situation where separation distance requirements (radiological safety) unduly restrict package accumulation (criticality safety). From a health and safety perspective, emergency responders in accident circumstances (thus public health and safety) benefit from more clearly displayed information upon arrival at the accident scene.

$\S \S \quad$ "This number is estimated by assuming 10 percent of the approximately 2.8 million total annual shipments (or 280,000) contain fissile material requiring labels [sic] indicating the CSI and TI. And of this 10 percent, NRC assumes five packages per shipment and \$1 per package for labeling, thus arriving at the $\$ 1.4$ million total annual licensee costs." (This footnote was part of the original citation.) 
"The NRC staff was unable to estimate the magnitude of the impact or cost savings that would arise to licensees due to the increase in the CSI per package limit. However, staff judged that cost savings could be realized because of increased licensee flexibility in shipping a larger number of fissile material packages on less expensive, nonexclusive use conveyances. Therefore, the NRC is requesting stakeholder input on the quantity of shipments in a typical year that would be affected by an increase in the per package CSI limit from 10 to 50 for nonexclusive use shipments and any associated cost savings. Because of lack of data, the NRC is also requesting stakeholder input on the current number of fissile material shipments typically made per year (i.e., fissile-exempt, fissile general license, or Type $A(F)$ or $\mathrm{B}(\mathrm{F})$ packages); the types of material shipped (e.g., waste, laboratory quantities, or production quantities); the shipment method used for these types of fissile material; and whether these are exclusive or nonexclusive use shipments.

"NRC Proposed Position. The NRC proposes to adopt the TS-R-1 (paragraph 218) which incorporates a CSI in Part 71 that would be determined in the same manner as the current Part 71 'TI for criticality control purposes.' The NRC also proposes to adopt TS-R-1 (paragraph 530) which increases the CSI per package limit from 10 to 50 for fissile material packages in nonexclusive use shipments. A TI will be determined in the same way as the 'TI for radiation control purposes.' The NRC believes the differentiation between criticality control and radiation protection would better define the hazards associated with a given package and, therefore, provide better package hazard information to emergency responders. The increase in the per package CSI limit may provide additional flexibility to licensees by permitting the increased use of lessexpensive, nonexclusive use shipments. However, licensees will still retain the flexibility to ship a larger number of packages of fissile material on an exclusive use conveyance.

“Affected Sections. §§ 71.4, 71.18, 71.20, 71.59.

"Issue 6. Type C Packages and Low Dispersible Material

"Background. TS-R-1 has introduced two new concepts: the Type C package (paragraphs 230, 667-670, 730, 734-737) and the Low Dispersible Material (LDM). The Type C packages are designed to withstand severe accident conditions in air transport without loss of containment or significant increase in external radiation levels. The LDM has limited radiation hazard and low dispersibility; as such, it could continue to be transported by aircraft in Type B packages (i.e., LDM is excepted from the TS-R-1 Type C package requirements). U.S. regulations do not contain a Type $C$ package or LDM category, but do have specific requirements for the air transport of plutonium ( $\S 71.64$ and 71.74).
These specific NRC requirements for air transport of plutonium would continue to apply.

"The Type $\mathrm{C}$ requirements apply to all radionuclides packaged for air transport that contain a total activity value above $3,000 \mathrm{~A}_{1}$ or $100,000 \mathrm{~A}_{2}$, whichever is lesser, for special form material, or above $3,000 \mathrm{~A}_{2}$ for all other radioactive material. Below these thresholds, Type B packages would be permitted to be used in air transport. The Type $\mathrm{C}$ package performance requirements are significantly more stringent than those for Type B packages. For example, a 90 -meter per second $(\mathrm{m} / \mathrm{s})$ impact test is required instead of the 9-meter drop test. A 60-minute fire test is required instead of the 30-minute requirement for Type B packages. There are other additional tests, such as a puncture/tearing test, imposed for Type $\mathrm{C}$ packages. These stringent tests are expected to result in package designs that would survive more severe aircraft accidents than Type B package designs.

"The LDM specification was added in TS-R-1 to account for radioactive materials (package contents) that have inherently limited dispersibility, solubility, and external radiation levels. The test requirements for LDM to demonstrate limited dispersibility and leachability are a subset of the Type $\mathrm{C}$ package requirements $(90-\mathrm{m} / \mathrm{s}$ impact and 60 -minute thermal test) with an added solubility test, and must be performed on the material without packaging for nonplutonium materials. The LDM must also have an external radiation level below $10 \mathrm{mSv} / \mathrm{hr}$ $(1 \mathrm{rem} / \mathrm{hr})$ at 3 meters. Specific acceptance criteria are established for evaluating the performance of the material during and after the tests (less than $100 \mathrm{~A}_{2}$ in gaseous or particulate form of less than 100-micrometer aerodynamic equivalent diameter and less than $100 \mathrm{~A}_{2}$ in solution). These stringent performance and acceptance requirements are intended to ensure that these materials can continue to be transported safely in Type B packages aboard aircraft.

"In 1996, the NRC communicated to the IAEA that the NRC did not oppose the IAEA adoption of the newly created Type $\mathrm{C}$ packaging standards (letter dated May 31, 1996, from James M. Taylor, EDO, $\mathrm{NRC}$, to A. Bishop, President, Atomic Energy Control Board, Ottawa, Canada). However, Mr. Taylor stated in the letter that to be consistent with U.S. law, any plutonium air transport to, within, or over the U.S. will be subject to the more rigorous U.S. packaging standards.

"Discussion: Comments from the public suggested that Type $\mathrm{C}$ standards might increase the number of shipments with smaller quantities of material using the same Type B containers to avoid the cost of developing Type $\mathrm{C}$ packages and to avoid the requirement of meeting the new Type $\mathrm{C}$ package standards. One commenter [sic] indicated that any proposal to change package design requirements should only be contemplated after a thorough 
technical review that has independently justified the change as protective.

"However, one commenter [sic] stated that NRC should remove from its regulations the plutoniumspecific requirements for air transport, and replace them with the Type $\mathrm{C}$ package requirements. Also, the commenter $[$ sic] stated that because Type C package development would take a number of years, industry would work with the NRC to define tests, analyses, and criteria for demonstrating compliance with the Type $\mathrm{C}$ package standards.

"One commenter [sic] questioned the rigorousness of the testing described in TS-R-1, indicating that the minimum acceptable impact speed should be increased to at least $129 \mathrm{~m} / \mathrm{s}$, as was mandated by Congress.

"The staff evaluated the Type C package, and proposes that the NRC not adopt Type C or LDM requirements at this time. The bases for this staff proposal include: (1) IAEA development of aircraft accident severity information through a coordinated research project for further evaluation of the Type $\mathrm{C}$ and LDM requirements; (2) the fact that there are very few anticipated shipments affected by these requirements; (3) DOT rules that permit the use of IAEA standards in nonplutonium import/export shipments of foreign certified Type $\mathrm{C}$ containers, so that international commerce is not impacted; (4) NRC's domestic regulations currently in place ( $§ 71.64$ and 71.74), based on specific statutory mandates, governing air transport of plutonium (plutonium air transport was a considerable factor in IAEA adoption of Type $\mathrm{C}$ provisions); and (5) comments made by the public on the issues which generally disagreed with or questioned the rigor of the Type $\mathrm{C}$ tests, and supported NRC maintaining its current regulatory requirements for the safety of plutonium air shipments.

"The DOT reviews the use of packages for import or export shipment. Consequently, foreign Type C packages could be approved by DOT for import and export only. The NRC does not believe that a Type $\mathrm{C}$ package is needed for domestic commerce; therefore, no provisions would be added to Part 71 relating to Type C packages. However, should DOT request that NRC perform a technical evaluation for a revalidation of a foreign Type $\mathrm{C}$ package design, NRC would evaluate the design against TS-R-1 Type C standards. Similarly, if requested by DOT, NRC would review a domestic Type $C$ package design intended for use in international commerce against TS-R-1, and provide NRC's recommendation to DOT. (Note that NRC revalidation of designs for DOT does not constitute NRC issuance of a CoC.)

"The NRC draft RA indicates that not adopting the TS-R-1 Type C or LDM provisions in Part 71 is appropriate from a safety, regulatory, and cost standpoint. There may be some reduction in regulatory efficiency as a result of the nonadoption of the TS-R-1 requirements, which could result in NRC case-by-case reviews to support international shipments. NRC would continue to use its proven, safe regulatory requirements for air transport of plutonium. Further, NRC staff resources are conserved by nonadoption, and no additional costs would be incurred by industry. Any additional costs to industry would involve development costs for the design of new packages to meet the Type $\mathrm{C}$ requirements rather than using existing Type B packages.

"NRC Proposed Position. The NRC would not adopt Type $\mathrm{C}$ or LDM requirements at this time.

"Affected Sections. None (not adopted).

"Issue 7. Deep Immersion Test

"Background. TS-R-1 expanded the performance requirement for the deep water immersion test (paragraphs 657 and 730) from the requirements in the IAEA Safety Series No. 6, 1985 edition. Previously, the deep immersion test was only required for packages of irradiated fuel exceeding $37 \mathrm{PBq}(1,000,000 \mathrm{Ci})$. The deep immersion test requirement is found in Safety Series No. 6, paragraphs 550 and 630, and basically stated that the test specimen be immersed under a head of water of at least 200 meters $(660 \mathrm{ft})$ for a period of not less than one hour, and that an external gauge pressure of at least $2 \mathrm{MPa}$ (290 psi) shall be considered to meet these conditions. The TS-R-1 expanded immersion test requirement (now called enhanced immersion test) now applies to all Type $\mathrm{B}(\mathrm{U})$ [Unilateral] and $\mathrm{B}(\mathrm{M})$ [Multilateral] packages containing more than $10^{5} \mathrm{~A}_{2}$, as well as Type $\mathrm{C}$ packages.

"In its September 28, 1995 (60 FR 50248), rulemaking for Part 71 compatibility with the 1985 edition of Safety Series No. 6, the NRC addressed the new Safety Series No. 6 requirement for spent fuel packages by adding $\S 71.61$, 'Special requirements for irradiated nuclear fuel shipments.' Currently, $\S 71.61$ is more conservative than Safety Series No. 6 with respect to irradiated fuel package design requirements. It requires that a package for irradiated nuclear fuel with activity greater than $37 \mathrm{PBq}$ $\left(10^{6} \mathrm{Ci}\right)$ must be designed so that its undamaged containment system can withstand an external water pressure of $2 \mathrm{MPa}$ (290 psi) for a period of not less than one hour without collapse, buckling, or inleakage of water. The conservatism lies in the test criteria of no collapse, buckling, or inleakage as compared to the 'no rupture' criteria found in Safety Series No. 6 and TS-R-1. The draft advisory document for TS-R-1 (TS-G-1.1, paragraphs 657.1 to 657.7) recognizes that leakage into the package and subsequent leakage from the package are possible while still meeting the IAEA requirement.

"The Safety Series No. 6 test requirements were based on risk assessment studies that considered the possibility of a ship carrying packages of radioactive 
material sinking at various locations. The studies found that, in most cases, there would be negligible harm to the environment if a package were not recovered. However, should a large irradiated fuel package (or packages) be lost on the continental shelf, the studies indicated there could be some long term exposure to man through the food chain. The 200-meter (660-ft) depth specified in Safety Series No. 6 is equivalent to a pressure of $2 \mathrm{MPa}$ (290 psi), and roughly corresponds to the continental shelf and to depths that the studies indicated radiological impacts could be important. Also, 200 meters (660 ft) was a depth at which recovery of a package would be possible, and salvage would be facilitated if the containment system did not rupture. (Reference Safety Series No. 7, paragraphs E-550.1 through E-550.3.)

"The expansion in scope of the deep immersion test was due to the fact that radioactive materials, such as plutonium and high-level radioactive wastes, are increasingly being transported by sea in large quantities. The threshold defining a large quantity as a multiple of $\mathrm{A}_{2}$ is considered to be a more appropriate criterion to cover all radioactive materials, and is based on a consideration of potential radiation exposure resulting from an accident.

"Discussion. Several comments received at the public meetings, as well as written comments received on the Issues Paper, indicated support for retaining the current, more stringent, requirements contained in $\S 71.61$ with respect to not allowing collapse, buckling, or inleakage of water in the containment vessel. One commenter [sic] was concerned that the term 'rupture' seemed less stringent than 'collapse, buckling, or inleakage of water.' The commenter [sic] noted, however, that the issues paper does not include definitions for 'rupture' or 'buckling,' so it is difficult to know which term is more or less stringent. Another commenter [sic] believed that the proposed test requirement of withstanding underwater pressure for at least an hour is insufficient. The commenter [sic] explained that it is unrealistic to expect to recover nuclear materials from the water within 1 hour after a major accident.

"One commenter [sic] questioned whether there was sufficient technical justification for relaxing the current NRC test criteria for packages of irradiated nuclear fuel. The commenter [sic] stated that a lot of environmental damage can occur before a rupture develops, and that the proposal does nothing to ensure that packages are as safe as they can be.

"Another commenter [sic] noted that TS-R-1 refers only to normal form material for the immersion test. Specifically, the commenter [sic] asked what the criteria are for a special form $A_{1}$ quantity, and whether the deep immersion test was necessary for $\mathrm{B}(\mathrm{U})$ packages for special form materials. NRC reviewed the IAEA regulations and believes that this requirement applies to both normal form and special form material. Similarly, one commenter [sic] noted that, in practicality, the quantities listed would be limited to irradiated fuel elements, and that shipment of radioisotopes rarely contain these amounts. This commenter [sic] suggested that the present criteria be maintained and extended to cover all packages with activity levels greater than or equal to $10^{5} \mathrm{~A}_{2}$ quantities with the note that this is more conservative than TS-R-1 requirements. The commenter [sic] stated this should eliminate the requirement for special review and certification of U.S. origin package designs. For nonirradiated fuel element shipments, the commenter [sic] believed there should be no impact on availability and shipping costs because there are few shipments of the required quantities of this material. Finally, the commenter [sic] questioned whether, with the application to $\mathrm{B}(\mathrm{U})$ packages containing $A_{1}$ special form sources, these packages are exempt from this test.

"In response to the question about how to address the differences in acceptance standards, two commenters [sic] stated that due to the international nature of transportation activities, U.S. transportation regulations should be consistent with IAEA transportation regulations and, therefore, NRC should adopt the TS-R-1 requirements for the enhanced deep immersion test.

"Two commenters [sic] also addressed whether U.S. origin package designs should be specifically reviewed and certified before shippers can export them. One commenter [sic] said that if the response is not specific to the deep immersion test, but applies to all package design criteria, then the shipment of U.S. certified package designs for import/export use beginning in mid-2001 is entirely dependent upon approval of these designs to TS-R-1 performance standards. The commenter [sic] believed that failure to grant U.S. Competent Authority certifications for these designs would seriously hinder the industrial radiography industry, and place U.S. package designers and manufacturers at a strong competitive disadvantage. The commenter [sic] added that several of its shipments were not acceptable in several countries when NRC and DOT failed to adopt Safety Series No. 6 in a timely manner.

"Another commenter [sic] stated that NRC should clarify if previously approved packages would be grandfathered, or if they would have to be recertified by means of a deep immersion test.

"The NRC proposes revising Part 71 requiring an enhanced water immersion test for packages used for radioactive contents with activity greater than $10^{5} \mathrm{~A}_{2}$. Section 71.61 currently refers to packages for irradiated fuel with activity greater than $37 \mathrm{PBq}$ $\left(10^{6} \mathrm{Ci}\right)$; the water immersion test would need to be changed to apply to Type $\mathrm{B}$ packages containing greater than $10^{5} \mathrm{~A}_{2}$ and Type $\mathrm{C}$ packages. Given that any package containing spent fuel with activity greater than $37 \mathrm{PBq}\left(10^{6} \mathrm{Ci}\right)$ would also have an activity significantly greater than $10^{5} \mathrm{~A}_{2}$, such a change would bound Type $\mathrm{B}$ spent fuel packages 
currently addressed in 10 CFR 71.61. Therefore, a specific reference to special requirements for irradiated nuclear fuel shipments would no longer be required.

"As mentioned earlier, there is a difference between the test acceptance criteria specified in TS-R-1 and $\S 71.61$. Safety Series No. 6 refers to no rupture, while $\S 71.61$ requires no collapse, buckling, or inleakage of water when subjected to the test conditions. In the September 28, 1995, rulemaking, NRC staff provided justification for the more specific NRC acceptance criteria. The rulemaking stated that: "NRC has since determined that the term "rupture" cannot be determined by engineering analysis and that NRC has decided to change the acceptance criteria for the deep immersion test from "rupture" to "collapse, buckling, or inleakage of water".

"Given that the TS-R-1 background material does not provide any new information on defining the term 'rupture' from that provided for Safety Series No. 6, the NRC intends to retain the current interpretation of 'rupture' to mean 'collapse, buckling, or inleakage of water,' in any revision to $\S 71.61$. During the comment period for the proposed rule, should information be provided about how the term 'rupture' should be defined, or on how foreign countries have certified packages to this criterion, then the NRC will consider this in determining whether the 'collapse, buckling, or inleakage of water' criteria should be revised before issuing the final rule.

"The NRC draft RA indicates that revising Part 71 to require an enhanced water immersion test for packages used for radioactive contents with activity greater than $10^{5} \mathrm{~A}_{2}$ while retaining the current $\S 71.61$ interpretation of 'rupture' to mean 'collapse, buckling, or inleakage of water,' is appropriate from a safety, regulatory, and cost perspective. The proposed change would improve regulatory efficiency by bringing U.S. regulations in harmony with the standards contained in TS-R-1. This would improve the efficiency of handling imports and exports and would make U.S. standards compatible with other IAEA Members States.

"Implementation of the proposed change could result in costs to licensees as they test and certify packages to the proposed standard. The NRC may incur costs for developing procedures, reviewing and approving test results, and recertifying packages. The proposed change may reduce impacts to public health in the case of an accident. A package tested to the new requirements would be able to withstand pressure at increased depths without collapsing, buckling, or allowing inleakage of water, thereby keeping the radioactive materials enclosed. The likelihood of a member of the public receiving a dose from a package resting in deep water is exceedingly small and would be even smaller if the proposed change were implemented in that the test would apply to a broad range of packages. Moreover, the duration of the test, 1 hour, is reasonable for a package resting in deep water, because the water pressure will be constant, and the 1-hour test will clearly establish if the package can withstand that pressure. A successfully-tested package would be able to withstand the pressure at this depth without rupturing, thereby keeping the radioactive materials enclosed and permitting a reasonable length of time for recovery. Retaining package integrity would prevent the possible expenses of restricting the area (to prevent users such as boaters or fishers from entering the vicinity) and remediating any contamination of the marine environment.

"NRC Proposed Position. The NRC proposes to adopt the requirement for enhanced water immersion test for packages used for radioactive contents with activity greater than $10^{5} \mathrm{~A}_{2}$. The NRC intends to retain the current test requirements in $\S 71.61$ of 'one hour without collapse, buckling, or inleakage of water.'

“Affected Sections. $\S \S 71.41,71.51,71.61$.

"Issue 8. Grandfathering Previously Approved Packages

"Background. Historically, the IAEA, DOT, and NRC regulations have included transitional arrangements or 'grandfathering' provisions whenever the regulations have undergone major revision. The purpose of grandfathering is to minimize the costs and impacts of implementing changes in the regulations on existing package designs and packagings. Grandfathering typically includes provisions that allow: (1) Continued use of existing package designs and packagings already fabricated, although some additional requirements may be imposed; (2) completion of packagings that are in the process of being fabricated or that may be fabricated within a given time period after the regulatory change; and (3) limited modifications to package designs and packagings without the need to demonstrate full compliance with the revised regulations, provided that the modifications do not significantly affect the safety of the package.

"Each transition from one edition of the IAEA regulations to another (and the corresponding revisions of the NRC and DOT regulations) has included grandfathering provisions. The 1985 and 1985 (as amended 1990) editions of Safety Series No. 6 contained provisions applicable to packages approved under the provisions of the 1967, 1973, and 1973 (as amended) editions of Safety Series No. 6. TS-R-1 includes provisions which apply to packages and special form radioactive material approved under the provisions of the 1973, 1973 (as amended), 1985, and 1985 (as amended 1990) editions of Safety Series No. 6.

"TS-R-1 grandfathering provisions (see TS-R-1, paragraphs 816 and 817 ) are more restrictive than those previously in place in the 1985 and 1985 (as 
amended 1990) editions of Safety Series No. 6. The primary impact of these two paragraphs is that packagings approved under the 1967 edition of Safety Series No. 6 are no longer grandfathered, i.e., cannot be used. The second impact is that fabrication of packagings designed and approved under Safety Series No. 61985 (as amended 1990) must be completed by a specified date. In regard to special form radioactive material, TS-R-1 paragraph 818 does not include provisions for special form radioactive material that was approved under the 1967 edition of Safety Series No. 6. Special form radioactive material that was shown to meet the provisions of the 1973, 1973 (as amended), 1985, and 1985 (as amended 1990) editions of Safety Series No. 6 may continue to be used. However, special form radioactive material manufactured after December 31, 2003, must meet the requirements of TS-R-1. Within current NRC regulations, the provisions for approval of special form radioactive material are already consistent with TS-R-1.

"In TS-R-1, packages approved under Safety Series No. 61973 and 1973 (as amended) can continue to be used through their design life, provided the following conditions are satisfied: multilateral approval is obtained for international shipment, applicable TS-R-1 QA requirements and $\mathrm{A}_{1}$ and $\mathrm{A}_{2}$ activity limits are met, and, if applicable, the additional requirements for air transport of fissile material are met. While existing packagings are still authorized for use, no new packagings can be fabricated to this design standard. Changes in the packaging design or content that significantly affect safety require that the package meet current requirements of TS-R-1.

"TS-R-1 further states that those packages approved for use based on the 1985 or 1985 (as amended 1990) editions of Safety Series No. 6 may continue to be used until December 31, 2003, provided the following conditions are satisfied: TS-R-1 QA requirements and $A_{1}$ and $A_{2}$ activity limits are met and, if applicable, the additional requirements for air transport of fissile material are met. After December 31, 2003, use of these packages for foreign shipments may continue under the additional requirement of multilateral approval. Changes in the packaging design or content that significantly affect safety require that the package meet current requirements of TS-R-1. Additionally, new fabrication of this type packaging must not be started after December 31, 2006. After this date, subsequent package designs must meet TS-R-1 package approval requirements.

"Discussion. Industry representatives were concerned that IAEA is adopting a 2-year revision cycle to TS-R-1. From a design approval point of view, the regulatory requirements to be met may not be understood, and, as a new design requirement is approved, new revisions to the regulations could conceivably be developed. In other words, industry may always be playing catch up with the regulations.
"Previously, the IAEA standards permitted a package to be manufactured for two revision cycles of the IAEA standard. Because the IAEA standard was revised every 10 years, this equated to a 20 -year period. However, IAEA is now changing to a 2 -year revision cycle. Retaining the two-cycle provision would now equate to a 4-year allowable manufacturing period. This issue is under review by IAEA. Therefore, the NRC is proposing to specify in existing $\S 71.13$ when packages can no longer be manufactured or used, rather than using a 'tworevision cycle' approach.

"Additionally, a commenter [sic] expressed concern that beyond 2006, while packages could continue to be used under a valid $\mathrm{CoC}$, no new packages could be manufactured based on any edition of Safety Series 6 . Furthermore, all packages fabricated after December 31, 2006, would have to fully meet TS-R-1 requirements. The commenter $[$ sic $]$ stated that the licensing process for a package could be impacted. While NRC is aware and understands this concern, the proposed changes to $\S 71.13$ are adequate to address the potential limitation on fabrication and use.

"One commenter [sic] stated that the expense of designing and fabricating large Type $\mathrm{B}$ and spent fuel packages cannot be justified if the potential lifetime of the cask is limited to as short a period of time as 6 years. The commenter [sic] also believed that design and contents modifications should be allowed as specified in the current $\S 71.13(\mathrm{c})$. Conversely, one commenter [sic] stated that a 2-year updating cycle would force safety considerations in cask design up front, rather than continuing the attitude that casks be used as long as possible.

"Another commenter [sic] urged NRC to include a grandfathering provision for continued transportation of packages, such as NRC-approved packages and DOT specification packages. The commenter [sic] explained that if NRC did not have a grandfathering provision, NRC would have to set aside hundreds of long-term disposal sites for the various Type B quantity containers currently in use at hospitals and research institutions.

"Several commenters [sic] believed that grandfathering would allow the NRC to maintain an adequate level of safety for package designs. Some commenters [sic] stated that existing packages (even older ones) were safe and durable, because these packages must be maintained in accordance with the QA regulations of Part 71. Another commenter [sic] added that under current regulations, NRC may immediately recall a certification if a particular package created a safety concern.

"One commenter [sic] voiced support for the proposal, assuming new regulations would continue to be more strict. Two commenters [sic] believed that while it is important for more stringent requirements to apply to all existing containers, relaxed provisions would effectively make newer containers less safe. In these 
instances, the commenters [sic] preferred that the older provisions remain in effect, instead of the newer, relaxed provisions. One commenter [sic] opposed grandfathering existing packages, and stated as a concern the unknown safety of older packages.

"One commenter [sic] believed that NRC should incorporate specific requirements into the grandfathering provision to effectively maintain a good package program. The commenter [sic] explained that manufacturers of $\mathrm{CoC}$ containers or packages should be allowed to show, by calculations or testing, that upgraded standards and TS-R-1 have been achieved.

"One commenter [sic] stated that the shorter cycle would put pressure on cask designers to make safety a more important design element.

"In response to the question about the type and magnitude of package design changes that should be allowed for grandfathered packages before recertification is required, two commenters [sic] stated that TS-R-1 allows for a phase out of manufacturing of any packages that are not certified to the 1996 version of TS-R-1 by December 31, 2006. The commenters [sic] added that this provides a window for the design, testing, and certification of new packages, the reevaluation of existing packages to the 1996 specification, or a request for special certification.

"The NRC recognizes that when the regulations change there is not necessarily an immediate need to discontinue use of packages that were approved under previous revisions of the regulations. Part 71 has included provisions that would allow previouslyapproved designs to be upgraded and to be evaluated to the newer regulatory standards. NRC believes that packages approved under the provisions of the 1967 edition of Safety Series No. 6, and which have not been updated to later editions, may lack safety enhancements which have been included in the packages approved under the provisions of the 1973, 1973 (as amended), 1985 and 1985 (as amended 1990) editions of Safety Series No. 6. Therefore, the NRC believes that it is appropriate to begin a phased discontinuance of these earlier packages (1967-approved) to further improve transport safety.

"The following enhanced safety features have been included in NRC-certified designs approved to these later standards. The NRC revised 10 CFR Part 71 in 1983 for compatibility with the provisions of the 1973 edition of Safety Series No. 6 to include:

1. The introduction of the $\mathrm{A}_{1}$ and $\mathrm{A}_{2}$ system. Before the 1973 edition of Safety Series No. 6, the regulations were based on Transport Groups. The $A_{1}$ and $A_{2}$ system was intended to use a consistent safety basis for package contents based on radiological protection in transportation under normal and accident conditions.
2. Standards for defining acceptable containment system performance. The 1973 edition of Safety Series No. 6 included for the first time activity limits for loss of radioactive contents from Type B packages under normal conditions of transport and under hypothetical accident conditions. The containment system performance requirements were tied to the $A_{1}$ and $\mathrm{A}_{2}$ values, as described above.

3. The immersion test for Type A fissile material packages. The 1973 edition of Safety Series No. 6 required that the 15 -meter $(50-\mathrm{ft})$ water immersion test, previously required as a hypothetical accident test only for Type B packages, also be applied to fissile material packages. This immersion test is important in considering the degree of internal moderation (i.e., possible inleakage of water) in the criticality safety evaluation for fissile material packages in arrays.

4. Maximum normal operating pressure (MNOP). The 1973 edition of Safety Series No. 6 added a revised definition of MNOP. The definition for MNOP was included in Part 71 and specifically excluded consideration of package venting and active cooling systems.

5. Environmental test conditions. The 1973 edition of Safety Series No. 6 specified for the first time the high and low temperatures, pressures, and weights that should be considered when evaluating the package under normal and accident condition tests.

6. Quality Assurance (QA) requirements. The requirements to apply QA to the design, fabrication, and use of transportation packages were proposed in Part 71 in 1973. Although the IAEA regulations did not adopt QA requirements until the 1985 edition of Safety Series No. 6, NRC regulations required QA controls before IAEA adopted these provisions. QA program requirements are only imposed on packages approved for use after 1979. Packages approved under the 1973 edition of Safety Series No. 6 include QA in their design and fabrication, whereas, with a few exceptions (such as spent fuel casks), packages approved under earlier editions do not include QA program requirements.

"The NRC draft RA indicates that adopting the grandfathering provisions for packagings approved under the 1985 editions of Safety Series No. 6 (known as ' -85 ' packagings) and the associated expiration dates, is appropriate from a safety, regulatory, and cost perspective. From a regulatory standpoint, the proposed revisions would result in enhanced regulatory efficiency by bringing NRC's requirements in harmony with those contained in TS-R-1. 
"NRC does not currently have sufficient information to quantify the economic impacts of adopting this provision. The estimated costs to industry are not quantifiable due to a lack of sufficient data. However, industry is expected to bear costs associated with the need to redesign existing packages, address the reduction in availability of packages, and determine the years of service expected from the original design. Should NRC receive comments providing detailed information on the potential economic impacts to industry, the draft RA would be revised accordingly.

"The proposed change would also result in implementation costs of approximately $\$ 3,500$ to the NRC. The NRC would have to revise regulatory guides and NUREG-series documents to indicate which packages are covered by the 'grandfathering of older packages' provision. Further, the proposed change could result in implementation and operation costs of approximately $\$ 1,000$ to Agreement States if they adopt and implement parallel requirements. (The proposed change is not expected to affect implementation or operation costs of DOT.) Agreement States use regulatory guides and NUREG-series documents published by the NRC. Thus, Agreement States would only need to revise documents that they have specifically developed for their licensees (e.g., application materials). In terms of public health and safety, the existing and proposed requirements are believed to be equally protective. Thus, neither an increase nor a decrease in potential health and safety impacts is expected as a result of adopting the proposed administrative changes. Should the NRC become aware that a package or package design is unsafe, that package or design would be removed from service.

"NRC Proposed Position. NRC supports the update to grandfathering in TS-R-1 and is proposing to revise Part 71 to discontinue authorization to use packages approved under the provisions of the 1967 edition of Safety Series No. 6. Specifically, NRC is proposing to make modifications to existing $\S 71.13$ to phase out these types of packages. NRC realizes the impact this proposal may have on shipments using existing NRC-approved packages. Therefore, NRC proposes a 3-year transition period for the grandfathering provision on packages approved under the provisions of the 1967 edition of Safety Series No. 6. This period would provide industry the opportunity to phase out old packages and phase in new ones, or demonstrate that current requirements are met.

"For transitional arrangements for newer designs, $\mathrm{NRC}$ is proposing to incorporate into $\S 71.13(\mathrm{c})$ the provisions for packagings approved under the 1985 editions of Safety Series No. 6 (known as '-85' packagings) and the associated expiration dates. Additionally, paragraph (e) of $\S 71.13$ has been revised to specify the process by which previouslyapproved designs may be amended to include the '-96' designation.
"In summary, the following conditions would apply: (1) Packages approved under NRC standards that are compatible with the provisions of the 1967 edition of Safety Series No. 6 may no longer be fabricated, but may be used for a 3-year period after adoption of a final rule; (2) Packages approved under NRC standards that are compatible with the provisions of the 1973 or 1973 (as amended) editions of Safety Series No. 6 may no longer be fabricated; however, the proposed rule would not impose any restrictions on the use of these packagings; (3) Packages approved under NRC standards that are compatible with the provisions of the 1985 or 1985 (as amended 1990) editions of Safety Series No. 6, and designated as ' -85 ' in the identification number, may not be fabricated after December 31, 2006, but may continue to be used; (4) Package designs approved under any pre-1996 IAEA standards (i.e., packages with a ' -85 ' or earlier identification number) may be resubmitted to the NRC for review against the current standards. If the package design described in the resubmitted application meets the current standards, the NRC may issue a new $\mathrm{CoC}$ for that package design with a '-96' designation.

"Affected Sections. § 71.13.

"Issue 9. Changes to Various Definitions

"Background. The changes contemplated by NRC in this proposed rulemaking would require changes to various definitions in $\S 71.4$ to provide internal consistency and compatibility with TS-R-1. The terms must be clearly defined so that they can be used to accurately communicate requirements to licensees. By modifying existing definitions and adding new definitions, the licensee would benefit through more effective understanding of the requirements of Part 71.

"Discussion. Eight commenters [sic] submitted information on changes to various definitions in the proposed rule. One commenter [sic] stated that the definitions should be adopted to the extent the terms are used in the updated regulations. Another commenter [sic] urged NRC to be clear, consistent, and precise, particularly regarding the definitions of 'rupture,' 'collapse,' 'buckling,' and 'inleakage.' Two other commenters [sic] stated that the TS-R-1 definition identifies the specific types of packaging allowed for Class 7, and unless DOT revises its regulations, there will be a domestic conflict. Therefore, these commenters [sic] do not recommend this change. The commenters [sic] added that NRC should consider definitions that explain the differences among 'uniformly distributed,' 'distributed throughout,' and 'homogeneous.'

"Another commenter [sic] stated that the existing regulation defines special form radioactive material that has been demonstrated to comply with specific tests. The commenter $[s i c]$ added that TS-R-1, paragraph 225, introduces the term 'low dispersible radioactive material,' but fails to provide any guidance as to what characteristics qualify the 
material. Another commenter [sic] stated that the definition for 'low dispersible radioactive material' should indicate that this does not refer to surface contamination, but rather activation of a solid material. This commenter [sic] also suggested adding the term 'sealed source' to mean (for use of $A_{1}$ values) encapsulated radioactive material that was designed and manufactured under a specific license and has been assigned a sealed source identification registry number.

"One commenter $[\mathrm{sic}]$ stated that the proposed definitions of 'confinement system' and 'package' are indistinguishable for packages intended to transport fissile material. The commenter [sic] urged NRC to use only one term or to clearly distinguish between the two definitions. The commenter [sic] added that if the definition of 'confinement system' is added, the term 'competent authority' must also be defined, and if the definition of 'package' is incorporated, definitions of 'excepted' and 'industrial' must be added. Another commenter [sic] stated that the confinement system definitions should be revised to include fuel assemblies, the PWR basket, and the shipping cask, because all three provide different levels and degrees of confinement.

"The NRC draft RA indicates that revising Part 71 to modify existing and add new definitions is appropriate from a safety, regulatory, and cost perspective. The proposed changes would provide greater internal consistency and compatibility with TS-R-1. By modifying existing definitions and adding new definitions, licensees would benefit through a more effective understanding of the requirements of Part 71.

"Specifically, industry will realize costs savings by benefitting $[\mathrm{sic}]$ from a more effective understanding of the requirements of Part 71. These costs savings are expected to be minimal, and are not quantifiable due to a lack of available data.

"The proposed changes would result in approximately $\$ 3,500$ in implementation costs to the NRC. The NRC would have to revise regulatory guides and NUREG-series documents to include the new or revised definitions of $\S 71.4$. The proposed changes could affect implementation and operation costs of Agreement States because they would have to adopt the revision to the various definitions in $\S 71.4$. (The proposed change is not expected to affect implementation or operation costs of DOT.) Because Agreement States use regulatory guides and NUREG-series documents published by the NRC, they would only need to revise documents that they have developed specifically for their licensees.

"Additionally, as a means of improving use and understanding of Part 71, the following existing definitions from $\S 71.4$ would be modified: $A_{1}, A_{2}$, and Low Specific Activity, specifically LSA-III. The definitions that are structured in $\S 71.4$ are presented in italicized print as a means of distinguishing them from the corresponding text. The definition of LSA-III material would be modified to reference the testing provisions for LSA-III material found in $\S 71.77$. Other definitions (e.g., Special form radioactive material) reference requirements within Part 71 that must be followed.

"Lastly, within the Issues Paper, NRC posed the idea of adopting the following definitions from TS-R-1: Confinement System (TS-R-1, paragraph 209) and Quality Assurance (TS-R-1, paragraph 232). NRC is excluding the definition of Confinement system because it is included within the broader definition of Containment system. Further, NRC's use of Quality assurance is somewhat different from that of the IAEA, and NRC will retain the description of Quality assurance found in Subpart $\mathrm{H}$.

"NRC Proposed Position. The NRC is proposing to adopt the TS-R-1 definition of Criticality Safety Index (CSI). Additionally, the following definitions would be revised to improve their clarity: $\mathrm{A}_{1}, \mathrm{~A}_{2}$, and LSA-III. Other changes to $\S 71.4$ are proposed in separate issues.

“Affected Sections. § 71.4.

"Issue 10. Crush Test for Fissile Material Package Design

"Background. In TS-R-1, the crush test requirements have been broadened to apply to fissile material package designs (regardless of package activity). Previously, IAEA Safety Series No. 6 and Part 71 have required the crush test for certain Type B packages. This broadened application was created in recognition that the crush environment was a potential accident force that should be protected against for both radiological safety purposes (packages containing more than $1,000 \mathrm{~A}_{2}$ in normal form) and criticality safety purposes (fissile material package design).

"Under requirements for packages containing fissile material, TS-R-1, paragraph 682(b), requires tests specified in paragraphs 719-724 followed by whichever of the following is the more limiting: (1) The drop test onto a bar as specified in paragraph 727(b) and either the crush test as indicated in paragraph 727 (c) for packages having a mass not greater than $500 \mathrm{~kg}(1,100 \mathrm{lbs})$ and an overall density not greater than $1,000 \mathrm{~kg} / \mathrm{m}^{3}$ $(62.4 \mathrm{lbs} / \mathrm{ft})$ based on external dimensions, or the 9-meter (30-ft) drop test as defined in paragraph 727 (a) for all other packages; or (2) the water immersion test as specified in paragraph 729.

"Both the Safety Series No. 6, paragraph 548, and the current $\S 71.73$ require the crush test for packages having a mass not greater than $500 \mathrm{~kg}(1,100 \mathrm{lbs})$, an overall density not greater than $1,000 \mathrm{~kg} / \mathrm{m}^{3}$ $(62.4 \mathrm{lbs} / \mathrm{ft})$ based on external dimensions, and radioactive contents greater than $1,000 \mathrm{~A}_{2}$ not as special form radioactive material. Under TS-R-1, the criterion for radioactive contents greater than 
1,000 $\mathrm{A}_{2}$ has been eliminated for packages containing fissile material. The $1,000 \mathrm{~A}_{2}$ criterion still applies to Type $\mathrm{B}$ packages and is also applied to the IAEA newly created Type $\mathrm{C}$ package category.

"Discussion. Several commenters [sic] provided feedback regarding crush test requirements for packages containing fissile material. A number of commenters [sic] urged NRC to keep the current regulations requiring the crush test and the free drop test. One commenter [sic] stated that the crush test was especially useful for large packages. Another commenter [sic] supported the test and stated that U.S. transportation activities should be consistent with IAEA transportation regulations. Similarly, one commenter [sic] stated that the testing sequence as required in TS-R-1 should be adopted to assure international uniformity. One commenter [sic] recommended removing the optional requirement of either a crush or a drop test, and replacing it with a requirement to conduct both tests.

"One commenter [sic] requested that NRC improve the realism associated with crush tests. The commenter [sic] stated that the crush test should be a physical test rather than using a computer model simulating a test. Additionally, the test should use full-scale packages that are loaded with nonradioactive materials to provide improved test reliability. This commenter [sic] stated that crush tests should be included for all package sizes, and the test parameters should be increased to reflect realworld conditions.

"A few commenters [sic] stated that the proposed requirement to use the free drop test or the crush test is problematic because the results of these tests are different and could require reanalysis of current packages.

"One commenter [sic] stated that elimination of the $1,000 \mathrm{~A}_{2}$ activity limit, without providing for flexibility in test sequencing, would be an unfair and costly burden. The commenter [sic] stated that Part 71 should be changed to conform to TS-R-1 in all aspects, or not be changed at all. Another commenter [sic] stated that the impact of the elimination of the $1,000 \mathrm{~A}_{2}$ activity limit for fissile material packages having a mass not greater than $500 \mathrm{~kg}(1,100 \mathrm{lbs})$, and overall density not greater than $1,000 \mathrm{~kg} / \mathrm{m}^{3}(62.4 \mathrm{lbs} / \mathrm{ft})$, based on external dimensions, is currently unknown. The commenter [sic] noted that shipping companies must use international standards established in TS-R-1 to allow international trade. Another commenter [sic] supported the removal of the $1,000 \mathrm{~A}_{2}$ threshold for fissile packages on the grounds that $A_{2}$ levels are intended as an index of radiological hazard rather than criticality potential, and it is inconsistent with TS-R-1.

"The NRC believes that full compliance with TS-R-1 requirements for fissile material packages would require changes to the hypothetical accident conditions test sequencing of $\S 71.73$ and would require performance of the 9 -meter $(30-\mathrm{ft})$ free drop test or the crush test, but not both, as presently required by $\S 71.73$. The TS-R-1 test requirements are essentially the same as those contained in Safety Series No. 6. In the previous NRC rulemaking for compatibility with Safety Series No. 6 (1985 edition), NRC staff addressed this difference in test requirements. In the June 8, 1988; 53 FR 21550, proposed rule, the NRC stated that: 'IAEA applies the crush test in place of the 9-meter drop test for the lightweight packages specified. In the absence of experience using the crush test, and because the crush test and drop test evaluate different features of a package, NRC is requiring both the crush test and the 9-meter drop test for the lightweight packages.' Further, in the September 28, 1995; 60 FR 50248, final rule, the NRC stated: 'NRC is requiring both the crush test and drop test, for lightweight packages, to ensure that the package response to both crush test and drop forces is within applicable limits.'

"The NRC draft RA indicates that revising Part 71 to adopt the TS-R-1 requirements for a crush test for fissile material package design, while maintaining the current testing sequence, is appropriate from a safety, regulatory, and cost perspective. Not adopting the requirement would result in an inconsistency between Part 71 requirements and TS-R-1, which could affect international shipments, and fissile material package designs would continue to not be evaluated for criticality safety against this potential accident condition. However, the NRC believes that further information on the impact of the TS-R-1 requirement for fissile material package testing is required. Imposing the crush test requirement on fissile material package designs may impact the industry through costs imposed to demonstrate compliance and may lead to the redesign of packages. Under present Part 71 standards and Safety Series No. 6, the $1,000 \mathrm{~A}_{2}$ criterion, used to identify packages that must meet the crush test, essentially exempts all packages designed to contain uranium enriched to five percent or less (due to an unlimited $\mathrm{A}_{2}$ value). For fissile material package designs, this would only apply to designs for plutonium contents. However, if TS-R-1 is adopted, only the weight and density criteria would apply to fissile uranium material packages, and packages that were previously exempted because of the $1,000 \mathrm{~A}_{2}$ criterion would now require crush testing. The potential impact on the industry is unknown due to a lack of data on the number of packages shipped under $\S 71.55$ where the $1,000 \quad \mathrm{~A}_{2}$ value allowed exemption from crush testing. However, to demonstrate compliance with the new regulations, industry may incur additional costs. These potential costs may stem from package redesign but, due to the lack of available data, these costs are not quantifiable. NRC would bear approximately $\$ 74,000$ in costs. These costs result from the need to prepare documents and conduct other activities (such as publishing notices of 
rulemakings, holding public hearings, and responding to public comments) as a result of the action.

"NRC Proposed Position. The NRC proposes to adopt the requirement for a crush test for fissile material packages, and eliminate the $1000 \mathrm{~A}_{2}$ criterion for fissile material packages. However, because there is no new information that addresses concerns from the previous rulemaking regarding the difference in test requirements between Part 71 and Safety Series No. 6, the NRC proposes not to change the testing sequence nor to change the drop and crush test requirements in this revision.

“Affected Sections. $\S 71.73$.

"Issue 11. Fissile Material Package Design for Transport by Aircraft

"Background. TS-R-1 introduced new requirements for fissile material package designs that are intended to be transported aboard aircraft. TS-R-1 requires that shipped-by-air fissile material packages with quantities greater than excepted amounts (which would include all NRC-certified fissile packages) be subjected to an additional criticality evaluation. Specifically, TS-R-1, paragraph 680, requires that packages must remain subcritical, assuming reflection by 20 centimeters ( 8 inches) of water but no water inleakage (i.e., moderation) when subjected to the tests for Type $\mathrm{C}$ packages. ${ }^{* * *}$ The specification of no water ingress is given because the objective of this requirement is protection from criticality events resulting from mechanical rearrangement of the geometry of the package (i.e., fast criticality). The provision also states that if a package takes credit for 'special features,' this package can only be presented for air transport if it is shown that these features remain effective even under the Type $C$ package test conditions followed by a water immersion test. 'Special features' generally mean features that could prevent water inleakage (and therefore credit could be taken in criticality analyses) under the hypothetical accident conditions. Special features are permitted under current $\S 71.55(\mathrm{c})$.

"TS-R-1, paragraph 680, requirements for packages to be transported by air are in addition to the normal condition and accident tests that the package must already meet. Thus:

“Type A fissile package by air must:

*** "The TS-R-1 imposition of Type C and LDM requirements (see Issue 6) was in recognition that severe aircraft accidents could result in forces exceeding those of the 'accident conditions of transport' that are imposed on Type B and fissile package designs. Because the hypothetical accident conditions for Type B packages are the same as those applied to package designs for fissile material, there was also a need to consider how these more severe test conditions should be applied to fissile package designs transported by air." (This footnote was part of the original citation.)
(A) Withstand normal conditions of transport with respect to release, shielding, and maintaining subcriticality (single package and $5 \times \mathrm{N}$ array ${ }^{\dagger \dagger \dagger}$ );

(B) Withstand accident condition tests with respect to maintaining subcriticality (single package and $2 \times \mathrm{N}$ array); and

(C) Comply with TS-R-1, paragraph 680, with respect to maintaining subcriticality (single package);

"Type B fissile package by air must:

(A) Withstand normal conditions of transport and Type B tests with respect to release, shielding, and maintaining subcriticality (single package and $5 \times \mathrm{N}$ array/normal and $2 \times \mathrm{N}$ array/accident); and

(B) Comply with TS-R-1, paragraph 680, with respect to maintaining subcriticality.

"There are no provisions in TS-R-1 for 'grandfathering' (Issue 8) fissile material package designs, which will be transported by air. TS-R-1, paragraphs 816 and 817 , state that these packages are not allowed to be grandfathered. Consequently, all fissile package designs intended to be transported by aircraft would have to be evaluated before their use.

"Discussion. Five commenters [sic] provided information regarding our proposal of the TS-R-1 provisions for fissile material package design for transport by aircraft. One commenter [sic] expressed concern about the comprehensibility of the regulations for Type $\mathrm{B}$ or below quantities of fissile materials. The commenter [sic] was aware that the IAEA went through efforts to try to clarify the requirements, but asserted that the regulations need to be understood consistently by the people who approve package designs for transport of fissile materials by air. The commenter [sic] stated that this is a critical issue for industry because the International Civil Aviation Organization (ICAO) has adopted TS-R-1 in 2001 and, therefore, shipments must meet the requirements in TS-R-1 for fissile materials. The commenter [sic] encouraged Federal agencies, including NRC and DOT, to push the concept of clarification of the rules and consider a streamlined approval process for designs of air transport of fissile material. Another commenter [sic] stated that TS-R-1 writers are working to develop a table that takes into consideration mass, enrichment, and moderation to define an acceptable limit for shipment by air.

"One commenter [sic] asked when and in what situations the transportation of fissile level material by air would be required.

iो " $\mathrm{N}$ represents the maximum number of fissile material packages that can be shipped on a single conveyance." (This footnote was also part of the original citation.) 
"Two commenters [sic] supported the inclusion of these requirements as they are generally in parallel with those in place for surface mode accidents.

"The NRC draft RA indicates that adopting TS-R-1 paragraph 680 for criticality evaluation (only applicable to air transport) is reasonable from a safety, regulatory, and cost perspective. Adopting this change would provide the NRC with the regulatory framework for approving package designs that will be used internationally. Shippers will be required to meet these requirements even if the $\mathrm{NRC}$ does not adopt them, because the ICAO has adopted regulations consistent with TS-R-1 on July 1, 2001. U.S. domestic air carriers require compliance with the ICAO regulations even for domestic shipments.

"These changes are expected to benefit industry by eliminating the need for two different package designs. The amount of these savings, however, are not quantifiable due to a lack of data.

"NRC Proposed Position. The NRC proposes to adopt TS-R-1, paragraph 680, Criticality evaluation, in a new proposed $\S 71.55(\mathrm{f})$ that only applies to air transport. Section 71.55 specifies the general package requirements for fissile materials, and the existing paragraphs of $\S 71.55$ are unchanged. Because (1) the NRC is deferring adoption of the Type C packaging tests (see Issue 6); (2) TS-R-1, paragraph 680 , references the Type $\mathrm{C}$ tests; and (3) paragraph 680 applies to more than Type C packages, only the salient text would be inserted into $\S 71.55(\mathrm{f})$, and would apply to domestic shipments.

“Affected Sections. $§ 71.55$.

\section{“D. NRC-Initiated Issues}

\section{"Issue 12. Special Package Authorizations}

"Background. The basic concept for radioactive material transportation is that radioactive contents are placed in an authorized container, or packaging, and then shipped. The packaging, together with its contents, is called the package. In general, the transportation regulations in TS-R-1, 10 CFR Part 71, and Title 49 are based on the shipment of radioactive contents in a separate, authorized packaging. There are a few exceptions, however. For example, TS-R-1 provides that the least radioactive of the Low Specific Activity materials (LSA-I) and Surface Contaminated Objects (SCO-I) may be shipped unpackaged, provided certain conditions are met. Title 49 permits shipment of LSA-I materials in bulk, where the conveyance (e.g., truck or freight container) serves as the packaging.

"In other cases involving larger quantities of radioactive material, the content to be shipped may itself be a container. A storage tank containing a radioactive residue is an example. It is not necessary for the shipper to place the tank within an authorized packaging, if the shipper demonstrates that the tank satisfies the requirements for the packaging. DOT and NRC have jointly provided guidance on such shipments (see 'Categorizing and Transporting Low Specific Activity Materials and Surface Contaminated Objects,' NUREG-1608, RAMREG-003, July 1998).

"As older nuclear facilities are decommissioned, DOT and NRC are being asked to approve the shipment of large components, including reactor vessels and steam generators. These components may contain significant quantities of radioactive material, but they are so large that it is not practical to fabricate authorized packagings for them. Because these components were not contemplated when the regulations were developed, the regulations do not specifically address them.

"Basically, large components can be shipped under DOT regulations if the components meet the definition of Surface Contaminated Object (SCO) or Low Specific Activity (LSA) material (see 49 CFR 173.403 for SCO and LSA definitions). For example, steam generators that meet the SCO definition are exempt from Part 71 and are shipped under Title 49, following guidance provided in NRC Generic Letter 96-07 dated December 5, 1996. This method has been applied to several shipments of steam generators and small reactor vessels to the low level waste disposal facility at Barnwell, SC. NRC and DOT intend to continue employing this approach and method for steam generators and similar components that can be shipped under DOT regulations.

"Large components that exceed the SCO and LSA definitions are subject to Part 71. An example is the Trojan reactor vessel. By letter dated March 31, 1997, Portland General Electric Company (PGE) requested approval of the Trojan Reactor Vessel Package (TRVP) (including internals) for transport to the disposal facility operated by U.S. Ecology on the Hanford Nuclear Reservation near Richland, Washington. The TRVP contained approximately $74 \mathrm{PBq}(2$ million $\mathrm{Ci})$ in the form of activated metal and 5.7 TBq $(155 \mathrm{Ci})$ in the form of internal surface contamination, was filled with lowdensity concrete and weighed approximately 900 metric tons (1,000 tons). Normally, large curie contents are required to be shipped in a Type B packaging, but the TRVP was too large and massive to be shipped within another packaging.

"PGE acknowledged that the TRVP could not meet Type B regulations and applied for a Type B package CoC for the TRVP itself, either under $\S 71.41(\mathrm{c})$, 'Demonstration of compliance,' or $\S 71.8$, 'Specific exemptions.' Section 71.41(c) provides that 'Environmental and test conditions different from those specified in $\S \S 71.71$ and 71.73 may be approved by the Commission if the controls proposed to be exercised by the shipper are demonstrated to be adequate to provide equivalent safety of the shipment.' Section 71.41(c) has been used to accommodate minor deviations in test environments (e.g., initial temperatures), and was not intended to be 
used to establish new test conditions for Type B packages. The use of this provision in the Trojan case would essentially have resulted in establishing new (and less rigorous) Type B test conditions that the Trojan vessel could meet. A CoC for a Type B package could then have been issued for Trojan, but the level of performance reflected in that Certificate would have been significantly different from that in other Type B Certificates. NRC decided against using $\S 71.41(\mathrm{c})$, and to use the $\S 71.8$ exemption provision - the only other option available.

"Section 71.8 provides that NRC may grant any exemption from the requirements of the regulations in Part 71 that it determines is authorized by law and will not endanger life or property nor the common defense and security. The exemption approach had three impacts on the TRVP review. First, the NRC's categorical exclusion from preparing an Environmental Assessment (EA) pursuant to the National Environmental Protection Act (NEPA) for package approvals $(\S 51.22(\mathrm{c})(13))$ does not apply to packages authorized under an exemption. Consequently, an EA of the proposed exemptions was required. Second, DOT's regulations that govern radioactive material shipments do not recognize packages approved via NRC exemption. PGE was therefore required to obtain an exemption from DOT regulations in 49 CFR Part 173 for the TRVP shipment. Third, use of the exemption option provided a mechanism for NRC to consider the operational and administrative controls, which were proposed by PGE to influence shipment risk factors. Considering the statements and representations contained in the application, as supplemented, and the conditions specified in the package approval, NRC concluded that the TRVP, as exempted, met the requirements of Part 71, and recommended that the Commission approve the exemptions and the TRVP shipment.

"Currently, no regulatory provisions exist in Part 71 for dealing with nonstandard packages, other than the exemption provisions and $\S 71.41(\mathrm{c})$. The NRC's policy is to avoid the use of exemptions for recurring licensing actions. Therefore, as a lesson learned from the Trojan approval, the NRC staff identified large component package authorizations as an issue for consideration in this proposed rule.

"Discussion. Numerous comments were received on the special package approvals issue in response to the Issues Paper, from the public meetings, and from NRC's website. One of the commenters [sic] supported the idea of creating a system for providing special package approvals without using the existing exemption requirements. This commenter $[\mathrm{sic}]$ noted that his agency found it very useful to realize that there are packages or materials outside the current scope of NRC regulations that still need to be transported as they cannot stay where they are. The commenter [sic] agreed that it is appropriate to have a method to address these issues.

"A number of commenters [sic] did not support the development of a special package approvals regulation. These commenters [sic] believed the issue of special package approvals should be conducted on a case-by-case basis, using the current exemption process. One commenter [sic] noted that 'hot decommissioning' and 'hot' shipping introduce a new regimen, and therefore, the commenter [sic] believed that the only way for the NRC to proceed is with a case-by-case, very individual and specialized exemption or allowance, if at all. The commenter [sic] went on to say that the people who are on the first lines, the first responders and the emergency management coordinators at the local level, and the people who are in transport corridor communities have a right to information that a specialized process (i.e., an exemption process) would provide. The commenter [sic] stated that the concerns of the public who are in these transport corridor communities are not being given adequate weight in decision making, and the opportunities for discussion are too limited. Finally, this commenter [sic] stated that removing the exemption process for big, unusual shipments could set the stage for applying this concept to other types of materials to be exempted from testing and packaging requirements which the commenter [sic] believed would be a bad precedent.

"Two commenters [sic] expressed concern over the definition of a 'special large object.' One commenter [sic] stated that if special provisions are added, then the term 'large' must be defined with respect to both size and weight. Another commenter $[$ sic $]$ requested that NRC consider revisions to Part 71 to address large objects in general, that would include reactor vessels.

"Three commenters $[s i c]$ spoke to the issue of Type B quantities. The first commenter [sic] stated that there could be overlap between orphan sources and Type B quantities. This commenter $[s i c]$ recommended that Type B orphan sources be included in a separate rule from the special large packages. The second commenter [sic] would like to see collaboration between the NRC and DOT to address the possibility of initiating a program that would minimize package review costs of decommissioning Type B quantities of cobalt- 60 and cesium-137. Two commenters [sic] stated that there have been cases where a Type B package has been damaged in a way that it will continue to secure and shield the sources, but does not meet compliance standards. The commenters [sic] noted that in these types of cases, a special arrangement certificate would be beneficial to allow transport of the damaged equipment for disposal.

"Several commenters [sic] did not believe that NRC's use of the shipment of the Trojan reactor vessel was an adequate basis for determining whether or not to remove the requirement for exemptions for special 
packages and replace it with other provisions. One commenter [sic] noted that because the Trojan vessel was shipped by barge, a lot of the risk of exposure that would normally be present in other transport modes was removed (e.g., a truck being caught in traffic). This commenter [sic] also stated that moving to a risk-informed decision making process for special package approvals may result in a situation where the public is 'informed to more risk while the industry is exposed to less regulation.' Another commenter [sic] noted that if NRC is using the shipment of the Trojan reactor vessel as its baseline for determining whether to revise its regulations, care should be taken to limit the scope of this special approval to NRC's responsibilities and expertise. The commenter [sic] noted that as the Trojan approval process moved along, there was a difference of opinion as to the extent of NRC's evaluation of river and barging conditions, when in reality, these issues are the jurisdiction of the Coast Guard, and if the Coast Guard had approved the waterway and the conveyance, it should not be necessary for this information to be a part of an application to NRC subject to NRC review and approval. Other commenters [sic] disagreed. One commenter [sic] added that significant experience has already been gained in exempting the Trojan reactor vessel, a precedent has been established, and the possibility exists that the requirements placed on the shipment of the Trojan reactor vessel might have been more restrictive than might have been determined as necessary. Two commenters [sic] stated that the Trojan shipment review is a point of reference for the basis of other similar shipments, but that each case should still be assessed on its own merits.

"A number of commenters [sic] raised specific issues that NRC should consider when deciding whether to propose a special package approval process and how that process should be defined. Two commenters [sic] noted that the system has been defined as to how these materials should be moved and what kind of information needs to be provided to the regulators to move the materials. These commenters [sic] further noted that any change to Part 71, with respect to these special shipments, needs to be specific to those items that are going to be regulated under the MOU between the NRC and DOT. The two commenters [sic] added that the majority of those items that get moved are large components and would fall under the DOT's jurisdiction under the MOU. Thus, DOT would regulate items like steam generators and demineralizers and pressurizers, all of which are pieces and parts of reactors that are being decommissioned. NRC would regulate items like reactor pressure vessels (e.g., the Trojan reactor pressure vessel).

"One commenter [sic] did not support the adoption of an analog of the IAEA special arrangements provisions in Part 71. The commenter [sic] did not support the adoption of this type of provision in Part 71 because the IAEA special arrangements were specifically designed for movement internationally, whereas most of these items would be moved domestically.

"One commenter [sic] provided input on the specific issue of what additional determinations should be included in an application for a special package approval. The commenter [sic] noted that a precedent has already been established with the requirement that a transportation plan be provided with the exemption requests. The transportation plan contains safety features that would be substituted for the current codified requirements that would provide an equivalent order of safety, considerations of the entire safety system versus independent components of safety, emergency response plans, and riskinformed considerations.

"The NRC processing of one-time exemptions for nonstandard packages, such as the Trojan vessel, represents expenditure of considerable staff resources. Once the application for exemption is received, the staff spends a significant amount of time reviewing the application and preparing an EA. The Commission itself has been involved in the approval of these actions. Rather than exempting nonstandard packages from regulations, as was necessary for Trojan, the staff is proposing that regulatory requirements be added to Part 71 which would address nonstandard packages. These special packages are likely to increase in number as a result of future decommissioning activities.

"The NRC is proposing a regulatory mechanism to address large component shipments. In this regard, NRC has considered TS-R-1, paragraph 312, entitled Special Arrangement:

Consignments for which conformity with the other provisions of these regulations is impracticable shall not be transported except under special arrangement. Provided the competent authority is satisfied that conformity with the other provisions of the regulations is impracticable and that the requisite standards of safety established by these regulations have been demonstrated through means alternative to the other provisions, the competent authority may approve special arrangement transport operations for single or a planned series of multiple consignments. The overall level of safety in transport shall at least be equivalent to that which would be provided if all the applicable requirements had been met. For international consignments of this type, multilateral approval shall be required.

"The Special Arrangement paragraph is intended to provide competent authorities (DOT in the U.S.) the authority to approve shipments that don't completely conform to the transportation safety standards, provided the overall level of safety established by the regulations is maintained. DOT consults with NRC regarding the approvals for shipment of packages containing larger quantities of radioactive material and/or fissile materials. $\mathrm{NRC}$ is proposing to add this provision to $\S 71.41$. 
"The NRC draft RA indicates that adopting the special package authorization requirements proposed for incorporation into Part 71 is appropriate from a safety, regulatory, and cost perspective. The proposed action would result in enhanced regulatory efficiency by standardizing the requirements to provide greater regulatory certainty and clarity, and would ensure consistent treatment among licensees requesting authorization for shipment of special packages. This increase in regulatory efficiency, however, would depend in part on modifications to DOT's regulations to recognize NRC special package exemptions. Further, NRC experience in handling the one-time exemption(s) during the transition period would be used in crafting the new requirements. As a result, applications for one-time exemptions would be eliminated, resulting in savings in licensee staff resources and NRC staff resources. Because the new section is expected to be better streamlined for handling these nonstandard packages, considerable savings would be realized, both in NRC and licensee staff time. These expected NRC savings are estimated to be approximately $\$ 500,000$. Special package shipments are likely to increase regardless of the outcome of this rulemaking, as a result of future decommissioning activities. The justification for authorizing special packages for shipment is a decreased risk of radiation exposure to the public and workers as opposed to the shipment alternatives. NRC believes that standardizing the method for reviewing these packages would provide adequate review without imposing unnecessary administrative burdens on NRC staff associated with the processing of exemption-based reviews.

"Industry may have costs associated with additional preparation of health and safety information for shipment of special packages. But, there may also be some inherent cost savings to industry with respect to preparing health and safety information. On the balance between the costs anticipated with developing an application for NRC approval and the savings expected from using an established process, the net effect on industry is expected to be negligible.

"NRC Proposed Position. NRC proposes a special package authorization that would apply only in limited circumstances, and only to one-time shipments of large components. Further, any such special package authorization would be issued on a case-by-case basis, and would require the applicant to demonstrate that the proposed shipment would not endanger life or property nor the common defense and security, following the basic process used by applicants to obtain nonspecial package authorizations from NRC.

"NRC proposes to adopt a provision that is analogous to TS-R-1, paragraph 312, for Part 71 with respect to the approval of large component packages. The applicant would need to provide reasonable assurance that the special package, considering operational procedures and administrative controls employed during the shipment, would not encounter conditions beyond those for which it had been analyzed and demonstrated to provide protection. NRC would review applications for large component special package authorizations. Approval would be based on a staff determination that the applicant met the requirements of Subpart D. If approved, the NRC would issue a $\mathrm{CoC}$ or other approval (i.e., special package authorization letter).

"NRC would consult with DOT on making the determinations required to issue an NRC special package authorization. The efficiency of the NRC special package process, in part, depends on a modification by DOT of its regulations to recognize NRC special package authorizations, so that a DOT exemption would not be required for use of the NRC authorization. DOT is proposing this change in its companion TS-R-1 compatibility rulemaking.

"Affected Sections. $§ 71.41$.

"Issue 13. Expansion of Part 71 Quality Assurance Requirements to Certificate of Compliance (CoC) Holders

"Background. The Commission recently issued a final rule to expand the QA provisions of Part 72, Subpart G, to specifically include certificate holders and applicants for a $\mathrm{CoC}$ (see 64 FR 56114; October 15, 1999). In development of the proposed rule for Part 72, the NRC staff submitted a rulemaking plan to the Commission in SECY-97-214. ${ }^{+*}$ In a Staff Requirements Memorandum (SRM) to SECY-97-214, the Commission approved the staff's rulemaking plan and directed the staff to also consider whether conforming changes to the QA regulations in Part 71 would be necessary because of the existence of dualpurpose cask designs. In a memorandum from the Executive Director for Operations to the Commission, dated December 3, 1997, the NRC staff indicated that expansion of the Part $71 \mathrm{QA}$ provisions to include certificate holders and applicants for a $\mathrm{CoC}$ would be made as part of the rulemaking to conform Part 71 to IAEA Standard TS-R-1. Furthermore, in the final rule expanding QA regulations in Part 72, Subpart G, the Commission did not include contractors or subcontractors (e.g., fabricators) within the scope of the revised Part 72, Subpart G. The Commission took this action in response to comments on the associated proposed rule. In the response to Comments 3 and 9 in the final Part 72 rule, the Commission indicated that Part 72 licensees, certificate holders, and applicants for a $\mathrm{CoC}$ are responsible for assuring that their contractors and

$4+$ "SECY-97-214, 'Changes to 10 CFR Part 72, Expand Applicability to Include Certificate Holders and Applicants and Their Contractors and Subcontractors,' dated September 24, 1997." (This footnote was part of the original citation.) 
subcontractors (e.g., fabricators) are implementing adequate QA programs. Similarly, Part 71 licensees, certificate holders, and applicants for a $\mathrm{CoC}$ are responsible under $\S 71.115$ for assuring that their contractors and subcontractors (e.g., fabricators) are implementing adequate $\mathrm{QA}$ programs.

"Under Part 71, the NRC reviews and approves applications for Type B and fissile material packages for the transport of radioactive material. The NRC's approval of a package is documented in a $\mathrm{CoC}$. Applicants for a $\mathrm{CoC}$ are currently required by $\S 71.37$ to describe their QA program for the design, fabrication, assembly, testing, maintenance, repair, modification, and use of the proposed package. Further, existing $\S$ 71.101(a) describes QA requirements that apply to design, purchase, fabrication, handling, shipping, storing, cleaning, assembly, inspection, testing, operation, maintenance, repair, and modification of components of packagings that are important to safety. Type B packages are intended to transport radioactive material that contains quantities of radionuclides greater than the $A_{1}$ or $A_{2}$ limits for each radionuclide (see Appendix A to Part 71 for examples of $A_{1}$ or $A_{2}$ limits). Fissile material packages are intended to transport fissile material in quantities greater than the Part 71, Subpart C, general license limits for fissile material (e.g., existing $\S \S 71.18,71.20,71.22$, and 71.24).

"Although CoCs are legally binding documents, certificate holders or applicants for a $\mathrm{CoC}$ and their contractors and subcontractors have not clearly been brought into the scope of Part 71 requirements. This is because the terms 'certificate holder' and 'applicant for a certificate of compliance' do not appear in Part 71, Subpart H; rather, Subpart H only mentions 'licensee' in these regulations. Consequently, the NRC has not had a clear basis to cite certificate holders and applicants for a $\mathrm{CoC}$ for violations of Part 71 requirements in the same way it has licensees.

"The NRC Enforcement Policy $\$ \S$ and its implementing program was established to support the NRC's overall safety mission in protecting public health and safety and the environment. Consistent with this purpose, enforcement actions are used as a deterrent to emphasize the importance of compliance with requirements and to encourage prompt identification and comprehensive correction of the violations. Enforcement sanctions consist of Notices of Violation (NOVs), civil penalties, and orders of various types. In addition to formal enforcement actions, the NRC also uses related administrative actions such as Notices of Nonconformance (NONs), Confirmatory Action Letters, and Demands for Information to supplement its enforcement program.

$\S \S \S$ "NUREG-1600, 'General Statement of Policy and Procedures for NRC Enforcement Actions,' dated May 2000." (This footnote was part of the original citation.)
The NRC expects licensees, certificate holders, and applicants for a $\mathrm{CoC}$ to adhere to any obligations and commitments that result from these actions and would not hesitate to issue appropriate orders to ensure that these obligations and commitments are met. The nature and extent of the enforcement action are intended to reflect the seriousness of the violation involved. An NOV is a written notice setting forth one or more violations of a legally binding requirement.

"When the NRC has identified a failure to comply with Part 71 QA requirements by certificate holders or applicants for a $\mathrm{CoC}$, it has issued an NON rather than an NOV. Although an NON and an NOV appear to be similar, the Commission prefers the issuance of an NOV because: (1) The issuance of an NOV effectively conveys to both the person violating the requirement and the public that a violation of a legally binding requirement has occurred; (2) the use of graduated severity levels associated with an NOV allows the NRC to effectively convey to both the person violating the requirement and the public a clearer perspective on the safety and regulatory significance of the violation; and (3) violation of a regulation reflects the NRC's conclusion that potential risk to public health and safety could exist. Therefore, the NRC believes that limiting the available enforcement sanctions to administrative actions is insufficient to address the performance problems observed in industry.

"Discussion. Sixteen commenters [sic] provided comments regarding the possible expansion of QA requirements to holders of, and applicants for, a $\mathrm{CoC}$. Of these, three supported expanding the QA requirements. Two commenters [sic] stated that the cask design and fabricating industry should be allowed flexibility to make design changes to the casks that would not impact safety. One of the commenters [sic] stated that cask designers and fabricators should be held responsible as are parties on the nuclear power reactor side.

"Four commenters $[\mathrm{sic}]$ did not support the overall proposed change to expand the QA requirements of Part 71. One commenter [sic] stated that it is the responsibility of the purchaser, user, or licensee of the cask or shipping container to ensure the container's QA, and therefore, NRC already has enforcement authority over that particular container. Two commenters [sic] stated that extending the responsibility to the fabricator or certificate holder would encourage fabricators to get out of business because of the regulatory and paper burden of the proposed provision. Another commenter [sic] stated that there is confusion between what is in the current regulations and what is in the proposed regulations. Another commenter [sic] stated that NRC could be regulating packages for which NRC is not responsible under the MOU between the NRC and the DOT. A commenter [sic] stated that NRC currently has adequate QA control on the Part 71 
packages under Subpart H. The commenters [sic] did not believe that issuing an NOV instead of an NON would result in additional compliance.

"Several commenters [sic] noted the need for consistency in the QA provisions between Parts 71 and 72, which should be maintained for dual purpose casks used for storage and transportation of spent nuclear fuel and high-level radioactive waste. Additionally, one commenter [sic] noted that a distinction has never been established between Part 71 and Part 72 packages used to transport/store spent fuel and the Part 71 packages used to transport sealed radioactive sources. The commenter [sic] suggested that 'Part 50 reactor licensees be specifically exempted from participation in nuclear power specific QA activities.'

"Representatives of DOT and DOE questioned whether this provision would apply to Type A packages. The NRC intends that this proposed change would apply only to NRC certificate holders and applicants for a $\mathrm{CoC}$ and only for package designs that are regulated by NRC (e.g., Type B or fissile packages).

"The principal changes to Subpart $\mathrm{H}$ would involve adding the terms 'certificate holder' and 'applicant for a $\mathrm{CoC}$ ' to indicate that these persons are also covered by the section, although in some cases, only 'certificate holder' would be added, because an applicant for a $\mathrm{CoC}$ would not be expected to accomplish these specific activities. Additional conforming changes would be made to various sections in Part 71 to ensure greater consistency between Part 71 and Part 72.

"The NRC draft RA indicates that expanding the QA provisions of Part 71, Subpart H, to certificate holders and applicants for a $\mathrm{CoC}$ is appropriate from a safety, regulatory, and cost perspective. Adopting these requirements would ensure that the regulatory scheme of Part 71 would remain more consistent with other NRC regulations in that certificate holders and applicants for a $\mathrm{CoC}$ would be responsible for the behavior of their contractors and subcontractors. Also, because this action would be limited to certificate holders and applicants for a $\mathrm{CoC}$, it may not be as likely to be challenged as an expansion of NRC authority. Inclusion of certificate holders and applicants for a $\mathrm{CoC}$ would make it possible for NRC to issue NOVs and orders, if appropriate, for violation to the regulatory requirements; this would allow the NRC to conduct its business of protecting public health and safety more efficiently and effectively. This proposed rule would not authorize the NRC to issue civil penalties to Part 71 certificate holders or applicants for a $\mathrm{CoC}$ who are found to be in violation of regulatory requirements. Alternatively, contractors and subcontractors of licensees, certificate holders, and applicants do have responsibility for safety, and omitting them from Part 71 would continue the present difficulty that
NRC has encountered in reaching these persons with its enforcement tools. Certificate holders and applicants for a $\mathrm{CoC}$ would incur costs associated with understanding and implementing the new regulations, as well as in preparing and submitting reports similar to those described in SECY 99-174. SECY 99-174 states that 'Additional requirements for recordkeeping and reporting for certificate holders are needed to include records required to be kept as a condition of the CoC. This will provide an enforcement basis equivalent to the recordkeeping and reporting regulations for licensees.' These costs are estimated to be approximately $\$ 239,000$ per year for the certificate holders and applicants for a $\mathrm{CoC}$. NRC would incur costs associated with monitoring certificate holders and applicants for a $\mathrm{CoC}$ and maintaining and reviewing the records for certificate holder submittals. These costs are estimated to be approximately $\$ 48,000$ per year. By specifically listing certificate holders and applicants for a $\mathrm{CoC}$ in Part 71, inspection deficiencies noted by NRC might result in an NOV. This authority would allow NRC to issue orders or take other enforcement actions (except civil penalties) necessary to ensure that certificate holders and applicants for a CoC comply with Part 71 requirements, similar to NRC enforcement actions in other program areas. However, this benefit is difficult to quantify and is estimated to be small.

"The NRC is proposing to expand the QA provisions of Part 71, Subpart $H$, to specifically include certificate holders and applicants for a CoC. This expansion is necessary to enhance NRC's ability to enforce nonconformance by the certificate holders and applicants for a CoC. The NRC is also proposing to add a new section $(\S 71.9)$ on employee protection to Part 71. Currently, regulations on employee protection are contained in the individual parts under which the NRC issued a specific license. Consequently, this regulation was not deemed necessary for a Part 71 general licensee. However, the equivalent requirement for certificate holders or applicants for a $\mathrm{CoC}$ does not exist. The NRC believes that employee protection regulations should be added for the employees of certificate holders and applicants for a $\mathrm{CoC}$ to provide greater regulatory equivalency between Part 71 licensees and certificate holders. Therefore, the NRC would add a requirement on employee protection to Part 71.

"NRC Proposed Position. The NRC is proposing to expand the QA provisions of Part 71, Subpart H, to specifically include certificate holders and applicants for a $\mathrm{CoC}$.

"In addition to the changes to Subpart $\mathrm{H}$, conforming changes would also be made to: $\S 71.0$, 'Purpose and scope'; $\S 71.1$, 'Communications and records'; $\S 71.6$, 'Information collection requirements: OMB approval'; $\S 71.7$, 'Completeness and accuracy of information'; § 71.91, 'Records'; § 71.93, 'Inspection 
and tests'; and $\S 71.100$, 'Criminal penalties.' Additionally, $\S 71.11$ would be redesignated as $\S$ 71.8; and a new $\S 71.9$, 'Employee protection,' would be added.

“Affected Sections. $\S \S ~ 71.0,71.1,71.6,71.7,71.8$, $71.9,71.91,71.93,71.100$, and 71.101 through 71.137.

"Issue 14. Adoption of American Society of Mechanical Engineers (ASME) Code

"Background. NRC considered the adoption of the American Society of Mechanical Engineers (ASME), Boiler and Pressure Vessel Code (B\&PV) Code, Section III, Division 3, for two reasons. First, previous NRC inspections at vendor and fabricator shops (for fabrication of spent fuel storage canisters and transportation casks) identified quality control (QC) and QA problems. Some of these problems would have been prevented with improved QA programs, and may have been prevented had fabrication occurred under more prescriptive requirements such as the ASME Code requirements. Second, Public Law 104-113, 'National Technology Transfer and Advancement Act,' enacted in 1996, requires that Federal agencies use, as appropriate, consensus standards (e.g., the ASME B\&PV Code), except when there are justified reasons for not doing so.

"Currently, no ASME Code requirements exist in Part 71 for fabrication/construction of spent fuel transportation packages.

"Discussion. NRC received numerous comments regarding the adoption of the ASME Code. Four commenters [sic] stated they favored adoption of the ASME Code. One commenter [sic] favored using ASME codes for all components used in the containment boundary of all products that are used in transportation and storage of radioactive materials. This commenter $[\mathrm{sic}]$ also supported an explanatory guideline in the ASME Code that speaks to the subject of categorization of materials, whereby all manufacturers are using the same criteria. Another commenter [sic] stated that using ASME standards would improve current problems with casks and the current lack of QA. One commenter [sic] stated that some benefits of a third party authorized nuclear inspector (ANI) would accrue to industry. These benefits are that common standards would decrease complexity and interpretation, lower cost, and increase safety.

"Eight commenters [sic] stated concerns or disapproval of the adoption of the ASME Code. One commenter [sic] was concerned with the adoption of the guidelines before a full review of the effects on transportation. Another commenter [sic] stated concern over adopting voluntary standards into regulations. Specifically, this concern was directed at the inconsistency between industry standards and regulations. Similarly, another commenter [sic] noted that changes within ASME might occur quickly, and it would be difficult to follow these changes. One commenter [sic] recommended that incorporation of the ASME Code by reference is the appropriate regulatory mechanism, following the precedent set by $\S 50.55$ (a) for the ASME Code, Section III, Division 1. Several commenters [sic] recommended that NRC place industry standards in regulatory guides, which would allow for simpler updating, recognize that other methods of demonstrating compliance are available, and satisfy the Congressional mandate to consider the use of consensus standards. One commenter [sic] stated a concern about the enforceability of the standard if it is not placed in the regulations. Conversely, another commenter $[\mathrm{sic}]$ noted that the regulatory burden is significantly increased when voluntary standards are changed to regulations, and compliance may not always be practical or accomplished.

"Other commenters [sic] were concerned about the widespread impact of the adoption. One commenter [sic] stated that there is no technical justification for adoption of the ASME Code, and it would have significant adverse impact on the ability of the U.S. Navy to refuel and defuel the U.S. nuclear powered warships. Another commenter [sic] stated that overseas market impacts need to be considered in the rulemaking. Another commenter [sic] stated that when an applicant commits to certain standards in his or her safety requirements during the license approval process, it becomes a license condition, and NRC can enforce it.

"One commenter [sic] stated that if the ASME Code is adopted, the development of it and the information involved must be publicly available. Two commenters [sic] specifically asked if the proposed change applies to all packages, dual-purpose spent fuel packages, or to all $\mathrm{CoC}$ holders. Another commenter [sic] questioned how, or whether, the requirement will change if the industry standard changes in the future.

"During the early period of spent fuel storage and transportation cask fabrication, NRC inspection staff consistently identified QC and QA problems at the vendor/fabricator facilities. At that time, NRC believed that these problems might have been prevented had fabrication occurred under ASME Code requirements. Therefore, there was an impetus to place consideration of the ASME Code requirements in the Part 71 rulemaking. However, since then, due to increased attention by the NRC and industry, the overall frequency and significance of QA and QC problems at fabricators and vendors have decreased.

"With respect to conformance to Public Law 104-113, the ASME issued a consensus standard in May 1997, entitled: 'Containment Systems and Transport Packages for Spent Fuel and High Level Radioactive Waste,' ASME B\&PV Code, Section III, Division 3. 
The ASME Code requires the presence of an $\mathrm{ANI}^{* * * *}$ during construction to ensure that the ASME Code requirements are met, and the stamping of components (i.e., the transportation cask's containment) constructed to the ASME Code. NRC staff participated, and continues to participate, in the ASME subcommittee that developed the ASME Code requirements. It is the NRC staff's understanding, through participation in the subcommittee, that the ASME Code document is undergoing extensive review and modification and that a major revision will be issued. Therefore, NRC staff believes that inclusion of the ASME Code in Part 71 is not appropriate at this time.

"Public Law 104-113 requires that Federal agencies use consensus standards in lieu of government-unique standards, if this use is not impractical or inconsistent with other existing laws. Because a major revision to the ASME Code is forthcoming and because the changes in that revision are not yet available for staff and stakeholder review, the NRC staff considers it an imprudent use of NRC and stakeholder resources to initiate rulemaking on the current ASME Code revision only to have the ASME Code requirements change during the Part 71 rulemaking. After the ASME Code revision is issued, the NRC staff can then consider its incorporation through the rulemaking process, or consider adopting and accepting the ASME Code as an acceptable method for complying with NRC requirements through endorsement in regulatory guidance.

"The NRC draft RA indicates that not adopting the ASME Code requirements in Part 71 is appropriate from a safety, regulatory, and cost perspective. While NRC resources would be conserved by not adopting the ASME Code, the proposed action would retain the current status. However, the proposed action would result in no benefits or negative impacts on industry.

"After consideration of the public comments and the NRC recently learning of the extensive review and revision of the ASME Code, the staff recommends not to incorporate the ASME Code, Section III, Division 3, requirements into Part 71. However, adoption of the ASME Code into Part 71 will be considered by the NRC staff in a future rulemaking or guidance document.

"NRC Proposed Position. The NRC staff recommends not incorporating the ASME Code, Section III, Division 3 requirements into Part 71.

"Affected Sections. None (not adopted).

"Issue 15. Change Authority for Dual-Purpose Package Certificate Holders

"Background: The Commission recently approved a final rule to expand the provisions of $\S 72.48$,

\footnotetext{
**** Author's Note: ANI means Authorized Nuclear Inspector.
}

'Changes, Tests, and Experiments,' to include Part 72 certificate holders (64 FR 53582; October 4, 1999). Part 72 certificate holders are allowed under the amended $\S 72.48$ to make certain changes to a spent fuel storage cask's design or procedures used with the storage cask and to conduct tests and experiments, without prior NRC review and approval. Part 71 does not contain any similar provisions to permit a certificate holder to change the design of a Part 71 transportation package, without prior NRC review and approval. The NRC has issued separate CoCs under Parts 71 and 72 for dual-purpose spent fuel casks and transportation packages (i.e., a container intended for both the storage and transportation of spent fuel). This has created the situation where an entity holding both a Part 71 and Part $72 \mathrm{CoC}$ would be allowed under Part 72 to make certain changes to the design of a dual-purpose cask, e.g., changes that affected a component or design feature that has a storage function, without obtaining prior NRC approval. However, the same entity would not be allowed under Part 71 to make changes to the design of this same dual-purpose cask (package), e.g., changes that affect the same component or design feature, if that component or feature also has a transportation function, without obtaining prior NRC approval, even when the same physical component and change is involved (i.e., the change involves a component that has both storage and transportation functions).

"In SECY-99-130 $0^{\text {titl }}$ and SECY-99-054, NRC indicated that comments had been received on the $\S 72.48$ proposed rule (63 FR 56098; October 21, 1998) that requested similar authority be created in Part 71, particularly with respect to dualpurpose casks. In SECY-99-054, NRC staff recommended that an authority similar to $\S 72.48$ be created for spent fuel transportation packages intended for domestic use only. NRC staff also recommended that this authority be limited to Parts 50 and 72 licensees shipping spent fuel and the Part 71 certificate holder. NRC indicated that providing change authority under Part 71 would be addressed in the current rulemaking. The Commission directed the staff to implement recommendations contained in SECY-99-130 and SECY-99-054, in an SRM dated June 22, 1999.

"NRC also identified other supporting changes to Part 71 that would be required to ensure consistency with the process contained in $\S 72.48$. These changes

†⿰讠十 “SECY-99-130; May 12, 1999, 'Final Rule-Revisions to Requirements of 10 CFR Parts 50 and 72 Concerning Changes, Tests, and Experiments."' (This footnote was part of the original citation.)

1+4 "SECY-99-054; February 22, 1999, 'Plans for Final Rule-Revisions to Requirements of 10 CFR Parts 50, 52, and 72 Concerning Changes, Tests, and Experiments." (This footnote was also part of the original citation.) 
include: (1) the use of common terminology such as 'changes to the cask design, as described in the final safety analysis report' (FSAR); (2) a process for requesting amendments to a $\mathrm{CoC}$; (3) periodic updates by certificate holders to the FSAR for a transportation package to ensure that an accurate 'licensing' basis is available when future proposed changes are evaluated; and (4) a requirement that licensees possess a copy of the FSAR as well as the $\mathrm{CoC}$ before making a shipment.

"NRC believes that the current IAEA standard TS-R-1 does not contain any equivalent provisions for changing a transportation package's design, without prior review by the agency that certified the design. $\mathrm{NRC}$ is the reviewing agency for Type B and fissile material package approvals. Therefore, any application of 'change authority' to Part $71 \mathrm{CoCs}$ would only apply to packages intended for the domestic transport of spent fuel.

"Discussion. The NRC has received 48 public comments on this issue in response to the issue paper, public meetings, and the website. Industry representatives and certain members of the public support the issue. Public interest organizations, State representatives, and other members of the public generally oppose the issue. The DOE also opposes this issue. Groups in favor of this issue pointed to similar provisions in Parts 50 and 72 where such changes have been safely made. Groups opposed to this issue believe that all changes to a transport package's design should be submitted to the NRC for prior review and approval. These commenters [sic] believed this is necessary because transportation packages are on the public roadways and railways, hence the public believes there is more immediate and greater exposure to the radioactive contents of the package in an accident. The following is a more detailed description of these comments.

"Seven commenters [sic] supported the effort to expand the provisions contained in $\S 72.48$ to include Part 71 certificate holders. Two commenters [sic] also requested that NRC expand the authority for all packages, not just dual-purpose spent nuclear fuel packages.

"Three commenters [sic] requested that NRC be consistent and revoke the change, test, and experiment authority for Part 72 certificate holders. One commenter [sic] opposed allowing the ability to make any changes to casks without prior NRC approval. Similarly, one commenter [sic] sought assurance that NRC would continue to be able to monitor industry performance (i.e., maintain regulatory oversight capability), and be able to undo or revise changes or force amendments when necessary.

"One commenter [sic], opposed to the expansion of authority, referenced a Government Accounting Office (GAO) report that highlighted problems with transportation casks fabricated by Westinghouse, claiming that 20 out of 40 casks had been found to be defective. Another commenter [sic] was opposed to any action, such as moving to performance- or riskbased management, that would increase the level and type of public risk.

"Another commenter [sic] stated that he does not support allowing change authority because the definition of 'minimal' has historically been illdefined. This commenter [sic] also expressed his belief that Issue 15 (change authorization issue), as currently proposed, would not result in Part 71 conforming with TS-R-1. The commenter [sic] cited as evidence the text in the Issues Paper that states, 'the current IAEA standard ST-1 does not contain any equivalent provisions for changing a transportation package's design, without prior review by the competent authority.'

"Most commenters [sic] expressed interest in receiving additional information from NRC about what changes might be allowable, and clarification that these allowable changes would only be for activities not important to safety (e.g., switching to nonreactive paints). One commenter [sic] also suggested that NRC and DOT be careful in determining allowable, nonsafety changes because with the effort to lengthen the certificate revalidation cycle, it is conceivable that these changes would just be rolled into the new certification without review. This commenter [sic] also questioned how NRC plans to address the issue of conformity with other nations' package requirements and certificates.

"NRC believes that the capability to make minor changes to a transportation package is similar to the capability to make minor changes to a reactor facility, to a spent fuel storage facility, or a spent fuel storage cask design. The Commission has recently issued a final rule which authorized Part 72 certificate holders to make minor changes to a spent fuel storage cask's design. Therefore, NRC believes that extending this authority to Part 71 packages is consistent with previous Commission actions.

"The current regulatory structure of Part 71 requires that all design changes to a transportation package, which would change the $\mathrm{CoC}$ or included drawings, be submitted to the NRC for prior review and approval. However, a package user (i.e., a Part 71 general licensee) is not currently required to obtain a copy of the safety analysis report (SAR) and understand it before shipping radioactive material. Rather, the licensee is only required to obtain a copy of the $\mathrm{CoC}$ and any referenced documents, determine that the package is properly configured for shipment (i.e., meets the requirements of $\S \S 71.85$ and 71.87 ), determine that the intended radioactive contents are within the conditions of the $\mathrm{CoC}$, implement any procedure required by the $\mathrm{CoC}$, and accomplish these activities under an NRC-approved QA program (in accordance with Part 71, Subpart H). Consequently, a licensee is not required to understand the technical bases of the Part 71 regulations on normal conditions of transport, hypothetical accident conditions, and 
criticality control (i.e., $\S \S 71.71,71.73$, and 71.55, respectively), before the licensee can use the package to transport radioactive material. Therefore, NRC staff believes that a significant increase in burden would be imposed on licensees to understand these technical bases, if they were permitted to make changes under a 'change authority' regulation.

"NRC also notes that Part 71 does not contain some of the regulatory foundations which support the recent revision to $\S 72.48$. For example, under $\S 72.48$, a licensee is required to evaluate proposed changes to the cask design against the FSAR (as updated), and to periodically incorporate these changes into the FSAR to ensure that an accurate licensing basis is maintained for use in evaluating future proposed changes. Additionally, a Part 71 licensee need not own the package it is using to transport radioactive material. Instead, the licensee is considered a 'registered user' of the package. This second circumstance, when coupled with a Part 71 change authority, might create a situation in which one licensee could make an authorized change to a package, without prior NRC approval, transfer that package to another registered user, without forwarding all change summaries to the next user, who would then be unable to verify or recognize that the package is in conformance with the $\mathrm{CoC}$ (i.e., acceptable for use under the requirements of Subpart G (e.g., § 71.87)).

"The design drawings for a transportation package are directly incorporated by reference into the Part 71 $\mathrm{CoC}$, whereas the design drawings for a spent fuel storage cask are contained in the FSAR. While changes to a design (as described in the FSAR) are permitted, changes to the $\mathrm{CoC}$ (or any drawings incorporated into the $\mathrm{CoC}$ by reference) would not be permitted. As a consequence, these referenced drawings limit the population of potential changes that a licensee or certificate holder could make under a Part 71 change authority equivalent to $\S 72.48$.

"Based upon review of the potential impacts, NRC believes that adding the necessary regulatory requirements (i.e., foundations) to Part 71 to support a change authority equivalent to $\S 72.48$ would unnecessarily increase the burden on all licensees without providing a corresponding benefit. Providing this change authority would also increase the complexity of the Part 71 regulations.

"The NRC believes the issue of inconsistent change authority between Parts 71 and 72 for a dual-purpose spent fuel package should be resolved. Performance of Parts 50 and 72 licensees and the Part 76 certificate holder in implementing the change processes of Parts 50, 72, and 76 has demonstrated that these types of changes can be made safely, without prior NRC approval. However, NRC staff also believes that the scope of this authority should be limited to dual-purpose packages, rather than all
NRC-certified spent fuel packages, and limited to only the certificate holders.

"Accordingly, the NRC staff considers the best approach in resolving these conflicts is through the use of a parallel regulatory structure in Part 71. While the NRC staff would retain the current process for existing transportation packages, a new process for approving dual-purpose transportation packages would be added to Part 71. Authority to make changes to a dual-purpose package design would be provided, and new requirements on the issuance and review of an SAR would also be provided. These new regulations would only apply to Type B(DP) dual-purpose packages intended for the domestic transportation and storage of spent fuel. Because IAEA standard TS-R-1 does not contain any provisions to permit a certificate holder to make changes to the design of a package without prior review and approval by the 'competent authority' that issued the certificate, a Type B(DP) package could not be approved for international use.

"To provide a clear distinction between these new and existing packages, the new packages would be classified as Type B(DP), would have a unique 'B(DP)' identifier, and for reasons discussed below, these packages would not be required to meet TS-R-1 standards and could not be used in international transport. For a Type B(DP) package, requirements on submitting an FSAR, periodically updating the FSAR, applying for an amendment to the $\mathrm{CoC}$, and changing the design of the dual-purpose package, without prior NRC approval, would be consolidated in a new Subpart I to Part 71. To provide greater consistency between the Parts 71 and $72 \mathrm{CoCs}$, the NRC staff would use the same 20-year term for both $\mathrm{CoCs}$ and would synchronize the CoCs' expiration dates. Further, the NRC staff would use the same 20-year term for a QA program approval to design or fabricate a Type B(DP) package.

"Additionally, a new general license ( $§ 71.18$ ) would be added to Subpart $C$ that would require a licensee shipping spent fuel in a Type B(DP) package to have both a copy of the $\mathrm{CoC}$ and the current updated FSAR before making the shipment. Licensees would not be authorized under this proposed rule to make changes to a Type B(DP) package's design by themselves, but would be required to obtain certificate holder (i.e., the package designer) review and approval of the proposed change. Further, should the evaluation of the proposed change indicate that prior NRC approval is required, then only the certificate holder would be authorized to submit an application to the NRC to amend the CoC.

"NRC believes that approval of proposed changes to the design of a Type B(DP) package, or submitting a request to modify a package's design, should be restricted to the certificate holder. As described above, licensees have not previously been required to understand the design bases for a transportation 
package or the technical bases of the Part 71 regulations.

"The NRC believes that the new parallel structure provides a choice to applicants desiring to obtain transportation certification for a spent fuel storage and transportation package. This proposed structure (in Subpart I) would not restrict an applicant's right to obtain a $\mathrm{CoC}$ for a spent fuel transportation package under the existing requirements in Subpart D. Applicants can weigh the costs and benefits associated with each approach against the needs of its customers and determine which approach is better. Consequently, the NRC believes the new parallel structure is voluntary and does not impose a backfit.

"Additional conforming changes would be made to $\S 71.0$ to include Type $\mathrm{B}(\mathrm{DP})$ packages within the scope of Part 71 ; to $\S 71.4$ to add a definition for Certificate of compliance, Type B(DP) packages, and Structures, systems, and components important to safety; to $\S 71.6$ to reflect the new recordkeeping and reporting requirements created by the addition of new Subpart I (required under the Paperwork Reduction Act); to add a new $\S 71.10$ to provide for public availability of applications; to $\S 71.51$ to exclude Type B(DP) packages; and to $\S 71.100$ to indicate which of these new sections (i.e., $\S 71.18$ and Subpart I) would be subject to criminal penalties.

"The NRC draft RA indicates that the proposed expansion of Part 71 to include a new $\S 71.175$, 'Changes, tests, and experiments,' to include Part 71 certificate holders is reasonable from a regulatory, cost, and safety perspective. As noted, however, NRC has very limited data from which to draw this conclusion. The NRC believes that not adopting these provisions may be awkward and appears to result in a regulatory inconsistency. Specifically, this inconsistency appears in situations where a certificate holder for a dual-purpose cask design could not modify the design of a component that had both storage and transport functions without prior NRC approval, irrespective of the certificate holder's authority under $\S 72.48$ to modify the design of a storage cask. While the adoption of this change would not be consistent with the requirements in TS-R-1, NRC believes the benefits to be gained by allowing Part 50 and Part 72 licensees and the Part 71 certificate holder to revise the cask design for a dualpurpose cask outweigh the potential impacts of this inconsistency. Further, these impacts would be offset by restricting this authority to packages intended for domestic shipments only. Preliminary estimates indicate that NRC costs would decline slightly by adopting this change, because NRC would not have to review as many license amendments each year. This cost savings was determined to be negligible in the $\S 72.48$ regulatory analysis, and would be offset by the agency having to adopt new document controls to handle the 'minimal change' submission required every 2 years for licensees making 'minimal changes.' For the 350 recordkeeping licensees listed in the Part 71 Supporting Statement, professional judgment was used to assume that, in any given year, 50 percent of licensees will perform a 'minimal change' as described in $\S 72.48$ over a 2 -year period. Submittals under $\S 72.48$ are required every 2 years; therefore, approximately 88 submittals are expected per year. The cost savings of reporting 'minimal changes' versus preparing license amendments is estimated at approximately $\$ 2.4$ million per year. The 350 licensees would incur a one-time recordkeeping cost of approximately $\$ 2.3$ million the first year this change is implemented.

"NRC Proposed Position. The NRC proposes to add a new type of package (dual-purpose) to Part 71 [i.e., Type B(DP)]. Type B(DP) transportation packages would be certified for the storage of spent fuel under Part 72 and for transportation of spent fuel under Part 71. Type B(DP) packages would be restricted to use in domestic commerce. Requirements on the submission, review, amendment, and issuance of a CoC for a Type B(DP) package would be contained in a new Subpart I to Part 71. A new general license providing for the use of a Type B(DP) package would be added to Subpart C (\$ 71.18). Certificate holders for Type B(DP) packages would also be required to submit, and periodically update, an FSAR describing the package's design. Additionally, only the certificate holder for a Type B(DP) package would be allowed under Subpart I to make changes to the package's design.

"Additionally, conforming changes would be made to $\S \S 71.0,71.4,71.6,71.10,71.17$, and 71.100.

“Affected Sections. $§ \S 71.0,71.4,71.6,71.10,71.17$, $71.18,71.100$, and 71.151 through 71.177.

"Issue 16. Fissile Material Exemptions and General License Provisions

"Background. The NRC published an emergency final rule amending its regulations on shipments of small quantities of fissile material (62 FR 5907; February 10, 1997). This rule revised the regulations on fissile exemptions in $\S 71.53$ and the fissile general licenses in $\S \S 71.18$ and 71.22. The NRC determined that good cause existed, under Section 553(b)(B) of the Administrative Procedure Act (APA) (5 U.S.C. 553(b)(B)), to publish this final rule without notice and opportunity for public comment. Further, the NRC also determined that good cause existed, under Section 553(d)(3) of the APA (5 U.S.C. 553(d)(3)), to make this final rule immediately effective. Notwithstanding the final status of the rule, the NRC provided for a 30-day public comment period. The NRC subsequently published in the Federal Register (64 FR 57769; October 27, 1999) a response to the comments received on the emergency final rule and a request for information on any unintended economic impacts caused by the emergency final rule. 
"The NRC issued this emergency final rule in response to a regulatory defect in the fissile exemption regulation in $\S 71.53$ which was identified by an NRC licensee. The licensee was evaluating a proposed shipment of a special fissile material and moderator mixture (beryllium oxide mixed with a low concentration of high-enriched uranium). The licensee concluded that while $\S 71.53$ was applicable to the proposed shipment, applying the requirements of $\S 71.53$ could, in certain circumstances, result in an inadequate level of criticality safety (i.e., an accidental nuclear criticality was possible in certain unique circumstances). ${ }^{\S \S \S \S}$

"The NRC staff confirmed the licensee's analysis that this beryllium oxide and high-enriched uranium mixture created the potential for inadequate criticality safety during transportation. An added factor in the urgency of the situation was that under the NRC regulations in $\S \S 71.18,71.20,71.22,71.24$, and 71.53 , these types of fissile material shipments could be made without prior approval of NRC. For many years, NRC allowed these shipments of small quantities of fissile material based on NRC's understanding of the level of risk involved with these shipments, as well as industry's historic transportation practices. This experience base had led NRC (and its predecessor, the Atomic Energy Commission (AEC)) to conclude that shipments made under the fissile exemption provisions of Part 71 typically required minimal regulatory oversight (i.e., NRC considered these types of shipments to be inherently safe).

"All public comments on the emergency final rule supported the need for limits on special moderators

$\S \S \S \S$ “For transportation purposes, 'nuclear criticality' means a condition in which an uncontrolled, self-sustaining, and neutron-multiplying fission chain reaction occurs. 'Nuclear criticality' is generally a concern when sufficient concentrations and masses of fissile material and neutron moderating material exist together in a favorable configuration. Neutron moderating material cannot achieve criticality by itself in any concentration or configuration. However, it can enhance the ability of fissile material to achieve criticality by slowing down neutrons or reflecting neutrons." (This footnote was part of the original citation.)

***** "The NRC's regulations in part 71 ensure protection of public health and safety by requiring that Type AF, B, or $\mathrm{BF}$ packages used for transportation of large quantities of radioactive materials be approved by the NRC. This approval is based upon the NRC's review of applications which contain an evaluation of the package's response to a specific set of rigorous tests to simulate both normal conditions of transport (NCT) and hypothetical accident conditions (HAC). However, certain types of packages are exempted from the testing and NRC prior approval; these are fissile material packages that either contain exempt quantities ( $\$ 71.53)$, or are shipped under the general license provisions of $\S \S 71.18,71.20,71.22$, or 71.24 .” (This footnote was part of the original citation.) (i.e., moderators with low neutron-absorption properties such as beryllium, graphite, and deuterium). However, the commenters [sic] stated that the restrictions were far too limiting (to the point that some inherently safe packages were excluded from the fissile exemption) and could lead to undue cost burdens with no benefit to safety. In addition, the commenters $[\mathrm{sic}]$ believed that the consignment mass limits set to deter undue accumulation of fissile mass would be extremely costly. Therefore, the commenters [sic] recommended that further rulemaking was necessary to resolve these excessive restrictions. Based on the public comments on the emergency final rule, NRC staff contracted with Oak Ridge National Laboratory (ORNL) to review the fissile material exemptions and general license provisions, study the regulatory and technical bases associated with these regulations, and perform criticality model calculations for different mixtures of fissile materials and moderators. The results of the ORNL study were documented in NUREG/CR-5342, ${ }^{\dagger+\dagger \dagger}$ and NRC published a notice of the availability of this document in the Federal Register (63 FR 44477; August 19, 1998). The ORNL study confirmed that the emergency final rule was needed to provide safe transportation of packages with special moderators that are shipped under the general license and fissile material exemptions, but the regulations may be excessive for shipments where water moderation is the only concern. The ORNL study recommended that NRC revise Part 71.

"Subsequently, NRC published a Federal Register notice that responded to public comments on the emergency final rule and requested additional information on the cost impact of the emergency final rule from the public, industry, and DOE (64 FR 57769; October 27, 1999). The Commission requested this cost impact information because the NRC staff was not successful in obtaining this information. Specifically, NRC requested information on the cost of shipments made under the fissile material exemptions and general license provisions of Part 71 before the publication of the emergency final rule, and those costs and/or changes in costs resulting from implementation of the emergency rule. One commenter $[$ sic] agreed with the NRC approach, but stated that, "the limits for those materials containing no special moderators can and should be increased, hopefully back to their preemergency rule levels.'

"As part of NUREG/CR-5342, ORNL performed computer model calculations of $\mathrm{k}_{\text {eff }}$ (k-effective) for various combinations of fissile material and

\footnotetext{
†⿰亻门广 "NUREG/CR-5342, 'Assessment and Recommendations for Fissile-Material Packaging Exemptions and General Licenses Within 10 CFR Part 71,' July 1998." (This footnote was also part of the original citation.)
} 
moderating material, including beryllium, carbon, deuterium, silicon-dioxide, and water, to verify the accuracy of current minimum critical mass values. These minimum critical mass values were then applied to the regulatory structure contained in Part 71, and revised mass limits for both the general license and exemption provisions to Part 71 were determined. Also, ORNL researched the historical bases for the fissile material exemption and general license regulations in Part 71 and discussed the impact of the emergency final rule's restrictions on NRC licensees. ORNL concluded that the restrictions imposed by the emergency final rule were necessary to address concerns relative to uncontrolled accumulation of exempt packages (and thus fissile mass) in a shipment and the potential for inadequate safety margin for exempt packages with large quantities of special moderators.

"Based on its new $\mathrm{k}_{\text {eff }}$ calculations, ORNL suggested that: (1) The mass limits in the general license and exemption provisions could be safely increased and thereby provide greater flexibility to licensees shipping fissile radioactive material; and (2) additional revisions to Part 71 were appropriate to provide increased clarification and simplification of the regulations....

"Discussion. The NRC has received public comments on this issue in response to the Issues Paper, public meetings, and the workshop. Industry representatives, public interest organizations, Agreement States, and members of the public supported the issue. None of the comments presented new issues from those previously presented in response to the emergency final rule or the Commission's request for additional cost information.

"Addressing the emergency final rule, one commenter [sic] agreed with the necessity for the rule, but stated that there are issues yet to be resolved for water moderated shipments. In comparison, another commenter [sic] took issue with our stated goal and NRC's methods. This commenter [sic] believed that if NRC adopts these provisions, then NRC will be unable to conform with TS-R-1. The commenter [sic] cited as evidence a statement in the issues paper, 'IAEA standard ST-1 (nee TS-R-1) contains language on fissile exemptions and restrictions on the use of special moderators. However, ST-1 does not currently contain provisions on general licenses for shipment of fissile material.'

"Similarly, one commenter [sic] raised the importance of coordinating regulatory actions on fissile material exemptions with the international community. The commenter $[\mathrm{sic}]$ noted the international community's interest in fissile material exemptions and encouraged NRC to listen to its international counterparts at the next IAEA meeting; the commenter's [sic] goal being to ensure that NRC is not out of step with the rest of the world (i.e., fissile material exempt in the U.S. is not exempt elsewhere, and vice-versa).

"One commenter $[$ sic $]$ raised questions concerning specific recommendations in NUREG/CR-5342. The commenter [sic] was concerned in how recommendations 3 and 4 would introduce unnecessary complexity and noted that this concern vanishes if the TS-R-1 definitions for regulated material are adopted. The commenter [sic] also stated that recommendation 17 could seemingly eliminate the fissile excepted category, which is something the commenter [sic] did not want to see occur. If such a change is necessary, the commenter [sic] requested that the NRC instead revise the excepted package's definition to reduce the amount of fissile material present and ensure that 10 CFR 71.53 and 49 CFR 173.453 are consistent with TS-R-1 (i.e., with respect to upper limits on a package's fissile material, as well as the total amount of fissile material in a fissile exempt consignment).

"The current restrictions on fissile exempt and general license shipments under $\S \S 71.53$, and 71.18 through 71.24, respectively, are burdensome for a large number of shipments that actually contain no special moderating materials (i.e., packages that are shipped with water considered as the potential moderating material). This problem was clearly expressed in public comments on the emergency final rule. Another regulatory problem is that the current fissile exempt and general license provisions are cumbersome and outdated; this was one of the main conclusions of the ORNL study. Therefore, the NRC would update, simplify, and streamline these sections of Part 71 to eliminate regulatory confusion.

"The proposed revisions in Table 16-1 are based on public comments received on the February 10, 1997, emergency final rule, on the subsequent Commission's direction in SRM-SECY-99-200 regarding the unintended economic impact of that emergency final rule, and on the latest public comments received on the July 2000 Issues Paper. Altogether, ORNL suggested 17 changes to the Part 71 regulations in NUREG/CR-5342. A summary of these changes and the NRC's assessment and recommendation are contained in Table 16-1. NUREG/CR-5342 contains a more detailed discussion of the proposed changes listed in Table 16-1 and ORNL's supporting calculations. 
"Table 16-1.-Summary of Recommended Changes in NUREG/CR-5342

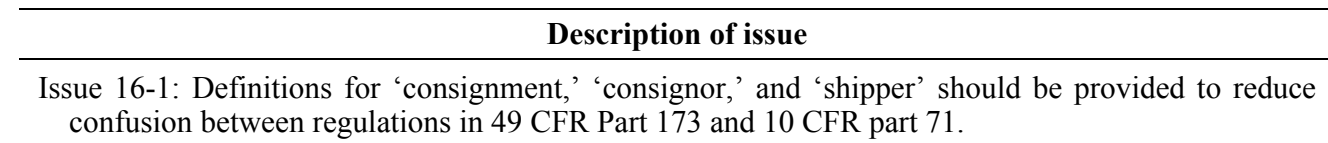

Issue 16-2: Plutonium-238 should be removed from the definition of 'fissile material,' because ${ }^{238} \mathrm{Pu}$ is only fissionable, not fissile.

Issue 16-3: The exemption for radioactive material in $\$ 71.10$ (a) should be revised to exclude fissile material. ORNL's concern was that a large quantity of a low-concentration fissile material could pose a criticality safety concern. The revised $\mathrm{k}_{\text {eff }}$ calculations indicate that a $43 \mathrm{~Bq} / \mathrm{g}$ $\left(1.16 \times 10^{-3} \mu \mathrm{Ci} / \mathrm{g}\right)$ limit for fissile material $\left({ }^{235} \mathrm{U}\right)$ would be necessary. However, other fissile nuclides have higher limits (e.g., $6,230 \mathrm{~Bq} / \mathrm{g}(0.168 \mu \mathrm{Ci} / \mathrm{g})$ for ${ }^{233} \mathrm{U}$ or $66,000 \mathrm{~Bq} / \mathrm{g}(1.784 \mu \mathrm{Ci} / \mathrm{g})$ for ${ }^{241} \mathrm{Pu}$ ) or the Appendix A, new Table A-2, values are only $10 \mathrm{~Bq} / \mathrm{g}\left(2.7 \times 10^{-4} \mu \mathrm{Ci} / \mathrm{g}\right)$ (e.g., $\left.{ }^{239} \mathrm{Pu}\right)$.

Issue 16-4: The exemption for radioactive material in existing $\$ 71.10$ should be revised to require shipment in an acceptable package as required by existing $\$ 71.11$ to improve safety.

Issue 16-5: Section 71.53 should be relocated from Subpart E-Package Approval Standards, to Subpart B-Exemptions, to provide greater consistency in Part 71. (Note: $\$ 71.53$ would also be redesignated as $\S 71.15$.).

Issue 16-6: The NRC or DOT should keep a database of shipments made under the fissile exemption or general licenses. Section 71.97 should be revised to require licensees to keep these records and report this information.

Issue 16-7: The provisions for plutonium-beryllium $(\mathrm{Pu}-\mathrm{Be})$ shipments should be removed from the four general licenses of existing $\$ \S 71.18,71.20,71.22$, and 71.24 and consolidated in a new general license. The mass limits for $\mathrm{Pu}-\mathrm{Be}$ shipments should be reduced, because the revised $\mathrm{k}_{\text {eff }}$ calculation indicate potential safety problems exist with the current limits.

Issue 16-8: The general licenses of existing $\S \S 71.18,71.20,71.22$, and 71.24 should be consolidated into one general license to simplify the regulations and consistently apply the criticality safety index (CSI).

Issue 16-9: The distinction between quantities of ${ }^{235} \mathrm{U}$ that can be shipped in a uniform distribution and nonuniform distribution should be eliminated from the general licenses. The bounding nonuniform quantities should be used to simplify compliance with the rule.

Issue 16-10: Restrictions on the quantities of $\mathrm{Be}, \mathrm{C}$, and $\mathrm{D}_{2} \mathrm{O}$ to less than $0.1 \%$ should be removed for the general licenses. A maximum of $500 \mathrm{~g}$ of $\mathrm{Be}, \mathrm{C}$, and $\mathrm{D}_{2} \mathrm{O}$ per package should be imposed to preclude the potential for these materials to be effective as reflector materials.

Issue 16-11: A separate mass control or restriction for moderators having a hydrogen density greater than water should be retained for general licenses. For mixtures of moderators, lower mass limits should be imposed if more than $15 \%$ of the moderating material has a moderating effectiveness greater than the hydrogen density of water. Use of a $15 \%$ mixture limit would reduce confusion when mixtures of moderators are present in a shipment.

Issue 16-12: Package mass limits for general licenses may be increased to reflect results of new analyses and still maintain equivalence of safety as provided for requirements certified packages.

\section{NRC staff recommendation}

Disagree. These changes are not necessary with the use of mass ratio limits and a criticality safety index when combined with the current requirement in $\$ 71.59$.

Agree.

Disagree. The existing exception to the exemption in paragraph (b) would be maintained (i.e., the reference to the fissile exemption in new §71.15). However, no change would be made to paragraph (a) because the values in Table A-2 are less than $43 \mathrm{~Bq} / \mathrm{g}\left(1.16 \times 10^{-3} \mu \mathrm{Ci} / \mathrm{g}\right)$ or the fissile nuclides have criticality limits which would be higher than the exempt concentration limits of Table A-2.

Agree.

Agree.

Disagree. The licensee's burden in keeping and reporting these records is not commensurate with the safety risk for fissile exemption shipments.

Agree.

Agree.

Agree.

Agree.

Agree.

Agree. Also, minimum package requirements should be established. However, imposing \$71.43 requirements would be excessive for the commensurate risk from these shipments. Instead the DOT Type A package requirements should be used. 
"Table 16-1.- Summary of Recommended Changes in NUREG/CR-5342—Continued

\begin{tabular}{|c|c|}
\hline Description of issue & NRC staff recommendation \\
\hline $\begin{array}{l}\text { Issue 16-13: Package mass limits for general licenses should be revised to reflect the new } \mathrm{k}_{\mathrm{eff}} \\
\text { calculations. These mass limits can be safely increased. }\end{array}$ & Agree. \\
\hline $\begin{array}{l}\text { Issue 16-14: The mass-limit based exemption in existing } \S 71.53(\mathrm{a}) \text { should be changed to a mass-ratio } \\
\text { based approach. In contrast to concentration-based approaches with consignment limits that are } \\
\text { now in use in the fissile exemptions, the mass-ration approach should provide a simpler, more cost- } \\
\text { effective approach to preventing the formation system configurations having inadequate subcritical } \\
\text { margins as a result of transport scenarios }(\$ \S 71.71 \text { and } 71.73) \text {. }\end{array}$ & $(\text { See Below })^{*}$ \\
\hline $\begin{array}{l}\text { Issue 16-15: If a mass-ratio approach is used, the restrictions on } \mathrm{Be}, \mathrm{C} \text {, and } \mathrm{D}_{2} \mathrm{O} \text { in existing } \S 71.53(\mathrm{a}) \text {, } \\
\text { (c), and (d) should be removed. }\end{array}$ & Agree. \\
\hline $\begin{array}{l}\text { Issue 16-16: The exemption for uranyl nitrate solutions in } \S 71.53(\mathrm{c}) \text { should include a packaging } \\
\text { requirement from existing } \$ 71.43 \text {. }\end{array}$ & $\begin{array}{l}\text { Agree in part. Minimum package } \\
\text { requirements should be established. How- } \\
\text { ever, } \$ 71.43 \text { is excessive for the } \\
\text { commensurate risk from these shipments. } \\
\text { The DOT Type A package requirements } \\
\text { should be used. }\end{array}$ \\
\hline $\begin{array}{l}\text { Issue 16-17: The exemption for uranium enriched to less than } 1 \mathrm{wt} \%{ }^{235} \mathrm{U} \text { in existing } \$ 71.53(\mathrm{~b}) \\
\text { should be modified to remove the homogeneity requirements and lattice prevention requirement. } \\
\text { Instead, retain the } 0.1 \% \mathrm{Be}, \mathrm{C} \text {, and } \mathrm{D}_{2} \mathrm{O} \text { limit because of the difficulty in defining and applying } \\
\text { 'homogenous' and 'lattice arrangement' restrictions. }\end{array}$ & Agree. \\
\hline
\end{tabular}

"In addition to the recommendations contained in NUREG/CR-5342, the Commission directed the NRC staff, in SRM-M970122B on SECY-96-268, to issue additional guidance in instances where fissile materials may be mixed in the same shipping container with different moderators (i.e., materials of differing moderator effectiveness). Therefore, the NRC would add a note to Table 71-1 in existing $\S 71.22$ to use reduced mass limits if more than 15 percent of the moderating materials in a package have a moderating effectiveness greater than the average hydrogen density of $\mathrm{H}_{2} \mathrm{O}$ (see Issue 16-11 in Table 16-1 above).

"The NRC believes these changes would provide greater flexibility in the shipment of fissile material under the fissile exemption and general license regulations. The NRC would revise these requirements using a risk-informed approach, and address the burden and excessiveness issues raised in the public comments on the emergency final rule. The NRC would use a graduated regulatory approach in establishing requirements for the shipment of fissile material. The graduated approach would involve three tiers of regulations consisting of: (1) The fissile material exemptions with low fissile mass limits and minimal requirements (i.e., the new $\S 71.15)$; (2) the fissile general licenses with higher mass limits and packaging and QA requirements (i.e., the new $\S \S 71.22$ and 71.23); and (3) the Type AF, BF, $\mathrm{B}(\mathrm{U}) \mathrm{F}$, or $\mathrm{B}(\mathrm{M}) \mathrm{F}$ fissile material packages with large mass limits that require prior NRC approval of the package design (i.e., the existing $\S 71.55)$. The NRC believes this approach would establish a risk-informed framework by imposing progressively stricter requirements as the quantity of fissile material being shipped increases (i.e., the criticality hazard increases). In accomplishing this risk-informed approach, some mass limits in the general licenses would increase, and others would decrease. These changes would reflect the new $\mathrm{k}_{\text {eff }}$ calculations in NUREG/CR-5342. To counterbalance the increases in mass limits in the general licenses, requirements would be added on the use of a Type A package, a CSI, and an NRC-approved QA program.

"While the NRC is proposing to adopt the use of the CSI for general licensed fissile packages, the NRC is proposing to retain the current per package (CSI) limit of 10, rather than raising the per package limit to 50 (see Issue 5). TS-R-1 does not address the issue of fissile general licenses, so no compatibility issues arise with retention of the current NRC per package limit of 10. NRC staff believes that because reduced regulatory oversight is imposed on fissile general license shipments (e.g., the package standards of $\S \S 71.71$ and 71.73 , fissile package standards of $\S 71.55$, and fissile array standards of $\S 71.59$ are not imposed for fissile general license shipments), retention of the current per package limit of 10 is appropriate. Furthermore, retention of the current per package limit of 10 would not impose a new burden on licensees; rather, licensees shipping fissile material under the general license provisions of $\S \S 71.22$ and 71.23 would not be permitted to take advantage of the relaxation of the per package CSI limit from 10 to 50 that would be permitted for Types $\mathrm{A}(\mathrm{F})$ and $\mathrm{B}(\mathrm{F})$ package shipments.

* Author's Note: This block was left blank in the original citation. 
"Overall, the NRC would amend Part 71 as follows: (1) Revise $\S 71.10$, 'Exemption for low level material,' to exclude fissile material, also redesignate $\S 71.10$ as 71.14 ; (2) redesignate $\S 71.53$ as $\S 71.15$, 'Exemption from classification as fissile material,' and revise the fissile exemptions; (3) consolidate the existing four general licenses in existing $\S \S 71.18$, $71.20,71.22$, and 71.24 into one general license in new $\S 71.22$, revise the mass limits, and add Type A package, CSI, and QA requirements; and (4) consolidate the existing general license requirements for plutonium-beryllium sealed sources, which are contained in existing $\S \S 71.18$ and 71.22 into one general license in new $\S 71.23$ and revise the mass limits. Additionally, conforming changes would be made to $\S 71.4$, 'Definitions' and $\S 71.100$, 'Criminal penalties.'

"The NRC draft RA indicates that incorporating revisions to the fissile material exemption and general license provisions in Part 71 is appropriate from a safety, regulatory, and cost perspective. As stated earlier, there is a shortage of data on the fissile material general license and exempt shipments; consequently, the NRC was not successful in obtaining data to quantify the economic impact which would result from adopting some or all of the 17 recommendations in NUREG/CR-5342. The impact of these amendments on the licensees and the NRC would be both positive and negative, depending on the specific recommendation. Recommendations 1, 2, and 5 would enhance regulatory efficiency due to the increase in clarity of the NRC regulations. Recommendations 3, 4, 6, 9, and 12 would increase costs to licensees. Recommendations $7,8,10,13,14$, and 15 would eliminate the potential for criticality accidents, which would, in turn, yield environmental and public health and safety benefits. Finally, recommendations 11, 16, and 17 would result in savings to licensees.

"NRC Proposed Position. The NRC proposes revisions to the fissile material exemptions and the general license provisions in Part 71.

"Affected Sections. $\S \S 71.4,71.10,71.11,71.18$, $71.20,71.22,71.24,71.53,71.59$, and 71.100.

"Issue 17. Double Containment of Plutonium (PRM-71-12)

"Background: In 1974, the AEC issued a final rule which imposed special requirements on the shipment of plutonium (39 FR 20960; June 17, 1974). These requirements are located in $\S 71.63$ and apply to shipments of radioactive material containing quantities of plutonium in excess of $0.74 \mathrm{TBq}$ (20 curies). Section 71.63 contains two principal requirements. First, the plutonium contents of the package must be in solid form (§ 71.63(a)). Second, the packaging containing the plutonium must provide a separate inner containment (i.e., the 'double containment' requirement) (§ 71.63(b)). In addition, the AEC specifically excluded from the double containment requirement of $\S 71.63(\mathrm{~b})$ plutonium in the form of reactor fuel elements, metal or metal alloys, and other plutonium-bearing solids that the Commission (AEC or NRC) may determine, on a case-by-case basis, do not require double containment. This regulation remained essentially unchanged from 1974 until 1998, when vitrified highlevel waste in sealed canisters was added to the list of exempt forms of plutonium in $\S$ 71.63(b) (63 FR 32600; June 15, 1998). The double containment requirement is in addition to the existing subparts $\mathrm{E}$ and $\mathrm{F}$ requirements imposed on Type $\mathrm{B}$ packagings (e.g., the normal conditions of transport and hypothetical accident conditions of $\S \S 71.71$ and 71.73, respectively, and the fissile package requirements of $\S \S 71.55$ and 71.59). Part 71 does not impose a double containment requirement for any radionuclide other than plutonium. Additionally, IAEA standard TS-R-1 does not provide for a double containment requirement (in lieu of the single containment Type B package standards) for any radionuclide.

"The AEC issued this regulation at a time when AEC staff anticipated widespread reprocessing of commercial spent fuel, and existing shipments of plutonium were made in the form of liquid plutonium nitrate. Because of physical changes to the plutonium that was expected to be reprocessed (i.e., higher levels of burnup in commercial reactors for spent fuel, which would then be reprocessed), and regulatory concerns with the possibility of package leakage, the AEC issued a regulation that imposed the double containment requirement when the package contained more than $0.74 \mathrm{TBq}(20 \mathrm{Ci})$ of plutonium. This double containment was in addition to the existing Type $\mathrm{B}$ package standards on packages intended for the shipment of greater than an $A_{1}$ or $A_{2}$ quantity of plutonium.

"NRC staff has reviewed the available regulatory history for $\S 71.63$, and has provided a recapitulation of the supporting information which led to the issuance of this regulation. NRC staff has extracted the following information from several SECY papers the AEC staff submitted to the Commission on this regulation. NRC staff believes this information is relevant and will provide stakeholders with perspective in understanding the bases for this regulation, and thereby assist stakeholders in evaluating the staff's proposed changes to this regulation.

"In SECY-R-702, the AEC staff identified two considerations that were the genesis of the rulemaking that led to $\S 71.63$. AEC staff stated:

First, increasingly larger quantities of plutonium will be recovered from power reactor spent fuel. Second, the specific activity of the plutonium will

"SECY-R-702, 'Consideration of Form for Shipping Plutonium,' June 1, 1973." (This footnote was part of the original citation.) 
increase with higher reactor fuel burnup resulting in greater pressure generation potential from plutonium nitrate solutions in shipping containers, greater heat generation, and higher gamma and neutron radiation levels. These changes will make the present nitrate packages obsolete. Thus, from both safety and economic considerations, the transportation of plutonium as [liquid] nitrate will soon require substantial redesign of packages to handle larger quantities as well as to deal with the higher levels of gas evolution (pressurization), heat generation, and gamma and neutron radiation.

There is little doubt that larger plutonium nitrate packages could be designed to meet regulatory standards. The increased potential for human error and the consequences of such error in the shipment of plutonium nitrate are not so easily controlled by regulation. Even though such packages may be adequately designed, their loading and closure requires high operation performance by personnel on a continuing basis. As the number of packages to be shipped increases, the probability of leakage through improperly assembled and closed packages also increases. *** More refined or stringent regulatory requirements, such as double containment, would not sufficiently lessen this concern because of the necessary dependence on people to affect engineered safeguards.

"In SECY-R-74-5, ${ }^{\dagger}$ AEC staff summarized the factors relevant to consideration of a proposed rule following a June 14, 1973, meeting to discuss SECY-R-702, between the Regulatory and General Manager's staffs (i.e., the rulemaking and operational sides of the AEC). The AEC stated:

As a result of this meeting [on June 14, 1973], the [Regulatory and General Manager's] staffs have agreed that the basic factors pertinent to the consideration of form for shipment of plutonium are:

1. The experience with shipping plutonium as an aqueous nitrate solution in packages meeting current regulatory criteria has been satisfactory to date.

2. The changing characteristic of plutonium recovered from power reactors will make the existing packaging obsolete for plutonium nitrate solutions and possibly for solid form. Economic factors will probably dictate considerably larger shipments (and larger packages) than currently used.

3. It is expected that packages can be designed to meet regulatory standards for either aqueous solutions or solid plutonium compounds. Just as in any situation involving the packaging of radioactive materials, a high level of human performance is necessary to assure against leakage caused by human error in packaging. As the number of plutonium shipments increases, as it will, and packages become larger and more complex in design, the probability of such human error increases.

4. The probability of human error with the packaging for liquid, anticipated to be more complex in

"SECY-R-74-5, 'Consideration of Form for Shipping Plutonium,' dated July 6, 1973.” (This footnote was part of the original citation.) design, is probably greater than with the packaging for solid. Furthermore, should a human error occur in package preparation or closure, the probability of liquid escaping from the improperly prepared package is greater than for most solids and particularly for solid plutonium materials expected to be shipped.

5. Staff studies reported in SECY-R-62 and SECY-R-509: conclude that the consequences of release of solid or aqueous solutions do not differ appreciably. Therefore, this paper (SECY-R-702) does not deal with the consequences of releases.

6. It is therefore concluded that safety would be enhanced if plutonium were shipped as a solid rather than in solution.

"The arguments for requiring a solid form of plutonium for shipment are largely subjective, in that there is no hard evidence on which to base statistical probabilities or to assess quantitatively the incremental increase in safety which is expected. The discussion in the regulatory paper, SECY-R-702, is not intended to be a technical argument which incontrovertibly leads to a conclusion. It is, rather, a presentation of the rationale which has led the Regulatory staff to its conclusion that a possible problem may develop and that the proposed action is a step towards increased assurance against the problem developing. In SECY-R-74-172, ${ }^{\S}$ AEC staff submitted a final rule to the Commission for approval.

"The proposed rule had contained a requirement that the plutonium be contained in a special form capsule. However, in response to comments from the AEC General Manager, the final rule changed this requirement to a separate inner container (i.e., the double containment requirement). The AEC staff indicated in a response to a public comment in Enclosure B (to SECY-R-74-172) that ' $[\mathrm{t}]$ he need for the inner containment is based on the desire to provide a substitute for not requiring the plutonium to be in a "nonrespirable" form.'

"The NRC staff believes the regulatory history of $\S 71.63$ indicates that the AEC's decision to require a separate inner container for shipments of plutonium in excess of $0.74 \mathrm{TBq}(20 \mathrm{Ci})$ was based on policy and regulatory concerns (i.e., 'that a possible problem may develop and that the proposed action [in SECY-R-702] is a step towards increased assurance against the problem developing'). Because of the expectation of a significant increase in the number of

$\$$ 'SECY-R-62, 'Shipment of Plutonium,' and SECY-R-509, 'Plutonium Handling and Storage,' dated October 16, 1970. These papers concluded that there is no scientific or technical reason to prohibit shipment of plutonium nitrate and recommended that Commission (AEC) efforts be directed toward providing improved safety criteria for shipping containers." (This footnote was part of the original citation.)

$\S \quad$ "SECY-R-74-172, 'Consideration of Form for Shipping Plutonium,' April 18, 1974.” (This footnote was also part of the original citation.) 
liquid plutonium nitrate shipments, the AEC used a defense-in-depth philosophy (i.e., the double containment and solid form requirements), to ensure that respirable plutonium would not be released to the environment during a transportation accident. However, the regulatory history does indicate that the AEC's concerns did not involve the adequacy of existing liquid plutonium nitrate packages. Rather, the AEC's regulatory concern was on the increased possibility of human error combined with an expected increase in the number of shipments would yield an increased probability of leakage during shipment. The AEC's policy concern was based on an economic decision on whether the AEC should require the reprocessing industry to build new, larger liquid plutonium-nitrate shipping containers, capable of handling higher burnup reactor spent fuel, or to build new, dry, powdered plutonium-dioxide shipping containers. The regulatory history indicates that the AEC staff judged that new, larger, higher burnup-capacity liquid plutonium-nitrate packages could be designed, approved, built, and safely used. However, one of the AEC's principal underlying assumptions for this rule was obviated in 1979 when the Carter administration decided that reprocessing of civilian spent fuel and reuse of plutonium was not desirable. Consequently, the expected plutonium reprocessing economy and widespread shipments of liquid plutonium nitrate within the U.S. never materialized.

"On June 15, 1998, in response to a petition for rulemaking submitted by DOE (PRM-71-11), the Commission issued a final rule revising $\S 71.63$ (b) to add vitrified high-level waste (HLW) contained in a sealed canister to the list of forms of plutonium exempt from the double containment requirement (June 15, 1998; 63 FR 32600). In its original response to PRM-71-11, NRC proposed in SECY-96-215 ${ }^{* *}$ to make a 'determination' under $\S 71.63(\mathrm{~b})(3)$ that vitrified HLW contained in a sealed canister did not require double containment. However, the Commission in an SRM on SECY-96-215, dated October 31, 1996, disapproved the staff's approach and directed that resolution of this petition be addressed through rulemaking (the June 15, 1998, final rule was the culmination of this effort). In addition to disapproving the use of a 'determination' process, the Commission also directed the staff to $* * * *$ also address whether the technical basis for 10 CFR 71.63 remains valid, or whether a revision or elimination of portions of 10 CFR 71.63 is needed to provide flexibility for current and future technologies.' In SECY-97-218, ${ }^{\dagger \dagger}$

** "SECY-96-215, 'Requirements for Shipping Packages Used to Transport Vitrified Waste Containing Plutonium,' dated October 8, 1996." (This footnote was part of the original citation.)

i† "SECY-97-218, 'Special Provisions for Transport of Large Quantities of Plutonium (Response to Staff
NRC responded to the SRM's direction and stated ' $[\mathrm{t}]$ he technical basis remains valid and the provisions provide adequate flexibility for current and future technologies.'

"Petition: The NRC received a petition for rulemaking from International Energy Consultants, Inc. (IEC), dated September 25, 1997. The petition was docketed as PRM-71-12 and was published for public comment (63 FR 8362; February 19, 1998). Based on a request from General Atomic, the comment period was extended to July 31, 1998 (see 63 FR 34335; June 24, 1998). Nine public comments were received on the petition. Four commenters [sic] supported the petition, and five commenters [sic] opposed the petition.

"The petitioner requested that $\S 71.63(\mathrm{~b})$ be removed. The petitioner argued that the double containment provisions of $\S 71.63(\mathrm{~b})$ cannot be supported technically or logically. The petitioner stated that based on the 'Q-system for the Calculation of $\mathrm{A}_{1}$ and $A_{2}$ Values,' an $A_{2}$ quantity of any radionuclide has the same potential for damaging the environment and the human species as an $\mathrm{A}_{2}$ quantity of any other radionuclide.

"NRC believes that the Q-values are based upon radiological exposure hazard models which calculate the allowable quantity limit (the $A_{1}$ or $A_{2}$ value) necessary to produce a known exposure (i.e., one $\mathrm{A}_{2}$ of plutonium-239 or one $A_{2}$ of cobalt- 60 will both yield the same radiation dose under the Q-system models, even though the $\mathrm{A}_{2}$ values for these nuclides are different [e.g., one $\mathrm{A}_{2}$ of plutonium-239 $=2 \times 10^{4} \mathrm{TBq}$ of plutonium and one $\mathrm{A}_{2}$ of cobalt- 60 $=1 \mathrm{TBq}$ of cobalt]). The Q-system models take into account the exposure pathways of the various radionuclides, typical chemical forms of the radionuclide, methods for uptake into the body, methods for removal from the body, the type of radiation the radionuclide emits, and the bodily organs the radionuclide preferentially affects. The specific $A_{1}$ and $A_{2}$ values for each nuclide are developed using radiation dosimetry approaches recommended by the World Health Organization and the International Commission on Radiological Protection (ICRP). The models are periodically reviewed by international health physics experts (including representatives from the United States), and the $A_{1}$ and $A_{2}$ values are updated during the IAEA revision process, based upon the best available data. (Note that changes to the $A_{1}$ and $A_{2}$ values as a result of changes to the models in TS-R-1 are also discussed in Issue 3.) These values are then issued by the IAEA in safety standards such as TS-R-1. When the IAEA has revised the $A_{1}$ and $A_{2}$ values in previous revisions of its transport regulations, these

Requirements Memorandum-SECY-96-215), dated September 29, 1997." (This footnote was part of the original citation.) 
revised values have been adopted by the NRC and DOT into the transportation regulations in 10 CFR Part 71 and 49 CFR Part 173, respectively.

"NRC's review of the current $A_{1}$ and $A_{2}$ values in Appendix A to Part 71, Table A-1, reveals that 5 radionuclides have an $\mathrm{A}_{2}$ value lower than plutonium (i.e., plutonium-239), and 11 radionuclides have an $A_{2}$ value that is equal to plutonium-239. Because the models used to determine the $A_{1}$ and $A_{2}$ values all result in the same radiation exposure (i.e., hazard), a smaller $A_{1}$ and $A_{2}$ value for one radionuclide would indicate a greater potential hazard to humans than a radionuclide with larger $\mathrm{A}_{1}$ and $\mathrm{A}_{2}$ value. Thus, the overall Table A-1 can also be viewed as a relative hazard ranking (for transportation purposes) of the listed radionuclides. In that light, requiring double containment for plutonium alone is not consistent with the relative hazard rankings in Table A-1.

"The petitioner also argued that the Type B package requirements should be applied consistently for any radionuclide, whenever a package's contents exceed an $\mathrm{A}_{2}$ limit. However, Part 71 is not consistent by imposing the double containment requirement for plutonium. The petitioner believes that if Type B package standards are sufficient for a quantity of a particular radionuclide which exceeds the $\mathrm{A}_{2}$ limit, then Type B package standards should also be sufficient for any other radionuclide which also exceeds the $\mathrm{A}_{2}$ limit. The petitioner stated that:

While, for the most part, Part 71 regulations embrace this simple logical congruence, the congruence fails under 10 CFR 71.63(b) wherein packages containing plutonium must include a separate inner container for quantities of plutonium having a radioactivity exceeding 20 curies $[0.74 \mathrm{TBq}]$ (with certain exceptions).

"The petitioner further stated that:

If the NRC allows this failure of congruence to persist, the regulations will be vulnerable to the following challenges: (1) The logical foundation of the adequacy of $\mathrm{A}_{2}$ values as a proper measure of the potential for damaging the environment and the human species, as set forth under the Q-System, is compromised; (2) the absence of a limit for every other radionuclide which, if exceeded, would require a separate inner container, is an inherently inconsistent safety practice; and (3) the performance requirements for Type $\mathrm{B}$ packages, as called for by 10 CFR Part 71, establish containment conditions under different levels of package trauma. The satisfaction of these Type B package standards should be a matter of proper design work by the package designer and proper evaluation of the design through regulatory review. The imposition of any specific package design feature such as that contained in 10 CFR 71.63(b) is gratuitous. The regulations are not formulated as package design specifications, nor should they be.

"NRC agrees that the Part 71 regulations are not formulated as package design specifications; rather, the Part 71 regulations establish performance standards for a package's design. The NRC reviews the application to evaluate whether the package's design meets the performance requirements of Part 71. Consequently, the NRC can then conclude that the design of the package provides reasonable assurance that public health and safety and the environment are adequately protected.

"The petitioner also believes that the continuing presence of $\S 71.63(\mathrm{~b})$ engenders excessively high costs in the transport of some radioactive materials without a clearly measurable net safety benefit. The petitioner stated that this is so, in part, because the ultimate release limits allowed under Part 71 package performance requirements are identical with or without a 'separate inner container,' and because the presence of a 'separate inner container' promotes additional exposures to radiation through the additional handling required for the 'separate inner container.' Consequently, the petitioner asserted that the presence or absence of a separate inner container barrier does not affect the standard to which the outer container barrier must perform in protecting public health and safety and the environment. Therefore, the petitioner concluded that given that the outer containment barrier provides an acceptable level of safety, the separate inner container is superfluous and results in unnecessary cost and radiation exposure. According to the petitioner, these unnecessary costs involve both the design, review, and fabrication of a package, as well as the costs of transporting the package. And the unnecessary radiation exposure involves workers having to handle (i.e., seal, inspect, or move) the 'separate inner container.'

"As an alternative to the primary petition, the petitioner believes that an option to eliminate both $\$ 71.63(\mathrm{a})$ and (b) should also be considered. Section 71.63(a) requires that plutonium in quantities greater than $0.74 \mathrm{TBq}(20 \mathrm{Ci})$ be shipped in solid form. This option would have the effect of removing $\S 71.63$ entirely. The petitioner believes that the arguments set forth to support the elimination of $\S 71.63(\mathrm{~b})$ also support the elimination of $\S 71.63(\mathrm{a})$. The petitioner did not provide a separate regulatory or cost analysis supporting the request to remove $\S 71.63(\mathrm{a})$.

"Comments on the Petition: The four commenters [sic] supporting the petition essentially stated that the IAEA's Q-system accurately reflects the dangers of radionuclides, including plutonium, and that elimination of $\S 71.63(\mathrm{a})$ and (b) would make the regulations more performance based, reduce costs and personnel exposures, and be consistent with the IAEA standards.

"The five commenters [sic] opposing the petition essentially stated that: (1) Plutonium is very dangerous, especially in liquid form, and therefore additional regulatory requirements are warranted; (2) Existing regulations are not overly burdensome, especially in light of the total expected transportation cost; (3) TRUPACT-II packages meet current 
$\S 71.63(\mathrm{~b})$ requirements (TRUPACT-II is a package developed by DOE to transport transuranic wastes (including plutonium) to the Waste Isolation Pilot Plant (WIPP) and has been issued a Part $71 \mathrm{CoC}$, No. 9218); (4) A commenter [sic] (the Western Governors' Association) has worked for over 10 years to ensure a safe transportation system for WIPP, including educating the public about the TRUPACT-II package; (5) Any change now would erode public confidence and be detrimental to the entire transportation system for WIPP shipments; and (6) Additional personnel exposure due to double containment is insignificant.

"Discussion: The NRC has received 48 public comments on this issue in response to the Issue Paper, public meetings, and the workshop. Industry representatives and some members of the public support the petition. Public interest organizations, Agreement States, State representatives, the Western Governors' Association, and other members of the public oppose the petition. Several commenters [sic] believe that Congress, in approving the Waste Isolation Pilot Plant Land Withdrawal Act (the Act), Pub. L. 102-579 (106 Stat. 4777), Section 16(a), which mandates that the NRC certify the design of packages used to transport transuranic waste to WIPP, expected those packages to have a double containment. The NRC researched this issue, and Section 16(a) of the Act does not contain any explicit provisions mandating the use of a double containment in packages transporting transuranic waste to or from WIPP. Section 16(a) of the Act states, in part, "[n]o transuranic waste may be transported by or for the Secretary [of the DOE] to or from WIPP, except in packages the design of which has been certified by the Nuclear Regulatory Commission* * *, Furthermore, the NRC has reviewed the legislative history ${ }^{\sharp 1}$ associated with the Act and has not identified any discussions on the use of double containment for the shipment of transuranic waste. The legislative history does mention that the design of these packages will be certified by the NRC; however, this language is identical to that contained in the Act itself. Therefore, the NRC believes the absence of specific language in Section 16(a) of the Act requiring double containment should be interpreted as requiring the $\mathrm{NRC}$ to apply its independent technical judgment in

$\$$ "See Congressional Record Vol. 137, November 5, 1991, pages S15984-15997 (Senate approval of S. 1671); Cong. Rec. Vol. 138, July 21, 1992, pages H6301-6333 (House approval of H.R. 2637); Cong. Rec. Vol. 138, October 5, 1992, pages H11868-11870 (House approval of Conference Report on S. 1671); Cong. Rec. Vol. 138, October 8, 1992 (Senate approval of Conference Report on S. 1671); and Cong. Rec. Vol. 138, October 5, 1992, pages H12221-12226 (Conference Report on S. 1671(H.) Rpt. 102-1037)." (This footnote was part of the original citation.) establishing standards for package designs and in evaluating applications for certification of package designs, to ensure that such packages would provide reasonable assurance that public health and safety and the environment would be adequately protected. In carrying out its mission, the courts have found that the NRC has broad latitude in establishing, maintaining, and revising technical performance criteria necessary to provide reasonable assurance that public health and safety and the environment are adequately protected. An example of these technical performance criteria is the Type B package design standards. Accordingly, the NRC believes that the proposed revision of a technical package standard (i.e., removal of the double containment requirement for plutonium from the Type B package standards) is not restricted by the mandate of Section 16(a) of the Act for the NRC to certify the design of packages intended to transport transuranic material to and from WIPP.

"Other commenters [sic] stated that stakeholders' expectations were that packages intended to transport transuranic material to and from WIPP would include a double containment provision. Consequently, the commenters $[s i c]$ believed that removal of the double containment requirement would decrease public confidence in the NRC's accomplishment of its mission in the approval of the design of packages for the transportation of transuranic waste to and from WIPP. The commenters [sic] believed the public would view elimination of the double containment requirement as a relaxation in safety. The presence of a separate inner container provides defense-indepth through an additional barrier to the release of plutonium during a transportation accident. In addition, the commenters [sic] believed that plutonium is so inherently deadly, that defense-indepth is appropriate. The NRC agrees that a double containment does provide an additional barrier. However, the NRC believes that, for the reasons discussed below, double containment is unnecessary to protect public health and safety. The NRC and AEC have not required an additional containment barrier for Type B packages transporting any radionuclides other than plutonium and, before 1974, the AEC did not require double containment for plutonium.

"In response to some of the comments opposed to the petition, the NRC believes that removal of $\S 71.63(\mathrm{~b})$ would not invalidate the design of existing packages intended for the shipment of plutonium. These packages could continue to be used with a separate inner container. The NRC agrees with the commenters $[\mathrm{sic}]$ that a quantitative cost analysis was not provided by the petitioner.

"The NRC has issued Part 71 CoC No. 9218 to DOE for the TRUPACT-II package (Docket No. 71-9218), for the transportation of transuranic waste (including plutonium) to and from the WIPP. The TRUPACT-II 
package complies with the current $\S$ 71.63(b) requirements and has a separate inner container. The TRUPACT-II SAR indicates that the weight of the inner container and its lid is approximately 2,620 lbs. Hypothetically, elimination of the separate inner container would increase the available payload for the TRUPACT-II package from the current 7,265 to 9,885 lbs. Thus, removal of the double containment requirement would potentially increase the TRUPACT-II's available payload by 36 percent. Further, the removal of the inner container from the TRUPACT-II would also potentially increase the available volume. The NRC believes that the proposed rule would not invalidate the existing TRUPACT-II design, and thus, DOE could continue to use the TRUPACT-II to ship transuranic waste to and from WIPP, or DOE could consider an alternate Type B package.

"Additionally, based on comments received in the public meetings, the NRC believes that a misperception exists with respect to TRUPACT-II shipments; removal of the $\S$ 71.63(b) double containment requirement would not result in loose plutonium waste being placed inside a TRUPACT-II package. Based upon information contained in the SAR, plutonium wastes (i.e., used gloves, anti-Cs, rags, etc.) are placed in plastic bags, and these bags are sealed inside lined 55-gallon steel drums. Plutonium residues are placed inside cans which are then sealed inside a pipe overpack (a 6-inch or 12-inch stainless steel cylinder with a bolted lid), and the pipe overpack is then sealed inside a lined 55-gallon steel drum. The 55-gallon drums are then sealed inside the TRUPACT-II inner containment vessel, and finally the inner containment vessel is sealed inside the TRUPACT-II package. Consequently, the TRUPACT-II shipping practices employ multiple barriers, and removal of the inner containment vessel would not be expected to produce a significant incremental increase in the possibility of leakage during normal transportation. The NRC notes that some NRC regulations have established additional requirements for plutonium (e.g., the special nuclear material license application provisions of $\S 70.22(\mathrm{f})$ ).

"The NRC believes that the Type B packaging standards, in and of themselves, provide reasonable assurance that public health and safety and the environment would be adequately protected during the transportation of radioactive material. This belief is supported by an excellent safety record in which no fatalities or injuries have been attributed to material transported in a Type B package. Type B packaging standards have been in existence for approximately 40 years and have been incorporated into the Part 71 regulations by both the $\mathrm{NRC}$ and its predecessor, the AEC. The NRC's Type B package standards are based on IAEA's Type B package standards. Moreover, IAEA's Type B package standards have never required a separate inner container for packages intended to transport plutonium, nor for any other radionuclide. The NRC believes that while U.S. shipments of plutonium subject to $\S 71.63(\mathrm{~b})$ have consisted primarily of solid plutonium contaminated wastes, other European countries have reprocessed plutonium in their reactor fuel cycles and have transported liquid plutonium nitrate. The NRC is not aware of any accidents involving a Type B liquid plutonium nitrate package which has led to the significant failure of the package and release of the contents.

"Therefore, the NRC believes that imposition of an additional packaging requirement (in the form of a separate inner container) is fundamentally inconsistent with the position that Type B packaging standards, in and of themselves, provide reasonable assurance that public health and safety and the environment would be adequately protected during the transportation of (any type of) radioactive material. Thus, the NRC believes that $\S 71.63(\mathrm{~b})$ is not consistent with the Type B packaging standards contained in part 71 .

"The NRC also believes that the regulatory history of $\S 71.63$ demonstrates that the AEC's decision was based on policy and regulatory concerns. However, the NRC also agrees that the use of a double containment does provide defense-in-depth and does decrease the absolute risk of the release of respirable plutonium to the environment during a transportation accident. Consequently, while the defense-in-depth afforded by a double containment does reduce risk, the NRC believes the question which should be focused on is whether the double containment requirement is risk-informed. The NRC is unaware of any risk studies that would provide either a qualitative or quantitative indication of the risk reduction associated with the use of double containment in transportation of plutonium. Rather, the NRC would look to the demonstrated performance record of existing Type $B$ package standards to conclude that double containment is not necessary.

"In summary, the AEC indicated (in SECY-R-702 and SECY-R-74-5), that liquid plutonium nitrate packages were safe, and new, larger packages to handle higher burnup reactor spent fuel could also be designed. NRC believes that the AEC's assumption for initiating this requirement was that large scale reprocessing of civilian reactor spent fuel and reuse of plutonium would occur. Former President Carter's administration's decision to forgo the reprocessing of civilian reactor spent fuel and reuse of plutonium obviated the AEC's assumption. Consequently, the AEC's supposition that a human error occurring while sealing a package of liquid plutonium nitrate was more likely to occur with the expected increase in shipments of plutonium nitrate was also obviated by the Government's decision to forgo the reprocessing of civilian reactor spent fuel. In SECY-97-218, NRC staff indicated that the separate inner container provided an additional barrier to the 
release of plutonium in an accident. NRC continues to believe that a separate inner container provides an additional barrier to the release of plutonium in an accident, just as a package with triple containment would provide an even greater barrier to the release of plutonium in an accident. However, this type of approach is not risk informed nor performance based. Consequently, based upon review of the petition, comments on the petition, and research into the regulatory history of the double containment requirement, the $\mathrm{NRC}$ agrees that a separate inner container is not necessary for Type B packages containing solid plutonium. NRC believes that the worldwide performance record over 40 years of Type B packages demonstrates that a single containment barrier is adequate. Therefore, the NRC agrees with the petitioner and believes that $\S 71.63(\mathrm{~b})$ is not technically necessary to provide a reasonable assurance that public health and safety and the environment will be adequately protected during the transportation of plutonium.

"While the NRC believes a case can be made for elimination of the separate inner container requirement in $\S 71.63(\mathrm{~b})$, elimination of the solid form requirement in $\S 71.63$ (a) is not as clear. While the same arguments can be made on the obviation of the AEC's basis for originally issuing $\S 71.63$ (a) (i.e., the elimination of reprocessing of plutonium), the same regulatory inconsistency between Type B package standards and the inner containment requirement does not exist for the liquid versus solid form argument. The NRC considers the contents of a package when it is evaluating the adequacy of a packaging's design. The approved content limits and the approved packaging design together define the $\mathrm{CoC}$ for a package. However, other than criticality controls and the liquid form requirement of $\S 71.63(\mathrm{a})$, Subparts $E$ and $F$ do not contain any restrictions on the contents of a package. Thus, while the inner containment requirement in $\S 71.63(\mathrm{~b})$ can be seen as conflicting with the Type B package standard because the inner containment affects the packaging's design, the solid form requirement of $\S 71.63(\mathrm{a})$ does not conflict with the packaging requirements of the Type B package standard because the solid form requirement affects only the contents of the package, not the packaging itself.

"The NRC expects that cost and dose savings would accrue from the removal of $\S 71.63(\mathrm{~b})$. However, because no shipments of liquid plutonium nitrate are contemplated in the U.S., NRC does not expect cost or dose savings to accrue from the removal of $\S 71.63(\mathrm{a})$. Further, the AEC's original bases have been obviated by former President Carter's administration's decision to not pursue a commercial fuel cycle involving the reprocessing of plutonium.

"After weighing this information, the NRC continues to believe that the Type B package standards, when evaluated against 40 years of use worldwide, and millions of safe shipments of Type B packages, together provide reasonable assurance that public health and safety and the environment would be adequately protected during the transportation of radioactive material. The NRC believes that, in this case, the reasonable assurance standard, provided by the Type B package requirements, provides an adequate basis for the public's confidence in the NRC's actions.

"NRC Proposed Position: The NRC would adopt, in part, the recommended action of PRM-71-12. Specifically, the NRC would remove the double containment requirement of $\S 71.63(\mathrm{~b})$. However, the NRC would retain the package contents requirement in $\S 71.63(\mathrm{a})$. Shipments whose contents contain greater than $0.74 \mathrm{TBq}(20 \mathrm{Ci})$ of plutonium must be made with the contents in solid form.

“Affected Sections. § 71.63.

"Issue 18. Contamination Limits as Applied to Spent Fuel and High Level Waste (HLW) Packages

"Background. In the period of December 1997 through April 1998, the French Nuclear Installations Safety Directorate inspected a French nuclear power plant and railway terminal used by the La Hague reprocessing plant. The inspectors noticed that, since the beginning of the 1990's [sic], a high percentage of spent fuel packages and/or railcars had a level of removable surface contamination that exceeded IAEA regulatory limits by as much as a factor of 1000. Subsequent investigations found that the contamination incidents involved shipments from other European countries, and the French transport authorities notified their counterparts of their findings. Subsequently, French, German, Swiss, Belgian, and Dutch spent fuel shipments were temporarily suspended.

"After estimating the occupational and public doses from the contamination incidents, the European transport authorities concluded that these incidents did not have any radiological consequence. The contamination was believed to be caused by contact of the spent fuel package surface with contaminated water from the spent fuel storage pool during package handling operations. The authorities concluded that there were deficiencies in the contamination measurement procedures and the distribution of that information.

"Media reports on these incidents focused attention on IAEA's regulations for removable contamination on package surfaces. TS-R-1 contains contamination limits for all packages of $4.0 \mathrm{~Bq} / \mathrm{cm}^{2}$ for beta and gamma and low toxicity alpha emitting radionuclides, and $0.4 \mathrm{~Bq} / \mathrm{cm}^{2}$ for all other alpha emitting radionuclides. Although TS-R-1 uses the term limit, IAEA considers these 'limits' to be guidance values, or derived values, above which appropriate action should be considered. In cases of contamination 
above the limit, that action is to decontaminate to below the limits.

"The current TS-R-1 limits for removable package surface contamination were derived from a radiological model developed for the 1961 Edition of the IAEA regulations. The exposure pathways considered in the model included external irradiation of the skin, and ingestion and inhalation from resuspension of the contamination in air. The model uses values for the degree to which surface contamination is resuspended in air, making it available for inhalation, and for the number of hours of exposure to the resuspended contamination. The values were chosen to represent occupational conditions at shipper and carrier facilities, in which workers manually handled many packages throughout the year. These exposure conditions are much greater than the public would experience from brief exposure to packages in transport. The values also exceed real occupational resuspension rates and exposure times and were believed to result in worker doses that would be well within the annual occupational dose limit. Exposure at the contamination limit does not pose a significant health hazard to workers. Therefore, members of the public, few of whom would ever be expected to encounter contaminated packages in transit, and then only briefly, are also protected against contamination hazards by the limit.

"TS-R-1 further provides that in transport, "*** the magnitude of individual doses, the number of persons exposed, and the likelihood of incurring exposure shall be kept as low as reasonable, economic and social factors being taken into account $* * *$, The IAEA contamination regulations have been applied to radioactive material packages in international commerce for almost 40 years, and practical experience demonstrates that the regulations can be applied successfully. With respect to contamination limits, TS-R-1 contains no changes from previous versions of IAEA's regulations.

"Part 71 does not contain contamination limits, but $\S 71.87$ (i) requires that licensees determine that the level of removable contamination on the external surface of each package offered for transport is as low as is reasonably achievable, and within the limits specified in DOT regulations in 49 CFR 173.443. The DOT contamination limits differ from TS-R-1 in that the contamination limits apply to the wipe material used to survey the surface of the package, not the surface itself. Also, the contamination limits are only 10 percent of the TS-R-1 values (e.g., wipe limit of $0.4 \mathrm{~Bq} / \mathrm{cm}^{2}\left(2200 \mathrm{dpm} / 100 \mathrm{~cm}^{2}\right)$ for beta and gamma and low toxicity alpha emitting radionuclides), because the DOT limits are based on the assumption that the wipe removes 10 percent of the surface contamination. In this regard, the DOT and TS-R-1 limits are equivalent.

"The DOT contamination regulations contain an additional provision for which there is no counterpart in TS-R-1. Section 173.443(b) provides that, for packages transported as exclusive use (see 49 CFR 173.403 for exclusive use definition) shipments by rail or public highway only, the removable contamination on any package at any time during transport may not exceed 10 times the contamination limits (e.g., wipe contamination of $4 \mathrm{~Bq} / \mathrm{cm}^{2}\left(22,000 \mathrm{dpm} / 100 \mathrm{~cm}^{2}\right)$ for beta and gamma and low toxicity alpha emitting radionuclides). In practice, this means that packages transported as exclusive use shipments (this includes spent fuel packages) that meet the contamination limits at shipment departure may have 10 times that contamination upon arrival at the destination. This provision is intended to address a phenomenon known as 'cask-weeping,' in which surface contamination that is nonremovable at the beginning of a shipment becomes removable during the course of the shipment. Nonremovable contamination is not measurable using wipe surveys and is not subject to the removable contamination limits. At the destination facility, a package exhibiting caskweeping can exceed the contamination limits by a considerable margin, even though the package met the limits at the originating facility, and was not subjected to any further contamination sources during shipment. Environmental conditions are believed to affect the cask-weeping phenomenon.

"Spent fuel packages and shipments differ from those considered in the 1961 model used to develop package surface contamination limits. Workers are exposed to only a few spent fuel packages per year at most, so their exposure time to package contamination is less than that modeled. Unlike the packages in the model, however, spent fuel package surface areas and radiation levels are significant. Exposure to the package radiation level while performing either contamination survey or decontamination activities contributes to worker dose, and this impact was not considered in the model.

"The IAEA has plans to establish a Coordinated Research Project (CRP) to review contamination models, approaches to reduce package contamination, strategies to address cask-weeping, and possible recommendations for revisions to the contamination standard that consider risks, costs, and practical experience. IAEA establishes CRPs to facilitate investigation of radioactive material transportation issues by key IAEA Member States. IAEA will then consider a CRP report and any further actions or remedies that may be warranted at periodic meetings (at TRANSSC). NRC informed IAEA that NRC supports the IAEA initiative to establish the CRP and that NRC would participate in the IAEA review of surface contamination standards.

"Discussion. During the three public meetings, NRC has received verbal public comments on the contamination issue. One commenter [sic] agreed that external contamination on packages of 
radioactive material in transport is a significant problem and is the source of actual or perceived hazard that can cause damage to the nuclear industry. The commenter [sic] would prefer not to change contamination limits (i.e., continuing to use TS-R-1 limits) unless there is a sound technical basis for doing so.

"NRC was requested to clarify its discussion of the $4 \mathrm{~Bq} / \mathrm{cm}^{2}$. The commenter [sic] stated that the current limit for removable contamination levels in 49 CFR 173.443 is $0.4 \mathrm{~Bq} / \mathrm{cm}^{2}$ before shipment, unless an assessment method with higher efficiency is used, in which case the limit may be as high as 10 times $0.4 \quad \mathrm{~Bq} / \mathrm{cm}^{2} \quad$ (i.e., $4 \mathrm{~Bq} / \mathrm{cm}^{2}$ ) $\left(22,000 \mathrm{dpm} / 100 \mathrm{~cm}^{2}\right)$.

"Four commenters $[\mathrm{sic}]$ stated they understood that existing surface contamination limits (i.e., $4 \mathrm{~Bq} / \mathrm{cm}^{2}$ ) $\left(2200 \mathrm{dpm} / 100 \mathrm{~cm}^{2}\right)$ [sic] were intended for small and not large packages and that using the limit for large packages, while it may reduce public exposure rates, would conceivably increase worker exposure rates. Another commenter [sic] added that worker exposure could actually increase when double containment is required, and expressed concern about how this issue with contamination limits impacts international shipments. Some commenters [sic] stated that it was doubtful that worker exposure rates could be reduced, even if allowable surface contamination rates were significantly increased.

"Several commenters [sic] addressed the issue that workers would be exposed to radiation while measuring the surface contamination level. Three of the commenters [sic] acknowledged that this is true regardless of the level of the package contamination limit. Two commenters [sic] suggested that NRC consider other ways to protect workers, including cask design. Another commenter [sic] stated that if the radiation is too great for workers to get close enough to measure it, it is too great to transport it.

"Absent public objection to the current standard and an overall significantly improved approach, NRC is planning no revisions to Part 71 regarding surface contamination in this proposed rule. The NRC intends to use the information it collects from public comments on this issue to continue to support DOT in U.S. participation in the IAEA CRP and to work with DOT and other IAEA Member States on this issue. Because IAEA has adopted a 2-year revision cycle for TS-R-1, a revision based on the CRP's results could be incorporated into TS-R-1 more quickly than under the previous 10-year revision cycle.

"NRC Proposed Position. The NRC proposes no changes to Part 71 for this issue.

"Affected Sections. None (not adopted).
"Issue 19. Modifications of Event Reporting
Requirements

"Background. The Commission recently issued a final rule to revise the event reporting requirements in 10 CFR Part 50 (see 65 FR 63769; October 20, 2000). This final rule revised the verbal and written event notification requirements for power reactor licensees in $\S \S 50.72$ and 50.73. In SECY-99-181, ${ }^{\S \S}$ NRC staff informed the Commission that public comments on the proposed Part 50 rule had suggested that conforming changes also be made to the event notification requirements in Part 72 (Licensing Requirements for the Independent Storage of Spent Fuel) and Part 73 (Physical Protection of Plants and Materials). In response, the Commission directed the NRC staff to study whether conforming changes should be made to Parts 72 and 73. During this study, the NRC also reviewed the Part 71 event reporting requirements in $\S 71.95$, and concluded that similar changes could be made to the Part 71 event reporting requirements.

"Discussion. This issue was not included in the Part 71 Issues Paper (65 FR 44360; July 17, 2000). Therefore, there were no public comments on this issue.

"The current regulations in $\S 71.95$ require that a licensee submit a written report to the NRC within 30 days of three events: (1) A significant decrease in the effectiveness of a packaging while it is in use to transport radioactive material; (2) details of any defects with safety significance found after first use of the cask; and (3) failure to comply with conditions of the $\mathrm{CoC}$ during use.

"The NRC has identified three principal concerns with the existing requirements in $\S 71.95$. First, the existing requirements only apply to licensees and not to certificate holders. Second, the existing requirements do not contain any direction on the content of these written reports. Third, inconsistencies existed in reporting time frames as a result of the Commission decision in the October 20, 2000, final rule which reduced the reporting burden on reactor licensees in the Part 50 final rule by changing the time for submittal of written reports from 30 days to 60 days.

"With respect to the first concern, NRC believes that events involving a significant reduction in effectiveness of a packaging during its use to transport radioactive material may call into question the design bases for the packaging. Examples of a significant reduction in effectiveness might involve an event that causes a package to exceed the $2 \mathrm{mSv}$ per hour (200-mrem per hour) dose limit or

$\S \S$ "SECY-99-181, 'Proposed Plans and Schedules to Modify Reporting Requirements Other than 10 CFR 50.72 and 50.73 for Power Reactors and Material Licensees,' dated July 9, 1999.” (This footnote was part of the original citation.) 
exceed the Type B package requirements of $\S 71.51$. In these cases, the cause of the reduction in effectiveness may be due to a design flaw. Because the certificate holder has the most in-depth understanding of the design basis for a packaging, the NRC believes that it is appropriate for the certificate holder to work with the licensee to jointly determine the root cause(s) for an event that resulted in a significant decrease in packaging effectiveness. Similarly, identification of safety-significant defects after first use of a packaging may reveal flaws with the packaging's basic design. Therefore, the NRC would revise $\S 71.95$ to require that the licensee request certificate holder input before submitting a written report for the criteria in new paragraphs (a)(1) and (a)(2). The licensee would also be required to provide the certificate holder with a copy of the written event report, after the report is submitted to the NRC. This would permit the certificate holder to monitor and trend package performance information arising from package use by multiple licensees. In new paragraph (a)(3), the NRC would retain the existing requirement for licensees to report instances of failure to follow the conditions of the $\mathrm{CoC}$ while a packaging was in use.

"With respect to the second concern, NRC believes that direction should be provided on the expected contents of these written reports. Currently, no direction is provided to licensees on the form or content of these written reports. The NRC believes that standards for the contents of written reports should be unambiguous. The NRC uses this information to determine if inspection and enforcement follow-up is required for the event or if a generic safety issue exists. Consequently, sufficient information must be provided to the NRC to fulfill its responsibilities to protect public health and safety and the environment. Therefore, NRC would add new paragraphs (c) and (d) to $\S 71.95$ which would provide guidance on the content of these written reports. This new requirement is consistent with the written report requirements for Parts 50 and 72 licensees (i.e., $\S \S 50.73$ and 72.75) and the direction from the Commission in SECY-99-181 to consider conforming event notification requirements to the recent changes made to Part 50. The NRC would also update the submission location for the written reports from the Director, Office of Nuclear Material Safety and Safeguards, to the NRC Document Control Desk. This action is consistent with previous Commission direction to standardize the location for incoming documents and correspondence and would bring Part 71 into greater conformity with Parts 50 and 72. Additionally, the NRC would remove the specific location for submission of written reports from $\S 71.95(\mathrm{c})$ and require that reports be submitted in accordance with $\S 71.1$. This action is also consistent with the approach taken in Parts 50 and 72 and would reduce future NRC burden should the submission address change. This proposed change to $\S 71.1$ is identical to a change made to $\S 72.4$ in a recent Part 72 final rule (see 64 FR 33178; June 22, 1999).

"With respect to the third concern, the NRC staff believes that lengthening the period for submitting reports from 30 days to 60 days would reduce the burden on licensees, while still providing the staff with the necessary information to fulfill the NRC's mission. The NRC uses written event reports for trending, analysis, and long-term follow-up of a licensee's corrective actions. In contrast, immediate reporting of events to the NRC provides indication of significant events when immediate action to protect public health and safety may be required or where the NRC needs timely and accurate information to respond (see 48 FR 39039; August 29, 1983, on the basis for Part 50 event reporting). For transportation events, the NRC receives early notification in the NRC's Operations Center either from a licensee, when a licensee declares an emergency under its emergency plan, for a transportation event, or from DOT's National Response Center, when a shipper notifies DOT of an accident involving radioactive material. Consequently, extending the submission time for written event reports to 60 days would not adversely affect the NRC's ability to promptly respond to an event, because these written reports are not used as the basis for immediate or short term actions.

"The Commission concluded in the October 20, 2000 (65 FR 63769), final rule revising Part 50 event reporting requirements that the length of time to submit a written report should be extended to permit a thorough evaluation of the event, identification of the root causes, and development of corrective actions. The Commission also indicated that a licensee's submission of written reports should not be unnecessarily delayed to take advantage of the full 60-day period. The NRC took this action because some events required a significant amount of time to evaluate the event, identify the root causes, and identify the corrective actions; and consequently, a supplemental written event report was necessary. In addition, a 60-day period is more consistent with the NRC's desire that the licensee and the certificate holder both be involved in the analysis of an event. The Commission indicated that the licensee's burden, in submitting a supplemental written event report, would be reduced by providing sufficient time to complete the original written event report.

"The NRC staff believes the Commission's rationale for lengthening the reporting period from 30 days to 60 days for Part 50 written event reports is also valid for Part 71 written event reports.

"The NRC draft RA indicates that adoption of the conforming change to Part 71 for event reporting requirements is appropriate from a safety, regulatory, and cost perspective. Regulatory efficiency within NRC would increase with adoption of this proposed change and would result in greater conformity among Parts 50, 71, and 72. Further, NRC burden (and thus 
costs) would be reduced should the submission address change in the future. There would be a onetime implementation cost for licensees for revising procedures and for training. A key benefit of the proposed amendments would be a reduction in the recurring annual reporting burden on licensees, as a result of reducing the efforts associated with reporting events of little or no risk or safety significance. It is anticipated that the NRC's recurring annual review efforts for telephone notifications and written reports would not be significantly reduced.

"NRC Proposed Position. The NRC proposes a reduction in regulatory burden for licensees by lengthening the $\S 71.95$ event reporting submission period from 30 to 60 days.

“Affected Sections. § 71.95....

\section{"V. Section-by-Section Analysis}

"Several sections in Part 71 would be redesignated in this rulemaking to improve consistency and ease of use. For some sections, only the section number would be changed. However, for other sections, revisions would also be made to the regulatory language. The following table is provided to aid the public in understanding the proposed numerical changes to sections of Part 71....[31]

\section{"Redesignation Table}

\begin{tabular}{|c|c|}
\hline New section number & $\begin{array}{c}\text { Existing section } \\
\text { number }\end{array}$ \\
\hline$\S 71.8 \ldots$. & $\S 71.11$ \\
\hline$\S 71.9 \ldots \ldots .$. & New Section \\
\hline$\S 71.10 \ldots .$. & New Section \\
\hline$\S 71.11$ (Reserved) ...... & NA \\
\hline$\S 71.12$. & $\S 71.8$ \\
\hline$\S 71.13 \ldots \ldots \ldots \ldots \ldots \ldots$ & $\S 71.9$ \\
\hline$\S 71.14 \ldots \ldots \ldots \ldots \ldots \ldots$ & $\S 71.10$ \\
\hline$\S 71.15 \ldots \ldots \ldots \ldots \ldots \ldots$ & $\S 71.53$ \\
\hline$\S 71.16$ (Reserved) ...... & NA \\
\hline$\S 71.17 \ldots \ldots \ldots$ & $\S 71.12$ \\
\hline$\S 71.18 \ldots \ldots \ldots \ldots \ldots \ldots \ldots$ & New Section \\
\hline$\S 71.19 \ldots .$. & $\S 71.13$ \\
\hline$\S 71.20 \ldots \ldots \ldots \ldots \ldots \ldots$ & $\S 71.14$ \\
\hline$\S 71.21 \ldots \ldots \ldots \ldots \ldots \ldots$ & $\S 71.16$ \\
\hline$\S 71.22 \ldots \ldots \ldots$ & $\S 71.18$ \\
\hline$\S 71.23 \ldots \ldots \ldots \ldots \ldots \ldots$ & $\S 71.20$ \\
\hline$\S 71.24$ (Reserved) ....... & $\begin{array}{l}\S 71.22 \text { (Section re- } \\
\text { moved) }\end{array}$ \\
\hline$\S 71.25$ (Reserved) ....... & $\begin{array}{l}\S 71.24 \text { (Section re- } \\
\text { moved) }\end{array}$ \\
\hline$\S 71.53$ (Reserved) ....... & $\begin{array}{l}\S 71.53 \text { (Section re- } \\
\text { designated) }\end{array}$ \\
\hline
\end{tabular}

\subsection{CFR 71, 2004 FINAL RULE}

In January 2004, the final rule for major changes to 10 CFR 71 was published in the Federal Register.[32] Although we will be taking a look at the information presented in the Preamble for the 2004 Final Rule, the format in this section has again been substantially modified from what has been presented previously. As was noted previously regarding the 2002 Proposed Rule, i.e., Section 52.16, the bureaucratic requirements, the format, and the content for NRC-Rulemakings had changed dramatically between what had been presented previously, and what was presented in that section. Because much of the information presented in the Preamble for the 2004 Final Rule was (is) a repeat of the comparable information already presented for the 2002 Proposed Rule, the information presented in this section will focus primarily on the final results.

Modified appropriately for this section, selected excerpts from the preamble for the 2004 Final Rule for 10 CFR 71 reads as follows:

"SUMMARY: The Nuclear Regulatory Commission (NRC) is amending its regulations on packaging and transporting radioactive material. This rulemaking will make the regulations compatible with the latest version of the International Atomic Energy Agency (IAEA) standards and codify other applicable requirements. This final rule also makes changes in fissile material exemption requirements to address the unintended economic impact of NRC's emergency final rule entitled 'Fissile Material Shipments and Exemptions' (February 10, 1997; 62 FR 5907). Lastly, this rule addresses a petition for rulemaking submitted by International Energy Consultants, Inc.

"EFFECTIVE DATE: This final rule is effective on October 1, 2004. Portions of $\S \S 71.19$ and 71.20 expire on October 1, 2008...

\section{"SUPPLEMENTARY INFORMATION: \\ "Contents}

"I. Background

"II. Analysis of Public Comments

"III. Discussion

A. TS-R-1 Compatibility Issues

Issue 1: Changing Part 71 to the International System of Units (SI) Only

Issue 2: Radionuclide Exemption Values

Issue 3: Revision of $A_{1}$ and $A_{2}$

Issue 4: Uranium Hexafluoride $\left(\mathrm{UF}_{6}\right)$ Package Requirements

Issue 5: Introduction of the Criticality Safety Index Requirements

Issue 6: Type C Packages and Low Dispersible Material

Issue 7: Deep Immersion Test

Issue 8: Grandfathering Previously Approved Packages

Issue 9: Changes to Various Definitions

Issue 10: Crush Test for Fissile Material Package Design

Issue 11: Fissile Material Package Design for Transport by Aircraft

B. NRC-Initiated Issues Issue 12: Special Package Authorizations 
Issue 13: Expansion of Part 71 Quality Assurance (QA) Requirements to Certificate of Compliance (CoC) Holders

Issue 14: Adoption of the American Society of Mechanical Engineers (ASME) Code

Issue 15: Change Authority for Dual-Purpose Package Certificate Holders

Issue 16: Fissile Material Exemptions and General License Provisions

Issue 17: Decision on Petition for Rulemaking on Double Containment of Plutonium (PRM-71-12)

Issue 18: Contamination Limits as Applied to Spent Fuel and High-Level Waste (HLW) Packages

Issue 19: Modifications of Event Reporting Requirements

"IV. Section-By-Section Analysis

"V. Criminal Penalties

"VI. Issues of Compatibility for Agreement States

"VII. Voluntary Consensus Standards

"VIII. Environmental Assessment: Finding of No Significant Environmental Impact

"IX. Paperwork Reduction Act Statement

"X. Regulatory Analysis

"XI. Regulatory Flexibility Act Certification

"XII. Backfit Analysis"*

\section{"I. Background}

"Before developing and publishing a proposed rule, the NRC began an enhanced public-participation process designed to solicit public input on the part 71 rulemaking. The NRC issued a part 71 issues paper for public comment (65 FR 44360; July 17, 2000). The issues paper presented the NRC's plan to revise part 71 and provided a summary of all changes being considered, both International Atomic Energy Agency (IAEA) - related changes and NRC-initiated changes. The NRC received 48 public comments on the issues paper. The NRC enhanced public participation process included establishing an interactive Web site and holding three facilitated public meetings: a 'roundtable' workshop at NRC Headquarters, Rockville, MD, on August 10, 2000, and two 'townhall' meetings - one in Atlanta, GA, on September 20, 2000, and a second in Oakland, CA, on September 26, 2000. Oral and written comments, received from the public meetings by mail and through the NRC Web site, in response to the issues paper were considered in drafting the proposed rule.

*** Author's Note: To give the reader some additional appreciation of the extent of the newer bureaucratic requirements, this was the second of the $10 \mathrm{CFR} 71$ rulemakings to need its own table of contents. (See also Section 52.16.) As can be seen in the Table of Contents for the 2004 Final Rule, there were (are) a total of 12 (XII) Sections. For purposes of this Section, however, we will be focusing primarily on the information in Sections I, III, and IV of the Final Rule, only. Readers interested in the complete text of the 2004 Final Rulemaking for 10 CFR 71 are referred directly to the full text of Reference [32].
"The NRC published the proposed rule in the Federal Register on April 30, 2002 (67 FR 21390), for a 90-day public comment period. In addition to approving the publication of the proposed rule, the Commission also directed the NRC staff to continue the enhanced public participation process. The NRC staff held two public meetings to discuss the proposed rule. The first meeting was held in Chicago, Illinois, on June 4, 2002, and the second was held at the TWFN Auditorium, NRC Headquarters, on June 24, 2002. In addition, the Department of Transportation (DOT) staff participated in these meetings. Transcripts of these meetings were made available for public review on the NRC Web site. The public comment period closed on July 29, 2002. A total of 192 comments were received. Although many comments were received after the closing date, all comments were analyzed and considered in developing this final rule....

\section{"III. Discussion}

"This section is structured to present and discuss each issue separately (with cross references as appropriate). Each issue has four parts: Summary of NRC Final Rule, Affected Sections, Background, and Analysis of Public Comments on the Proposed Rule. $^{\dagger \dagger}$

“A. TS-R-1 Compatibility Issues

"Issue 1. Changing Part 71 to the International System of Units (SI) Only

"Summary of NRC Final Rule. The NRC has decided to continue using the dual-unit system (SI units and customary units) in part 71. This will not conflict with TS-R-1, which uses SI units only, because TS-R-1 does not specifically prohibit the use of a dual-unit system.

"We have decided not to change part 71 to use SI units only nor to require NRC licensees and holders and applicants for a Certificate-of-Compliance $(\mathrm{CoC})$ to use SI units only because doing so will conflict with NRC's Metrication Policy (61 FR 31169; June 19, 1996) which allows a dual-use system. The NRC did not make metrication mandatory because no corresponding improvement in public health and safety would result; rather, costs would be incurred without benefit. Moreover, as noted in the proposed rule (67 FR 21395-21396), the change to SI units only could result in the potential for adverse impact on the health and safety of workers and the general public as a result of unintended exposure in the event of shipping accidents, or medical dose errors, caused by confusion or erroneous conversion between the currently prevailing customary units and the new

itt Author's Note: For purposes of this discussion, the Summary of the NRC Final Rule and the Affected Sections will be presented, verbatim. For the complete discussion on the Background and the Analysis of Public Comments on the Proposed Rule, readers are again encouraged to see the full text of Reference [32]. 
SI units by emergency responders or medical personnel.

"Affected Sections. None (not adopted)....

"Issue 2. Radionuclide Exemption Values

"Summary of NRC Final Rule. The final rule adopts, in $\S \S 71.14,71.88$ and Appendix A, Table A-2, the radionuclide activity concentration values and consignment activity limits in TS-R-1 for the exemption from regulatory requirements for the shipment or carriage of certain radioactive low-level materials. In addition, the final rule provides an exemption from regulatory requirements for natural material and ores containing naturally occurring radionuclides that are not intended to be processed for use of these radionuclides, provided the activity concentration of the material does not exceed 10 times the applicable values. These amendments conform part 71 with TS-R-1 and with DOT's parallel IAEA compatibility rulemaking for CFR 49.

"During the development of TS-R-1, it was recognized that there was no technical justification for the use of a single activity-based exemption value for all radionuclides for defining a material as radioactive for transportation purposes (a uniform activity concentration basis) and that a more rigorous technical approach would be to base radionuclide exemptions on a uniform dose basis. The values and limits in TS-R-1, and adopted in Appendix A, Table A-2, establish a consistent dose-based model for minimizing public exposure. Overall, NRC's analysis shows that the new system would result in lower actual doses to the public than the uniform activity concentration basis system. NRC's regulatory analysis indicated that adopting the radionuclide-specific exemption values contained in TS-R-1 is appropriate from a safety, regulatory, and cost perspective. Moreover, the final rule assures continued consistency between domestic and international regulations for the basic definition of radioactive material in transport.

“Affected Sections. Sections 71.14, 71.88, and Appendix A....

"Issue 3. Revision of $\mathrm{A}_{1}$ and $\mathrm{A}_{2}$

"Summary of NRC Final Rule. The final rule adopts, in Appendix A, Table A-1 of part 71, the new $\mathrm{A}_{1}$ and $\mathrm{A}_{2}$ values from TS-R-1, except for molybdenum-99 and californium-252. The final rule does not include $A_{1}$ and $A_{2}$ values for the 16 radionuclides that were previously listed in part 71 but which do not appear in TS-R-1.

"The $A_{1}$ and $A_{2}$ values were revised by IAEA based on refined modeling of possible doses from radionuclides. The NRC believes that these changes are based on sound science, incorporating the latest in dosimetric modeling and that the changes improve the transportation regulations. The regulatory analysis indicates that adopting these values is appropriate from a safety, regulatory, and cost perspective. Further, adoption of the new $\mathrm{A}_{1}$ and $\mathrm{A}_{2}$ values will be an overall benefit to public and worker health and international commerce by ensuring that the $A_{1}$ and $A_{2}$ values are consistent within and between international and domestic transportation regulations. The NRC is not adopting the $A_{1}$ value for californium-252 because the IAEA is considering changing the value that appears in TS-R-1 back to what presently appears in part 71. The NRC is not adopting the $A_{2}$ value for molybdenum-99 for domestic commerce because this would result in a significant increase in the number of packages shipped, and therefore in potential occupational doses, due to the lower $\mathrm{A}_{2}$ value in TS-R-1.

"Affected Sections. Appendix A....

"Issue 4. Uranium Hexafluoride $\left(\mathrm{UF}_{6}\right)$ Package Requirements

"Summary of NRC Final Rule. The final rule provides, in new $\S 71.55(\mathrm{~g})$, a specific exception for certain uranium hexafluoride $\left(\mathrm{UF}_{6}\right)$ packages from the requirements of $\S 71.55(\mathrm{~b})$. The exception allows $\mathrm{UF}_{6}$ packages to be evaluated for criticality safety without considering the in leakage of water into the containment system provided certain conditions are met, including that the uranium is enriched to not more than 5 weight percent uranium-235. The rule makes part 71 compatible with TS-R-1, paragraph 677(b). Other uranium hexafluoride package requirements in TS-R-1 (paragraphs 629, 630 and 631) do not necessitate changes for compatibility because NRC uses analogous national standards and addresses package design requirements in its design review process.

"The specific exception being placed into the regulations for the criticality safety evaluation of certain uranium hexaflouride $[s i c]$ packages does not alter present practice which has allowed the same type of evaluation under other more general regulatory provisions. NRC has decided to provide this specific exception: (1) To be consistent with the worldwide practice and limits established in national and international standards (ANSI N14.1 and IS 7195) and current U.S. regulations (49 CFR 173.417(b)(5)); (2) because of the history of safe shipment; and (3) because of the essential need to transport the commodity.

"Affected Sections. Section 71.55....

"Issue 5. Introduction of the Criticality Safety Index Requirements

"Summary of NRC Final Rule. The final rule adopts the TS-R-1 (paragraphs 218 and 530). Paragraph 218 results in NRC incorporating a Criticality Safety Index (CSI) in part 71 that is determined in the same manner as current part 71 'Transport Index for criticality control purposes,' but now it must be displayed on shipments of fissile material (paragraphs 544-545) using a new 'fissile material' label. NRC's adoption of TS-R-1 (paragraph 530) 
increases the CSI-per package limit from 10 to 50 for fissile material packages in nonexclusive use shipments. (The previous Transport Index criticality limit was 10.) The TI is determined in the same way as the 'TI for radiation control purposes' and continues to be displayed on the traditional 'radioactive material' label. The basis for these changes that makes part 71 compatible with TS-R-1 is that NRC believes the differentiation between criticality control and radiation protection would better define the hazards associated with a given package and, therefore, provide better package hazard information to emergency responders. The increase in the per package CSI limit may provide additional flexibility to licensees by permitting the increased use of less expensive, nonexclusive use shipments. However, licensees will still retain the flexibility to ship a larger number of packages of fissile material on an exclusive use conveyance. The adoption of the CSI values would make part 71 consistent with TS-R-1 and, therefore, would enhance regulatory efficiency.

"Affected Sections. Sections 71.4, 71.18, 71.20, $71.59 \ldots$

"Issue 6. Type C Packages and Low Dispersible Material

"Summary of NRC Final Rule. The final rule does not adopt the Type $\mathrm{C}$ or Low dispersible material (LDM) requirements for plutonium air transport as introduced in the IAEA TS-R-1. NRC decided not to adopt Type $\mathrm{C}$ or LDM requirements because the U.S. regulations in $\S \S 71.64$ and 71.71 governing plutonium air transportation to, within, or over the United States contains more rigorous packaging standards than those in the IAEA TS-R-1. Furthermore, the NRC's perception is that there is a lack of current or anticipated need for such packages, and NRC acknowledges that the DOT import/export provisions permit use of IAEA regulations.

"Affected Sections. None (not adopted)....

"Issue 7. Deep Immersion Test

"Summary of NRC Final Rule. The final rule adopts the requirement for an enhanced water immersion test (deep immersion test) which is applicable to any Type $\mathrm{B}$ or $\mathrm{C}$ packages containing activity greater than $10^{5} \mathrm{~A}_{2}$. The purpose of the deep immersion test is to ensure package recoverability. The basis for expanding the scope of the deep immersion test to include additional Type $\mathrm{B}$ or $\mathrm{C}$ packages containing activity greater that $10^{5} \mathrm{~A}_{2}$ was due to the fact that radioactive materials, such as plutonium and highlevel radioactive waste, are increasingly being transported by sea in large quantities. The threshold defining a large quantity as a multiple of $\mathrm{A}_{2}$ is considered to be a more appropriate criterion to cover all radioactive materials and is based on a consideration of potential radioactive exposure resulting from an accident. Also, the NRC is retaining the current test requirements in $\S 71.61$ of 'one hour w/o collapse, buckling or leakage of water.' The NRC is retaining this acceptance criterion of 'w/o collapse, buckling, or leakage' as opposed to the acceptance criterion specified in TS-R-1 of only 'no rupture' of the containment. NRC has determined that the term 'rupture' cannot be determined by engineering analysis and the term ' $\mathrm{w} / \mathrm{o}$ collapse, buckling or leakage of water' is a more precise definition for acceptance criterion.

“Affected Sections. Sections 71.41, 71.51, 71.61...

"Issue 8. Grandfathering Previously Approved Packages

"Summary of NRC Final Rule. The final rule adopts the following grandfathering provisions for previously approved packages in section 71.13:

(1) Packages approved under NRC standards that are compatible with the provisions of the 1967 edition of Safety Series No. 6 may no longer be fabricated, but may be used for a 4-year period after adoption of a final rule;

(2) Packages approved under NRC standards that are compatible with the provisions of the 1973 or 1973 (as amended) editions of Safety Series No. 6 may no longer be fabricated; however, may still be used;

(3) Packages approved under NRC standards that are compatible with the provisions of the 1985 or 1985 (as amended 1990) editions of Safety Series No. 6, and designated as ' -85 ' in the identification number, may not be fabricated after December 31, 2006, but may be continued to be used; and

(4) Package designs approved under any pre-1996 IAEA standards (i.e., packages with an ' -85 ' or earlier identification number) may be resubmitted to the NRC for review against the current standards. If the package design described in the resubmitted application meets the current standards, the NRC may issue a new $\mathrm{CoC}$ for that package design with a ' -96 ' designation.

"Thus, the final rule adopts, in part, the provisions for grandfathering contained in TS-R-1. The NRC believes that packages previously approved under the 1967 edition of Safety Series No. 6 lack the enhanced safety enrichments which have been incorporated in the packages approved under the provisions of the 1973, 1973 (as amended), 1985 and 1985 (as amended) editions of Safety Series No. 6. For example, later designs demonstrate a greater degree of leakage resistance and are subject to quality assurance requirements in subpart $\mathrm{H}$ of part 71 . Furthermore, NRC believes that by discontinuing the use of package designs that have been approved to Safety Series No. 6, 1967, for both domestic and international transport of radioactive material, it will ensure safety during transportation and thus will increase public confidence. However, NRC has not adopted the immediate phase out of 1967-approved 
packages as the IAEA has, [sic] Instead, NRC implemented a 4-year transition period for the grandfathering provision on packages approved under the provisions of the 1967 edition of Safety Series No. 6. This period provides industry the opportunity to phase out old packages and phase in new ones, or demonstrate that current requirements are met. NRC recognizes that when the regulations change there is not necessarily an immediate need to discontinue use of packages that were approved under previous revisions of the regulations. The final rule includes provisions that would allow previously-approved designs to be upgraded and to be evaluated to the newer regulatory standards. Note that in 1996, IAEA first published that the 1967-approved packages would be eliminated from use. Thus, with the final rule 4-year phase out of these older packages, industry will have had 12 years (i.e., until 2008) to evaluate its package designs and prepare for the eventual phase out.

"Affected Sections. Section 71.13....

"Issue 9. Changes to Various Definitions

"Summary of NRC Final Rule. The final rule adopts the TS-R-1 definition of Criticality Safety Index (CSI). NRC believes this provides internal consistency and compatibility with TS-R-1. Additionally, the following definitions have been revised to improve their clarity and maintain consistency with DOT: $\mathrm{A}_{1}, \mathrm{~A}_{2}$, Consignment, LSA-I, LSA-II, LSA-III, and Unirradiated uranium. NRC believes that terms must be clearly defined so that they can be used to accurately communicate requirements to licensees. By modifying existing definitions and adding new definitions, the licensee would benefit through more effective understanding of the requirements of part 71.

"Affected Sections. Section 71.4....

"Issue 10. Crush Test for Fissile Material Package Design

"Summary of NRC Final Rule. The final rule adopts, in $\S 71.73$, the TS-R-1 requirement for a crush test for fissile material package designs and eliminated the $1000 \mathrm{~A}_{2}$ criterion, but maintained the current part 71 testing sequence and drop and crush test requirements.

"By adopting TS-R-1, the weight and density criteria will apply to fissile uranium material packages, and packages that were previously exempted because of the $1000 \mathrm{~A}_{2}$ criterion will now require crush testing. Adopting crush test requirements and eliminating the $1000 \mathrm{~A}_{2}$ criterion is appropriate because not adopting the TS-R-1 requirements would result in an inconsistency between part 71 requirements and TS-R-1, which could affect international shipments, and fissile material package designs would continue to not be evaluated for criticality safety against a potential crush test accident condition.
"The NRC did not adopt the TS-R-1 test sequence requirements because no new information existed to address concerns from a previous rulemaking regarding the difference in test requirements between essentially the same IAEA requirements contained in Safety Series No. 6 and part 71. The NRC chose to remain more conservative than the IAEA by requiring both a drop and crush test, rather than one or the other as TS-R-1 would permit.

"Affected Sections. Section 71.73....

"Issue 11. Fissile Material Package Design for Transport by Aircraft

"Summary of NRC Final Rule. The final rule adopts TS-R-1, paragraph 680, Criticality evaluation, in a new $\S 71.55$ (f) that only applies to fissile material package designs that are intended to be transported aboard aircraft. Section 71.55 specifies the general package requirements for fissile materials, and the existing paragraphs of $\S 71.55$ are unchanged. Among other requirements, TS-R-1, paragraph 680, requires that packages must remain subcritical when subjected to the tests for Type $\mathrm{C}$ packages, because:

(1) The NRC has deferred adoption of the Type C packaging tests (see Issue 6);

(2) TS-R-1, paragraph 680 requires Type C tests; and

(3) Paragraph 680 applies to more than Type C packages; only the salient text of paragraph 680 was inserted into $\S 71.55(\mathrm{f})$ and applies to domestic shipments.

"Adopting this change will provide regulatory consistency. Shippers would have been required to meet the TS-R-1 air transport requirements even if the NRC did not adopt them, because the International Civil Aviation Organization had adopted regulations consistent with TS-R-1 on July 1, 2001. U.S. domestic air carriers require compliance with the ICAO regulations even for domestic shipments. Therefore, these changes are expected to benefit industry by eliminating the need for two different package designs.

"Affected Sections. Section 71.55....

\section{"B. NRC-Initiated Issues}

"Issue 12. Special Package Authorizations

"Summary of NRC Final Rule. The final rule adopts, in $\S 71.41$, special package authorizations that will apply only in limited circumstances and only to onetime shipments of large components. Special package authorization regulations are necessary because there are no regulatory provisions in part 71 for dealing with nonstandard packages, other than the exemption provisions and $\S 71.41(\mathrm{c})$. The NRC processing of one-time exemptions for nonstandard packages, such as the Trojan reactor vessel, has required the expenditure of considerable NRC resources. Further, the NRC's policy is to 
avoid the use of exemptions for recurring licensing actions. Special package authorization requirements will result in enhanced regulatory efficiency by standardizing the requirements to provide greater regulatory certainty and clarity, and will ensure consistent treatment among licensees requesting authorization for shipment of special packages.

"Any special package authorization will be issued on a case-by-case basis, and requires the applicant to demonstrate that the proposed shipment would not endanger life or property nor the common defense and security, following the basic process used by applicants to obtain a $\mathrm{CoC}$ for nonspecial packages from NRC.

"The applicant will be required to provide reasonable assurance that the special package, considering operational procedures and administrative controls employed during the shipment, would not encounter conditions beyond those for which it had been analyzed and demonstrated to provide protection. The NRC will review applications for special package authorizations. Approval will be based on NRC staff determination that the applicant will meet the requirements of subpart $\mathrm{D}$ of $10 \mathrm{CFR}$ part 71 . If approved, the NRC will issue a $\mathrm{CoC}$ or other approval (i.e., special package authorization letter).

"NRC will consult with DOT on making the determinations required to issue an NRC special package authorization.

"Affected Sections. Section 71.41....

"Issue 13. Expansion of Part 71 Quality Assurance (QA) Requirements to Certificate of Compliance (CoC) Holders

"Summary of NRC Final Rule. The final rule adds the terms 'certificate holder' and 'applicant for a $\mathrm{CoC}$ ' to subpart $H$, part 71 and adds a new section, $\S 71.9$, on employee protection. Adopting these requirements will ensure that the regulatory scheme of part 71 will remain more consistent with other NRC regulations in that certificate holders and applicants for a CoC will be responsible for the behavior of their contractors and subcontractors.

“This expansion is necessary to enhance NRC's ability to enforce nonconformance by the certificate holders and applicants for a CoC. Although CoC's [sic] are legally binding documents, certificate holders and/or applicants and their contractors and subcontractors have not clearly been brought into the scope of part 71 requirements. This is because the terms 'certificate holder' and 'applicant for a certificate of compliance' do not appear in part 71, subpart $\mathrm{H}$; rather, subpart $\mathrm{H}$ only mentions 'licensee' in these regulations. Consequently, the $\mathrm{NRC}$ has not had a clear basis to cite applicants for, and holders of CoC's [sic] for violations of part 71 requirements in the same way it has licensees.

"The NRC also added a new section ( $§ 71.9)$ on employee protection to part 71. The NRC believes that employee protection regulations should be added to cover the employees of certificate holders and applicants for a $\mathrm{CoC}$ to provide greater regulatory equivalency between part 71 licensees and certificate holders.

"Affected Sections. Sections 71.0, 71.1, 71.6, 71.7, $71.8,71.9,71.91,71.93,71.100$, and 71.101 through $71.137 \ldots$

"Issue 14. Adoption of the American Society of Mechanical Engineers (ASME) Code

"Summary of NRC Final Rule. The NRC has decided not to incorporate the ASME Code, section III, division 3 requirements into part 71. Public Law 104-113 requires that Federal agencies use consensus standards in lieu of government-unique standards, if this use is practical or inconsistent with other existing laws. Because a major revision to the ASME Code is forthcoming and because the changes in that revision are not yet available for staff and stakeholder review, the NRC staff considered it an imprudent use of NRC and stakeholder resources to initiate rulemaking on the current ASME Code revision only to have the ASME Code requirements change during the part 71 rulemaking.

"Affected Sections. None (not adopted)....

"Issue 15. Change Authority for Dual-Purpose Package Certificate Holders

"Summary of NRC Final Rule. The Commission does not reach a final decision on the issue of change authority for dual-purpose package certificate holders in this final rule. The NRC has determined that implementation of this change would result in new regulatory burdens and costs which could be significant. The Commission believes it needs further input from stakeholders on the values and impacts of this change before deciding whether to adopt a final rule providing change authority for dualpurpose package certificate holders. The NRC staff plans to conduct public meetings with appropriate stakeholders to develop a final regulatory solution which it will propose to the Commission. At that time, the Commission will either issue a final rule resolving this issue, taking into account the comments received on the proposed rule and in any future public meetings, or will withdraw 10 CFR part 71 subpart I of the proposed rule.

"Affected Sections. None....

"Issue 16. Fissile Material Exemptions and General License Provisions

"Summary of NRC Final Rule. The final rule adopts various revisions to the fissile material exemptions and the general license provisions in part 71 to facilitate effective and efficient regulation of the transport of small quantities of fissile material. The fissile exemptions $(\S 71.15)$ have been revised to include controls on fissile package mass limit combined with package fissile-to-nonfissile mass ratio. The general license for fissile material (§71.22) has been revised to consolidate and 
simplify current fissile general license provisions from $\S \S 71.18,71.20,71.22$, and 71.24. Under the final rule, the general license is based on mass-based limits and the CSI. In light of comments and applicable DOT requirements, the final rule removes proposed rule language references to 'storage incident to transportation.' Also, the exemptions for low level materials in $\S 71.14$ were revised to apply only to nonfissile and fissile-exempt materials.

"Affected Sections. Sections 71.4, 71.10, 71.11, $71.18,71.20,71.22,71.24,71.53,71.59$, and 71.100 . (Currently effective $\S 71.10$ was relocated to $\S 71.14$ with additional language. Currently effective $\S \S 71.18,71.20,71.22,71.24$, and 71.53 are replaced by new $\S \S 71.15$ and 71.22.)...

"Issue 17. Decision on Petition for Rulemaking on Double Containment of Plutonium (PRM-71-12)

"Summary of Decision on PRM-71-12. Currently in 10 CFR 71.63(b), plutonium in excess of $0.74 \mathrm{TBq}$ $(20 \mathrm{Ci})$ must be packaged in a separate inner container placed within an outer packaging. This is referred to as double containment. It is the combination of the inner container and the outer packaging that is subjected to the normal conditions of transport ( $(71.71)$ and the hypothetical accident conditions ( $\S 71.73)$. Upon application of the normal conditions of transport and hypothetical accident conditions, the acceptance criteria for shielding, containment, and subcriticality in $\S 71.51$ must be also met for the total package (inner container and outer packaging), but the containment dispersal acceptance $\left(10^{-6} \mathrm{~A}_{2} /\right.$ hour or $1 \mathrm{~A}_{2} /$ week $)$ are applied to each boundary (i.e., the inner container and the outer packaging). Note however, as a point of clarification, double containment does not mean two Type B containers nested into one.

"The final rule grants the petitioner's request to remove the double containment requirement of $\S 71.63(\mathrm{~b})$. However, the requirement of $\S 71.63(\mathrm{a})$ that shipments whose contents contain greater than $0.74 \mathrm{TBq}(20 \mathrm{Ci})$ of plutonium must be made with the contents in solid form is retained. Thus, the petitioner's alternative proposal is denied. This completes action on PRM-71-12.

"The NRC has decided to remove the double containment requirement because this regulation is neither risk informed nor performance-based. There are many nuclides with $A_{2}$ values the same or lower than plutonium's for which double containment has never been required. Thus, requiring double containment for plutonium alone is not consistent with the relative hazard rankings in Table A-1. The Type B packaging standards, which the outer containment of plutonium shipments must meet, in and of themselves, provide reasonable assurance that public health and safety and the environment are protected during the transportation of radioactive material. This position is supported by an excellent safety record in which no fatalities or injuries have been attributed to material transported in a Type B package. The imposition of an additional packaging requirement (in the form of a separate inner container) is fundamentally inconsistent with this position and is technically unnecessary to assure safe transport. Further, removal of this requirement will reduce an unnecessary regulatory burden on licensees, will likely result in reduced risk to radiation workers, and will serve to harmonize part 71 with TS-R-1.

"On the other hand, the imposition of the requirement that plutonium in excess of $0.74 \mathrm{TBq}(20 \mathrm{Ci})$ per package be shipped as a solid does not create a regulatory inconsistency with the Type B package standards. The NRC considers the contents of a package when it is evaluating the adequacy of a packaging's design. The approved content limits and the approved packaging design together define the $\mathrm{CoC}$ for a package. However, other than criticality controls and the solid form requirement of $\S$ 71.63(a), subparts $\mathrm{E}$ and $\mathrm{F}$ do not contain any restrictions on the contents of a package. Thus, while the inner containment requirement in $\S 71.63(\mathrm{~b})$ can be seen as conflicting with the Type B package standard because the inner containment affects the packaging design, the solid form requirement of $\S 71.63$ (a) does not conflict with the packaging requirements of the Type B package standard because the solid form requirement affects only the contents of the package, not the packaging itself.

“Affected Sections. Section 71.63....

"Issue 18. Contamination Limits as Applied to Spent Fuel and High-Level Waste (HLW) Packages

"Summary of NRC Final Rule. The final rule does not adopt any changes to part 71 for this issue because experience with regulations requiring that licensees monitor the external surfaces of labeled radioactive material packages for contamination upon receipt and opening indicates the rate of packages exceeding allowable levels en route is low, and therefore, in transit decontamination of packages is not warranted. Further, requiring such decontamination of packages could result in a significant increase in worker doses without a commensurate increase in public health and safety.

"Affected Sections. None (not adopted)....

"Issue 19. Modifications of Event Reporting Requirements

"Summary of NRC Final Rule. The final rule revises, in $\S 71.95$, the event reporting submission period to provide a written report from 30 to 60 days. Other regulatory requirements to orally notify the NRC Operations Center promptly of an event and for licensees to report instances of failure to follow the conditions of the $\mathrm{CoC}$ while packaging was in use remain unchanged. The revision lengthening the time for submission of the written report is consistent with changes to similar requirements in Part 50. 
"Affected Sections. Section 71.95....

\section{"IV. Section-by-Section Analysis}

"Several sections in part 71 are redesignated in this rulemaking to improve consistency and ease of use. For some sections, only the section number is changed. However, for other sections, revisions are being made to the regulatory language. The following table is provided to aid the public in understanding the numerical changes to sections of part 71 .

"Redesignation Table

\begin{tabular}{|c|c|}
\hline New section number & $\begin{array}{l}\text { Existing section } \\
\text { number }\end{array}$ \\
\hline$\S 71.8 \ldots \ldots$ & $\S 71.11$. \\
\hline$\S 71.9$. & New Section. \\
\hline$\S 71.10 \ldots \ldots \ldots \ldots \ldots \ldots$ & New Section. \\
\hline$\S 71.11$ (Reserved) ....... & NA. \\
\hline$\S 71.12 \ldots$ & $\S 71.8$. \\
\hline$\S 71.13 \ldots .$. & $\S 71.9$. \\
\hline$\S 71.14 \ldots$ & $\S 71.10$. \\
\hline$\S 71.15 \ldots .$. & $\S 71.53$. \\
\hline$\S 71.16$ (Reserved) ...... & NA. \\
\hline$\S 71.17 \ldots \ldots \ldots \ldots \ldots \ldots$ & $\S 71.12$. \\
\hline$\S 71.18$ (Reserved)...... & NA. \\
\hline$\S 71.19 \ldots \ldots \ldots \ldots \ldots \ldots$ & $\S 71.13$. \\
\hline$\S 71.20$. & $\S 71.14$. \\
\hline$\S 71.21 \ldots .$. & $\S 71.16$. \\
\hline$\S 71.22 \ldots$. & $\S 71.18$. \\
\hline$\S 71.23 \ldots \ldots \ldots \ldots \ldots \ldots$ & $\S 71.20$. \\
\hline$\S 71.24$ (Reserved) ...... & $\begin{array}{l}\S 71.22 \text { (Section re- } \\
\text { moved). }\end{array}$ \\
\hline$\S 71.25$ (Reserved) .... & $\begin{array}{l}\S 71.24 \text { (Section re- } \\
\text { moved). }\end{array}$ \\
\hline$\S 71.53$ (Reserved) ...... & $\begin{array}{l}\S 71.53 \text { (Section re- } \\
\text { designated). }\end{array}$ \\
\hline
\end{tabular}

The changes introduced by the 2004 Final Rule for 10 CFR 71 went into effect on October 1, 2004.

\subsection{CONCLUSIONS}

In the preceding pages, we have taken a look at the development of U.S. regulations for the transportation of radioactive materials. Primarily based on the requirements for Type B quantities of radioactive material, the information included a number of detailed interactions that have taken place between a variety of U.S. governmental agencies, commissions, and departments. The information also included the numerous interactions that have taken place between these governmental agencies and the IAEA.

From a regulatory perspective, the information presented covered the time period from 1965 through 2004, or about 40 years. Starting in 1978, however, we also began to look at the interactions between the regulatory requirements of 10 CFR 71 and the regulatory guidance provided by the NRC in the form of Reg. Guides, NUREGs, and NUREG/CRs. As we have seen above in Sections 52.7, 52.9, 52.11, and 52.13, the regulatory guidance provided by the NRC specifically noted that the requirements of $10 \mathrm{CFR} 71$ could be met by using the requirements defined in specific sections of the ASME's Boiler \& Vessel Pressure Code (the Code) as a metric for the design, fabrication, assembly, testing, use, and maintenance of packagings used for the transport of Type B quantities of radioactive materials.

We have also seen that, for the most part, the NRC has been reluctant to introduce the requirements of the Code directly into the requirements of 10 CFR 71, preferring instead to introduce Code requirements through the use of its guidance documents. The one exception to this occurred with the adoption of the 1998 Final Rule for the Elimination of Double Containment for Plutonium for Vitrified High Level Waste (see Section 52.15.3). In this case, however, all direct references to Code requirements were later eliminated from 10 CFR 71 with the adoption of the 2004 Final Rule, and the simultaneous elimination of the long-standing, double-containment requirement for Plutonium.

Finally, we noted in the 2004 Final Rule that the NRC has chosen not to adopt ASME Boiler \& Pressure Vessel Code requirements directly into the regulatory requirements for 10 CFR 71. Although it would now seem that we have come full circle, this may not be the case. In reality, two additional situations are at work: 1) the IAEA has adopted a two-year revision cycle for its regulations, in the hope that the latest revisions can be incorporated more quickly than under the previous ten-year revision cycle, and 2) major revisions to the ASME's Boiler \& Pressure Vessel Code have, for some time now, been a work in progress with respect to transportation packages. (For additional detail on this subject, see Chapter 15, Containment Systems for Transportation and Storage Packaging of Spent Fuel and High-Level Radioactive Waste and Spent Fuel, by John D. Stevenson.) At some point in time, it should be expected that both of these situations will eventually cross paths, and that the requirements specified in a totally revised version of the ASME's Boiler \& Pressure Vessel Code will eventually find their way back into the regulatory requirements of $10 \mathrm{CFR} 71$.

\subsection{ACKNOWLEDGEMENTS}

The author would like to thank Roger W. Carlson, Larry E. Fischer, Jack Hovingh, Gerald C. Mok, Edward W. Russell, Jr., and Michael K. Sheaffer, of Lawrence Livermore National Laboratory, for their help and guidance over the past several years. Without their dedication and their long-term commitments to the regulatory issues associated with the requirements of $10 \mathrm{CFR} 71$, this Chapter could not have been written.

This work was performed under the auspices of the U.S. Department of Energy by University of California, Lawrence Livermore National Laboratory under contract W-7405-Eng-48. 


\subsection{REFERENCES}

[1] Atomic Energy Commission, Final Rule, "Part 71Packaging of Radioactive Material for Transport," 31 F.R. 9941, pp. 9941-9949, July 22, 1966.

[2] Title 10, Code of Federal Regulations, Part 71, "Regulations to Protect Against Accidental Conditions of Criticality in the Shipment of Special Nuclear Material," 23 F.R. 7666, pp. 7666-7668, October 3, 1958.

[3] Atomic Energy Commission, Proposed Rule Making, 10 CFR Part 71, "Shipment of Special Nuclear Material," 28 F.R. 2134, pp. 2134-2142, March 5, 1963.

[4] Atomic Energy Commission, Proposed Rule Making, 10 CFR Part 72, "Protection Against Radiation in the Shipment of Irradiated Fuel Elements," 26 F.R. 8982, pp. 8982-8989, September 3, 1961.

[5] Atomic Energy Commission, Proposed Rule Making, 10 CFR Part 72, "Protection Against Radiation in the Shipment of Irradiated Fuel Elements," 28 F.R. 2142, March 5, 1963.

[6] "Regulations for the Safe Transport of Radioactive Materials," International Atomic Energy Agency, Safety Series No. 6, 1964 Revised Edition.

[7] Atomic Energy Commission, Proposed Rule Making, [10 CFR Parts 40, 71, 72], "Transport of Licensed Material," 30 F.R. 15748, pp. 15748-15759, December 21, 1965.

[8] Hazardous Materials Regulations Board, [49 CFR Parts 170-190; 14 CFR Part 103], RADIOACTIVE MATERIALS, Notice of Proposed Rulemaking, 33 F.R. 750, pp. 750-765, January 20, 1968.

[9] Title 49-TRANSPORTATION, Chapter I-Department of Transportation, "Radioactive Materials and Other Miscellaneous Amendments," Final Rule, 33 F.R. 14918, pp. 14918-14936, October 4, 1968.

[10] Title 10-Atomic Energy, Chapter 1-Atomic Energy Commission, "Part 71-Packaging of Radioactive Material for Transport," Miscellaneous Amendments, 33 F.R. 17621, pp. 17621-17624, November 26, 1968.

[11] Atomic Energy Commission, 10 CFR Part 71, Shipment of Radioactive Material, "Approval of Type B, Large Quantity, and Fissile Material Packagings," Proposed Rule, 36 F.R. 22184, pp. 22184-22186, November 20, 1971.

[12] Title 10-Atomic Energy, Chapter 1-Atomic Energy Commission, "Part 71- Approval of Type B, Large Quantity, and Fissile Material Packagings, 1973 Final Rule," 38 F.R. 10437, pp. 10437-10439, April 27, 1973.

[13] Atomic Energy Commission, 10 CFR Part 71, "Packaging and Transportation of Radioactive Material," Form of Shipping Plutonium, 38 F.R. 20482, pp. 2048220483, August 1, 1973.

[14] Title 10-Energy, Chapter I-Atomic Energy Commission, "Part 71-Quality Assurance Requirements for Shipping Containers," 38 F.R. 35490, pp. 35490 35494, December 28, 1973.

[15] Title 10-Energy, Chapter I-Atomic Energy Commission, "Part 71-Packaging of Radioactive Material for Transport and Transportation of Radioactive Materials Under Certain Conditions," Form of Shipping Plutonium, 39 F.R. 20960, June 17, 1974.

[16] Title 10-Energy, Chapter I-Atomic Energy Commission, "Part 71-Quality Assurance Requirements for Transport Packages," 42 F.R. 39364, pp. 3936439368, August 4, 1977.

[17] Title 10-Energy, Chapter I-Atomic Energy Commission, "Part 71 - Extension of the Implementation Period for QA Program Requirements," 43 F.R. 27174, June 23, 1978.

[18] Nuclear Regulatory Commission, Office of Standards Development, Regulatory Guide 7.6, Design Criteria for the Structural Analysis of Shipping Cask Containment Vessels, Washington, DC, Revision 1, March 1978.

[19] Nuclear Regulatory Commission, 10 CFR Part 71, Proposed Rule, "Packaging of Radioactive Material for Transportation and Transportation of Radioactive Material Under Certain Conditions; Compatibility with IAEA Regulations," 44 F.R. 48234, pp. 48234-48257, August 17, 1979.

[20] W. R. Holman and R. T. Langland, Recommendations for Protecting Against Failure by Brittle Fracture in Ferritic Steel Shipping Containers Up to Four Inches Thick, Nuclear Regulatory Commission, NUREG/CR-1815 (UCRL-53013), August 1981.

[21] Title 10-Energy, Chapter I-Nuclear Regulatory Commission, "Final Rule: 10 CFR Part 71—Packaging of Radioactive Material for Transportation and Transportation of Radioactive Material Under Certain Conditions; Compatibility with IAEA Regulations," 48 F.R. 35600, pp. 35600-35627, August 5, 1983.

[22] R. E. Monroe, H. H. Woo, and R. G. Sears, Recommended Welding Criteria for Use in the Fabrication of Shipping Containers for Radioactive Materials, Nuclear Regulatory Commission, NUREG/CR-3019 (UCRL-53044), March 1985.

[23] L. E. Fischer and W. Lai, Fabrication Criteria for Shipping Containers, Nuclear Regulatory Commission, NUREG/CR-3854 (UCRL-53544), March 1985.

[24] Nuclear Regulatory Commission, 10 CFR Part 71, Proposed Rule, "Transportation Regulations; Compatibility with International Atomic Energy Agency (IAEA)," 53 F.R. 21550, pp. 21550-21581, June 8, 1988.

[25] Nuclear Regulatory Commission, Office of Nuclear Regulatory Research, Regulatory Guide 7.11, Fracture Toughness of Base Material for Ferritic Steel Shipping Cask Containment Vessels with a Maximum Wall Thickness of 4 Inches, Washington, DC, June 1991.

[26] Nuclear Regulatory Commission, Office of Nuclear Regulatory Research, Regulatory Guide 7.12, Fracture Toughness Criteria of Base Material for Ferritic Steel 
Shipping Cask Containment Vessels with a Wall Thickness Greater than 4 Inches $(0.1 \mathrm{~m})$ But Not Exceeding 12 Inches $(0.3 \mathrm{~m})$, Washington, DC, June 1991.

[27] Nuclear Regulatory Commission, 10 CFR Part 71, "Compatibility with International Atomic Energy Agency (IAEA), Final Rule" 60 F.R. 50248, pp. 5024850289, September 28, 1995.

[28] Nuclear Regulatory Commission, 10 CFR Part 71, "Requirements for Shipping Packages Used To Transport Vitrified High-Level Waste," Proposed Rule, 62 F.R. 25146, pp. 25146-25150, May 8, 1997.

[29] Nuclear Regulatory Commission, 10 CFR Part 71, [Docket No. PRM-71-12], "International Energy Consultants, Inc.; Receipt of Petition for Rulemaking" 63 F.R. 8362, pp. 8362-8363, February 19, 1998.

[30] Nuclear Regulatory Commission, 10 CFR Part 71, "Requirements for Shipping Packages Used To Transport Vitrified High-Level Waste," Final Rule, 63 F.R. 32600, pp. 32600-32605, June 15, 1998.

[31] Nuclear Regulatory Commission, 10 CFR Part 71, "Compatibility with IAEA Transportation Standards (TS-R-1) and Other Transportation Safety Amendments," 67 F.R. 21390, pp. 21390-21484, April 30, 2002.

[32] Nuclear Regulatory Commission, 10 CFR Part 71, "Compatibility with IAEA Transportation Standards (TS-R-1) and Other Transportation Safety Amendments; Final Rule," 69 F.R. 3698, pp. 3698-3814, January 26, 2004. 